\title{
Supplementary Material to paper 'Estimating actual, potential, reference crop and pan evaporation using standard meteorological data: A pragmatic synthesis'
}

\section{Thomas A McMahon, Murray C Peel, Lisa Lowe, R Srikanthan, Tim R McVicar}

This supplementary material consists of a list of symbols and variables used in the paper and in the following 21 appendices. Appendix S1 discusses data used or referred to in the appendices. Appendix S2 addresses the computation of some common meteorological variables and Appendix S3 outlines the computation of net solar radiation. The application of the evaporation models, Penman and Penman-Monteith, is discussed in Appendices S4 and S5. Computation of Class-A pan evaporation by the PenPan model is outlined in Appendix S6. Actual evaporation estimates using Morton, and Advection-Aridity and like models are discussed in Appendices S7 and S8. Appendix S9 describes the computation of potential evaporation by several other models. Two methods to estimate deep lake evaporation where advected energy and heat storage should be accounted for are outlined in Appendix S10 and Appendix S11 describes the application of four methods to estimate shallow lake evaporation. The next four appendices deal with evaporation from lakes covered by vegetation (Appendix S12), estimating potential evaporation in rainfall-runoff modelling (Appendix S13), estimating evaporation from intercepted rainfall (Appendix S14) and estimating bare soil evaporation (Appendix S15). In Appendix S16 there is a discussion of Class-A pan evaporation equations and pan coefficients. Appendix S17 includes a summary of published evaporation estimates. Appendix S18 is a summary of a comparison of evaporation estimates by 14 models for six sites across Australia. Detailed worked examples for most models are carried out in Appendix S19. Appendix S20 is a Fortran 90 listing of Morton's WREVAP program and Appendix S21 is a worked example of Morton's CRAE, CRWE and CRLE models within the WREVAP framework.

\section{List of Supplementary Material}

List of variables and symbols in the paper and supplementary appendices excluding Appendices 20 and 21

Appendix S1 Data

Appendix S2 Computation of some common variables

Appendix S3 Estimating net solar radiation

Appendix S4 Penman model

Appendix S5 Penman-Monteith and FAO-56 Reference Crop models

Appendix S6 PenPan model

Appendix S7 Morton models

Appendix S8 Advection-Aridity and like models

Appendix S9 Additional evaporation equations

Appendix S10 Estimating deep lake evaporation

Appendix S11 Estimating shallow lake evaporation 
Appendix S12 Estimating evaporation from lakes covered by vegetation

Appendix S13 Estimating potential evaporation in rainfall-runoff modelling

Appendix S14 Estimating evaporation of intercepted rainfall

Appendix S15 Estimating bare soil evaporation

Appendix S16 Class-A pan evaporation equations and pan coefficients

Appendix S17 Comparing published evaporation estimates

Appendix S18 Comparing evaporation estimates based on measured climate data for six Australian automatic weather stations

Appendix S19 Worked examples

Appendix S20 Listing of Fortran 90 version of Morton's WREVAP program

Appendix S21 Worked example of Morton's CRAE, CRWE and CRLE models within the WREVAP framework

References for Supplementary Material

Table S1 Values of specific constants

Table S2 Roughness height, aerodynamic and surface resistance of typical surfaces

Table S3 Albedo values

Table S4 Median, $10^{\text {th }}$ and $90^{\text {th }}$ percentile monthly evaporation based on data recorded at the 68 Australian AWSs for three Penman wind functions, and for FAO-56 Reference Crop and Priestley-Taylor algorithms expressed as a percentage of the Penman (1948) median estimate

Table S5 Guideline for defining shallow and deep lakes and the methods to estimate lake evaporation

Table S6 Mean monthly guarded Class-A evaporation pan coefficients for 68 Australian locations

Table S7 Comparison of equations to estimate evaporation from a lake covered with vegetation

Table S8 Measured values of Priestley-Taylor coefficient $\left(\alpha_{P T}\right)$

Table S9 Effect of type and length fetch, wind speed and humidity on Class-A pan coefficients without bird-guard

Table S10 Published references listing annual Class-A pan coefficients based on the Penman equation with wind functions of Penman (1948) and Penman (1956), Reference Crop equation and Priestley-Taylor equation

Table S11 Monthly Class-A evaporation pan coefficients for selected Australian lakes

Table S12 Annual Class-A evaporation pan coefficients for selected Australian lakes

Table S13 Comparison of annual estimates of evaporation (mm day ${ }^{-1}$ ) at six Australian locations by 13 daily and monthly models plus Class-A pan and mean annual rainfall for period January 1979 to March 2010

Figure S1 Location of the 68 Automatic Weather Stations and Class-A evaporation pans (of which 39 pans are high quality) used in the analyses 
Figure S2 Plot showing Priestley-Taylor pan coefficients against mean annual unscreened Class-A pan evaporation based on six years of climate station data in Jordon (Weiß and Menzel, 2008)

Figure S3 Comparison of monthly PenPan evaporation and Class-A pan evaporation for 68 Australian climate stations 


\section{List of variables and symbols in the paper and supplementary appendices excluding Appendices S20 and S21}

\begin{tabular}{|c|c|c|}
\hline Variable/symbol & Description & Units* \\
\hline \multicolumn{3}{|l|}{ Symbols } \\
\hline AA & Advection-Aridity model & symbol \\
\hline AWBM & Rainfall-runoff model & symbol \\
\hline AWS & Automatic Weather Station & symbol \\
\hline $\mathrm{BC}$ & Blaney-Criddle evapotranspiration model & symbol \\
\hline BS & Brutsaert-Strickler evaporation model & symbol \\
\hline CR & Complementary Relationship & symbol \\
\hline CRAE & Complementary Relationship Areal Evapotranspiration & symbol \\
\hline CRLE & Complementary Relationship Lake Evaporation & symbol \\
\hline CRWE & Complementary Relationship Wet-surface Evaporation & symbol \\
\hline$E T$ & Evapotranspiration & symbol \\
\hline FAO56 RC & FAO-56 Reference Crop model & symbol \\
\hline GG & Granger-Gray evaporation model & symbol \\
\hline HS & Hargreaves-Samani evapotranspiration model & symbol \\
\hline M & Month & symbol \\
\hline Mo & Morton evaporation model & symbol \\
\hline Ма & Makkink evaporation equation & symbol \\
\hline $\operatorname{modH}$ & Modified Hargreaves evaporation model & symbol \\
\hline PM & Penman-Monteith evapotranspiration model & symbol \\
\hline PET & Potential evapotranspiration & symbol \\
\hline PT & Priestley-Taylor evaporation model & symbol \\
\hline P48 & Penman equation with 1948 wind function & symbol \\
\hline P56 & Penman equation with 1956 wind function & symbol \\
\hline SILO & An enhanced Australian climate database & symbol \\
\hline SW & Shuttleworth-Wallace model & symbol \\
\hline SHE & Système Hydrologique Européen rainfall-runoff model & symbol \\
\hline SIMHYD & Rainfall-runoff model & symbol \\
\hline SWAT & Soil and Water Assessment Tool & symbol \\
\hline Th & Thornthwaite evapotranspiration model & symbol \\
\hline TIN & Triangular irregular networks & symbol \\
\hline
\end{tabular}




\begin{tabular}{|c|c|c|}
\hline $\mathrm{Tu}$ & Turc evaporation model & symbol \\
\hline WREVAP & $\begin{array}{l}\text { Program combining three Morton models CRAE, CRWE and } \\
\text { CRLE }\end{array}$ & symbol \\
\hline \multicolumn{3}{|l|}{ Variables } \\
\hline$A$ & Evaporating area & $\mathrm{m}^{2}$ \\
\hline$A_{L}$ & Lake area (in Kohler and Parmele (1967) procedure) & $\mathrm{km}^{2},\left(\mathrm{~m}^{2}\right)$ \\
\hline$A_{W}$ & $\begin{array}{l}\text { Net water advected energy during } \Delta t \text { (net inflow from inflows } \\
\text { and outflows of water) }\end{array}$ & $\mathrm{mm}_{\text {day }}{ }^{-1}$ \\
\hline$A_{e}$ & Available energy (sensible and latent heat) above canopy & MJ m ${ }^{-2}$ day $^{-1}$ \\
\hline$A_{p}$ & Gradient in Equation (S13.1) & undefined \\
\hline$A_{w}$ & Net water advected energy during $\Delta t$ & $\mathrm{~mm}$ day $^{-1}$ \\
\hline$A_{s}$ & Surface area of the lake & $\mathrm{m}^{2}$ \\
\hline$A_{s S}$ & Available energy at sub-strate & MJ m² day $^{-1}$ \\
\hline$A_{i+1}, A_{i}$ & Area of adjacent layers & $\mathrm{m}^{2}$ \\
\hline$a$ & Coefficient & undefined \\
\hline$a_{p}$ & Constant in PenPan equation & dimensionless \\
\hline$a_{s}$ & Constant for Ángström -Prescott formula & dimensionless \\
\hline$a_{T h}$ & Exponent in Thornthwaite 1948 procedure & undefined \\
\hline$a_{o}$ & Constant & dimensionless \\
\hline$b$ & Coefficient or slope of the regression between two variables & undefined \\
\hline$b_{0}$ & Constant, or constant in CRAE and CRWE models & dimensionless \\
\hline$b_{s}$ & Constant for Ángström -Prescott formula & dimensionless \\
\hline$b_{\text {var }}$ & Working variable & undefined \\
\hline$b_{1}, b_{2}$ & Empirical coefficients for Morton’s procedure & $\mathrm{W} \mathrm{m}^{-2}$ \\
\hline$B$ & Bowen Ratio & dimensionless \\
\hline$B_{p}$ & Intercept in Equation (S13.1) & undefined \\
\hline C & Constant = $13 \mathrm{~m}$ & $\mathrm{~m}$ \\
\hline$C_{H S}$ & Hargreaves-Samani working coefficient & undefined \\
\hline$C_{o}$ & Cloud cover & oktas \\
\hline$C_{c a}, C_{s u}$ & Working variables & undefined \\
\hline$C_{\text {ret }}$ & Amount of water retained on the canopy & $\mathrm{mm}$ \\
\hline$c$ & Parameter in linear Budyko-type relationship & undefined \\
\hline$c_{a}$ & Specific heat of air & $\mathrm{MJ} \mathrm{kg}^{-1 \circ} \mathrm{C}^{-1}$ \\
\hline
\end{tabular}




\begin{tabular}{|c|c|c|}
\hline$C_{f}$ & Fraction of cloud cover & dimensionless \\
\hline$c_{o}$ & Constant & dimensionless \\
\hline$c_{s}$ & Volumetric heat capacity of soil & $\mathrm{MJ} \mathrm{m}^{-3}{ }^{\circ} \mathrm{C}^{-1}$ \\
\hline$C_{u}$ & Wind function coefficient & undefined \\
\hline$c_{w}$ & Specific heat of water & $\mathrm{MJ} \mathrm{kg}^{-1}{ }^{\circ} \mathrm{C}^{-1}$ \\
\hline$C_{D}$ & Number of tenths of the sky covered by cloud & dimensionless \\
\hline$C_{a t m}$ & Atmospheric conductance & $\mathrm{m} \mathrm{s}^{-1}$ \\
\hline$C_{\text {can }}$ & Canopy conductance & $\mathrm{m} \mathrm{s}^{-1}$ \\
\hline$C_{e m p}$ & Empirical coefficient & undefined \\
\hline$D$ & Day or dimensionless relative drying power & dimensionless \\
\hline DoY & Day of Year & dimensionless \\
\hline$D_{p}$ & Dimensionless relative drying power & dimensionless \\
\hline$d$ & Zero plane displacement height & $\mathrm{m}$ \\
\hline daymon & Number of days in month & day \\
\hline$d_{r}$ & Relative distance between the earth and the sun & undefined \\
\hline$d_{s}$ & Effective soil depth & $\mathrm{m}$ \\
\hline$d_{o}$ & Constant & dimensionless \\
\hline$E$ & Surface evaporation & $\mathrm{mm} \mathrm{day}^{-1}$ \\
\hline Elev & Elevation above sea level & $\mathrm{m}$ \\
\hline$E_{\text {Act }}$ & Actual evaporation rate & $\mathrm{mm} \mathrm{day}^{-1}$ \\
\hline$E_{E Q}$ & Equilibrium evaporation rate & $\mathrm{mm} \mathrm{day}^{-1}$ \\
\hline$E_{M a k}$ & Makkink potential evaporation & $\mathrm{mm} \mathrm{day}^{-1}$ \\
\hline$E_{\text {PenPan }}$ & Modelled Class-A (unscreened) pan evaporation & $\mathrm{mm} \mathrm{day}^{-1}$ \\
\hline$E_{i}$ & Lake evaporation on day $i$ & $\mathrm{~mm} \mathrm{day}^{-1}$ \\
\hline$E_{p a}$ & Working variable & undefined \\
\hline$E P 2, E P 3, E P 5$ & Various definitions of potential evaporation & undefined \\
\hline$E_{S W}$ & $\begin{array}{l}\text { Shuttleworth-Wallace combined evaporation from vegetation } \\
\text { and soil }\end{array}$ & $\mathrm{mm}_{\text {day }}{ }^{-1}$ \\
\hline$E_{P T}\left(T_{e}\right)$ & $\begin{array}{l}\text { Wet-environment evaporation estimated by Priestley-Taylor } \\
\text { at } T_{e}\end{array}$ & mm day ${ }^{-1}$ \\
\hline$E_{P e n, j}$ & Penman estimate of evaporation for specific period & mm/unit time \\
\hline$E_{D L}$ & Evaporation from a deep lake & $\mathrm{mm} \mathrm{day}^{-1}$ \\
\hline$E_{L}$ & $\begin{array}{l}\text { Lake evaporation large enough to be unaffected by the upwind } \\
\text { transition }\end{array}$ & $\mathrm{mm}^{\mathrm{day}}{ }^{-1}$ \\
\hline$E_{M c J}$ & Evaporation from a water body using McJannet et al (2008a) & $\mathrm{mm} \mathrm{day}^{-1}$ \\
\hline
\end{tabular}




\begin{tabular}{|c|c|c|}
\hline$E_{P T}$ & Priestley-Taylor potential evaporation & $\mathrm{mm} \mathrm{day}^{-1}$ \\
\hline$E_{P a n, j}$ & Monthly (daily) Class-A pan data in month (day) $j$ & mm/unit time \\
\hline$E_{\text {Pan }}$ & Daily Class-A pan evaporation & $\mathrm{mm}_{\mathrm{day}}{ }^{-1}$ \\
\hline$E_{P e n}$ & Penman potential evaporation & $\mathrm{mm}_{\mathrm{day}}{ }^{-1}$ \\
\hline$E_{\text {Penow }}$ & Penman open-surface water evaporation & $\mathrm{mm}_{\mathrm{day}}{ }^{-1}$ \\
\hline$E_{\text {Pot }}$ & $\begin{array}{l}\text { Potential evaporation (in the land environment) or pan-size wet } \\
\text { surface evaporation }\end{array}$ & $m m$ day $^{-1}$ \\
\hline$E_{S L}$ & Shallow lake evaporation & $\mathrm{mm}_{\mathrm{month}}{ }^{-1}$ \\
\hline$E_{S}$ & Evaporation component due to net heating & $\mathrm{mm}_{\text {day }}{ }^{-1}$ \\
\hline$E_{\text {can }}$ & Transpiration from canopy & $\mathrm{mm}_{\mathrm{day}}{ }^{-1}$ \\
\hline$E_{\text {soil }}$ & Soil evaporation & $\mathrm{mm}_{\mathrm{day}}{ }^{-1}$ \\
\hline$E_{\text {water }}$ & Evaporation from standing water & $\mathrm{mm}_{\text {day }}{ }^{-1}$ \\
\hline $\bar{E}_{\text {Trans }}$ & Mean transpiration & $\mathrm{mm}_{\mathrm{day}}{ }^{-1}$ \\
\hline $\bar{E}_{\text {Inter }}$ & Mean interception evaporation & $\mathrm{mm} \mathrm{day}^{-1}$ \\
\hline$E_{\text {wetland }}$ & Evapotranspiration from the wetland & $\mathrm{mm}_{\mathrm{day}}{ }^{-1}$ \\
\hline $\bar{E}_{\text {pot }}$ & Mean annual catchment potential evapotranspiration & mm year $^{-1}$ \\
\hline $\bar{E}_{\text {Soil }}$ & Mean soil evaporation & $\mathrm{mm}_{\mathrm{day}}{ }^{-1}$ \\
\hline$E_{L, d}$ & Daily estimate of lake evaporation from Webb (1966) equation & $\mathrm{cm} \mathrm{day}^{-1}$ \\
\hline$E_{\text {pan }}^{\prime}$ & Daily Class-A pan evaporation from Webb (1966) equation & $\mathrm{cm}$ day $^{-1}$ \\
\hline$E_{\text {Penow }}^{\prime}$ & $\begin{array}{l}\text { Open-water evaporation based on modified Penman equation } \\
\text { incorporating aerodynamic resistance }\end{array}$ & $m m$ day $^{-1}$ \\
\hline$E_{1^{s t}}, E_{2^{n d}}$ & $\begin{array}{l}\text { Radiation and aerodynamic terms respectively in the PM } \\
\text { model }\end{array}$ & mm day ${ }^{-1}$ \\
\hline $\bar{E}_{T h, j}$ & $\begin{array}{l}\text { Thornthwaite (1948) estimate of mean monthly PET for month } \\
j\end{array}$ & $\mathrm{~mm}_{\mathrm{month}}{ }^{-1}$ \\
\hline$E_{S L x}$ & Average lake evaporation for a crosswind width of $x \mathrm{~m}$ & $\mathrm{~mm} \mathrm{day}^{-1}$ \\
\hline $\bar{E}_{\text {Penman }}$ & $\begin{array}{l}\text { Average daily stage } 1 \text { evaporation which is assumed to be at or } \\
\text { near the rate of Penman evaporation }\end{array}$ & $m m$ day $^{-1}$ \\
\hline $\bar{E}_{\text {Act }}$ & Mean annual catchment evaporation & mm year ${ }^{-1}$ \\
\hline$E T_{A c t}$ & Actual daily evaporation & $\mathrm{mm}_{\text {day }}{ }^{-1}$ \\
\hline$E T_{c}$ & $\begin{array}{l}\text { Well-watered crop evapotranspiration in a semi-arid windy } \\
\text { environment }\end{array}$ & $\mathrm{mm}_{\text {day }}{ }^{-1}$ \\
\hline$E T_{A c t}^{B S}$ & $\begin{array}{l}\text { Actual evapotranspiration estimated by Brutsaert-Strickler } \\
\text { equation }\end{array}$ & mm day ${ }^{-1}$ \\
\hline$E T_{A c t}^{G G}$ & Granger-Gray actual evapotranspiration & $\mathrm{mm}_{\mathrm{day}}{ }^{-1}$ \\
\hline$E T_{A c t}^{S J}$ & $\begin{array}{l}\text { Actual evapotranspiration based on the Szilagyi-Jozsa } \\
\text { equation }\end{array}$ & $\mathrm{mm}_{\text {day }}{ }^{-1}$ \\
\hline$E T_{B C}$ & Evaporation based on the Blaney-Criddle method without & $\mathrm{mm} \mathrm{day}^{-1}$ \\
\hline
\end{tabular}




\begin{tabular}{|c|c|c|}
\hline & height adjustment & \\
\hline$E T_{B C}^{H}$ & $\begin{array}{l}\text { Evaporation based on the Blaney-Criddle method with height } \\
\text { adjustment }\end{array}$ & $\mathrm{mm}_{\text {day }}{ }^{-1}$ \\
\hline$E T_{A c t}^{M o}$ & Morton's estimate of actual areal evapotranspiration & $\mathrm{mm} \mathrm{day}^{-1}$ \\
\hline$E T_{P o t}^{M o}$ & Morton's estimate of potential evapotranspiration & $\mathrm{mm} \mathrm{day}^{-1}$ \\
\hline$E T_{W e t}^{M o}$ & $\begin{array}{l}\text { Morton’s estimate of wet-environmental areal } \\
\text { evapotranspiration }\end{array}$ & $\mathrm{mm}_{\text {day }}{ }^{-1}$ \\
\hline$E T_{H S}$ & Hargreaves-Samani reference crop evapotranspiration & $\mathrm{mm} \mathrm{day}^{-1}$ \\
\hline$E T_{\text {Harg }, j}$ & $\begin{array}{l}\text { Modified Hargreaves monthly potential evapotranspiration } \\
\text { (month } j \text { ) }\end{array}$ & $\mathrm{mm} \mathrm{month}^{-1}$ \\
\hline$E T_{P}$ & Potential evaporation of the land environment & $\mathrm{mm} \mathrm{day}^{-1}$ \\
\hline$E T_{P E T}$ & Daily potential evaporation & $\mathrm{mm} \mathrm{day}^{-1}$ \\
\hline$E T_{P M}$ & Penman-Monteith potential evapotranspiration & $\mathrm{mm} \mathrm{day}^{-1}$ \\
\hline$E T_{\text {Pot }}$ & Potential evapotranspiration & $\mathrm{mm} \mathrm{day}^{-1}$ \\
\hline$E T_{R C}$ & Reference crop evapotranspiration & $\mathrm{mm} \mathrm{day}^{-1}$ \\
\hline$E T_{R C s h}$ & $\begin{array}{l}\text { Reference crop evapotranspiration for short grass (0.12 m } \\
\text { high) }\end{array}$ & $\mathrm{mm}_{\text {day }}{ }^{-1}$ \\
\hline$E T_{R C t a}$ & Reference crop evapotranspiration for tall grass (0.5 m high) & $\mathrm{mm} \mathrm{day}^{-1}$ \\
\hline$E T_{\text {Turc }}$ & Turc’s reference crop evapotranspiration & $\mathrm{mm} \mathrm{day}^{-1}$ \\
\hline$E T_{W e t}$ & Wet environment areal evapotranspiration & $\mathrm{mm}_{\mathrm{day}}{ }^{-1}$ \\
\hline$E T_{e q P M}$ & $\begin{array}{l}\text { Daily equivalent Penman-Monteith potential } \\
\text { evapotranspiration }\end{array}$ & mm day ${ }^{-1}$ \\
\hline$\overline{E T}_{A c t}$ & Mean annual catchment evapotranspiration & mm year $^{-1}$ \\
\hline$E_{a}$ & $\begin{array}{l}\text { Aerodynamic component of Penman's equation; regional } \\
\text { drying power of atmosphere; evaporative component due to } \\
\text { wind }\end{array}$ & mm day ${ }^{-1}$ \\
\hline$E_{\text {Larea }}$ & $\begin{array}{l}\text { Estimate of open-surface water evaporation as a function of } \\
\text { lake area }\end{array}$ & $\mathrm{mm}_{\text {day }}{ }^{-1}$ \\
\hline$E_{f w, j}$ & Monthly (daily) open water evaporation in month (day) $j$ & $\mathrm{~mm} / \mathrm{unit}$ time \\
\hline$E_{f w}$ & Daily open water evaporation & $\mathrm{mm} \mathrm{day}^{-1}$ \\
\hline$E_{i c}$ & Evaporation from an irrigation channel & $\mathrm{mm}_{\text {day }}{ }^{-1}$ \\
\hline$E_{\text {bsoil }}(t)$ & Cumulative bare soil evaporation up to time $t$ & $\mathrm{~mm}$ \\
\hline$E_{\text {stage } 1}$ & Cumulative stage 1 bare soil evaporation & $\mathrm{mm}$ \\
\hline$e$ & Turc-Pike parameter & dimensionless \\
\hline$e_{0}, e_{1}, \ldots, e_{4}$ & Coefficients in Blaney-Criddle model & undefined \\
\hline$F$ & Upwind grass fetch & $\mathrm{m}$ \\
\hline FET & Fetch or length of the identified surface & $\mathrm{m}$ \\
\hline$F_{100}$ & Working variable & undefined \\
\hline
\end{tabular}




\begin{tabular}{|c|c|c|}
\hline$f$ & Fu-Zhang parameter & dimensionless \\
\hline$f(\phi)$ & Aridity function & undefined \\
\hline$f(u)$ & Wind speed function & units of $u$ \\
\hline$f\left(u_{2}\right)$ & Wind speed function at $u_{2}$ & units of $u_{2}$ \\
\hline$f(u)_{48}$ & 1948 Penman wind function & units of $u$ \\
\hline$f(u)_{56}$ & 1956 Penman wind function & units of $u$ \\
\hline$f(u)_{L I N}$ & Linacre Penman wind function & units of $u$ \\
\hline$f_{\text {Pan }}(u)$ & Wind function for Class-A pan & units of $u$ \\
\hline$f_{\text {dir }}$ & Fraction of $R_{S}$ that is direct & dimensionless \\
\hline$f_{v}$ & Vapour transfer coefficient in Morton's procedure & $\mathrm{W} \mathrm{m}^{-2} \mathrm{mbar}^{-1}$ \\
\hline$f_{Z}$ & Constant in Morton’s procedure & $\mathrm{W} \mathrm{m}{ }^{-2} \mathrm{mbar}^{-1}$ \\
\hline$G$ & Soil heat flux & $\mathrm{MJ} \mathrm{m}^{-2} \mathrm{day}^{-1}$ \\
\hline$G_{L}$ & $\begin{array}{l}\text { Monthly solar and waterborne energy input into lake for } \\
\text { Morton's procedure }\end{array}$ & $\mathrm{W} \mathrm{m}^{-2}$ \\
\hline$G_{w}$ & Daily change in heat storage of water body & $\mathrm{MJ} \mathrm{m}^{-2} \mathrm{day}^{-1}$ \\
\hline$G_{w}(t)$ & $d H(t) / d t$ & $\mathrm{MJ} \mathrm{m}^{-2}$ day $^{-1}$ \\
\hline$G_{L B}$ & $\begin{array}{l}\text { Available solar and waterborne heat energy at the beginning of } \\
\text { the month for Morton's procedure }\end{array}$ & $\mathrm{W} \mathrm{m}^{-2}$ \\
\hline$G_{L E}$ & $\begin{array}{l}\text { Available solar and waterborne heat energy at the end of the } \\
\text { month for Morton's procedure }\end{array}$ & $\mathrm{W} \mathrm{m}^{-2}$ \\
\hline$G_{W}^{[t]}, G_{W}^{[t+1]}$ & $\begin{array}{l}\text { Value of } G_{W}^{0} \text { computed }[t] \text { and }[t+1] \text { months previously for } \\
\text { Morton's procedure }\end{array}$ & $\mathrm{W} \mathrm{m}^{-2}$ \\
\hline$G_{W}^{0}$ & Solar and waterborne heat input for Morton's procedure & $\mathrm{W} \mathrm{m}^{-2}$ \\
\hline$G W_{\text {in }}$ & Groundwater inflows to lake & $\mathrm{mm} \mathrm{day}^{-1}$ \\
\hline$G W_{\text {out }}$ & Groundwater outflows from lake & $\mathrm{mm} \mathrm{day}^{-1}$ \\
\hline$G_{W}^{t}$ & Delayed energy input into the lake for Morton's procedure & $\mathrm{W} \mathrm{m}^{-2}$ \\
\hline$G_{g}$ & Dimensionless relative evaporation parameter & dimensionless \\
\hline $\bar{G}$ & Mean heat conductance into the soil & $\mathrm{MJ} \mathrm{m}^{-2}$ day $^{-1}$ \\
\hline$G_{j}$ & Coefficient in Equation (S16.4) & undefined \\
\hline$G_{S C}$ & Solar constant & $\mathrm{MJ} \mathrm{m}^{-2} \mathrm{~min}^{-1}$ \\
\hline $\bar{G}_{D S}$ & Mean annual deep seepage & $\mathrm{mm}_{\text {year }}{ }^{-1}$ \\
\hline$g$ & Working variable & undefined \\
\hline$H$ & Sensible heat flux & $\mathrm{MJ} \mathrm{m}^{-2}$ day $^{-1}$ \\
\hline $\bar{H}$ & Mean sensible heat flux & $\mathrm{MJ} \mathrm{m}^{-2}$ day $^{-1}$ \\
\hline$H(t)$ & $\begin{array}{l}\text { Total heat energy content of the lake per unit area of the lake } \\
\text { surface at time } t\end{array}$ & $\mathrm{MJ} \mathrm{m}^{-2}$ \\
\hline
\end{tabular}




\begin{tabular}{|c|c|c|}
\hline$h$ & Mean height of the roughness obstacles (including crop) & $\mathrm{m}$ \\
\hline$h_{w}$ & Water depth & $\mathrm{m}$ \\
\hline$h_{i}, h_{i+1}$ & Depth of water in lake on day $i$ and day $i+1$ respectively & $\mathrm{m}$ \\
\hline $\bar{h}$ & Mean lake depth & $\mathrm{m}$ \\
\hline$\overline{\overline{h r d a y}}$ & Mean monthly daylight hours in month & hour \\
\hline$i$ & Monthly heat index & undefined \\
\hline$i, i-1$ & Index for days & undefined \\
\hline$I$ & Annual heat index & undefined \\
\hline$I_{j}$ & Intercept in Equation (S16.4) & undefined \\
\hline$j, j-1$ & Index for months & undefined \\
\hline$K_{c}$ & Crop coefficient & dimensionless \\
\hline$K_{E}$ & $\begin{array}{l}\text { Coefficient that represents the efficiency of the vertical } \\
\text { transport of water vapour }\end{array}$ & $\mathrm{m}$ day $^{2} \mathrm{~kg}^{-1}$ \\
\hline$K_{u s}$ & Unsaturated hydraulic conductivity & $\mathrm{mm}_{\mathrm{day}}{ }^{-1}$ \\
\hline$K_{j}$ & Monthly (daily) Class-A pan coefficient & dimensionless \\
\hline$K_{\text {ratio }}$ & Ratio of incoming solar radiation to clear sky radiation & dimensionless \\
\hline$K_{\text {Pan }}$ & Class-A pan coefficient & dimensionless \\
\hline$k$ & von Kármán’s constant & dimensionless \\
\hline lat & Latitude & radians \\
\hline$L A I$ & Leaf area index & $\mathrm{m}^{2} \mathrm{~m}^{-2}$ \\
\hline LAI active & Active (sunlit) leaf area index & $\mathrm{m}^{2} \mathrm{~m}^{-2}$ \\
\hline$m$ & Number of horizontal layers & dimensionless \\
\hline$M$ & Month of the year & dimensionless \\
\hline$N$ & Total day length & hour \\
\hline$n$ & Duration of sunshine hours in a day & hour \\
\hline$P_{d}$ & Daily precipitation & $\mathrm{mm}_{\mathrm{day}}{ }^{-1}$ \\
\hline$P M_{c a}, P M_{s u}$ & $\begin{array}{l}\text { Evaporation from respectively a closed canopy and bare } \\
\text { substrate }\end{array}$ & $\mathrm{mm}$ day $^{-1}$ \\
\hline $\bar{P}$ & Mean rainfall or mean annual rainfall & $\begin{array}{l}\mathrm{mm}_{\text {day }}{ }^{-1} \\
\mathrm{~mm}_{\text {year }}{ }^{-1}\end{array}$ \\
\hline$P_{i+1}$ & Rainfall on day $i+1$ & $\mathrm{~mm} \mathrm{day}^{-1}$ \\
\hline$P_{j}$ & Monthly precipitation in month $j$ & mm month $^{-1}$ \\
\hline$P_{\text {rad }}$ & Pan radiation factor & dimensionless \\
\hline$p$ & Atmospheric pressure (for Morton’s procedure) & $\mathrm{kPa}(\mathrm{mbar})$ \\
\hline$p_{s}$ & Sea-level atmospheric pressure & mbar \\
\hline
\end{tabular}




\begin{tabular}{|c|c|c|}
\hline$p_{y}$ & $\begin{array}{l}\text { Percentage of actual daytime hours for the specific day } \\
\text { compared to the day-light hours for the entire year }\end{array}$ & $\%$ \\
\hline$Q_{t}$ & Heat flux increase in stored energy & $\mathrm{MJ} \mathrm{m}^{-2}$ day $^{-1}$ \\
\hline$Q_{v}$ & Heat flux advected into the water body & $\mathrm{MJ} \mathrm{m}^{-2}$ day $^{-1}$ \\
\hline $\bar{Q}$ & Mean runoff or mean annual runoff & $\begin{array}{l}\text { mm day } \text { da }^{-1} \\
\text { mm year }^{-1}\end{array}$ \\
\hline$Q^{*}$ & Net radiation & $\mathrm{MJ} \mathrm{m}^{-2}$ day $^{-1}$ \\
\hline$Q_{w b}^{*}$ & Net radiation at wet-bulb temperature & $\mathrm{MJ} \mathrm{m}^{-2}$ day $^{-1}$ \\
\hline RH & Average monthly relative humidity & $\%$ \\
\hline $\bar{R}$ & Mean net radiation received & $\mathrm{MJ} \mathrm{m}^{-2}$ day $^{-1}$ \\
\hline REW & Readily evaporable water & $\mathrm{mm}$ \\
\hline$R_{i l}$ & Incoming longwave radiation & $\mathrm{MJ} \mathrm{m}^{-2}$ day $^{-1}$ \\
\hline$R_{o l}$ & Outgoing longwave radiation & $\mathrm{MJ} \mathrm{m}^{-2}$ day $^{-1}$ \\
\hline$R H_{\max }$ & Maximum daily relative humidity & $\%$ \\
\hline$R H_{\text {mean }}$ & Mean daily relative humidity & $\%$ \\
\hline$R H_{\min }$ & Minimum daily relative humidity & $\%$ \\
\hline$R_{a}$ & Extraterrestrial radiation & $\mathrm{MJ} \mathrm{m}^{-2}$ day $^{-1}$ \\
\hline$R_{N P a n}$ & Net radiation at Class-A pan & $\mathrm{MJ} \mathrm{m}^{-2}$ day $^{-1}$ \\
\hline$R_{\text {SPan }}$ & Total shortwave irradiance of pan & $\mathrm{MJ} \mathrm{m}^{-2}$ day $^{-1}$ \\
\hline$R_{i l}$ & Incoming longwave radiation & $\mathrm{MJ} \mathrm{m}^{-2}$ day $^{-1}$ \\
\hline$R_{n}$ & $\begin{array}{l}\text { Net radiation at evaporating surface at air temperature (for } \\
\text { Morton's procedure) }\end{array}$ & $\begin{array}{l}\mathrm{MJ} \mathrm{m}^{-2} \text { day }^{-1} \\
\left(\mathrm{~W} \mathrm{~m}^{-2}\right)\end{array}$ \\
\hline$R_{n e}$ & $\begin{array}{l}\text { Net radiation for the soil-plant surface at } T_{e} \text { for Morton's } \\
\text { procedure }\end{array}$ & $\mathrm{W} \mathrm{m}^{-2}$ \\
\hline$R_{n l}$ & Net longwave radiation & $\mathrm{MJ} \mathrm{m}^{-2}$ day $^{-1}$ \\
\hline$R_{n s}$ & Net incoming shortwave radiation & $\mathrm{MJ} \mathrm{m}^{-2}$ day $^{-1}$ \\
\hline$R_{n w}$ & Net radiation at water surface & $\mathrm{MJ} \mathrm{m}^{-2}$ day $^{-1}$ \\
\hline$R_{o l}$ & Outgoing longwave radiation & $\mathrm{MJ} \mathrm{m}^{-2}$ day $^{-1}$ \\
\hline$R_{S}$ & Measured or estimated incoming solar radiation & $\mathrm{MJ} \mathrm{m}^{-2}$ day $^{-1}$ \\
\hline$R_{\text {so }}$ & Clear sky radiation & $\mathrm{MJ} \mathrm{m}^{-2}$ day $^{-1}$ \\
\hline$R_{n}^{c a n}$ & Net radiation to canopy & $\mathrm{MJ} \mathrm{m}^{-2}$ day $^{-1}$ \\
\hline$R_{n}^{\text {soil }}$ & Net radiation to soil & $\mathrm{MJ} \mathrm{m}^{-2}$ day $^{-1}$ \\
\hline$R_{n}^{\text {water }}$ & Net radiation to water based on surface water temperature & $\mathrm{MJ} \mathrm{m}^{-2}$ day $^{-1}$ \\
\hline$R_{n}^{w}$ & Net daily radiation based on water temperature & $\mathrm{MJ} \mathrm{m}^{-2} \mathrm{day}^{-1}$ \\
\hline$R_{o l}^{w a}$ & Outgoing longwave radiation based on water temperature & $\mathrm{MJ} \mathrm{m}^{-2}$ day $^{-1}$ \\
\hline$R_{o l}^{w b}$ & Outgoing longwave radiation based on wet-bulb temperature & $\mathrm{MJ} \mathrm{m}^{-2}$ day $^{-1}$ \\
\hline
\end{tabular}




\begin{tabular}{|c|c|c|}
\hline$R_{w b}^{*}$ & Net radiation to water based on wet-bulb temperature & $\mathrm{MJ} \mathrm{m}^{-2}$ day $^{-1}$ \\
\hline $\mathrm{R}^{2}$ & Square of the correlation coefficient & dimensionless \\
\hline RMSE & Root mean square error & various \\
\hline$r_{\text {clim }}$ & Climatological resistance & $\mathrm{s} \mathrm{m}^{-1}$ \\
\hline$r_{a}$ & $\begin{array}{l}\text { Aerodynamic or atmospheric resistance to water vapour } \\
\text { transport }\end{array}$ & $\mathrm{s} \mathrm{m}^{-1}$ \\
\hline$r_{c}$ & Bulk stomatal resistance & $\mathrm{s} \mathrm{m}^{-1}$ \\
\hline$r_{l}$ & Bulk stomatal resistance of a well-illuminated leaf & $\mathrm{s} \mathrm{m}^{-1}$ \\
\hline$r_{c}^{50}$ & Aerodynamic resistance for crop height, $h$ & $\mathrm{~s} \mathrm{~m}^{-1}$ \\
\hline$r_{s}$ & Surface resistance & $\mathrm{s} \mathrm{m}^{-1}$ \\
\hline$\left(r_{s}\right)_{c}$ & $\begin{array}{l}\text { Surface resistance of a well-watered crop equivalent to FAO } \\
\text { crop coefficient }\end{array}$ & $\mathrm{s} \mathrm{m}^{-1}$ \\
\hline$R_{A}$ & Average monthly extraterrestrial solar radiation & $\mathrm{MJ} \mathrm{m}^{-2}$ day $^{-1}$ \\
\hline$r_{a}^{a}$ & $\begin{array}{l}\text { Aerodynamic resistance between canopy source height and } \\
\text { reference level }\end{array}$ & $\mathrm{s} \mathrm{m}^{-1}$ \\
\hline$r_{a}^{c}$ & $\begin{array}{l}\text { Bulk boundary layer resistance of vegetation elements in } \\
\text { canopy }\end{array}$ & $\mathrm{s} \mathrm{m}^{-1}$ \\
\hline$r_{a}^{S}$ & $\begin{array}{l}\text { Aerodynamic resistance between substrate and canopy source } \\
\text { height }\end{array}$ & $\mathrm{s} \mathrm{m}^{-1}$ \\
\hline$r_{s}^{c}$ & Bulk stomatal resistance of canopy & $\mathrm{s} \mathrm{m}^{-1}$ \\
\hline$r_{s}^{S}$ & Surface resistance of substrate & $\mathrm{s} \mathrm{m}^{-1}$ \\
\hline S & Proportion of bare soil & dimensionless \\
\hline$S_{\text {con }}$ & Solar constant & $\mathrm{MJ} \mathrm{m}^{-2}$ day $^{-1}$ \\
\hline$S_{O}$ & $\begin{array}{l}\text { Mean water equivalent for extraterrestrial solar radiation in } \\
\text { month } j\end{array}$ & mm month $^{-1}$ \\
\hline SEE & Standard error of estimate & \begin{tabular}{|l} 
units of \\
dependent \\
variable
\end{tabular} \\
\hline$S M$ & Soil moisture level & $\mathrm{mm}$ \\
\hline$S W_{\text {in }}$ & Surface water inflows to lake & $\mathrm{mm}_{\mathrm{day}}{ }^{-1}$ \\
\hline SW $W_{\text {out }}$ & Surface water outflows from lake & $\mathrm{mm}_{\mathrm{day}}{ }^{-1}$ \\
\hline$S_{c}$ & Storage constant & month \\
\hline$S_{\text {can }}$ & Storage capacity of the canopy & $\mathrm{mm}$ \\
\hline$S$ & Lake salinity for Morton’s procedure & ppm \\
\hline$T$ & Temperature, the generalised Turc-Pike coefficient & ${ }^{\circ} \mathrm{C}$, undefined \\
\hline TEW & Total evaporable water & $\mathrm{mm}$ \\
\hline$T_{a}$ & Air temperature & ${ }^{\circ} \mathrm{C}$ \\
\hline$T_{d}$ & Dewpoint temperature & ${ }^{\circ} \mathrm{C}$ \\
\hline
\end{tabular}




\begin{tabular}{|c|c|c|}
\hline$T_{e}$ & Equilibrium temperature (at evaporating surface) & ${ }^{\circ} \mathrm{C}$ \\
\hline$T_{j}$ & Monthly mean daily air temperature in month $j$ & ${ }^{\circ} \mathrm{C}$ \\
\hline$T_{\text {pan }}$ & Mean daily pan water temperature & ${ }^{\circ} \mathrm{C}$ \\
\hline$T_{S}$ & Temperature of the surface or evaporated water & ${ }^{\circ} \mathrm{C}$ \\
\hline$T_{w}$ & Temperature of the water & ${ }^{\circ} \mathrm{C}$ \\
\hline$T_{w b}$ & Wet-bulb temperature & ${ }^{\circ} \mathrm{C}$ \\
\hline$T_{w 0}$ & Temperature from previous time-step & ${ }^{\circ} \mathrm{C}$ \\
\hline$T_{w, j}-T_{w, j-1}$ & $\begin{array}{l}\text { Change in surface water temperature from month } j-1 \text { to } \\
\text { month } j\end{array}$ & ${ }^{\circ} \mathrm{C}$ \\
\hline$T_{L 1}, T_{L 2}$ & Average lake temperature at the beginning and end of period & ${ }^{\circ} \mathrm{C}$ \\
\hline$T_{e}^{\prime}$ & Working estimate of the equilibrium temperature & ${ }^{\circ} \mathrm{C}$ \\
\hline$T_{\text {gwin }}$ & Temperature of the groundwater inflows to lake & ${ }^{\circ} \mathrm{C}$ \\
\hline$T_{\text {gwout }}$ & Temperature of the groundwater outflows from lake & ${ }^{\circ} \mathrm{C}$ \\
\hline$T_{i}, T_{i-1}$ & Average air temperatures on day $i$ and day $i-1$ respectively & ${ }^{\circ} \mathrm{C}$ \\
\hline$T_{w, i}, T_{w, i-1}$ & Surface water temperatures on day $i$ and day $i-1$ respectively & ${ }^{\circ} \mathrm{C}$ \\
\hline$T_{\max }$ & Maximum daily air temperature & ${ }^{\circ} \mathrm{C}$ \\
\hline$T_{\min }$ & Minimum daily air temperature & ${ }^{\circ} \mathrm{C}$ \\
\hline$T_{\text {mean }}$ & Mean daily temperature & ${ }^{\circ} \mathrm{C}$ \\
\hline$T_{p}$ & Temperature of precipitation & ${ }^{\circ} \mathrm{C}$ \\
\hline$T_{\text {swin }}$ & Temperature of the surface water inflows to lake & ${ }^{\circ} \mathrm{C}$ \\
\hline$T_{\text {swout }}$ & Temperature of the surface water outflows from lake & ${ }^{\circ} \mathrm{C}$ \\
\hline $\bar{T}$ & Mean monthly air temperature & ${ }^{\circ} \mathrm{C}$ \\
\hline $\bar{T}_{j}$ & Mean monthly air temperature in month $j$ & ${ }^{\circ} \mathrm{C}$ \\
\hline$\overline{T D}_{j}$ & $\begin{array}{l}\text { Mean monthly difference between mean daily maximum air } \\
\text { temperature and mean daily minimum air temperature (month } \\
\text { j) }\end{array}$ & ${ }^{\circ} \mathrm{C}$ \\
\hline$t$ & Cumulative time of bare soil evaporation & day \\
\hline$t_{L}$ & Lake lag time & month \\
\hline$t_{1}$ & $\begin{array}{l}\text { Length of the stage-1 atmosphere-controlled bare soil } \\
\text { evaporation period }\end{array}$ & day \\
\hline$t_{\text {day }}$ & Local time of day & undefined \\
\hline$t_{0}$ & Intermediate variable defined by Equation (S7.15) & month \\
\hline$t_{m}$ & Number of days in the month & day \\
\hline$\left[t_{L}\right]$ & Integral component of lag time & month \\
\hline $\begin{array}{l}T_{w}\left(z_{i}\right) \\
T_{w}\left(z_{i+1}\right)\end{array}$ & Water temperature at depths $z_{i}$ and $z_{i+1}$ & ${ }^{\circ} \mathrm{C}$ \\
\hline
\end{tabular}




\begin{tabular}{|c|c|c|}
\hline $\mathrm{u}$ & Mean daily wind speed & m day ${ }^{-1}$ \\
\hline$u_{2}$ & $\begin{array}{l}\text { Average daily wind speed at } 2 \mathrm{~m} \text { height (original Penman } 1948 \\
\text { and } 1956 \text { and Linacre wind function) }\end{array}$ & $\begin{array}{l}\mathrm{m} \mathrm{s}^{-1} \\
\left(\text { miles day }^{-1}\right)\end{array}$ \\
\hline$u_{10}$ & Average daily wind speed at $10 \mathrm{~m}$ height & $\mathrm{m} \mathrm{s}^{-1}$ \\
\hline$u_{\text {Pan }}$ & Average daily wind speed over pan & $\mathrm{m} \mathrm{s}^{-1}$ \\
\hline$u_{z}$ & Average daily wind speed at height $\mathrm{z}$ & $\mathrm{m} \mathrm{s}^{-1}$ \\
\hline$u_{*}$ & Friction velocity & $\mathrm{m} \mathrm{s}^{-1}$ \\
\hline $\bar{u}$ & Mean wind speed & $\mathrm{m} \mathrm{s}^{-1}$ \\
\hline$V P D$ & Vapour pressure deficit & $\mathrm{kPa}$ \\
\hline$V_{i}$ & Volume of each layer & $\mathrm{m}^{3}$ \\
\hline$V_{1}, V_{2}$ & Lake volume at the beginning and end of period & $\mathrm{m}^{3}$ \\
\hline$V P D_{2}, V P D_{50}$ & Vapour pressure deficit at $2 \mathrm{~m}$ and $50 \mathrm{~m}$ respectively & $\mathrm{kPa}$ \\
\hline$W$ & Proportion of open water & dimensionless \\
\hline $\mathrm{W}$ & Plant available water coefficient in Zhang 2-parameter model & dimensionless \\
\hline$x$ & Cross wind width of lake & $\mathrm{m}$ \\
\hline$z$ & Height of wind speed measurement & $\mathrm{m}$ \\
\hline$z_{e}$ & Depth of surface soil layer & $\mathrm{m}$ \\
\hline$z_{i+1}-z_{i}$ & Thickness of each layer & $\mathrm{m}$ \\
\hline$z_{2}$ & Height above ground of the water vapour measurement & $\mathrm{m}$ \\
\hline$z_{1}$ & Height above ground of the wind speed measurement & $\mathrm{m}$ \\
\hline$z_{h}$ & Height of the humidity measurements & $\mathrm{m}$ \\
\hline$z_{d}$ & Zero-plane displacement & $\mathrm{m}$ \\
\hline$z_{m}$ & Height of the instrument above ground & $\mathrm{m}$ \\
\hline$z_{o}$ & Roughness length or roughness height & $\mathrm{m}$ \\
\hline$z_{o h}$ & Roughness length governing transfer of heat and vapour & $\mathrm{m}$ \\
\hline$z_{\text {om }}$ & Roughness length governing momentum transfer & $\mathrm{m}$ \\
\hline$z_{o v}$ & Roughness length governing water transfer & $\mathrm{m}$ \\
\hline$\alpha$ & Albedo of the evaporating surface & dimensionless \\
\hline$\alpha_{A}$ & Albedo for Class-A pan & dimensionless \\
\hline$\alpha_{K P}$ & $\begin{array}{l}\text { Proportion of the net addition of energy from advection and } \\
\text { storage used in evaporation during } \Delta t\end{array}$ & dimensionless \\
\hline$\alpha_{S S}$ & Albedo of ground surface surrounding evaporation pan & dimensionless \\
\hline$\alpha_{\text {pan }}$ & $\begin{array}{l}\text { Proportion of energy exchanged through sides of evaporation } \\
\text { pan }\end{array}$ & dimensionless \\
\hline
\end{tabular}




\begin{tabular}{|c|c|c|}
\hline$\alpha_{P T}$ & Priestley-Taylor coefficient & dimensionless \\
\hline$\gamma$ & Psychrometric constant (for Morton's procedure) & $\begin{array}{l}\mathrm{kPa}{ }^{\circ} \mathrm{C}^{-1} \\
\left(\mathrm{mbar}^{\circ} \mathrm{C}^{-1}\right)\end{array}$ \\
\hline$\Delta$ & Slope of the saturation vapour pressure curve & $\mathrm{kPa}{ }^{\circ} \mathrm{C}^{-1}$ \\
\hline$\Delta^{\prime}$ & $d v_{T}^{*} / d T$ slope of the saturation vapour pressure curve at $\mathrm{T}$ & $\mathrm{kPa}^{\circ} \mathrm{C}^{-1}$ \\
\hline$\Delta H$ & $\begin{array}{l}\text { Change in heat storage (net energy gained from heat storage in } \\
\text { the water body) }\end{array}$ & MJ m-2 day-1 \\
\hline$\Delta Q$ & Change in stored energy during $\Delta t$ & $\mathrm{~mm}_{\mathrm{day}}{ }^{-1}$ \\
\hline$\Delta S$ & Change in soil moisture storage or stored water & $\begin{array}{l}\mathrm{mm}_{\text {day }}{ }^{-1} \\
\mathrm{~mm}_{\text {year }}{ }^{-1}\end{array}$ \\
\hline$\Delta W$ & $\begin{array}{l}\text { Change in heat storage in water column during the current time } \\
\text { step }\end{array}$ & $\mathrm{MJ} \mathrm{m}^{-2}$ day $^{-1}$ \\
\hline$\Delta t$ & Time interval & day \\
\hline$\Delta_{\mathrm{e}}$ & $\begin{array}{l}\text { Slope of the saturation vapour pressure curve at temperature } \\
T_{e} \text { for Morton's procedure }\end{array}$ & $\operatorname{mbar}^{\circ} \mathrm{C}^{-1}$ \\
\hline$\Delta_{\mathrm{w}}$ & Slope of the vapour pressure curve at water temperature & $\mathrm{kPa}^{\circ} \mathrm{C}^{-1}$ \\
\hline$\Delta_{\mathrm{wb}}$ & Slope of the vapour pressure curve at wet-bulb temperature & $\mathrm{kPa}^{\circ} \mathrm{C}^{-1}$ \\
\hline$\Delta\left(T_{e}\right)$ & Slope of the vapour pressure curve at temperature $T_{e}$ & $\mathrm{kPa}^{\circ} \mathrm{C}^{-1}$ \\
\hline$\Delta H_{j, j-1}$ & $\begin{array}{l}\text { Change in heat storage from month } j-1 \text { to month } j \text { for } \\
\text { Vardavas and Fountoulakis (1996) procedure }\end{array}$ & $\mathrm{W} \mathrm{m}^{-2}$ \\
\hline$\Delta T_{w l}$ & $\begin{array}{l}\text { Change in lake surface water temperature month } j-1 \text { to } \\
\text { month } j\end{array}$ & ${ }^{\circ} \mathrm{C}$ \\
\hline$\Delta_{\mathrm{e}}^{\prime}$ & $\begin{array}{l}\text { Working estimate of the slope of the saturation vapour } \\
\text { pressure curve at } T_{e} \text { for Morton's procedure }\end{array}$ & $\operatorname{mbar}{ }^{\circ} \mathrm{C}^{-1}$ \\
\hline$\delta$ & Solar declination & radians \\
\hline$\delta h$ & $\begin{array}{l}\text { Difference between heat content of inflows and outflows from } \\
\text { lake for Morton's procedure }\end{array}$ & $\mathrm{W} \mathrm{m}^{-2}$ \\
\hline$\delta T_{e}$ & A small change in the equilibrium temperature & undefined \\
\hline$\delta v_{e}$ & $=\Delta_{\mathrm{e}}^{\prime} \delta T_{e}$ & undefined \\
\hline$\varepsilon_{s}$ & Surface emissivity & dimensionless \\
\hline$\varepsilon$ & $\begin{array}{l}\text { Ratio of the temperature variations in the latent heat and } \\
\text { sensible heat contents of saturated air }\end{array}$ & dimensionless \\
\hline$\varepsilon_{w}$ & Emissivity of water & dimensionless \\
\hline$\theta$ & Sun's altitude & degrees \\
\hline$\theta_{F C}$ & Soil moisture content at field capacity & $\%$ \\
\hline$\theta_{W P}$ & Soil moisture content at wilting point & $\%$ \\
\hline$\lambda$ & Latent heat of vaporisation (for Morton's procedure) & $\begin{array}{l}\mathrm{MJ} \mathrm{kg}^{-1} \\
(\mathrm{~W} \text { day kg-1) }\end{array}$ \\
\hline$\lambda_{e}$ & Working variable & undefined \\
\hline$\xi$ & Dimensionless stability factor & dimensionless \\
\hline
\end{tabular}




\begin{tabular}{|c|c|c|}
\hline$\tau$ & Time constant for the storage & day \\
\hline$v$ & Kinematic viscosity of air & $\mathrm{m}^{2} \mathrm{~s}^{-1}$ \\
\hline$v_{4}$ & $\begin{array}{l}\text { Afternoon average vapour pressure } 4 \mathrm{~m} \text { above ground for } \\
\text { Webb (1966) procedure }\end{array}$ & mbar \\
\hline$v_{a}$ & Mean daily actual vapour pressure at air temperature & $\mathrm{kPa}$ \\
\hline$v_{d}$ & Vapour pressure at the reference height & $\mathrm{kPa}$ \\
\hline$v_{a}^{*}$ & $\begin{array}{l}\text { Daily saturation vapour pressure at air temperature (for } \\
\text { Morton's procedure) }\end{array}$ & $\begin{array}{l}\mathrm{kPa} \\
\text { (mbar) }\end{array}$ \\
\hline$v_{e}^{*}$ & Saturation vapour pressure at $T_{e}$ (for Morton's procedure) & $\begin{array}{l}\mathrm{kPa} \\
\text { (mbar) }\end{array}$ \\
\hline$v_{D}^{*}$ & $\begin{array}{l}\text { Saturation vapour pressure at dew point temperature for } \\
\text { Morton's procedure }\end{array}$ & mbar \\
\hline$v_{L}^{*}$ & $\begin{array}{l}\text { Afternoon average lake saturation vapour pressure for Webb } \\
\text { (1966) procedure }\end{array}$ & mbar \\
\hline$v_{P}^{*}$ & $\begin{array}{l}\text { Afternoon maximum pan saturation vapour pressure for Webb } \\
\text { (1966) procedure }\end{array}$ & mbar \\
\hline$\left(v_{a}^{*}-v_{a}\right)$ & Vapour pressure deficit at air temperature & $\mathrm{kPa}$ \\
\hline$v_{s}^{*}$ & Saturation vapour pressure at the water surface & $\mathrm{kPa}$ \\
\hline$v_{w}^{*}$ & Saturation vapour pressure at the evaporating surface & $\mathrm{kPa}$ \\
\hline$v_{a}\left(T_{a}\right)$ & $\begin{array}{l}\text { Vapour pressure at a given height above the water surface } \\
\text { evaluated at the air temperature } T_{a} \text { for Vardavas and } \\
\text { Fountoulakis (1996) procedure }\end{array}$ & mbar \\
\hline$v_{a}^{*}\left(T_{a}\right)$ & $\begin{array}{l}\text { Saturated vapour pressure at the water surface evaluated at air } \\
\text { temperature } T_{a} \text { for Vardavas and Fountoulakis (1996) } \\
\text { procedure }\end{array}$ & mbar \\
\hline$v_{e}^{*^{\prime}}$ & $\begin{array}{l}\text { Working estimate of the saturation vapour pressure at } \\
\text { equilibrium temperature (for Morton's procedure) }\end{array}$ & mbar \\
\hline$v_{T}^{*}$ & Saturation vapour pressure at temperature, $T$ & mbar \\
\hline$v_{T_{a}}^{*}$ & Saturation vapour pressure at air temperature, $T_{a}$ & $\mathrm{kPa}$ \\
\hline$v_{T_{S}}^{*}$ & Saturation vapour pressure at surface temperature, $T_{S}$ & $\mathrm{kPa}$ \\
\hline $\bar{v}_{a}$ & Mean daily actual vapour pressure & $\mathrm{kPa}$ \\
\hline$\rho_{a}$ & Mean air density at constant pressure & $\mathrm{kg} \mathrm{m}^{-3}$ \\
\hline$\rho_{w}$ & Density of water & $\mathrm{kg} \mathrm{m}^{-3}$ \\
\hline$\sigma$ & Stefan-Boltzmann constant (for Morton’s procedure) & $\begin{array}{l}\mathrm{MJ} \mathrm{K}-4 \mathrm{~m}^{-2} \\
\operatorname{day}^{-1} \\
\left(\mathrm{~W} \mathrm{~m} \mathrm{~m}^{-2} \mathrm{~K}^{-4}\right)\end{array}$ \\
\hline$\phi$ & Aridity index & dimensionless \\
\hline$\omega_{s}$ & Sunset hour angle & radian \\
\hline$\Omega$ & Decoupling coefficient & dimensionless \\
\hline$\eta_{a}, \eta_{c}, \eta_{s}$ & Working variables & undefined \\
\hline
\end{tabular}




\begin{tabular}{|l|l|l|}
\hline$v_{T \text { max }}^{*}$ & Saturated vapour pressure at Tmax & $\mathrm{kPa}$ \\
\hline$v_{T \min }^{*}$ & Saturated vapour pressure at Tmin & $\mathrm{kPa}$ \\
\hline
\end{tabular}

*Where possible a consistent set of units is used throughout the paper and supplementary appendices except for Appendices S20 and S21 which relate to Morton's (1983a, b and 1986) procedures. In this list of variables where the units are different from the common set, model names or references are included in the description. Non-SI units are either included in parenthesis along with the model name or the relevant reference is included in parenthesis in the description or, if listed separately, the model name or the relevant reference is also included. For some intermediate and working variables and where the source reference has not identified, the units are described as undefined. 


\section{Supplementary Material}

\section{Appendix S1 Data}

In this appendix, five issues are addressed - sources of climate data in Australia, climate data used in the analyses reported in later appendices, remotely sensed actual evapotranspiration, daily and monthly data, and location of meteorological stations relative to the target evaporating site.

\section{Sources of climate data in Australia}

1. In Australia at Automatic Weather Stations (AWSs) maintained by the Bureau of Meteorology and other operators, the following data as a minimum are monitored at a short time-step and are recorded as cumulative or average values over a longer interval: rainfall, temperature, humidity, wind speed and direction, and atmospheric pressure. Information is available at:

\section{http://www.bom.gov.au/inside/services_policy/pub_ag/aws/aws.shtml}

For Australian at-site daily wind data, it is recommended that, if available, 24-hour wind run data $\left(\mathrm{km} \mathrm{day}^{-1}\right)$ be used and converted to wind speed $\left(\mathrm{m} \mathrm{s}^{-1}\right)$.

2. Class-A pan evaporation data are also measured on a daily basis and, at some locations, the associated temperature and wind at or near the pan water surface are also recorded. A high-quality monthly Class-A pan data set of 60 stations across Australia is listed by Jovanovic et al. (2008). (Lavery et al. (1997) identified for Australia an extended highquality daily rainfall data set consisting of 379 gauges.)

3. In many parts of the world an alternative approach to using measured data directly is to deploy outputs from spatial interpolation and spatial modelling. If seeking to estimate evaporation at a point or localised area using data from a proximally located meteorological station, at-site data are optimal; however, these do not always exist. Specific to Australia, if seeking an estimate of evaporation for a larger area (e.g., a catchment or an administrative region) then gridded output is available. Donohue et al. (2010a; 2010b) have made available five potential evaporation formulations being: (i) Morton point; (ii) Morton areal; (iii) Penman; (iv) Priestley-Taylor; and (v) Thornthwaite in:

http://www-data.iwis.csiro.au/ts/climate/evaporation/donohue/Donohue_readme.txt.

It should be noted here that R. Donohue (pers. comm.) advised that "the reason Morton point potential values were so high in Donohue et al (2010b) was because, in their modelling of net radiation, they explicitly accounted for actual land-cover dynamics. Donohue et al (2010b) modelled $R_{S}$ (incoming shortwave radiation) using the Bristow and Campbell (1984) model calibrated to Australian conditions (McVicar and Jupp, 1999), and combined this with remotely sensed estimates of albedo (Saunders, 1990) to model $R_{n s}$ (net incoming shortwave radiation). $R_{n l}$ (net longwave radiation) was modelled according to Allen et al (1998) with soil and vegetation emissivity weighted by their per-pixel fractions determined from remotely sensed data (Donohue et al., 2009). This procedure differs from Morton’s (1983a) methodology, developed over 25 years ago, when remotely sensed data were not routinely available, and thus Donohue et al. (2010b) is in contradiction to Morton's (1983a) methodology."

The evaporation formulations in the above web-site are available at $0.05^{\circ}$ resolution from 1982 onwards at a daily $\left(\mathrm{mm} \mathrm{day}^{-1}\right)$, a monthly $\left(\mathrm{mm} \mathrm{month}^{-1}\right)$, an annual $\left(\mathrm{mm} \mathrm{year}^{-1}\right)$, or an annual average $\left(\mathrm{mm}\right.$ year $\left.{ }^{-1}\right)$ time-step. From the same web-site, at the same spatial and 
temporal resolutions as above, nine variables associated with the surface radiation balance are provided. They are: surface albedo (unitless), fractional cover (unitless), incoming longwave radiation ( $\left.\mathrm{MJ} \mathrm{m}^{-2} \mathrm{day}^{-1}\right)$, incoming shortwave radiation $\left(\mathrm{MJ} \mathrm{m}^{-2}\right.$ day $\left.^{-1}\right)$, outgoing longwave radiation $\left(\mathrm{MJ} \mathrm{m}^{-2}\right.$ day $\left.^{-1}\right)$, outgoing shortwave radiation $\left(\mathrm{MJ} \mathrm{m}^{-2}\right.$ day $\left.^{-1}\right)$, net radiation $\left(\mathrm{MJ} \mathrm{m}^{-2}\right.$ day $^{-1}$ ), top-of-atmosphere radiation ( $\mathrm{MJ} \mathrm{m}^{-2} \mathrm{day}^{-1}$ ), and diffuse radiation fraction (unitless). Additionally, the following reference datasets are also available including: wind speed at $2 \mathrm{~m}$ (TIN-based (Triangular Irregular Networks), units are $\mathrm{m} \mathrm{s}^{-1}$ ), saturated vapour pressure $(\mathrm{Pa})$, vapour pressure deficit $(\mathrm{Pa})$, slope of the saturated vapour pressure curve $\left(\mathrm{Pa} \mathrm{K}^{-1}\right)$, diurnal air temperature range $(\mathrm{K})$, mean air temperature $(\mathrm{K})$, Class-A pan evaporation modelled using the PenPan formulation ( $\mathrm{mm}_{\text {period }}{ }^{-1}$ ), and FAO-56 Reference Crop evapotranspiration (mm period $^{-1}$ ). It should be noted that Penman (1948) potential evaporation and PenPan evaporation are calculated with both a TIN-based wind data and a spline-based wind data. The latter for the period from 1 January 1975 can be accessed from (McVicar et al., 2008):

http://www-data.iwis.csiro.au/ts/climate/wind/mcvicar_etal_grl2008/.

We prefer using the spline-based wind data for spatial modelling, and when assessing trends the TIN-based model provided improved results (Donohue et al., 2010b). The FAO-56 Reference Crop (Allen et al., 1998) evapotranspiration only uses the spline-based wind speed data. These data can be linked with basic daily meteorological data (Jones et al., 2009) including: precipitation, maximum air temperature, minimum air temperature, and actual vapour pressure $(\mathrm{Pa})$ which are all available from:

http://www.bom.gov.au/climate/

The vegetation fractional cover data which are also available (Donohue et al., 2008) have been split into its persistent and recurrent components (Donohue et al., 2009); both available from:

http://datanet.csiro.au/dap/public/landingPage.zul?pid=csiro:AVHRR-derived-fPAR)

Thus, there is a now a very powerful resource of freely available data for regional ecohydrological modelling across Australia. There is also available a commercially-based SILO product of many of the key meteorological grids that are required to model evaporation across Australia (Jeffrey et al., 2001).

\section{Data used in later appendices}

The data used in the later appendices cover the period from January 1979 to February 2010 and include daily data for Class-A pan evaporation, sunshine hours, maximum and minimum temperature, maximum and minimum humidity and average wind speed. A minimum amount of missing daily temperature $(0.37 \%)$, relative humidity $(0.16 \%)$, sunshine hours $(0.43 \%)$ and wind speed $(0.35 \%)$ data was infilled for only days in which values were available on adjacent days from which the average was used to infill. Only months with a complete record of all variables were analysed. As a result the average length of station record with all variables is 15.9 years. Some of the analyses in this paper are based on daily data for 68 stations located across Australia (Figure S1). Class-A evaporation pan and climate data were obtained from the Climate Information Services, National Climate Centre, Bureau of Meteorology. Of these stations, 39 are part of the high quality Class-A pan evaporation network (Jovanovic et al., 2008, Table 1).

\section{Remotely sensed actual evapotranspiration}


Remotely sensed estimates of actual evapotranspiration (usually combining remotely sensed data with some climate data) are becoming more accurate and more accessible to analysts who are not experts in this technology. There are three main approaches to estimate actual evapotranspiration using remote sensing, namely: (i) thermal based methods based on the land surface energy balance (e.g., Sobrino et al. (2005), Kalma et al. (2008), Jia et al. (2009), Elhaddad et al. (2011), and Yang and Wang (2011)); (ii) methods that use the vegetation (and shortwave infrared) indices (e.g., Glenn et al., 2007; 2010; Guerschman et al (2009)); and (iii) hybrid methods that combine the surface temperature and vegetation index (e.g., Carlson, 2007; Tang et al., 2010). Readers wishing to pursue such approaches are referred to the growing volume of material that is accessible in the international literature.

\section{Daily and monthly data}

Analyses of most procedures are carried out for a daily and a monthly time-step. In the daily analysis, daily values of maximum and minimum temperature, maximum and minimum relative humidity, sunshine hours and daily wind run are required. For the analysis using a monthly time-step, the average daily values for each month and for each variable are the basis of computation.

\section{Location of meteorological stations relative to the target evaporating site}

In discussing evaporation procedures, most writers are silent on where to measure meteorological data to achieve the most accurate estimate of evaporation. For estimating evaporation from lakes using Morton's CRWE or CRLE model, land-based meteorological data can be used (Morton, 1983b, page 82). Furthermore, Morton (1986, page 378) notes that data measured over water have only a "...relatively minor effect..." on the estimate of lake evaporation. Morton (1986, page 378) says the CRAE, which estimate landscape evaporation (see Section 2.5.2), is different because “...the latter requires accurate temperature and humidity data from a representative [land-based] location”. (A discussion of Morton's evaporation models is presented in Section 2.5.2 and in Appendix S7.)

Based on a 45,790 ha lake in Holland, Keijman and Koopmans (1973) compared Penman (1948) evaporation for seven periods over 32 days with a water balance estimate, an energy budget estimate and observed pan evaporation data, where the meteorological instruments were located on a floating raft. The authors observed that the Penman (1948) lake evaporation estimates are highly correlated and show little bias with the water balance estimates and the energy balance estimates. Based on further analysis, Keijman (1974) concluded that for estimating energy balance at the centre of a lake land-based meteorological measurements downwind from the lake are preferred over measurements upwind.

In a major study of evaporation from Lake Nasser using three floating AWS, Elsawwaf et al. (2010) compared Penman (1956) evaporation with estimates from the Bowen Ratio Energy Budget method. The Penman method exhibited negative bias (Elsawwaf et al., 2010) which is consistent with the Penman (1948) results recorded in Holland. (In Appendix S4, the differences expected between Penman (1948) and Penman (1956) are discussed). 


\section{Supplementary Material}

\section{Appendix S2 Computation of some common variables}

This appendix includes equations to estimate common variables used in the evaporation equations. Values of specific constants are listed in Table S1.

\section{Mean daily temperature}

Mean daily temperature $=\frac{T_{\max }+T_{\min }}{2}$ (Allen et al., 1998, Equation 9)

where $T_{\max }$ and $T_{\min }$ are the maximum and minimum air temperatures $\left({ }^{\circ} \mathrm{C}\right)$, respectively, recorded over a 24-hour period.

Wet-bulb temperature

$$
T_{w b}=\frac{0.00066 \times 100 T_{a}+\frac{4098 v_{a}}{\left(T_{d}+237.3\right)^{2}} T_{d}}{0.00066 \times 100+\frac{4098 v_{a}}{\left(T_{d}+237.3\right)^{2}}} \text { (McJannet et al., 2008b, Equation 25) }
$$

where $T_{w b}$ is wet-bulb temperature $\left({ }^{\circ} \mathrm{C}\right), T_{d}$ is the dew point temperature $\left({ }^{\circ} \mathrm{C}\right)$ and $v_{a}$ is actual vapour pressure $(\mathrm{kPa})$.

\section{Dew point temperature}

$T_{d}=\frac{116.9+237.3 \ln \left(v_{a}\right)}{16.78-\ln \left(v_{a}\right)} \quad$ (McJannet et al., 2008b, Equation 26)

\section{Slope of the saturation vapour pressure curve}

$$
\Delta=\frac{4098\left[0.6108 \exp \left(\frac{17.27 T_{a}}{T_{a}+237.3}\right)\right]}{\left(T_{a}+237.3\right)^{2}} \text { (Allen et al., 1998, Equation 13) }
$$

where $\Delta$ is the slope of the saturation vapour pressure curve $\left(\mathrm{kPa}^{\circ} \mathrm{C}^{-1}\right)$ at the mean daily air temperature, $T_{a}\left({ }^{\circ} \mathrm{C}\right)$.

\section{Saturation vapour pressure at temperature, $T\left({ }^{\circ} \mathrm{C}\right)$}

$$
v_{T}^{*}=0.6108 \exp \left[\frac{17.27 T}{T+237.3}\right] \text { (Allen et al., 1998, Equation 11) }
$$

where $v_{T}^{*}$ is the saturation vapour pressure $(\mathrm{kPa})$ at temperature, $T\left({ }^{\circ} \mathrm{C}\right)$.

\section{Daily saturation vapour pressure}

$$
v_{a}^{*}=\frac{v_{a}^{*}\left(T_{\max }\right)+v_{a}^{*}\left(T_{\min }\right)}{2} \text { (Allen et al., 1998, Equation 12) }
$$

where $v_{a}^{*}$ is the daily (24-hour period) saturation vapour pressure $(\mathrm{kPa})$ at air temperature, and where the saturation vapour pressures are evaluated at temperatures $\left({ }^{\circ} \mathrm{C}\right) T_{\max }$ and $T_{\min }$.

\section{Mean daily actual vapour pressure}

$$
v_{a}=\frac{v_{a}^{*}\left(T_{\min }\right) \frac{R H_{\max }}{100}+v_{a}^{*}\left(T_{\max }\right) \frac{R H_{\min }}{100}}{2} \text { (Allen et al., 1998, Equation 17) }
$$

where $v_{a}$ is the mean daily actual vapour pressure $(\mathrm{kPa}), R H_{\max }$ is the maximum relative humidity (\%) in a day, and $R H_{\min }$ is the minimum relative humidity (\%) in a day.

\section{Mean daily actual vapour pressure using dew point temperature}

If daily dew point temperature is known, then daily actual vapour pressure can be estimated thus: 


$$
v_{a}=0.6108 \exp \left[\frac{17.27 T_{d}}{T_{d}+237.3}\right] \text { (Allen et al., 1998, Equation 14) }
$$

where $T_{d}$ is the dew point temperature $\left({ }^{\circ} \mathrm{C}\right)$.

\section{Psychrometric constant}

$$
\gamma=0.00163 \frac{p}{\lambda} \text { (Allen et al., 1998, Equation 8) }
$$

where $\gamma$ is the psychrometric constant $\left(\mathrm{kPa}^{\circ} \mathrm{C}^{-1}\right), \lambda$ is the latent heat of vaporization $=2.45$ $\mathrm{MJ} \mathrm{kg}^{-1}$ (at $20^{\circ} \mathrm{C}$ ), and $p$ is atmospheric pressure at elevation $z \mathrm{~m}$.

\section{Atmospheric pressure}

$$
p=101.3\left(\frac{293-0.0065 \text { Elev }}{293}\right)^{5.26} \text { (Allen et al., 1998, Equation 7) }
$$

where $p$ is the atmospheric pressure $(\mathrm{kPa})$ at elevation Elev $(\mathrm{m})$ above mean sea level.

\section{Zero-plane displacement (displacement height)}

Zero-plane displacement $\left(z_{d}\right)(\mathrm{m})$ can be explained as the height within obstacles, e.g., trees, in which wind speed is zero. Values are listed in Table S2. Allen et al. (1998, Box 4) reported that for a natural crop-covered surface and Wieringa (1986, Table 1) noted for an average obstacle height:

$$
z_{d}=\frac{2}{3} h
$$

where $h$ is the mean height of the roughness obstacles (including vegetation) (m).

\section{Roughness length (height)}

Roughness length $\left(z_{o}\right)(\mathrm{m})$ is related to the roughness of the evaporating surface and is the optimal parameter for defining terrain effects on wind (Wieringa, 1986, Table 1). Values are listed in Table S2. If values are not available for a particular terrain or surface, the following relationship can be used:

$$
z_{o} \cong \frac{(\text { vegetation height })}{10}
$$

\section{Units of evaporation}

Evaporation rates are expressed as depth per unit time, e.g., mm day ${ }^{-1}$, or the rates can also be expressed as energy flux and, noting that the latent heat of water is $2.45 \mathrm{MJ} \mathrm{kg}^{-1}$, it follows that $1 \mathrm{~mm} \mathrm{day}^{-1}$ of evaporation is equivalent to $2.45 \mathrm{MJ} \mathrm{m}^{-2}$ day$^{-1}$. 


\section{Supplementary Material}

\section{Appendix S3 Estimating net solar radiation}

This appendix outlines how net radiation is estimated with and without incoming solar radiation data. The method is based on the procedure outlined in Allen et al. (1998, pages 41 to 53).

$$
R_{n}=R_{n s}-R_{n l}
$$

where $R_{n}$ is the net radiation ( $\mathrm{MJ} \mathrm{m}^{-2}$ day $^{-1}$ ), $R_{n s}$ is the net incoming shortwave radiation ( $\mathrm{MJ} \mathrm{m}^{-2}$ day $^{-1}$ ), and $R_{n l}$ is the net outgoing longwave radiation ( $\mathrm{MJ} \mathrm{m}^{-2} \mathrm{day}^{-1}$ ).

Net shortwave solar radiation is estimated from the measured incoming solar radiation $\left(R_{S}\right)$ at an Automatic Weather Station and albedo for the evaporating surface as:

$$
R_{n s}=(1-\alpha) R_{s}
$$

where $R_{s}$ is the measured or estimated incoming solar radiation ( $\mathrm{MJ} \mathrm{m}^{-2}$ day $\left.^{-1}\right)$, and $\alpha$ is the albedo of the evaporating surface. Several albedo values are listed in Table S3.

Except for eight sites in Australia (Roderick et al., 2009a, Section 2.3), measured values of net longwave radiation are not available. Hence, net outgoing longwave radiation is estimated by:

$$
R_{n l}=\sigma\left(0.34-0.14 \bar{v}_{a}^{0.5}\right)\left(\frac{\left(T_{\max }+273.2\right)^{4}+\left(T_{\min }+273.2\right)^{4}}{2}\right)\left(1.35 \frac{R_{S}}{R_{S o}}-0.35\right)
$$

noting that $\frac{R_{S}}{R_{S o}} \leq 1$, and where $R_{n l}$ is the net outgoing longwave radiation $\left(\mathrm{MJ} \mathrm{m}^{-2} \mathrm{day}^{-1}\right), R_{S}$ is the measured or estimated incoming solar radiation $\left(\mathrm{MJ} \mathrm{m}^{-2}\right.$ day-1), $R_{s o}$ is the clear sky radiation $\left(\mathrm{MJ} \mathrm{m}^{-2}\right.$ day $\left.^{-1}\right), \bar{v}_{a}$ is the mean actual daily vapour pressure $(\mathrm{kPa}), T_{\text {max }}$ and $T_{\text {min }}$ are respectively the maximum and the minimum daily air temperature $\left({ }^{\circ} \mathrm{C}\right)$, and $\sigma$ is StefanBoltzmann constant ( $\mathrm{MJ} \mathrm{K}^{-4} \mathrm{~m}^{-2}$ day $^{-1}$ ).

$$
R_{\text {so }}=\left(0.75+2 \times 10^{-5} \text { Elev }\right) R_{a}
$$

where Elev is the ground elevation (m) above mean sea level of the automatic weather station (AWS), and $R_{a}$ is the extraterrestrial radiation ( $\mathrm{MJ} \mathrm{m}^{-2}$ day-1$^{-1}$ ) which is the solar radiation on a horizontal surface at the top of the earth's atmosphere and is computed by:

$$
R_{a}=\frac{1440}{\pi} G_{s c} d_{r}^{2}\left[\omega_{s} \sin (\text { lat }) \sin (\delta)+\cos (\text { lat }) \cos (\delta) \sin \left(\omega_{s}\right)\right]
$$

where $G_{s c}$ is the solar constant $=0.0820 \mathrm{MJ} \mathrm{m}^{-2} \mathrm{~min}^{-1}, d_{r}$ is the inverse relative distance Earth-Sun, $\omega_{s}$ is the sunset hour angle (rad), lat is latitude (rad) (negative for southern hemisphere), and $\delta$ is the solar declination (rad).

$$
d_{r}^{2}=1+0.033 \cos \left(\frac{2 \pi}{365} D o Y\right)
$$

This equation and Equation (S3.5) are modified from the errata provided with Allen et al. (1998) for their Equation 23. The amended Equation (S3.6) is shown in McCullough and Porter (1971, Equation 2) and amended Equation (S3.5) is shown in McCullough (1968, Equation 3).

$$
\delta=0.409 \sin \left(\frac{2 \pi}{365} D o Y-1.39\right)
$$

where $D o Y$ is Day of Year (see below). 
The sunset hour angle $\omega_{s}$ is estimated from:

$$
\omega_{s}=\operatorname{arcos}[-\tan (l a t) \tan (\delta)]
$$

If measured values of $R_{S}$ are not available, $R_{S}$ can be calculated from the ÁngströmPrescott equation (see Martinez-Lonano et al. (1984) and Ulgen and Hepbasli (2004) for historical developments and review of the equation) as follows:

$$
R_{s}=\left(a_{s}+b_{s} \frac{n}{N}\right) R_{a}
$$

where $n$ is the observed duration of sunshine hours, $N$ is the maximum possible duration of daylight hours, and $a_{s}$ and $b_{s}$ are constants. $a_{s}$ represents the fraction of extraterrestrial radiation reaching earth on sunless days $(n=0)$ and $a_{s}+b_{s}$ is the fraction of extraterrestrial radiation reaching earth on full-sun days $(n=N)$. Where calibrated values of $a_{s}$ and $b_{s}$ are not available, values of $a_{s}=0.25$ and $b_{s}=0.5$ are preferred (Fleming et al, 1989, Equation 3; Allen et al., 1998, page 50). A literature review of more than 50 models revealed that many estimates of $a_{s}$ and $b_{s}$, based on a monthly time-step have been developed (Menges et al., 2006, Yang et al, 2006, Roderick, 1999), although only five models are simple linear relationships as in Equation (S3.9). For these five models (Bahel et al., 1986; Benson et al., 1984; Louche et al., 1991; Page, 1961; Tiris et al., 1997 as reported in Menges et al., 2006), the average values of $a_{s}$ and $b_{s}$ are, respectively, 0.20 and 0.55 . Roderick (1999, page 181) in estimating monthly average daily diffuse radiation for 25 sites in Australia and Antarctica commented that his results were consistent with $a_{s}=0.23$ and $b_{s}=0.50$ based on Linacre (1968) and Stitger (1980). More recently, McVicar et al. (2007, page 202) considered the study by Chen et al. (2004) and adopted $a_{s}=0.195$ and $b_{s}=0.5125$ for their analysis of the middle and lower catchments of the Yellow River. It is recommended, however, that if local calibrated values are available for the study area, these values should be used.

If the number of sunshine hours is unavailable, alternatively cloudiness (in terms of oktas - the number of eights of the sky covered by cloud) may have been measured. Chiew and McMahon (1991) developed the following empirical relationship relating oktas to sunshine hours:

$$
n=a_{o}+b_{o} C_{O}+c_{o} C_{O}^{2}+d_{o} C_{O}^{3}
$$

where $n$ is the estimated sunshine hours, $C_{O}$ is cloud cover in oktas, and $a_{o}, \ldots, d_{o}$ are empirical constants and have been estimated for 26 climate stations across Australia. Values are provided in Chiew and McMahon (1991, Table A1). Errors in ground-based cloud cover estimates are discussed by Hoyt (1977).

The maximum daylight hours, $N$, is given by:

$$
N=\frac{24}{\pi} \omega_{s}
$$

where $\omega_{s}$ is the sunset hour angle (rad).

If sunshine hours or cloudiness are not available for Australia, following Linacre (1993, Equation 20) cloudiness can be estimated from:

$$
\begin{aligned}
& C_{D}=1+0.5 \log P_{j}+\left(\log P_{j}\right)^{2}, P_{j} \geq 1 \\
& C_{D}=1, P_{j}<1
\end{aligned}
$$

where $P_{j}$ is the monthly precipitation (mm). 
Thus, as an alternative to Equation (S3.9), $R_{S}$ can be computed from (Linacre (1993, Equation 19):

$$
R_{s}=\left(0.85-0.047 C_{D}\right) R_{a}
$$

where $C_{D}$ is the number of tenths of the sky covered by cloud, $R_{a}$ is the extraterrestrial radiation, and $R_{S}$ is the estimate of the incoming solar radiation.

\section{Estimating separately incoming and outgoing longwave radiation}

In some procedures to estimate evaporation e.g., McJannet et al. (2008b) discussed in Appendix S5, outgoing longwave radiation needs to be computed separately from incoming longwave radiation rather than being combined as in Equation S3.3. In McJannet et al. (2008b) outgoing longwave radiation is estimated as a function of water surface temperature and separately as a function of wet-bulb temperature.

In Equation (S3.1), $R_{n s}$ is estimated from Equations (S3.2), (S3.5), and (S3.9), and

$$
R_{n l}=R_{o l}-R_{i l}
$$

where $R_{o l}$ is the outgoing longwave radiation $\left(\mathrm{MJ} \mathrm{m}^{-2}\right.$ day $\left.^{-1}\right)$, and $R_{i l}$ is the incoming longwave radiation ( $\left.\mathrm{MJ} \mathrm{m}^{-2} \mathrm{day}^{-1}\right)$.

Following McJannet et al. (2008b, Equation 13) incoming longwave radiation may be estimated as follows:

$$
R_{i l}=\left(C_{f}+\left(1-C_{f}\right)\left(1-\left(0.261 \exp \left(-7.77 \times 10^{-4} T_{a}^{2}\right)\right)\right)\right) \sigma\left(T_{a}+273.15\right)^{4}
$$

where $R_{i l}$ is the incoming longwave radiation $\left(\mathrm{MJ} \mathrm{m}^{-2}\right.$ day $\left.^{-1}\right), T_{a}$ is the mean daily air temperature $\left({ }^{\circ} \mathrm{C}\right), \sigma$ is the Stefan-Boltzman constant $\left(\mathrm{MJ} \mathrm{K}^{-4} \mathrm{~m}^{-2}\right.$ day $\left.^{-1}\right)$, and $C_{f}$ is the fraction of cloud cover estimated from (McJannet et al, 208b, Equations 14 and 15):

$$
\begin{aligned}
& C_{f}=1.1-K_{\text {ratio }}, K_{\text {ratio }} \leq 0.9 \\
& C_{f}=2\left(1-K_{\text {ratio }}\right), K_{\text {ratio }}>0.9
\end{aligned}
$$

where $K_{\text {ratio }}=\frac{R_{S}}{R_{s o}}, R_{\text {so }}$ and $R_{S}$ are estimated from Equations (S3.4) and (S3.9).

Outgoing longwave radiation is estimated as a function of water temperature and/or wet-bulb temperature as follows McJannet at al. (2010, Equations 22 and 29):

$$
R_{o l}^{w a}=0.97 \sigma\left(T_{w}+273.15\right)^{4}
$$

where $R_{o l}^{w a}$ is the outgoing longwave radiation $\left(\mathrm{MJ} \mathrm{m}^{-2}\right.$ day $\left.^{-1}\right)$ based on water temperature, and $T_{w}$ is the water temperature $\left({ }^{\circ} \mathrm{C}\right)$,

$$
R_{o l}^{w b}=\sigma\left(T_{a}+273.15\right)^{4}+4 \sigma\left(T_{a}+273.15\right)^{3}\left(T_{w b}-T_{a}\right)
$$

where $R_{o l}^{w b}$ is the outgoing longwave radiation $\left(\mathrm{MJ} \mathrm{m} \mathrm{m}^{-2}\right.$ day $\left.^{-1}\right)$ based on wet-bulb temperature, and $T_{w b}$ is the wet-bulb temperature $\left({ }^{\circ} \mathrm{C}\right)$.

Estimating Day of Year (adapted from Allen et al., 1998, page 217)

The Day of Year (DoY) is computed for each day (D) of each month (M) as:

DoY=INTEGER $(275 * \mathrm{M} / 9-30+\mathrm{D})-2$

IF $(\mathrm{M}<3)$ THEN DoY $=$ DoY +2 
IF(leap year and $(M>2)$ THEN DoY $=$ DoY +1

Note that year 2000 is a leap year, whereas 1900 is not a leap year. 


\section{Appendix S4}

\section{Penman model}

The Penman or combination equation (Penman, 1948, Equation 16) for estimating open-water evaporation is defined as:

$$
E_{\text {Penow }}=\frac{\Delta}{\Delta+\gamma} \frac{R_{n w}}{\lambda}+\frac{\gamma}{\Delta+\gamma} E_{a}
$$

where $E_{\text {Penow }}$ is the daily open-water evaporation (mm day ${ }^{-1}$ ), $R_{n w}$ is the net radiation at the water surface ( $\mathrm{MJ} \mathrm{m}^{-2}$ day $\left.^{-1}\right), E_{a}\left(\mathrm{~mm} \mathrm{day}^{-1}\right)$ is a function of wind speed, saturation vapour pressure and average vapour pressure, $\Delta$ is the slope of the vapour pressure curve $\left(\mathrm{kPa}^{\circ} \mathrm{C}^{-1}\right)$ at air temperature, $\gamma$ is the psychrometric constant $\left(\mathrm{kPa}^{\circ} \mathrm{C}^{-1}\right)$, and $\lambda$ is the latent heat of vaporization (MJ kg-1). See Dingman (1992, Section 7.3.5) for a detailed discussion of Penman and evaporation issues in general.

In preparing this supplementary appendix, we were cognisant of de Bruin's (1987) comment. "The result of the [recent] developments ... is that Penman's formula experienced a large number of changes in the last decades and that at this very moment tens of different versions of the formula exist. This causes a tremendous confusion.” Thus, in the following material we identified several keys features of the Penman equation for inclusion herein.

It is noted in Section 2.1.1 that Equation (S4.1) is based on simplifying assumptions to account for the fact that the temperature of the evaporating surface is unknown. References for readers wishing to follow up on this topic include Monteith (1965), Monteith (1981) and Raupach (2001). Some commentary is provided at the end of this Section.

To estimate $R_{n w}$, details are given in Appendix S3. In estimating $R_{n w}$ an appropriate value of albedo $(\alpha)$ should be used, which depends on the evaporating surface (Table S3); for open-water $\alpha=0.08$. Although Penman (1948, pages 132 and 137) used 6-day and monthly time-steps in his studies, several analysts have used a daily time-step.

To estimate $E_{a}\left(\mathrm{~mm} \mathrm{day}^{-1}\right)$ in Equation (S4.1), one should use:

$$
E_{a}=f(u)\left(v_{a}^{*}-v_{a}\right)
$$

where $f(u)$ is the wind function and $\left(v_{a}^{*}-v_{a}\right)$ is the vapour pressure deficit $(\mathrm{kPa})$. In this paper, although there are several wind functions available (their application is discussed at the end of this appendix), we have adopted Penman's (1956) equation as standard:

$$
f(u)=1.313+1.381 u_{2}
$$

where $u_{2}$ is the average daily wind speed $\left(\mathrm{m} \mathrm{s}^{-1}\right)$ at $2 \mathrm{~m}$, and vapour pressure is measured in $\mathrm{kPa}$. (In Australia, wind run is recorded at $9 \mathrm{am}$ as the accumulated value over the previous 24 hours and, therefore, in Equation (S4.3) mean daily wind speed is based on the accumulated 24-hour value.)

\section{Equations for estimating $v_{a}^{*}, v_{a}$ and $\Delta$ are set out in Appendix S2.}

In the Penman equation, it is assumed there is no change in heat storage nor heat exchange with the ground, and no advected energy and, hence, the actual evaporation does not affect the overpassing air (Dingman, 1992, Section 7.3.5). Data required to apply the equation includes solar radiation (or sunshine hours or cloudiness), wind speed, air temperature and relative humidity, all averaged over the time-step adopted.

\section{Adjustment for the height of the wind speed measurement in Penman equation}


If wind measurements are not available at $2 \mathrm{~m}$ the following equation may be used to adjust $u_{z}$. This is important as the wind speed coefficients in Penman have been calibrated for wind speed at $2 \mathrm{~m}$.

$$
u_{2}=u_{z} \frac{\ln \left(\frac{2}{z_{0}}\right)}{\ln \left(\frac{z}{z_{0}}\right)}
$$

where $u_{2}$ and $u_{z}$ are respectively the wind speeds ( $\mathrm{m} \mathrm{s}^{-1}$ ) at heights $2 \mathrm{~m}$ and $z \mathrm{~m}$, and $z_{0}$ is the roughness height.

\section{Form of wind function}

Over the years Penman and other authors have suggested several forms for the wind function. The form of the original Penman (1948) wind function (using wind speed $u_{2}$ in miles day ${ }^{-1}$ and vapour pressure in mm of mercury) is:

$$
f(u)_{48}=0.35\left(1+9.8 \times 10^{-3} u_{2}\right)
$$

where $f(u)_{48}$ is the 1948 Penman wind function. Some authors (e.g., Szilagyi and Jozsa, 2008, page 173) have labelled this equation as the Rome wind function.

In 1956, Penman (1956) suggested that the original wind function should be reduced to accommodate both the Lake Hefner evaporation results and the original Rothamsted tank evaporation as follows:

$$
f(u)_{56}=0.35\left(0.5+9.8 \times 10^{-3} u_{2}\right)
$$

where $f(u)_{56}$ is the 1956 Penman wind function.

This equation in which $u_{2}$ is in miles per day and the saturation deficit is in units of mm of mercury is equivalent to Equation (S4.3) in which the average daily wind speed $u_{2}$ is in m $\mathrm{s}^{-1}$ and the vapour pressure deficit is in units of $\mathrm{kPa}$. Based on a study of several reservoirs in Australia and Botswana, Fleming et al. (1989, page 59) adopted this form of the wind function. Shuttleworth (1992, Section 4.4.4) observed that the Penman equation with the original wind function overestimated evaporation from large lakes by $10 \%$ to $15 \%$. Linacre (1993, page 243 and Appendix 1) observed from the median of 26 studies he identified and his own analysis of the heat transfer coefficient of water, that the coefficient was in the range $2.3 u$ to $2.6 u \mathrm{~W} \mathrm{~m}^{-2} \mathrm{~K}^{-1}$ (and $u$ in $\mathrm{m} \mathrm{s}^{-1}$ ), which implies that

$$
f(u)_{\text {LIN }} \text { is between } 0.31\left(9.8 \times 10^{-3} u_{2}\right) \text { and } 0.35\left(9.8 \times 10^{-3} u_{2}\right)
$$

where $f(u)_{L I N}$ is the Linacre wind function, $u_{2}$ is in miles day-1 and vapour pressure in $\mathrm{mm}$ of mercury for comparison with Equations S4.5 and S4.6.

Based on Brutsaert (1982), Valiantzas (2006, page 695) reported that the 1948 function is used more frequently than the 1956 function in hydrologic applications. However, Cohen et al. (2002, Section 4) reporting Stanhill (1963) noted the 1948 wind function to be unrealistically high. Using the FAO CLIMWAT global data ( 5000 stations world-wide), Valiantzas (2006) compared the $E_{P e n}$ values for the three wind functions and found that the following relationships held with an $\mathrm{R}^{2}=0.991$ :

$$
E_{\text {Penow }}\left|f(u)_{48} \approx 1.06 E_{\text {Penow }}\right| f(u)_{56} \approx 1.12 E_{\text {Penow }} \mid f(u)_{\text {LIN }}
$$

This result approximates our analysis which is based on applying the three wind functions to the 68 Australian stations (Table S4) as summarised below:

$$
E_{\text {Penow }}\left|f(u)_{48} \approx 1.11 E_{\text {Penow }}\right| f(u)_{56} \approx 1.19 E_{\text {Penow }} \mid f(u)_{L I N}
$$


Table S4 also shows a comparison with FAO-56 Reference Crop evapotranspiration and Priestley-Taylor evaporation as well as $10^{\text {th }}$ and $90^{\text {th }}$ percentile values.

Valiantzas (2006, page 696) suggested the 1948 wind function be adopted as standard in the Penman equation, however, noting the comments above by Shuttleworth (1992, Section 4.4.4), Linacre (1993) and Cohen et al (2002), we have adopted the Penman (1956) form of the wind function in this paper. In terms of the units used (vapour pressure in $\mathrm{kPa}$, and mean daily wind speed in $\mathrm{m} \mathrm{s}^{-1}$ ), the Penman 1956 wind function is:

$$
f(u)=1.313+1.381 u_{2}
$$

For comparison, Penman's 1948 wind function in the same units as Equation (S4.10) (vapour pressure in $\mathrm{kPa}$, and wind speed in $\mathrm{m} \mathrm{s}^{-1}$ ) is:

$$
f(u)=2.626+1.381 u_{2}
$$

\section{Penman equation without wind data}

Valiantzas (2006, Equation 33) proposed the following equation for situations where no wind data are available:

$$
E_{\text {Penow }} \approx 0.047 R_{S}\left(T_{a}+9.5\right)^{0.5}-2.4\left(\frac{R_{S}}{R_{a}}\right)^{2}+0.09\left(T_{a}+20\right)\left(1-\frac{R H_{\text {mean }}}{100}\right)
$$

where $E_{\text {Penow }}$ is Penman's open-water evaporation (mm day $\left.{ }^{-1}\right), R_{S}$ is the measured or estimated incoming solar radiation $\left(\mathrm{MJ} \mathrm{m}^{-2}\right.$ day $\left.^{-1}\right), T_{a}$ is the mean daily temperature $\left({ }^{\circ} \mathrm{C}\right), R_{a}$ is the extraterrestrial solar radiation $\left(\mathrm{MJ} \mathrm{m}^{-2}\right.$ day $\left.^{-1}\right)$ and $R H_{\text {mean }}$ is the mean daily relative humidity (\%). This assumes the albedo for water is 0.08 and the "0.09" in Equation (S4.12) applies to the Penman (1948) wind function. If one uses the Penman (1956) wind function, "0.09" should be replaced by "0.06". Based on six years of daily data from California, Valiantzas (2006) compared Equation (S4.12) with Equation (S4.1) using monthly data and found the modified equation performed satisfactorily $\left(\mathrm{R}^{2}=0.983\right.$, the long term ratio of "approximate" to "reference" evaporation was 0.995 , and SEE $=0.25 \mathrm{~mm} \mathrm{day}^{-1}$ ) compared with the standard Penman equation.

\section{Modifying Penman equation by including aerodynamic turbulence}

According to Fennessey (2000), van Bavel (1966) modified the original Penman 1948 equation to take into account boundary layer resistance as follows:

$$
E_{\text {Potow }}^{\prime}=\frac{\Delta}{\Delta+\gamma} \frac{R_{n}-G}{\lambda}+\frac{\gamma}{\Delta+\gamma} \frac{\rho_{a} c_{a}\left(v_{a}^{*}-v_{a}\right)}{\lambda r_{a}}
$$

where $E_{\text {Potow }}^{\prime}$ is the modified Penman open water evaporation ( $\mathrm{mm} \mathrm{day}^{-1}$ ) incorporating aerodynamic resistance, $\rho_{a}$ is the mean air density at constant pressure $\left(\mathrm{kg} \mathrm{m}^{-3}\right), c_{a}$ is the specific heat of the air ( $\mathrm{MJ} \mathrm{kg}^{-1}{ }^{\circ} \mathrm{C}^{-1}$ ), and $r_{a}$ is an "aerodynamic or atmospheric resistance" to water vapour transport $\left(\mathrm{s} \mathrm{m}^{-1}\right)$. Equation (S4.13) for open water is equivalent to the Penman-Monteith Equation (S5.1) with the surface resistance $r_{S}$ set to zero.

To estimate aerodynamic resistance, McJannet et al. (2008a) introduced a specific wind function incorporating lake area into the Calder and Neal (1984) aerodynamic resistance equation as follows:

$$
r_{a}=\frac{86400 \rho_{a} c_{a}}{\gamma\left(\frac{5}{A}\right)^{0.05}\left(3.80+1.57 u_{10}\right)}
$$


where $r_{a}$ is the aerodynamic resistance over a lake $\left(\mathrm{s} \mathrm{m}^{-1}\right), A$ is the lake area $\left(\mathrm{km}^{2}\right) \rho_{a}$ is the mean air density at constant pressure $\left(1.2 \mathrm{~kg} \mathrm{~m}^{-3}\right), c_{a}$ is the specific heat of the air $\left(0.001013 \mathrm{MJ} \mathrm{kg}^{-1}{ }^{\circ} \mathrm{C}^{-1}\right), \gamma$ is the psychrometric constant $\left(0.0668 \mathrm{kPa}^{\circ} \mathrm{C}^{-1}\right.$ at mean sea-level pressure $101.3 \mathrm{kPa}), u_{10}$ is the wind speed $\left(\mathrm{m} \mathrm{s}^{-1}\right)$ at $10 \mathrm{~m}$ height, yielding $r_{a}$ for a lake at sealevel as:

$$
r_{a}=\frac{410}{\left(\frac{5}{A}\right)^{0.05}\left(1+0.413 u_{10}\right)}
$$

It is noted here that $r_{a}$ is a function of wind speed as well as lake area.

Chin (2011, Equation 12) offered an alternative equation to estimate $r_{a}$ for wind speeds $\left(u_{2}\right)\left(\mathrm{m} \mathrm{s}^{-1}\right)$ measured at $2 \mathrm{~m}$ height and for no adjustment for lake area as follows:

$$
r_{a}=\frac{400}{\left(1+0.536 u_{2}\right)}
$$

Price (1994) estimated $r_{a}$ for Lake Ontario, Canada during a six-week summer period in 1991. Based on 2015 samples he determined a mean value of $r_{a}=201 \pm 122 \mathrm{~s} \mathrm{~m}^{-1}$. The wide range of observed values is a function of wind-speed.

\section{Estimating $\Delta$ under extreme conditions}

McArthur (1992, page 306) explains the assumptions behind $\Delta$ in the Penman equation (Equation (S4.1)). Equation (S4.17) provides the physically correct estimate of $\Delta$, which requires knowledge of the evaporating surface temperature $\left(T_{s}\right)$.

$$
\Delta=\frac{\left[v_{T_{S}}^{*}-v_{T_{a}}^{*}\right]}{\left(T_{s}-T_{a}\right)}
$$

However, because $T_{S}$ is generally unknown, $\Delta$ is approximated as the slope of the saturated vapour pressure curve at air temperature as follows:

$$
\Delta^{\prime}=\frac{d v_{T}^{*}}{d T} \quad \text { evaluated at air temperature }\left(T_{a}\right)
$$

In most practical situations $\Delta^{\prime}$ is an acceptable approximation to $\Delta$ when the surface and air temperatures are close (McArthur (1992, page 306)). Under extreme conditions, high aerodynamic resistance, high humidity and low temperature, the surface and air temperatures diverge and this approximation breaks down (Paw U (1992, page 299)) and can lead to underestimating evaporation by about 10\% (Slatyer and McIlroy, 1961; Paw U and Gao, 1988). Milly (1991), McArthur (1992) and Paw U (1992) provide a discussion of alternate procedures to estimate evaporation under such conditions. 


\section{Supplementary Material}

\section{Appendix S5 Penman-Monteith and FAO-56 Reference Crop models}

The Penman-Monteith model defined below is usually adopted to estimate potential evapotranspiration, $E_{P M}\left(\mathrm{~mm} \mathrm{day}^{-1}\right)$. The equation is based on Allen et al. (1998, Equation 3):

$$
E T_{P M}=\frac{1}{\lambda} \frac{\Delta\left(R_{n}-G\right)+\rho_{a} c_{a} \frac{\left(v_{a}^{*}-v_{a}\right)}{r_{a}}}{\Delta+\gamma\left(1+\frac{r_{s}}{r_{a}}\right)}
$$

where $E T_{P M}$ is the Penman-Monteith potential evapotranspiration (mm day ${ }^{-1}$ ), $R_{n}$ is the net radiation at the vegetated surface $\left(\mathrm{MJ} \mathrm{m}^{-2}\right.$ day $^{-1}$ ) incorporating an albedo value appropriate for the evaporating surface (Table S3), $G$ is the soil heat flux ( $\mathrm{MJ} \mathrm{m}^{-2}$ day $\left.^{-1}\right), \rho_{a}$ is the mean air density at constant pressure $\left(\mathrm{kg} \mathrm{m}^{-3}\right), c_{a}$ is the specific heat of the air $\left(\mathrm{MJ} \mathrm{kg}^{-1}{ }^{\circ} \mathrm{C}^{-1}\right), r_{a}$ is an "aerodynamic or atmospheric resistance" to water vapour transport, i.e., from the leaf surface to the atmosphere ( $\mathrm{s} \mathrm{m}^{-1}$ ) (Dunin and Greenwood, 1986, page 48), $r_{s}$ is a "surface resistance" term, that is the resistances from within the plant to the bulk leaf surfaces $\left(\mathrm{s} \mathrm{m}^{-1}\right)$ (Dunin and Greenwood, 1986, page 48), $\left(v_{a}^{*}-v_{a}\right)$ is the vapour pressure deficit $(\mathrm{kPa}), \lambda$ is the latent heat of vaporization ( $\left.\mathrm{MJ} \mathrm{kg}^{-1}\right), \Delta$ is the slope of the vapour pressure curve $\left(\mathrm{kPa}^{\circ} \mathrm{C}^{-}\right.$ ${ }^{1}$ ) at air temperature, and $\gamma$ is the psychrometric constant $\left(\mathrm{kPa}^{\circ} \mathrm{C}^{-1}\right) . G$ is defined as (Allen et al., 1998, Equation 41):

$$
G=c_{S} d_{s}\left(\frac{T_{i}-T_{i-1}}{\Delta t}\right)
$$

where $c_{s}$ is the volumetric heat capacity of soil $\left(\mathrm{MJ} \mathrm{m}^{-3}{ }^{\circ} \mathrm{C}^{-1}\right.$ ) (for an average soil moisture $c_{s} \cong 2.1$, Grayson et al., 1996, page 33), $d_{s}$ is the effective soil depth (m), $T_{i}$ and $T_{i-1}$ are the average air temperatures $\left({ }^{\circ} \mathrm{C}\right)$ on day $i$ and $i-1$ respectively, and $\Delta t$ is time-step (day).

It is noted in Section 2.1.2 that Equation (S5.1) is based on simplifying assumptions to account for the fact that the temperature of the evaporating surface is unknown. References for readers wishing to follow up on this topic include Monteith (1965), Monteith (1981) and Raupach (2001). An aspect of this issue is discussed in the previous section dealing with Equation (S4.14).

Generally, for daily time-steps $G$ can be assumed to be negligible (Allen et al., 1998, page 68).

\section{Values of aerodynamic resistance and surface (or canopy) resistance}

$r_{a}$, the aerodynamic resistance, controls the removal of water vapour from the plant surface under neutral stability conditions and is defined for an evaporating surface by Allen et al. (1998, Equation 4) as follows:

$$
r_{a}=\frac{\ln \left[\frac{z_{m}-d}{z_{o m}}\right] \ln \left[\frac{z_{h}-d}{z_{o h}}\right]}{k^{2} u_{z}}
$$

where $z_{m}$ is the height of the wind instrument (m), $z_{h}$ is the height of the humidity measurements $(\mathrm{m}), d$ is the zero plane displacement height $(\mathrm{m}), z_{o m}$ is the roughness length governing momentum transfer $(\mathrm{m}), z_{o h}$ is the roughness length governing transfer of heat and vapour (m), $k$ is von Kármán's constant (0.41), and $u_{z}$ is the wind speed at height $z_{m}\left(\mathrm{~m} \mathrm{~s}^{-1}\right)$.

According to Allen et al. (1998, page 21), for a wide range of crops, $d$ and $z_{o m}$ can be estimated from the crop height $(h)$ as: 
$d=0.67 h$, and

$z_{\text {om }}=0.123 h$

and $z_{o h}$ can be approximated from:

$z_{o h}=0.1 z_{o m}$

Some typical values of $r_{a}$ are listed in Table S2.

According to Chin (2011, Equation 12), Equation (S5.3) and the following Equation (S5.7), which is for water, are conventional practice for the PM equation.

$$
r_{a}=\frac{4.72\left[\ln \left(\frac{z_{m}}{z_{o}}\right)^{2}\right]^{2}}{1+0.54 u_{z}}
$$

where $z_{m}$ is the height of wind measurements and $z_{o}$ (roughness length) is:

$$
Z_{o}=\frac{(\text { vegetation height })}{10}
$$

For water $z_{o}=0.001 \mathrm{~m}$ (Table S2).

$r_{s}$, the surface resistance term, in vegetation represents bulk stomatal resistance or canopy resistance, which is a property of the plant type and its water stress level. This term controls the release of water to the plant or soil surface; some typical values of $r_{s}$ are listed in Table S2. For water, $r_{S}=0$.

Again following Allen et al. (1998, Equation 5), an alternative definition of $r_{s}$ after Szeicz et al. (1969, Equation 9) is:

$$
r_{s}=\frac{r_{l}}{L A I_{\text {active }}}
$$

where $r_{l}$ is the bulk stomatal resistance of a well-illuminated leaf $\left(\mathrm{s} \mathrm{m}^{-1}\right)$, and $L A I_{\text {active }}$ is the active (sunlit) leaf area index ( $\mathrm{m}^{2}$ (of leaf area) $\mathrm{m}^{-2}$ (of soil surface)). It is further noted by Allen et al. (1998) that $r_{l}$ is influenced by climate, water availability and vegetation type. They provide a simple example for a grass reference crop as follows:

$$
L A I_{\text {active }}=0.5 L A I \text {, and }
$$

and a general equation for LAI of grass is:

$$
L A I=24 h
$$

where $h$ is the crop height (m).

Given the stomatal resistance of a single leaf of grass is $\sim 100 \mathrm{~s} \mathrm{~m}^{-1}$ and the crop height is $0.12 \mathrm{~m}$ (Allen et al., 1998, page 22), then $r_{s}$ for a grass reference surface is:

$$
r_{s}=\frac{100}{0.5 \times 24 \times 0.12}=70 \mathrm{~s} \mathrm{~m}^{-1}
$$

Dingman (1992, page 296, footnote 9) notes that atmospheric conductance, $C_{a t m}$, is the inverse of aerodynamic resistance:

$$
C_{a t m}=\frac{1}{r_{a}}
$$

Also, it is implied from Dingman (1992, page 299) that canopy conductance, $C_{\text {can }}$, is the inverse of surface resistance:

$$
C_{\text {can }}=\frac{1}{r_{s}}
$$


Based on data collected in the Amazonian forest, Shuttleworth (1988) proposed that for a dry canopy the surface resistance can be described by the following quadratic function of time of day, with $r_{s}$ falling to a minimum late morning and rising to a very large value at dusk as follows:

$$
r_{s}=\frac{1000}{12.17-0.531\left(t_{d a y}-12\right)-0.223\left(t_{d a y}-12\right)^{2}}
$$

where $r_{s}$ is surface or canopy resistance $\left(\mathrm{s} \mathrm{m}^{-1}\right)$ and $t_{\text {day }}$ is local time of day in hours.

Readers interested in this topic are referred to Sharma (1984), Kelliher et al (1995), Magnani et al. (1998), Silberstein et al. (2003) and Amer and Hatfield (2004).

To understand the relative importance of radiation and atmospheric demand (through the vapour pressure deficit) in the transpiration process, Jarvis and McNaughton (1986, A16) introduced a decoupling coefficient, $\Omega$, (Equation S5.16) which ranges between 0 and 1 and is a measure of the decoupling between the conditions at the surface of a leaf and in the surrounding air:

$$
\Omega=\frac{\frac{\Delta}{\gamma}+1}{\frac{\Delta}{\gamma}+1+\frac{r_{S}}{r_{a}}}
$$

Wallace and McJannet (2010, page 109) explain the significance of $\Omega$ as follows. When $\Omega$ is small there is a strong coupling between the canopy and the atmosphere and, consequently, canopy conductance, the vapour pressure deficit and wind speed strongly influence transpiration, whereas as $\Omega$ approached 1 (complete decoupling) radiation is the dominant factor affecting transpiration. This relationship is explained mathematically by Kumagai et al (2004, Equation 3) as follows:

$$
E T_{P M}=\Omega E_{1 s t}+(1-\Omega) E_{2 n d}
$$

where $E_{1 s t}$ is the radiation (first) term in the PM model (Equation S5.1) and $E_{2 n d}$ is aerodynamic (second) term.

\section{FAO-56 Reference Crop Evapotranspiration}

If we substitute for $r_{a}$ and $r_{s}$ in Equation (S5.1) using the relevant equations in Allen et al. (1998, Equations (3) and (4)) and adopting the properties of the FAO-56 hypothetical crop of assumed height of $0.12 \mathrm{~m}$, a surface resistance of $70 \mathrm{~s} \mathrm{~m}^{-1}$ and an albedo of 0.23 , the substitutions yield the familiar FAO-56 Reference Crop evapotranspiration, $E T_{R C}$, equation (Allen et al., 1998, Equation 6):

$$
E T_{R C}=\frac{0.408 \Delta\left(\mathrm{R}_{\mathrm{n}}-\mathrm{G}\right)+\gamma \frac{900}{\mathrm{~T}_{\mathrm{a}}+273} \mathrm{u}_{2}\left(v_{a}^{*}-v_{a}\right)}{\Delta+\gamma\left(1+0.34 \mathrm{u}_{2}\right)}=E T_{R C s h}
$$

where $E T_{R C s h}$ is the Reference Crop evapotranspiration for short grass (mm day ${ }^{-1}$ ), $\mathrm{u}_{2}$ is the average daily wind speed $\left(\mathrm{m} \mathrm{s}^{-1}\right)$ at $2 \mathrm{~m}$, and $\mathrm{T}_{\mathrm{a}}$ is the mean daily air temperature $\left({ }^{\circ} \mathrm{C}\right)$. Meyer (1999) discusses the application of the Penman-Monteith equation to inland south-eastern Australia.

\section{ASCE-EWRI Standardized Penman-Monteith Equation}

The ASCE-EWRI Standardized Penman-Monteith Equation (S5.19) (ASCE, 2005, Equation 1, Table 1) was developed to estimate potential evapotranspiration from a tall crop with the following characteristics: vegetation height $0.50 \mathrm{~m}$, surface resistance $45 \mathrm{~s} \mathrm{~m}^{-1}$ and albedo of 0.23 . The equivalent equation to Equation (S5.18) for tall grass is: 


$$
E T_{R C t a}=\frac{0.408 \Delta\left(\mathrm{R}_{\mathrm{n}}-\mathrm{G}\right)+\gamma \frac{1600}{\mathrm{~T}_{\mathrm{a}}+273} \mathrm{u}_{2}\left(v_{a}^{*}-v_{a}\right)}{\Delta+\gamma\left(1+0.38 \mathrm{u}_{2}\right)}
$$

where $E T_{R C t a}$ is the Reference Crop evapotranspiration for tall grass (mm day ${ }^{-1}$ ).

\section{Adjustment for height of wind speed measurement in Penman-Monteith and FAO-56 Reference Crop equations}

The following equation is to adjust wind speed for instrument height associated with short grassed surfaces (Allen et al., 1998, Equation (47)):

$$
u_{2}=u_{z} \frac{4.87}{\ln (67.8 z-5.42)}
$$

where $u_{2}$ and $u_{z}$ are respectively the wind speeds at heights $2 \mathrm{~m}$ and $z \mathrm{~m}$.

\section{Reference Crop equation without wind data}

Valiantzas (2006, Equation 39) proposed the following equation (which is similar to the simplified Penman equation, see Equation (S4.12)), to estimate monthly Reference Crop evapotranspiration for situations where no wind data are available:

$$
E T_{R C} \approx 0.038 R_{S}(\bar{T}+9.5)^{0.5}-2.4\left(\frac{R_{S}}{R_{A}}\right)^{2}+0.075(\bar{T}+20)\left(1-\frac{R H}{100}\right)
$$

where $E T_{R C}$ is the Reference Crop estimate of evapotranspiration for short grass (mm day ${ }^{-1}$ ), $R_{S}$ is the measured or estimated average monthly incoming solar radiation $\left(\mathrm{MJ} \mathrm{m}^{-2}\right.$ day $\left.^{-1}\right), \bar{T}$ is the mean monthly air temperature $\left({ }^{\circ} \mathrm{C}\right), R_{A}$ is the average monthly extraterrestrial solar radiation ( $\mathrm{MJ} \mathrm{m}^{-2}$ day $^{-1}$ ) and $R H$ is the mean monthly relative humidity (\%). This procedure assumes the albedo $=0.25$ (rather than the standard 0.23) for a crop. For 535 northern hemisphere climate stations, monthly estimates of $E_{R C}$ based on Equation (S5.21) were compared with the standard reference crop Equation (S5.18). The approximate model performed very well on a sub-set of 4461 monthly estimates $\left(\mathrm{R}^{2}=0.951\right)$, the long term ratio of "approximate" to "reference" was 1.03 , and SEE $=0.34 \mathrm{~mm}^{-1} \mathrm{day}^{-1}$.

\section{Application of Penman-Monteith to water bodies based on equilibrium temperature}

An interesting application of the Penman-Monteith equation (Equation (S5.1) to a range of water bodies (irrigation channels, ponds, lakes, reservoirs streams and floodplains) was carried out by McJannet et al. (2008b) who set $r_{s}=0$ for water bodies (Table S2). The approach is outlined in Appendix S11.

\section{Shuttleworth-Wallace}

To deal with sparse vegetation Shuttleworth and Wallace (1985, Equations 11 to 18) modified the PM model to separate evapotranspiration into soil evaporation and transpiration. Wessel and Rouse (1994) further modified the Shuttleworth-Wallace (SW) model to accommodate evaporation from water surfaces but recommended that this component be not included in the SW approach. The Shuttleworth and Wallace (1985) equations are:

$$
\begin{aligned}
& E_{S W}=\frac{1}{\lambda}\left(C_{c a} P M_{c a}+C_{s u} P M_{s u}\right) \\
& P M_{c a}=\frac{1}{\lambda} \frac{\Delta A_{e}+\frac{\left[\rho c_{a}\left(v_{a}^{*}-v_{a}\right)-\Delta r_{a}^{c} A_{S S}\right]}{r_{a}^{a}+r_{a}^{c}}}{\Delta+\gamma\left[1+\frac{r_{s}^{c}}{r_{a}^{a}+r_{a}^{c}}\right]}
\end{aligned}
$$




$$
\begin{aligned}
P M_{s u} & =\frac{1}{\lambda} \frac{\Delta A_{e}+\frac{\left[\rho c_{a}\left(v_{a}^{*}-v_{a}\right)-\Delta r_{a}^{s}\left(A_{e}-A_{S S}\right)\right]}{r_{a}^{a}+r_{a}^{s}}}{\Delta+\gamma\left[1+\frac{r_{s}^{s}}{r_{a}^{a}+r_{a}^{s}}\right]} \\
C_{c a} & =\frac{1}{\left[1+\frac{\eta_{c} \eta_{a}}{\eta_{s}\left(\eta_{c}+\eta_{a}\right)}\right]} \\
C_{s u} & =\frac{1}{\left[1+\frac{\eta_{s} \eta_{a}}{\eta_{c}\left(\eta_{s}+\eta_{a}\right)}\right]} \\
\eta_{a} & =(\Delta+\gamma) r_{a}^{a} \\
\eta_{s} & =(\Delta+\gamma) r_{a}^{s}+\gamma r_{s}^{s} \\
\eta_{c} & =(\Delta+\gamma) r_{a}^{c}+\gamma r_{s}^{c}
\end{aligned}
$$

where $E_{S W}$ is the Shuttleworth-Wallace combined evaporation ( $\mathrm{mm} \mathrm{day}^{-1}$ ) from the vegetation and the soil, $P M_{c a}$ and $P M_{s u}$ are respectively the evaporation (mm day ${ }^{-1}$ ) from a closed canopy and from bare substrate, $A_{e}$ is the available energy ( $\mathrm{MJ} \mathrm{m}^{-2}$ day-1$^{-1}$ ) defined as the above-canopy fluxes of sensible heat and latent heat, and $A_{s s}$ is the energy ( $\mathrm{MJ} \mathrm{m}^{-2} \mathrm{day}^{-1}$ ) available at the substrate, $\lambda$ is the latent heat of vaporization $\left(\mathrm{MJ} \mathrm{kg}^{-1}\right), \Delta$ is the slope of the vapour pressure curve $\left(\mathrm{kPa}{ }^{\circ} \mathrm{C}^{-1}\right), \gamma$ is the psychrometric constant $\left(\mathrm{kPa}{ }^{\circ} \mathrm{C}^{-1}\right), c_{a}$ is the specific heat of the air ( $\mathrm{MJ} \mathrm{kg}^{-1}{ }^{\circ} \mathrm{C}^{-1}$ ) at air temperature, $\left(v_{a}^{*}-v_{a}\right)$ is the vapour pressure deficit $(\mathrm{kPa}), r_{a}^{a}$ is the aerodynamic resistance between the canopy source height and the reference level $\left(\mathrm{s} \mathrm{m}^{-1}\right), r_{a}^{c}$ is the bulk boundary layer resistance of the vegetative elements in the canopy level $\left(\mathrm{s} \mathrm{m}^{-1}\right), r_{a}^{s}$ is the aerodynamic resistance between the substrate and canopy source height level $\left(\mathrm{s} \mathrm{m}^{-1}\right), r_{s}^{c}$ is the bulk stomatal resistance of the canopy level $\left(\mathrm{s} \mathrm{m}^{-1}\right)$, and $r_{s}^{S}$ is the surface resistance of the substrate level $\left(\mathrm{s} \mathrm{m}^{-1}\right)$. Wessel and Rouse (1994, Section 4.1) were unable to determine the soil surface resistance, $r_{s}$, and adopted a value of $500 \mathrm{~s} \mathrm{~m}^{-1}$ for their hourly analysis.

It appears that Shuttleworth and Wallace (1985) did not prescribe the appropriate timestep that should be used in their model but Wessel and Rouse (1994) adopted both an hourly and daily time-step in their simulations. Readers interested in applying the SW model should refer to Stannard (1993) and Federer et al. (1996).

\section{Weighted Penman-Monteith}

In order to estimate the evaporation from a wetland, Wessel and Rouse (1994, Equation 14) proposed the following weighted Penman-Monteith approach:

$$
E_{\text {wetland }}=L A I E_{\text {can }}+S E_{\text {soil }}+W E_{\text {water }}
$$

where $E_{\text {wetland }}$ is the evapotranspiration $\left(\mathrm{mm} \mathrm{day}^{-1}\right)$ from the wetland, $E_{\text {can }}$ is the transpiration $\left(\mathrm{mm} \mathrm{day}^{-1}\right)$ from the canopy, $E_{\text {soil }}$ is the soil evaporation $\left(\mathrm{mm} \mathrm{day}^{-1}\right), E_{\text {water }}$ is the evaporation $\left(\mathrm{mm} \mathrm{day}^{-1}\right.$ ) from the standing water, $L A I$ is the leaf area index, and $\mathrm{S}$ and $\mathrm{W}$ are respectively the proportion of total area of bare soil and open water. $E_{c a n}, E_{\text {soil }}$ and $E_{\text {water }}$ are the Penman-Monteith estimates of ET for the canopy, soil and water as specified by Drexler et al. (2004, Equations 17 to 19):

$$
\begin{aligned}
& E_{\text {can }}=\frac{1}{\lambda} \frac{\Delta\left(R_{n}^{c a n}-G\right)+\frac{\rho c_{a}\left(v_{a}^{*}-v_{a}\right)}{r_{a}}}{\Delta+\gamma\left(1+\frac{r_{c}}{r_{a}}\right)} \\
& E_{\text {soil }}=\frac{1}{\lambda} \frac{\Delta\left(R_{n}^{\text {soil }}-G\right)+\frac{\rho c_{a}\left(v_{a}^{*}-v_{a}\right)}{r_{a}}}{\Delta+\gamma\left(1+\frac{r_{s}^{S}}{r_{a}}\right)}
\end{aligned}
$$




$$
E_{\text {water }}=\frac{1}{\lambda} \frac{\Delta\left(R_{n}^{\text {water }}-G\right)+\frac{\rho c_{a}\left(v_{a}^{*}-v_{a}\right)}{r_{a}}}{\Delta+\gamma}
$$

where $E_{\text {can }}, E_{\text {soil }}$, and $E_{\text {water }}$ are respectively the evaporation ( $\mathrm{mm} \mathrm{day}^{-1}$ ) from the canopy, soils and water, $R_{n}^{\text {can }}, R_{n}^{\text {soil }}$, and $R_{n}^{\text {water }}$ are respectively the net solar radiation ( $\mathrm{MJ} \mathrm{m}^{-2}$ day $^{-}$ $\left.{ }^{1}\right)$ to the canopy, soil and water, $G$ is the heat flux transfer ( $\mathrm{MJ} \mathrm{m}^{-2}$ day $^{-1}$ ) to and from the soil and water, and other variables are defined above.

\section{Matt-Shuttleworth}

Shuttleworth and Wallace (2009, page 1904) recommend that the FAO-56 Reference Crop method (Allen et al., 1998) should not be applied to irrigation areas like those in Australia that are semi-arid and windy. They recommend that the Matt-Shuttleworth (M-S) model be adopted in place of the FAO-56 Reference Crop method. The M-S model consists of five steps (details are given in Shuttleworth and Wallace (2009, as Equations 5, 8, 9, and 10):

1. Select the surface resistance for the target crop (from Shuttleworth and Wallace (2009, Table 3). For example, for rye grass the surface resistance is $66 \mathrm{~s} \mathrm{~m}^{-1}$.

2. Calculate

$$
r_{\text {clim }}=86400 \frac{\rho_{a} c_{a}(V P D)}{\Delta R_{n}}
$$

where $r_{\text {clim }}$ is termed the climatological resistance $\left(\mathrm{s} \mathrm{m}^{-1}\right), \rho_{a}$ is the mean air density $\left(\mathrm{kg} \mathrm{m}^{-3}\right)$ at constant pressure, $c_{a}$ is the specific heat of the air $\left(\mathrm{MJ} \mathrm{kg}^{-1}{ }^{\circ} \mathrm{C}^{-1}\right),(V P D)$ is the vapour pressure deficit $(\mathrm{kPa}), \Delta$ is the slope of the vapour pressure curve $\left(\mathrm{kPa}{ }^{\circ} \mathrm{C}^{-1}\right)$ at air temperature, and $R_{n}$ is the net radiation $\left(\mathrm{MJ} \mathrm{m}^{-2}\right.$ day $^{-1}$ ) at the vegetated surface. The 86,400 constant converts the radiation energy from $\mathrm{MJ} \mathrm{m}^{-2}$ day $^{-1}$ to $\mathrm{MJ} \mathrm{m}^{-2} \mathrm{sec}^{-1}$.

3. Calculate

$$
\frac{V P D_{50}}{V P D_{2}}=\left(\frac{302(\Delta+\gamma)+70 \gamma u_{2}}{208(\Delta+\gamma)+70 \gamma u_{2}}\right)+\frac{1}{r_{c l i m}}\left[\left(\frac{302(\Delta+\gamma)+70 \gamma u_{2}}{208(\Delta+\gamma)+70 \gamma u_{2}}\right)\left(\frac{208}{u_{2}}\right)-\left(\frac{302}{u_{2}}\right)\right]
$$

where $V P D_{50}$ and $V P D_{2}$ are the vapour pressure deficits $(\mathrm{kPa})$ at $50 \mathrm{~m}$ and $2 \mathrm{~m}$ height, and $u_{2}$ is the mean daily wind speed $\left(\mathrm{m} \mathrm{s}^{-1}\right)$ at $2 \mathrm{~m}$ height.

4. Calculate

$$
r_{C}^{50}=\frac{1}{(0.41)^{2}} \ln \left[\frac{(50-0.67 h)}{(0.123 h)}\right] \ln \left[\frac{(50-0.67 h)}{(0.0123 h)}\right] \frac{\ln \left[\frac{(2-0.08)}{0.0148}\right]}{\ln \left[\frac{(50-0.08)}{0.0148}\right]}
$$

where $r_{c}^{50}$ is the aerodynamic coefficient ( $\mathrm{s} \mathrm{m}^{-1}$ ) for crop height $(h)$

5. Calculate

$$
E T_{c}=\frac{1}{\lambda} \frac{\Delta R_{n}+\frac{\rho_{a} c_{a} u_{2}\left(V P D_{2}\right)}{r_{c}^{50}}\left(\frac{V P D_{50}}{V P D_{2}}\right)}{\Delta+\gamma\left(1+\frac{\left(r_{s}\right) c_{2}}{r_{c}^{50}}\right)}
$$

where $E T_{c}$ is the well-watered crop evapotranspiration in a semi-arid and windy location, $\lambda$ is the latent heat of vaporization ( $\left.\mathrm{MJ} \mathrm{kg}^{-1}\right),\left(r_{s}\right)_{c}$ is the surface resistance $\left(\mathrm{s} \mathrm{m}^{-1}\right)$ of a wellwatered crop equivalent to the FAO crop coefficient (Shuttleworth and Wallace, 2009, Table 3), and other variables are defined previously.

At five locations in Australia, Shuttleworth and Wallace (2009) compared water requirements estimated by the Matt-Shuttleworth method with the requirements estimated by 
FAO-56 Reference Crop method (Allen et al., 1998, Chapter 4) for irrigated sugar cane, cotton and short pasture. The analysis showed that within a growing season the differences between the two procedures varied considerably. However, over an entire season the M-S evapotranspiration estimate was 3\% to $15 \%$ higher for sugar cane, $6 \%$ higher for cotton and between $0.5 \%$ and $2.5 \%$ for pasture compared to the FAO-56 method (Shuttleworth and Wallace, 2009, Table 4 and page 1905). 


\section{Supplementary Material}

\section{Appendix S6 PenPan model}

There have been several variations of the Penman equation to model the evaporation from a Class-A evaporation pan. Linacre (1994) developed a physical model which he called the Penpan formula or equation. Rotstayn et al. (2006) coupled the radiative component of Linacre (1994) and the aerodynamic component of Thom et al. (1981) to develop the PenPan model which is defined, using the symbols of Johnson and Sharma (2010), as follows:

$$
E_{\text {PenPan }}=\frac{\Delta}{\Delta+a_{p} \gamma} \frac{R_{N P a n}}{\lambda}+\frac{a_{p} \gamma}{\Delta+a_{p} \gamma} f_{\text {Pan }}(u)\left(v_{a}^{*}-v_{a}\right)
$$

where $E_{\text {PenPan }}$ is the modelled Class-A (unscreened) pan evaporation (mm day-1), $R_{N P a n}$ is the net radiation ( $\mathrm{MJ} \mathrm{m}^{-2}$ day $\left.^{-1}\right)$ at the pan, $\Delta$ is the slope of the vapour pressure curve $(\mathrm{kPa}$ $\left.{ }^{\circ} \mathrm{C}^{-1}\right)$ at air temperature, $\gamma$ is the psychrometric constant $\left(\mathrm{kPa}^{\circ} \mathrm{C}^{-1}\right)$, and $\lambda$ is the latent heat of vaporization ( $\left.\mathrm{MJ} \mathrm{kg}^{-1}\right), a_{p}$ is a constant adopted as $2.4, v_{a}^{*}-v_{a}$ is the vapour pressure deficit $(\mathrm{kPa})$, and $f_{\text {Pan }}(u)$ is defined as (Thom et al., 1981, Equation 34):

$$
f_{\text {Pan }}(u)=1.201+1.621 u_{2}
$$

where $u_{2}$ is the average daily wind speed at $2 \mathrm{~m}$ height $\left(\mathrm{m} \mathrm{s}^{-1}\right)$.

To estimate $R_{N P a n}$, we refer to Rotstayn et al. (2006, Equations 4 and 5)):

$$
\begin{aligned}
& R_{N P a n}=\left(1-\alpha_{A}\right) R_{\text {SPan }}-R_{n l} \\
& R_{\text {SPan }}=\left[f_{\text {dir }} P_{\text {rad }}+1.42\left(1-f_{\text {dir }}\right)+0.42 \alpha_{\text {SS }}\right] R_{S}
\end{aligned}
$$

where $R_{S P a n}$ is the total shortwave radiation $\left(\mathrm{MJ} \mathrm{m}^{-2}\right.$ day-1) received by the pan, $R_{n l}$ is the net outgoing longwave radiation $\left(\mathrm{MJ} \mathrm{m}^{-2}\right.$ day $\left.^{-1}\right)$ from the pan, $R_{S}$ is the incoming solar radiation (shortwave) ( $\mathrm{MJ} \mathrm{m}{ }^{-2}$ day $^{-1}$ ) at the surface, $f_{\text {dir }}$ is the fraction of $R_{S}$ that is direct, $P_{\text {rad }}$ is a pan radiation factor, $\alpha_{A}$ is the albedo for a Class-A pan given as 0.14 (Linacre, 1992) as reported by Rotstayn et al. (2006, page 2), and $\alpha_{s s}$ is the albedo of the ground surface surrounding the evaporation pan (Table S3). To be consistent with Equation (S3.1) we have assumed the net outgoing longwave radiation $R_{n l}$ as positive. As noted by Roderick et al. (2007, page 1), $R_{S P a n}>R_{S}$ because of the interception of energy by the pan walls.

$$
\begin{aligned}
& f_{\text {dir }} \text { and } P_{\text {rad }} \text { are defined as: } \\
& f_{\text {dir }}=-0.11+1.31 \frac{R_{S}}{R_{a}} \\
& P_{\text {rad }}=1.32+4 \times 10^{-4} \text { lat }+8 \times 10^{-5} \text { lat }^{2}
\end{aligned}
$$

where $R_{a}$ is the extraterrestrial radiation $\left(\mathrm{MJ} \mathrm{m}^{-2} \mathrm{day}^{-1}\right)$, and lat is the absolute value of latitude in degrees.

The equations to estimate $R_{n l}$ are set out in Appendix S3. The above analysis is carried out on a monthly time-step.

\section{Application to Australian data}

Using the PenPan model (with $a_{s}=0.23$ and $b_{s}=0.50$ as noted in Appendix S3), the mean monthly ratio of the PenPan evaporation, adjusted for the bird-screen, to the Class-A pan evaporation over the 68 stations (consisting of approximately 11840 ratios over all months) is 1.078. The monthly evaporation estimates are plotted in Figure S3. The performance of the PenPan model in estimating Class-A pan evaporation is satisfactory 
although the PenPan values are biased towards slightly higher values at lower evaporations. These results compare favourably with PenPan versus Class-A pan evaporation results of Rotstayn et al. (2006, Figure 4), Roderick et al. (2007, Figure 1) and Johnson and Sharma (2010, Figure 1) especially as we use the standard climate data available through the Bureau of Meteorology National Climate Centre and sunshine hours as the basis of estimating solar radiation.

An objective of this supplementary material was to develop for Australia mean monthly evaporation pan coefficients (relating open surface-water based on Penman to Class-A pan evaporation). Confidence in the monthly Penman estimates is based on the fact that the PenPan estimates, which utilise the same climatic data and a similar model structure as for the Penman model, were found to estimate the monthly pan evaporation very satisfactorily. In order to estimate Penman evaporation suitable for computing pan coefficients, we varied $a_{s}$ and $b_{s}$ values so that the overall monthly PenPan/Class-A pan ratio for the 68 stations was unity. We argue that the optimised values of $a_{s}=0.05$ and $b_{s}=0.65$ obtained in this way provided realistic monthly Penman values and, therefore, realistic pan coefficients. The mean monthly pan coefficients for the 68 Australian stations are listed in Table S6. 


\section{Supplementary Material}

\section{Appendix S7 Morton models}

In 1985, Morton et al. (1985) published the program WREVAP which sets out operational aspects for computing estimates of areal evapotranspiration and lake evaporation. WREVAP contains three models CRAE (Complementary Relationship Areal Evapotranspiration) (Morton, 1983a), CRWE (Complementary Relationship Wet-Surface Evaporation) (Morton, 1983b) and CRLE (Complementary Relationship Lake Evaporation) (Morton, 1986). CRAE computes evapotranspiration for the land-based environment whereas CRWE deals with shallow lakes and CRLE considers deep lakes where water-borne heat input and energy storage are key issues. The three models are shown comparatively in Table 2 and are described in detail below.

In Morton's procedure, measurements of solar radiation are not required but are estimated through sunshine duration. However, if solar radiation data are available they may be used. The climate variables necessary to compute Morton's monthly evaporation are mean monthly maximum and minimum air temperature, dew point temperature (or monthly relative humidity), monthly sunshine duration and mean annual rainfall. For periods shorter than one month, Morton (1983a, page 28) imposed a limit on the shortest time-step for analysis and advocated a minimum of five days. However, for hydrological applications, Morton (1986, page 379 ) permits daily time-step analysis so long as the daily values are accumulated to a week or longer. But, it is important for lake analysis, described in CRLE below, that the timestep of analysis be one month (Morton (1986, page 379).

Morton (1986, page 378) notes that the CRLE model estimates are sensitive to radiation inputs (or sunshine hours) but insensitive to errors in air temperature and relative humidity inputs, whereas the CRAE model requires accurate air temperature and relative humidity from a representative location. For lakes, land-based meteorological data can be used (Morton, 1983b, page 82). Furthermore, Morton (1986, page 378) notes that data measured over water have only a “...relatively minor effect...” on the estimate of lake evaporation.

\section{CRAE}

The CRAE model consists of three components: potential evapotranspiration, wetenvironment areal evapotranspiration and actual areal evapotranspiration. A discussion of each component follows.

\section{Estimating potential evapotranspiration (ET $T_{\text {Pot }}$ in Figure 1)}

Morton's approach to estimating potential evapotranspiration for a catchment or a large vegetated surface is to solve the energy-balance and the vapour transfer equations respectively for potential evapotranspiration and the equilibrium temperature:

$$
\begin{aligned}
& E T_{P o t}^{M o}=\frac{1}{\lambda}\left(R_{n}-\left[\gamma p f_{v}+4 \epsilon_{s} \sigma\left(T_{e}+273\right)^{3}\right]\left(T_{e}-T_{a}\right)\right) \\
& E T_{P o t}^{M o}=\frac{1}{\lambda}\left(f_{v}\left(v_{e}^{*}-v_{D}^{*}\right)\right)
\end{aligned}
$$

where $E T_{P o t}^{M o}$ is Morton's estimate of point potential evaporation (mm day ${ }^{-1}$ ), $R_{n}$ is the net radiation $\left(\mathrm{W} \mathrm{m} \mathrm{m}^{-2}\right.$ ) for soil-plant surfaces at air temperature, $\gamma$ is the psychrometric constant (mbar ${ }^{\circ} \mathrm{C}^{-1}$ ), $p$ is the atmospheric pressure (mbar), $f_{v}$ is a vapour transfer coefficient ( $\mathrm{W} \mathrm{m}^{-2}$ mbar $\left.^{-1}\right), \epsilon_{s}$ is the surface emissivity, $\sigma$ is the Stefan-Boltzmann constant $\left(\mathrm{W} \mathrm{m}^{-2} \mathrm{~K}^{-4}\right), T_{e}$ and $T_{a}$ are the equilibrium and air temperatures $\left({ }^{\circ} \mathrm{C}\right), v_{e}^{*}$ is the saturation vapour pressure (mbar) 
at $T_{e}, v_{D}^{*}$ is the saturation vapour pressure (mbar) at dew point temperature, and $\lambda$ is the latent heat of vaporisation ( $\mathrm{W}$ day $\mathrm{kg}^{-1}$ ). (Note, the units used in Morton's procedures have been adopted here to ensure that the correct values of the empirical constants are included.)

$f_{v}$ is given by:

$$
f_{v}=\left(\frac{p_{s}}{p}\right)^{0.5} \frac{f_{z}}{\xi}
$$

where $p_{s}$ and $p$ are the sea-level atmospheric pressure (mbar) and at-site atmospheric pressure (mbar) respectively, $f_{Z}$ is a constant $\left(\mathrm{W} \mathrm{m} \mathrm{mbar}^{-1}\right)$, and $\xi$ is a dimensionless stability factor estimated from:

$$
\xi=\frac{1}{0.28\left(1+\frac{v_{D}^{*}}{v_{a}^{*}}\right)+\frac{R_{n} \Delta}{\left[\gamma p\left(\frac{p_{s}}{p}\right)^{0.5} b_{0} f_{z}\left(v_{a}^{*}-v_{D}^{*}\right)\right]}} \text { noting that } \xi \geq 1
$$

where $v_{D}^{*}$ is the saturation vapour pressure (mbar) at dew point temperature, $v_{a}^{*}$ is the saturation vapour pressure (mbar) at air temperature, $\Delta$ is the slope of the saturation vapour pressure curve (mbar ${ }^{\circ} \mathrm{C}^{-1}$ ) at air temperature, and $b_{0}=1.0$ for the CRAE model (Table 2).

Morton (1983a, Section 5.1) sets out the following procedure to find $T_{e}$ by iteration, and then $E_{P o t}^{M O}$ can be estimated from Equation (S7.1). Assume a trial value of $T_{e}^{\prime}$, which yields $\Delta_{\mathrm{e}}^{\prime}$ and $\delta T_{e}=T_{e}-T_{e}^{\prime}$, hence $\delta v_{e}=\Delta_{\mathrm{e}}^{\prime} \delta T_{e}$ and $v_{e}^{* \prime}=v_{e}^{*}+\delta v_{e}$. Equating Equations (S7.1) and (S7.2) and substituting gives:

$$
\delta T_{e}=\frac{\frac{R_{n}}{f_{v}}+v_{a}^{*}-v_{e}^{* \prime}+\lambda_{e}\left(T-T_{e}^{\prime}\right)}{\left(\Delta_{\mathrm{e}}^{\prime}+\lambda_{e}\right)}
$$

where $\lambda_{e}=\gamma p+\frac{4 \epsilon \sigma\left(T_{e}+273\right)^{3}}{f_{v}}$

and variables are defined previously.

Initially, $T_{e}^{\prime}$ is set equal to the air temperature and the iterative procedure continues until $\delta T_{e}$ becomes $<0.01^{\circ} \mathrm{C}$. Further details of the procedure are not included here but a worked example is provided in Appendix S21.

\section{Estimating wet-environment areal evapotranspiration (ET $T_{W e t}$ in Figure 1)}

To estimate the wet-environment areal evapotranspiration, which is equivalent to the conventional definition of potential evapotranspiration, Morton added an empirically derived advection constant $\left(b_{1}\right)$ to the Priestley-Taylor equation (Equation (6) with $G=0$ ) as follows:

$$
E T_{W e t}^{M o}=\frac{1}{\lambda}\left(b_{1}+b_{2} \frac{R_{n e}}{\left(1+\frac{\gamma p}{\Delta_{\mathrm{e}}}\right)}\right)
$$

where $E T_{W e t}^{M o}$ is the wet-environment areal evapotranspiration $\left(\mathrm{mm} \mathrm{day}^{-1}\right), R_{n e}$ is the net radiation $\left(\mathrm{W} \mathrm{m}^{-2}\right)$ for the soil-plant surface at $T_{e}\left({ }^{\circ} \mathrm{C}\right), \Delta_{\mathrm{e}}$ is the slope of the saturation vapour pressure curve (mbar ${ }^{\circ} \mathrm{C}^{-1}$ ) at $T_{e}\left({ }^{\circ} \mathrm{C}\right), b_{1}$ and $b_{2}$ are empirical coefficients, and the other variables are as defined previously. Values of $b_{1}$ and $b_{2}$, which were derived by Morton (1983a, page 25) for representative regions, are set out in Table 2. $R_{n e}$ is estimated as follows (Morton, 1983a, Equation C37):

$$
R_{n e}=E T_{P o t}^{M o}+\gamma p f_{v}\left(T_{e}-T_{a}\right)
$$


In their analysis of Australian data, Wang et al. (2001) adopted after calibration $f_{Z}=$ 29.2 $\mathrm{Wm}^{-2} \mathrm{mbar}^{-1}$ (Equation (S7.3)) and $b_{1}$ and $b_{2}$ (Equation S7.7) equal to $13.4 \mathrm{Wm}^{-2}$ and $1.13 \mathrm{Wm}^{-2}$ instead of $28 \mathrm{Wm}^{-2} \mathrm{mbar}^{-1}, 14 \mathrm{Wm}^{-2}$, and $1.2 \mathrm{Wm}^{-2}$ respectively (Table 2) to give an overall value of the Priestley-Taylor coefficient, $\alpha_{P T}$, equal to 1.26 rather than Morton's 1.32 value. Chiew and Leahy (2003, Section 2.3) argue that the recalibrated values better represent Australian data. Our analysis for Australia stations (to be reported in later document) confirms that the Wang et al. (2001) calibrated parameters yield more realistic results than those of Morton.

\section{Estimating actual areal evapotranspiration (ET $T_{A c t}$ in Figure 1)}

To estimate Morton's actual areal evapotranspiration $\left(E T_{A c t}^{M o}\right)\left(\mathrm{mm} \mathrm{day}^{-1}\right)$, one uses the results from Equations (S7.1) and (S7.7) in the Complementary Relationship as follows:

$$
E T_{A c t}^{M o}=2 E T_{W e t}^{M o}-E T_{P o t}^{M o}
$$

Morton (1983a, page 29) argues that as the models are completely calibrated they are accurate world-wide.

\section{Limitations of CRAE model}

Morton (1983a, page 28) points out five limitations of the CRAE model:

1. The model requires accurate measurements of humidity data.

2. The model should not be used for intervals of three days or less, however, as Morton (1983a) notes, so long as the accumulated values for a week or longer are accurate then a daily time-step is acceptable. (For lake evaporation, a monthly time-step should be used (Morton et al., 1985)).

3. The CRAE model should not be used near sharp discontinuities, e.g., near the edge of an oasis.

4. The climatological station should be representative of the area of interest.

5. Because the CRAE model does not use knowledge about the soil-vegetation system, it should not be used to examine the impact of natural or man-made change in the system.

\section{Documentation of CRAE model}

Documentation of the detailed steps to apply the CRAE model is given in Morton (1983a), Appendix C, and will not be repeated here. Our Appendix S21 provides a worked example.

\section{CRWE}

In CRWE, the only difference to CRAE is that the radiation absorption and the vapour transfer characteristics reflect the water surface rather than a vegetated surface (Morton, 1983b) (Table 2). The CRWE model provides estimates of lake-size wet surface evaporation from routine climate data observed in the land environment. Furthermore, according to Morton (1986, page 371) monthly evaporation can be accumulated to provide reliable estimates of lake evaporation at the annual time-step for lakes up to approximately $30 \mathrm{~m}$ deep. To estimate the evaporation from a shallow lake, Equation (S7.7) is applied with coefficients $b_{1}$ and $b_{2}$ taking values given in Table 2 .

\section{CRLE}

In the CRLE model, the computational procedure to estimate lake evaporation is the same as that used in CRWE except that the energy term is net energy available, which depends on solar and water inputs for the current and previous months. In estimating deep 
lake evaporation on a monthly time-step, where changes in sub-surface heat storage may be important, Morton (1986, page 376) adopts a classical lag and route procedure where the routing is a linear storage function. The 1986 method, which we adopt herein, is different to Morton's (1983b, Section 3) method. In the 1983 method, storage routing is applied to estimates of the shallow lake evaporation, whereas in Morton's (1986) procedure, the solar and water borne inputs are routed and then lake evaporation is estimated. Using Morton's symbols we summarise the four-step procedure of Morton (1986) as follows. Firstly, estimates of the solar and water borne heat input are computed:

$$
G_{W}^{0}=(1-\alpha) R_{s}-R_{n l}+\delta h
$$

where $G_{W}^{0}$ is the solar and waterborne heat input $\left(\mathrm{W} \mathrm{m}^{-2}\right), R_{S}$ is the incident global radiation $\left(\mathrm{W} \mathrm{m} \mathrm{m}^{-2}\right), R_{n l}$ is the net outgoing longwave radiation $\left(\mathrm{W} \mathrm{m}^{-2}\right), \alpha$ is albedo for water, (1$\alpha R s$ is the net incoming shortwave radiation $\left(\mathrm{W} \mathrm{m}^{-2}\right)$, and $\delta h$, which is usually small, is the difference between heat content of inflows and outflows from the lake $\left(\mathrm{W} \mathrm{m}^{-2}\right)$. However, $\delta h$ may be important for small lakes that receive cooling water with elevated temperatures, e.g., from a thermal power station or for a small deep lake with seasonal heat input from a large river (Morton, 1986, page 376). Note that Equation (S7.10) is different to Morton (1986, Equation 2) in that he appears not to have included net longwave radiation at this point in the analysis.

Secondly, the delayed energy input is computed from:

$$
G_{W}^{t}=G_{W}^{\left[t_{L}\right]}+\left(t_{L}-\left[t_{L}\right]\right)\left(G_{W}^{\left[t_{L}+1\right]}-G_{W}^{\left[t_{L}\right]}\right)
$$

where $\left[t_{L}\right]$ and $\left(t_{L}-\left[t_{L}\right]\right)$ are the integral and fractional components of the lake lag or delay time, $t_{L}$, (months), $G_{W}^{\left[t_{L}\right]}$ and $G_{W}^{\left[t_{L}+1\right]}$ are respectively the value $\left(\mathrm{W} \mathrm{m}{ }^{-2}\right)$ of $G_{W}^{0}$ computed for $\left[t_{L}\right]$ and for $\left[t_{L}+1\right]$ months previously.

The third step uses a linear routing procedure to route on a monthly time-step the available input energy, $G_{W}^{t}$, through the storage as follows:

$$
\begin{aligned}
& G_{L E}=G_{L B}+\frac{G_{W}^{t}-G_{L B}}{0.5+S_{c}} \\
& G_{L}=0.5\left(G_{L E}+G_{L B}\right)
\end{aligned}
$$

where $G_{L}$ is the monthly lake energy input $\left(\mathrm{W} \mathrm{m}^{-2}\right), G_{L B}$ and $G_{L E}$ are the available solar and waterborne heat energy $\left(\mathrm{W} \mathrm{m}^{-2}\right)$ at the beginning and end of the month respectively, and $S_{c}$ is the storage coefficient or routing constant (months).

To compute $S_{c}$ and $t_{L}$, the average lake depth and the lake salinity are taken into account as follows:

$$
\begin{aligned}
S_{c} & =\frac{t_{0}}{\left[1+\left(\frac{\bar{h}}{93}\right)^{7}\right]} \\
t_{0} & =0.96+0.013 \bar{h} \text { with } 0.039 \bar{h} \leq t_{0} \leq 0.13 \bar{h} \\
t_{L} & =\frac{t_{0}}{\left(1+\frac{s}{27000}\right)^{2}} \text { with } t \leq 6.0
\end{aligned}
$$

where $t_{0}$ is the soft water delay time (months), $\bar{h}$ is the average depth of the lake (m), and $s$ is the lake salinity (ppm) (1 ppm 1.56 microS $\mathrm{cm}^{-1}$ or EC units). 
The final step is to input monthly values of $G_{L}$ as $R_{n}$ into Equation S7.1 to estimate deep lake monthly evaporation.

Typically, reservoir evaporation exceeds the evapotranspiration that would have occurred from the inundated area in the natural state. This net evaporation can be estimated as the difference between lake evaporation and actual areal evapotranspiration (Morton, 1986, item 4, page 386).

In Morton's procedure, solar radiation measurements are not required as these are estimated from the other observed climate variables in the model. Chiew and Jayasuriya (1990) and Szilagyi (2001, page 198) indicate that estimates of daily global and net radiation by the Morton (1983a, Appendix C.1.2) procedure are accurate. Some researchers, e.g., Wang et al. (2001) and Szilagyi and Jozsa (2008) have used observed solar radiation data instead of Morton's empirical estimate of $R_{T}$, which is equivalent to $R_{S}$ in this paper.

A listing of a Fortran 90 version of Program WREVAP, which follows closely Morton (1983a, Appendix C) and the routing scheme described in Morton (1986), is provided in Appendix S20.

\section{Australian application of the complementary relationship}

Wang et al. (2001) used Morton's (1983a) model to produce a series of maps for Australia showing mean monthly areal potential evapotranspiration, point potential evapotranspiration and areal actual evapotranspiration; these terms were adopted by Wang et al (2001). The maps, which are at $0.1^{\circ}(\sim 10 \mathrm{~km})$ grid resolution, are available at http://www.bom.gov.au/climate/averages and as a hard-copy in Wang et al. (2001). The detailed methodology is described in Chiew et al. (2002). Wang et al. (2001) provides the following guidelines for the application of the maps noting that they should not be used in estimating open water evaporation:

- Areal potential evapotranspiration (equivalent to Morton's wet environment areal evapotranspiration $E T_{\text {Wet }}^{\text {Mo }}$ )

o Large area with unlimited water supply

o “Areal” $>1 \mathrm{~km}^{2}$

o Upper limit to actual evapotranspiration in rainfall-runoff modelling studies

o Evapotranspiration from a large irrigation area with no shortage of water

- Point potential evapotranspiration (equivalent to Morton's potential evapotranspiration $E T_{\text {Pot }}^{M o}$ )

o ET from a point with unlimited water supply

o A small irrigation area surrounded by unirrigated area

o Approximate preliminary estimate of evaporation from farm dams and shallow water storages

Based on 55 locations across Australia Chiew and Leahy (2003) found that $E T_{\text {Pot }}$ could be used as a substitute for Class-A pan evaporation.

Following an extensive analysis of potential evaporation formulations across Australia, Donohue et al. (2010b, page 192) have provided two of the Morton evaporation estimates namely areal potential evapotranspiration and point potential evapotranspiration as daily time-step grids. However, they concluded that the Morton point potential method is unable to reproduce evaporation dynamics observed across Australia and is unsuitable for general use. However, R. Donohue (pers. comm.) advised that "the reason Morton point potential values were so high in Donohue et al. (2010b) was because, in their modelling of net radiation, they explicitly accounted for actual land-cover dynamics. This procedure differs from Morton's 
(1983) methodology, developed over 25 years ago, when remotely sensed data were not routinely available, and thus Donohue et al. (2010b) is in contradiction to Morton's (1983) methodology." 


\section{Supplementary Material}

\section{Appendix S8 Advection-Aridity and like models}

\section{Advection-aridity model}

Based on the Complementary Relationship, Brutsaert and Strickler (1979, page 445) proposed the Advection-Aridity (AA) model to estimate actual evapotranspiration $\left(E T_{A c t}\right)$ in which they adopted the Penman equation for potential evapotranspiration $\left(E T_{P o t}\right)$ and the Priestley-Taylor equation for the wet-environment $\left(E T_{W e t}\right)$. The Complementary Relationship is:

$$
E T_{A c t}=2 E T_{W e t}-E T_{\text {Pot }}
$$

and substituting for the Penman (Equation (4)) and Priestley-Taylor (Equation (6)) and rearranging yields:

$$
E T_{A c t}^{B S}=\left(2 \alpha_{P T}-1\right) \frac{\Delta}{\Delta+\gamma} \frac{R_{n}}{\lambda}-\frac{\gamma}{\Delta+\gamma} f\left(u_{2}\right)\left(v_{a}^{*}-v_{a}\right)
$$

where $E T_{A c t}^{B S}$ is the actual areal evapotranspiration $\left(\mathrm{mm} \mathrm{day}^{-1}\right)$ based on Brutsaert and Strickler (1979), $R_{n}$ is the net radiation ( $\mathrm{MJ} \mathrm{m}^{-2}$ day $^{-1}$ ) at the evaporating vegetative surface, $\alpha_{P T}$ is the Priestley-Taylor parameter, $u_{2}$ is the average daily wind speed in $\mathrm{m} \mathrm{s}^{-1}, v_{a}^{*}$ and $v_{a}$ are respectively the saturation vapour pressure and the vapour pressure of the overpassing air $(\mathrm{kPa})$ at aie temperature, $\Delta$ is the slope of the saturation vapour pressure curve at air temperature $\left(\mathrm{kPa}^{\circ} \mathrm{C}^{-1}\right), \gamma$ is the psychrometric constant $\left(\mathrm{kPa}^{\circ} \mathrm{C}^{-1}\right)$ and $\lambda$ is the latent heat of vaporization $\left(\mathrm{MJ} \mathrm{kg}^{-1}\right)$.

Based on an energy budget for a rural catchment in Holland, Brutsaert and Strickler (1979, page 445) adopted a Priestley and Taylor (1972) constant $\alpha_{P T}$ of 1.28 rather than 1.26 (see Section 2.1.3) and Penman's (1948) wind function $f\left(u_{2}\right)$ as:

$$
f\left(u_{2}\right)=2.626+1.381 u_{2}
$$

which, according to Brutsaert and Strickler (1979, page 445), is equivalent to a surface of moderate roughness. In the comparison, $R_{n}$ was measured by a net radiometer and surface albedo did not need to be assessed. If measured values of $R_{n}$ are not available the adopted value of albedo should be appropriate for the surface conditions (see Table S3).

Brutsaert and Strickler (1979, Figures 1 to 4 ) tested their model at a daily time-step and observed that integrating the daily ET estimates over three days achieved better agreement with energy budget estimates than single day estimates. Equation (S8.2) sometimes generates negative ET values at the daily time-step.

Hobbins et al. (2001a) applied the AA model of Brutsaert and Strickler (1979) and the CRAE model of Morton (1983a) to 120 minimally impacted U.S. catchments and found the AA model underestimated annual actual evapotranspiration by $10.6 \%$ of mean annual precipitation; the CRAE model overestimated annual evapotranspiration by only $2.5 \%$ of precipitation (Hobbins et al., 2001a, Abstract). Hobbins et al. (2001b) recalibrated the AA model for a larger data set (139 minimally impacted basins) and adopted monthly regional wind functions, $f\left(u_{2}\right)$. Using $\alpha_{P T}=1.3177$ they achieved a more satisfactory result than the original AA model. Another application of the AA model and the Zhang et al. (2001) model is by Brown et al. (2008, Table 1) who examined the spatial distribution of water supply in the United States. Across the U.S., the AA model overestimated the US Geological Survey gauged data by $4 \%$ and the Zhang model underestimated the gauged data by $5 \%$. 
Monteith (1981, page 24) offers the following comment regarding the Brutsaert and Strickler equation. "The scheme ... has the merit of elegance and simplicity but its foundations need strengthening. Apart from the uncertainty which surrounds the value of $\alpha$ and it physical significance, Bouchet's hypothesis of complementarity between actual and potential rates of evaporation needs to be substantiated by an appropriate model of the planetary boundary layer.”

\section{Granger-Gray model}

To estimate actual evapotranspiration from non-saturated lands, Granger and Gray (1989) developed a modified form of the Penman (1948) equation following Granger (1998) as follows:

$$
E T_{A c t}^{G G}=\frac{\Delta G_{g}}{\Delta G_{g}+\gamma} \frac{R_{n}-G}{\lambda}+\frac{\gamma G_{g}}{\Delta G_{g}+\gamma} E_{a}
$$

where $E T_{A c t}^{G G}$ is the actual evapotranspiration (mm day ${ }^{-1}$ ) based on Granger and Gray (1989), $R_{n}$ is the net radiation ( $\mathrm{MJ} \mathrm{m}^{-2}$ day $^{-1}$ ) near the evaporating surface (hence the albedo adopted is for the evaporating surface), $G$ is the heat flux into the soil ( $\mathrm{MJ} \mathrm{m}^{-2} \mathrm{day}^{-1}$ ), $\lambda$ is the latent heat of vaporization (MJ kg-1), $\Delta$ is the slope of the saturation vapour pressure curve at air temperature $\left(\mathrm{kPa}{ }^{\circ} \mathrm{C}^{-1}\right)$, and $\gamma$ is the psychrometric constant $\left(\mathrm{kPa}^{\circ} \mathrm{C}^{-1}\right), E_{a}$ is the drying power of the air (Equation S4.2), and $G_{g}$ is a dimensionless evaporation parameter, which is based on several surface types, and is defined as (Granger, 1998, Equations 6 and 7):

$$
G_{g}=\frac{1}{0.793+0.20 e^{4.902 D_{p}}}+0.006 D_{p}
$$

where $D_{p}$, a dimensionless relative drying power, is defined as:

$$
D_{p}=\frac{E_{a}}{E_{a}+\frac{R_{n}-G}{\lambda}}
$$

where $G$ is set to zero.

Adopting a daily time-step, $\mathrm{Xu}$ and Chen (2005, page 3725) compared, inter alia, Granger-Gray (GG) model with 12 years of daily lysimeter observations located at Mönchengladbach-Rheindahlen meteorological station in Germany and found the GG model performed better than the Brutsaert and Strickler Advection-Aridity model and the Morton CRAE model (Xu and Chen (2005, Abstract).

\section{Szilagyi-Jozsa model}

Based on theoretical considerations, Szilagyi (2007) offered an alternative modification of the AA model which was further amended by Szilagyi and Jozsa (2008, Equation (10)) to the following:

$$
E T_{A c t}^{S J}=2 E_{P T}\left(T_{e}\right)-E_{P e n}
$$

where $E T_{A c t}^{S J}$ is actual evapotranspiration $\left(\mathrm{mm} \mathrm{day}^{-1}\right), E T_{P T}\left(T_{e}\right)$ is wet-environment evaporation (mm day ${ }^{-1}$ ) estimated by Priestley-Taylor at $T_{e}\left({ }^{\circ} \mathrm{C}\right), E_{P e n}$ is potential evapotranspiration ( $\mathrm{mm} \mathrm{day}^{-1}$ ) estimated by Penman using the 1948 wind function.

To evaluate $T_{e}$, Szilagyi and Jozsa (2008) considered the Bowen Ratio (Bowen, 1926) for a small lake or sunken pan and found the equilibrium surface temperature, $T_{e}$, could be estimated iteratively on a daily basis from (Szilagyi and Jozsa, 2008, Equation (8)):

$$
\frac{R_{n}}{\lambda E_{\text {Pen }}}=1+\frac{\gamma\left(T_{e}-T_{a}\right)}{v_{e}^{*}-v_{a}}
$$


where $R_{n}$ is the available energy ( $\mathrm{MJ} \mathrm{m}^{-2}$ day $\left.^{-1}\right), E_{P e n}$ is the Penman evaporation (mm day ${ }^{-1}$ ) based on $T_{a}$, and $T_{e}$ and $T_{a}$ are respectively the equilibrium and air temperatures $\left({ }^{\circ} \mathrm{C}\right), v_{e}^{*}$ is the saturation vapour pressure $(\mathrm{kPa})$ at $T_{e}, v_{a}$ is the actual vapour pressure $(\mathrm{kPa})$ at $T_{a}, \lambda$ is the latent heat of vaporization $\left(\mathrm{MJ} \mathrm{kg}^{-1}\right)$, and $\gamma$ is the psychrometric constant $\left(\mathrm{kPa}^{\circ} \mathrm{C}^{-1}\right)$.

Based on daily data and adopting $\alpha_{P T}=1.31$ but applying the Complementary Relationship to obtain monthly $E T_{A c t}^{S J}$ values, Szilagyi and Jozsa (2008) tested Equation (S8.7) against actual evaporation estimated by Morton's WREVAP model for 210 SAMSON (Solar and Meteorological Surface Observation Network) stations in the United States and found excellent agreement $\left(\mathrm{R}^{2}=0.95\right)$ (Szilagyi and Jozsa, 2008, Figure 6). Szilagyi et al (2009, page 574) applied their modified AA model to 25 watersheds, 194 SAMSON sites and 53 semi-arid SAMSON sites and concluded that their modified AA model performed better than the Brutsaert and Strickler (1979) traditional AA model.

In applying Equation (S8.7), a daily time-step is used and an albedo value for the vegetative surface is adopted. We note that when we applied Equation (S8.7) to days of very low net radiation, negative values of evaporation were occasionally estimated, a feature also observed in the Brutsaert and Strickler (1979, page 448) Aridity-Advection model (see Appendix S18). 


\section{Supplementary Material}

\section{Appendix S9 Additional evaporation equations}

Although the following empirical equations (except the energy based procedure described at the end of this appendix) have been extensively referenced or widely used in past practice and therefore are included in this paper, we are of the view that the more physicallybased equations described earlier are generally more appropriate for estimating evaporation or evapotranspiration. This is particularly so in regions where empirical coefficients have not been derived.

\section{Dalton-type equations}

Mass-transfer equations of the following form were first described by John Dalton in 1802 and are known as Dalton-type equations (Dingman, 1992, Section 7.3.2):

$$
E=C_{e m p} f(u)\left(v_{s}^{*}-v_{a}\right)
$$

where $E$ is the actual surface evaporation ( $m$ day $\left.^{-1}\right), f(u)$ is an appropriate wind function, $v_{s}^{*}$ is the saturation vapour pressure $(\mathrm{kPa})$ at the evaporating surface, $v_{a}$ is the atmospheric vapour pressure (kPa), and $C_{e m p}$ is an empirical constant. McJannet et al. (2012) reviewed 19 studies for estimating open water evaporation and proposed a wind function (Equation 14) that depends on the area of the evaporating surface (see Section 2.4.2).

\section{Thornthwaite (1948)}

In the Thornthwaite evaporation method, the only meteorological data required to compute mean monthly potential evapotranspiration is mean monthly air temperature, The original steps in Thornthwaite's (1948) procedure involved a nomogram and tables, which can be represented by the follow equations (Xu and Singh, 2001, Equations 4a and 4b):

$$
\bar{E}_{T h, j}=16\left(\overline{\frac{h r d a y}{12}}\right)\left(\frac{\text { daymon }}{30}\right)\left(\frac{10 \bar{T}_{J}}{I}\right)^{a_{T h}}
$$

where $\bar{E}_{T h, j}$ is the Thornthwaite 1948 estimate of mean monthly potential evapotranspiration

(mm month ${ }^{-1}$ ) for month $j$, ( $j=1$ to 12 ), $\overline{h r d a y}$ is the mean daily daylight hours in month $j$, daymon is the number of days in month $j, \bar{T}_{J}$ is the mean monthly air temperature $\left({ }^{\circ} \mathrm{C}\right)$ in month $j$, and $I$ is the annual heat index. The annual heat index is estimated as the sum of the monthly indices:

$$
I=\sum_{j=1}^{12} i_{j}
$$

where $i=\left(\frac{\bar{T}_{J}}{5}\right)^{1.514}$

and $a_{T h}=6.75 \times 10^{-7} I^{3}-7.71 \times 10^{-5} I^{2}+0.01792 I+0.49239$

It is noted that strict application of Thornthwaite (1948) yields only 12 values of potential evapotranspiration, a mean value for each calendar month. However, in several studies, Thornthwaite's procedure has been modified to allow a time series of daily (Federer et al., 1996; Donohue et al., 2010b) or monthly (Xu and Singh, 2001; Lu et al., 2005; Amatya et al., 1995; Xu and Chen, 2005; Trajkovic and Kolakovic, 2009) potential evaporation values to be computed.

Building on Thornthwaite's (1948) water balance procedure used in his climate classification analysis, Thornthwaite and Mather (1957) developed a procedure for computing a water balance. We suggest readers planning to use the Thornthwaite-Mather method pay 
attention to Black's (2007) paper in which he notes that there are significant differences between a 1955 version of the methodology and the 1957 version which, according to Black (2007), is the correct procedure. The Thornthwaite and Mather (1957) methodology consists of applying the 1948 procedure in a water balance context. Scozzafava and Tallini (2001) provide an example.

\section{Makkink model}

G.F. Makkink, as reported by de Bruin (1981, Equation 5), simplified the Penman (1948) equation by disregarding the aerodynamic term but compensated the evaporation estimate by introducing two empirical coefficients as follows:

$$
E_{\text {Mak }}=0.61\left(\frac{\Delta}{\Delta+\gamma} \frac{R_{S}}{2.45}\right)-0.12
$$

where $E_{\text {Mak }}$ is the Makkink potential evaporation $\left(\mathrm{mm} \mathrm{day}^{-1}\right), R_{S}$ is the solar radiation (incoming shortwave) ( $\mathrm{MJ} \mathrm{m}^{-2} \mathrm{day}^{-1}$ ) at the water surface, $\Delta$ is the slope of the vapour pressure curve $\left(\mathrm{kPa}^{\circ} \mathrm{C}^{-1}\right)$ at air temperature, and $\gamma$ is the psychrometric constant $\left(\mathrm{kPa}^{\circ} \mathrm{C}^{-1}\right)$. According to Rosenberry et al. (2004, Table 1), a monthly time-step is used in the Makkink computations.

\section{FAO-24 Blaney and Criddle (Allen and Pruitt, 1986)}

There have been a number of modifications made to the original Blaney (1959) equation for estimating the consumptive use or reference crop evapotranspiration. We outline here the Reference Crop FAO-24 (Allen and Pruitt, 1986; Jensen et al, 1990) version of Blaney and Criddle which is for a grass-related crop evapotranspiration. The method is based on several empirical coefficients which were developed from data measured at adequately watered, agricultural lysimeter sites (Allen and Pruitt, 1986), located in the dry western United States where advection effects were strong (Yin and Brook, 1992).

The FAO-24 Reference Crop version of Blaney-Criddle is defined as (Allen and Pruitt, 1986, Equations 1, 2 and 3; Shuttleworth, 1992, Equation 4.2.45):

$$
\begin{aligned}
& E T_{B C}=\left(0.0043 R H_{\text {min }}-\frac{n}{N}-1.41\right)+b_{v a r} p_{y}\left(0.46 T_{a}+8.13\right) \\
& b_{v a r}=e_{0}+e_{1} R H_{\text {min }}+e_{2} \frac{n}{N}+e_{3} \mathrm{u}_{2}+e_{4} R H_{\min } \frac{n}{N}+e_{5} R H_{\min } \mathrm{u}_{2}
\end{aligned}
$$

where $E T_{B C}$ is the Blaney-Criddle Reference Crop evapotranspiration (mm day ${ }^{-1}$ ), $R H_{\text {min }}$ is the minimum relative daily humidity (\%), $n / N$ is the measured sunshine hours divided by the possible daily sunshine hours, $p_{y}$ is the percentage of actual daytime hours for the day compared to the day-light hours for the entire year, $T_{a}$ is the average daily air temperature $\left({ }^{0} \mathrm{C}\right)$, and $\mathrm{u}_{2}$ is average daily wind speed $\left(\mathrm{m} \mathrm{s}^{-1}\right)$ at $2 \mathrm{~m}$. The recommended values of the coefficients are from Frevert et al. (1983, Table 1) as follows: $e_{0}=0.81917, e_{1}=-0.0040922$, $e_{2}=1.0705, e_{3}=0.065649, e_{4}=-0.0059684, e_{5}=-0.0005967$. Due to lower minimum daily temperatures at higher elevation (McVicar et al., 2007 Figure 3), Allen and Pruitt (1986) incorporate an adjustment for elevation to the FAO-24 Blaney-Criddle equation for arid and semi-arid regions following Allen and Brockway (1983) as follows:

$$
E T_{B C}^{H}=E T_{B C}\left[1+0.1 \frac{E l e v}{1000}\right]
$$


where $E T_{B C}^{H}$ is the Blaney-Criddle Reference Crop evapotranspiration adjusted for site elevation and Elev is the elevation of the site above mean sea level (m).

Doorenbos and Pruitt (1992, page 4) note that the BC procedure should be used "with scepticism" in equatorial regions (where air temperatures are "relatively constant”), for small islands and coastal areas (where air temperature is affected by sea temperature), for high elevations (due to environmental lapse rate induced low mean daily air temperature) and in monsoonal and mid-latitude regions (with a wide variety of sunshine hours).

It is noted that the original Blaney-Criddle procedure incorporates only monthly temperature data. Consequently, the coefficients $e_{0}, \ldots, e_{5}$ and the climate variables $R H_{\text {min }}$, , $T_{a}, u_{2}$ in Equations (S9.7) and (S9.8), which were based on the crop consumptive use in western United States using the original BC model, will not represent potential evaporation in regions with climates differing from those in western United States. This may explain the Doorenbos and Pruitt (1992) comment in the previous paragraph.

Although the BC method has been used at both a daily and a monthly time-step (Allen and Pruitt, 1986), a monthly period is recommended (Doorenbos and Pruitt, 1992, page 4; Nandagiri and Kovoor, 2006, page 240).

\section{Turc (1961)}

The Turc method (Turc 1961) is one of the simplest empirical equations used to estimate reference crop evapotranspiration under humid conditions. (Note that the Turc (1961) equations are very different to those proposed in Turc $(1954,1955)$.) The Turc 1961 equation, based on daily data, is quoted by Trajković and Stojnić (2007, Equation 1) as:

$$
E T_{\text {Turc }}=0.013\left(23.88 R_{S}+50\right)\left(\frac{T_{a}}{T_{a}+15}\right)
$$

where $E T_{\text {Turc }}$ is the reference crop evapotranspiration $\left(\mathrm{mm}\right.$ day $\left.^{-1}\right), T_{a}$ is the average air temperature $\left({ }^{\circ} \mathrm{C}\right)$, and $R_{s}$ is the incoming solar radiation $\left(\mathrm{MJ} \mathrm{m}^{-2}\right.$ day $\left.{ }^{-1}\right)$.

For non-humid conditions ( $\mathrm{RH}<50 \%$ ), the adjustment provided by Alexandris et al. (2008, Equation 5b) may be used.

$$
E T_{\text {Turc }}=0.013\left(23.88 R_{S}+50\right)\left(\frac{T_{a}}{T_{a}+15}\right)\left(1+\frac{50-R H}{70}\right)
$$

where $R H$ is the relative humidity (\%).

Because Jensen et al. (1990) identified that the Turc (1961) method performs satisfactorily in humid regions (see Table 5), Trajković and Kolaković (2009) developed an empirical factor to adjust $E T_{\text {Turc }}$ for wind speed. Details are given in Trajković and Kolaković (2009).

\section{Hargreaves-Samani (Hargreaves and Samani, 1985)}

The Hargreaves-Samani equation (Hargreaves and Samani, 1985, Equations 1 and 2), which estimates reference crop evapotranspiration, is as follows:

$$
E T_{H S}=0.0135 C_{H S} \frac{R_{a}}{\lambda}\left(T_{\max }-T_{\min }\right)^{0.5}\left(T_{a}+17.8\right)
$$

where $E T_{H S}$ is the reference crop evapotranspiration $\left(\mathrm{mm} \mathrm{day}^{-1}\right), C_{H S}$ is an empirical coefficient, $R_{a}$ is the extraterrestrial radiation $\left(\mathrm{MJ} \mathrm{m}^{-2}\right.$ day $\left.^{-1}\right), T_{\max }, T_{\min }, T_{a}$ are respectively the maximum, minimum and average daily air temperature $\left({ }^{\circ} \mathrm{C}\right)$. Samani (2000, Equation 3) proposed a modification to the empirical coefficient to reduce the error associated with the estimation of solar radiation as follows: 


$$
C_{H S}=0.00185\left(T_{\max }-T_{\min }\right)^{2}-0.0433\left(T_{\max }-T_{\min }\right)+0.4023
$$

According to Amatya et al. (1995, Table 4), weekly or monthly data should be used in the Hargreaves-Samani model in the computation of reference crop evapotranspiration rates.

\section{Modified Hargreaves}

The modified Hargreaves procedure (Droogers and Allen, 2002), as adapted by Adam et al (2006, Equation 6), allows one to estimate the reference crop evapotranspiration without wind data using monthly values of rainfall, air temperature, daily air temperature range, and extra-terrestrial solar radiation as follows:

$$
E T_{H a r g, j}=0.0013 S_{O}\left(T_{j}+17.0\right)\left(\overline{T D}_{j}-0.0123 P_{j}\right)^{0.76}
$$

where, for a given month $j E T_{\text {Harg, } j}$ is the modified Hargreaves monthly reference crop evapotranspiration $\left(\mathrm{mm} \mathrm{day}{ }^{-1}\right), T_{j}$ is the monthly mean daily air temperature $\left({ }^{\circ} \mathrm{C}\right), \overline{T D}_{j}$ is the mean monthly difference between mean daily maximum air temperature and mean daily minimum air temperature $\left({ }^{\circ} \mathrm{C}\right)$ for month $j, P_{j}$ is the monthly precipitation $\left(\mathrm{mm} \mathrm{month}{ }^{-1}\right.$ ), and $S_{0}$ is the mean monthly water equivalent for extraterrestrial solar radiation (mm day ${ }^{-1}$ ). If $\overline{T D}_{j}$ data are unavailable, New et al. (2002) have provided 10' latitude/longitude gridded mean monthly diurnal air temperature range. Again, following the approach of Adam et al. (2006, Equations 7, 8, 9 and 10), $S_{0}$ is estimated by:

$$
S_{0}=15.392 d_{r}^{2}\left(\omega_{s} \sin (\text { lat }) \sin (\delta)+\cos (\text { lat }) \cos (\delta) \sin \left(\omega_{s}\right)\right)
$$

where lat is the latitude of the location in radians (negative for southern hemisphere), $d_{r}$ is the relative distance between the earth and the sun, given by:

$$
d_{r}^{2}=1+0.033 \cos \left(\frac{2 \pi}{365} D o Y\right)
$$

where $D o Y$ is the Day of Year (see Appendix S3), $\omega_{s}$ is the sunset hour angle in radians (see Adam et al., 2006, page 22 for boundary conditions) and is given by:

$$
\omega_{s}=\operatorname{arcos}(-\tan (\text { lat }) \tan (\delta))
$$

and $\delta$ is the solar declination in radians given by:

$$
\delta=0.4093 \sin \left(\frac{2 \pi}{365} D o Y-1.405\right)
$$

Evapotranspiration estimates are based on a monthly time-step.

\section{Application based on energy balance}

A very different approach to the application of energy balance is by McLeod and Webster (1996, Equations 8 and 9) who used data from an instrumented irrigation channel to estimate channel evaporation from:

$$
E_{i c}=\frac{\left(R_{n}+Q_{v}-Q_{t}\right)}{\left(1+B+\frac{c_{W} T_{s}}{\lambda}\right)} \frac{\Delta t}{\lambda}
$$

where $E_{i c}$ is the evaporation from the irrigation channel $\left(\mathrm{mm} \mathrm{day}^{-1}\right), R_{n}$ is the net radiation on the water surface ( $\left.\mathrm{MJ} \mathrm{m}^{-2} \mathrm{day}^{-1}\right), Q_{v}$ is the heat flux advected into the water body ( $\mathrm{MJ} \mathrm{m}^{-2}$ day $\left.^{-1}\right), Q_{t}$ is the heat flux increase in stored energy ( $\mathrm{MJ} \mathrm{m}^{-2}$ day $\left.^{-1}\right), B$ is the Bowen Ratio, $c_{w}$ is specific heat of water ( $\left.\mathrm{MJ} \mathrm{kg}^{-1}{ }^{\circ} \mathrm{C}^{-1}\right), T_{S}$ is the temperature of the evaporated water $\left({ }^{\circ} \mathrm{C}\right), \Delta t$ is time interval over which the fluxes are estimated (day), and $\lambda$ is the latent heat of vaporisation $\left(\mathrm{MJ} \mathrm{kg}^{-1}\right)$. 


\section{Supplementary Material}

\section{Appendix S10 Estimating deep lake evaporation}

Based on a review of the literature, Table S5 provides guidelines to define deep and shallow lakes for the purpose of estimating lake evaporation. (The background to Table S5 is discussed in the Appendix S11.)

\section{Kohler and Parmele (1967)}

The Penman estimate of open-water evaporation, $E_{\text {Penow }}$, (Equation (12)) is a starting point to estimate evaporation from a deep lake using the Kohler and Parmele (1967) procedure. To account for water advected energy and heat storage, Kohler and Parmele (1967, Equation 12) recommended the following relationship:

$$
E_{D L}=E_{\text {Penow }}+\alpha_{K P}\left(A_{w}-\frac{\Delta Q}{\Delta t}\right)
$$

where $E_{D L}$ is the evaporation from the deep lake (mm day $\left.{ }^{-1}\right), E_{P e n o w}$ is the Penman openwater evaporation (mm day $\left.{ }^{-1}\right), \alpha_{K P}$ is the proportion of the net addition of energy from advection and storage used in evaporation during $\Delta t, A_{w}$ is the net water advected energy during $\Delta t\left(\mathrm{~mm} \mathrm{day}^{-1}\right)$, and $\frac{\Delta Q}{\Delta t}$ is the change in stored energy (mm day $\left.{ }^{-1}\right)$. Kohler and Parmele (1967, page 1002) illustrated their method adopting $\Delta t=1$ day. The three other terms are complex and following Dingman (1992, Equations 7.38, 7.31 and 7.32 respectively) can be computed from:

$$
\begin{aligned}
& \alpha_{K P}=\frac{\Delta}{\Delta+\gamma+\frac{4 \varepsilon_{w} \sigma\left(T_{w}+273.2\right)^{3}}{\rho_{w} \lambda K_{E} u}} \\
& A_{w}=\frac{c_{w} \rho_{w}}{\lambda}\left(P_{d} T_{p}+S W_{\text {in }} T_{\text {swin }}-S W_{\text {out }} T_{\text {swout }}+G W_{\text {in }} T_{\text {gwin }}-G W_{\text {out }} T_{\text {gwout }}\right) \\
& \Delta Q=\frac{c_{w} \rho_{w}}{A_{L} \lambda}\left(V_{2} T_{L 2}-V_{1} T_{L 1}\right)
\end{aligned}
$$

where $\Delta$ is the slope of the vapour pressure curve $\left(\mathrm{kPa}^{\circ} \mathrm{C}^{-1}\right)$ at air temperature, $\varepsilon_{w}$ is the effective emissivity of the water (dimensionless), $\sigma$ is the Stefan-Boltzman constant ( $\mathrm{MJ} \mathrm{m}^{-2}$ day $\left.^{-1} \mathrm{~K}^{-4}\right), T_{w}$ is the temperature of the water $\left({ }^{\circ} \mathrm{C}\right), T_{p}$ is the temperature of precipitation $\left({ }^{\circ} \mathrm{C}\right), c_{w}$ is the specific heat of water $\left(\mathrm{MJ} \mathrm{kg}^{-1}{ }^{\circ} \mathrm{C}^{-1}\right), P_{d}$ is the precipitation rate (mm day $\left.{ }^{-1}\right), \lambda$ is the latent heat of vaporization ( $\left.\mathrm{MJ} \mathrm{kg}^{-1}\right), K_{E}$ is a coefficient that represents the efficiency of the vertical transport of water vapour $\left(\mathrm{kPa}^{-1}\right), u$ is mean daily wind speed (m day-1), SW and GW represent surface and ground water inflows and outflows as per subscript (mm day $\left.{ }^{-1}\right)$ and V's and T's represent respective average lake volumes $\left(\mathrm{m}^{3}\right)$ and temperatures $\left({ }^{\circ} \mathrm{C}\right), A_{L}$ is lake area $\left(\mathrm{m}^{2}\right)$, and 1 and 2 identify values at the beginning and end of $\Delta t$. Generally, for surface lakes GW will be small with respect to SW and can be ignored, but for a deep void following surface mining, groundwater may need to be assessed. Estimation of $K_{E}$ (m day ${ }^{2}$ $\mathrm{kg}^{-1}$ ) is based on Equation (S10.5), but may need to be adjusted for atmospheric stability (see Dingman, 1992, Equation 7.2):

$$
K_{E}=0.622 \frac{\rho_{a}}{p \rho_{w}} \frac{1}{6.25\left[\ln \left(\frac{z_{m}-z_{d}}{z_{0}}\right)\right]^{2}}
$$

where $\rho_{a}$ is the density of air $\left(\mathrm{kg} \mathrm{m}^{-3}\right), \rho_{w}$ is the density of water $\left(\mathrm{kg} \mathrm{m}^{-3}\right), p$ is the atmospheric pressure $(\mathrm{kPa}), z_{m}$ is the height above ground level $(\mathrm{m})$ at which the wind speed 
and vapour pressure are measured $(\mathrm{m}), z_{d}$ is the zero-plane displacement $(\mathrm{m})$, and $z_{0}$ is the roughness height of the surface $(\mathrm{m})$.

Harbeck (1962) found that lake area accounted for much of the variability in $K_{E}$ and, as an alternative to Equation (S10.5), $K_{E}$ can be estimated by (Dingman, 1992, Equation 7-19):

$$
K_{E}=1.69 \times 10^{-5} A_{L}^{-0.05}
$$

where $A_{L}$ is the lake area $\left(\mathrm{km}^{2}\right)$.

Because changes in daily energy cannot be estimated with sufficient accuracy relative to the other fluxes, Kohler and Parmele (1967, page 1002) based their comparisons on periods of a week to a month, not daily.

\section{Vardavas and Fountoulakis (1996)}

The Vardavas and Fountoulakis (1996) method for estimating monthly evaporation from a deep lake, in which seasonal heat storage effects are significant, is based on the Penman equation (Penman, 1948):

$$
E_{D L}=\left(\frac{\Delta}{\Delta+\gamma}\right) E_{s}+\left(\frac{\gamma}{\Delta+\gamma}\right) E_{a}
$$

where $E_{D L}$ is the evaporation (mm day ${ }^{-1}$ ) for a deep lake, $E_{S}$ is the evaporation component (mm day-1) due to net heating, $E_{a}$ is the evaporation component $\left(\mathrm{mm} \mathrm{day}^{-1}\right)$ due to wind, $\Delta$ is the slope of the vapour pressure curve $\left(\mathrm{kPa}^{\circ} \mathrm{C}^{-1}\right)$ at air temperature, and $\gamma$ is the psychrometric constant $\left(\mathrm{kPa}^{\circ} \mathrm{C}^{-1}\right)$.

$$
E_{s}=\frac{1}{\lambda}\left(R_{n}+\Delta H\right)
$$

where $R_{n}$ is the net radiation ( $\mathrm{MJ} \mathrm{m} \mathrm{m}^{-2}$ day $^{-1}$ ) at the water surface, $\lambda$ is the latent heat of vaporization (MJ kg-1), and $\Delta H$ is the net energy gained from heat storage in the water body $\left(\mathrm{MJ} \mathrm{m}^{-2}\right.$ day $\left.^{-1}\right)$.

Following Vardavas and Fountoulakis (1996, Equation 28), $\Delta H$ is determined on a monthly basis using:

$$
\Delta H_{j, j-1}=-48.6 \bar{h} \frac{\Delta T_{w l}}{t_{m}}
$$

where $\Delta H_{j, j-1}$ is the change in heat storage $\left(\mathrm{W} \mathrm{m}^{-2}\right)$ from month $\mathrm{j}-1$ to month $\mathrm{j}, \bar{h}$ is the mean lake depth (m), $\Delta T_{w l}=T_{w, j}-T_{w, j-1}$, i.e., the change in surface water temperature $\left({ }^{\circ} \mathrm{C}\right)$ from month $\mathrm{j}-1$ to month $\mathrm{j}$, and $t_{m}$ is the number of days in the month.

$E_{a}$ is the wind component defined by Penman (1948) as:

$$
E_{a}=f(\bar{u})\left[v_{a}^{*}\left(T_{a}\right)-v_{a}\left(T_{a}\right)\right]
$$

where $\bar{u}$ is average daily wind speed $\left(\mathrm{m} \mathrm{s}^{-1}\right), v_{a}^{*}\left(T_{a}\right)$ is the saturation vapour pressure (mbar) at the water surface evaluated at air temperature $T_{a}\left({ }^{\circ} \mathrm{C}\right)$, and $v_{a}\left(T_{a}\right)$ is the vapour pressure (mbar) at a given height above the water surface evaluated at the air temperature $\left({ }^{\circ} \mathrm{C}\right.$ ), and

$$
f(\bar{u})=C_{u} \bar{u}
$$

where $C_{u}$ can be evaluated as set out below. Estimated values of $C_{u}$ by Vardavas and Fountoulakis (1996, page 144) for four Australian reservoirs (Manton, Cataract, Mundaring and Eucumbene) range from 0.11 to $0.13 \mathrm{~mm} \mathrm{day}^{-1} /\left(\mathrm{m} \mathrm{s}^{-1} \mathrm{mbar}\right)$. 
Following Vardavas (1987, Equation 23) $C_{u}$ can be evaluated from:

$$
C_{u}=\frac{3966}{T_{a} \ln \left(\frac{z_{2}}{z_{o v}}\right) \ln \left(\frac{z_{1}}{z_{o m}}\right)}
$$

where $T_{a}$ is the air temperature $(\mathrm{K}), z_{1}$ is the height above ground of the wind speed measurement $(\mathrm{m}), z_{2}$ is the height above ground of the water vapour measurement $(\mathrm{m}) . z_{\text {om }}$, the momentum roughness $(\mathrm{m})$, and $z_{o v}$, the roughness length for water vapour (m), are given by:

$$
\begin{aligned}
& z_{o m}=0.135 \frac{v}{u_{*}} \\
& z_{o v}=0.624 \frac{v}{u_{*}}
\end{aligned}
$$

where $v$ is the kinematic viscosity of air $\left(\mathrm{m}^{2} \mathrm{~s}^{-1}\right)$ and is estimated by:

$$
v=2.964 \times 10^{-7} \frac{T_{a}^{3 / 2}}{p}
$$

where $T_{a}$ is the air temperature $(\mathrm{K})$, and $p$ is the atmospheric pressure $(\mathrm{kPa})$.

The friction velocity, $u_{*}$, is computed from:

$$
\bar{u}=\frac{u_{*}}{k} \ln \left(\frac{z_{2} u_{*}}{0.135 v}\right)
$$

where $k$ is von Kármán's constant, $\bar{u}$ is the mean wind speed ( $\left.\mathrm{m} \mathrm{s}^{-1}\right), z_{2}$ is the height above ground of water vapour measurement $(\mathrm{m})$, and $v$ is the kinematic viscosity of air $\left(\mathrm{m}^{2} \mathrm{~s}^{-1}\right)$. $u_{*}$ can be estimated by a numerical iteration technique, e.g., Newton-Raphson.

\section{Other approaches that may be appropriate}

Several approaches that have been included under Appendix S11 Estimating shallow lake evaporation may be appropriate for deep lakes. In particular, McJannet et al. (2008b) procedure has been tested for two deep lakes. 


\section{Supplementary Material}

\section{Appendix S11 Estimating shallow lake evaporation}

Based on a review of the literature, Table S5 provides guidelines to define deep and shallow lakes for the purpose of estimating lake evaporation. According to Monteith (1981, page 9), it is inappropriate to apply the Penman equation to estimating evaporation from open water bodies that exceed "... a metre or so in depth..." because of the damping due to heat stored in the water. Morton's (1986) analysis indicates “... the CRLE model has little advantage over the CRWE at depths less than $1.5 \mathrm{~m}$ ”. For shallow lakes of $3 \mathrm{~m}$ mean depth, de Bruin (1978) and Sacks et al (1994) consider it unnecessary to take account of seasonal heat storage in estimating lake evaporation, whereas Fennessey (2000), in his study of a shallow lake of $2 \mathrm{~m}$ mean depth, incorporated monthly heat storage. For a shallow lake (average depth of $0.6 \mathrm{~m}$ and characterised by a bottom crust of a thick frozen mud layer) in Hudson Bay, Canada, Stewart and Rouse (1976) incorporated heat flux through the bottom of the lake and the heat capacity of the water.

Based on the above evidence we suggest as a general guide that seasonal heat storage be taken into account for shallow lakes with an average water depth of $2 \mathrm{~m}$ or more. For shallow lakes with water depth less than $2 \mathrm{~m}$, we prefer the Penman equation (Equation (12)) with the 1956 wind function..

Shallow lake evaporation by Penman equation based on the equilibrium temperature (Finch, 2001)

To take heat storage into account, Finch (2001) used the concept of equilibrium temperature and tested the accuracy of the method by estimating evaporation from a shallow lake. A description of the model is presented by Keijman (1974) and de Bruin (1982). As noted in Section (2.1.4), the equilibrium temperature is the temperature of the surface water when the net rate of heat exchange at the water surface is zero (Edinger et al., 1968, page 1139). In this context, Sweers (1976, page 377) assumes that, although on clear calm days a water body will exhibit strong temperature gradients near the water surface, the top $0.5 \mathrm{~m}-$ $1.0 \mathrm{~m}$ or so is well mixed and its mean temperature specifies the surface temperature.

To estimate shallow lake evaporation, Finch (2001) adopted Penman (1948) but incorporated the Sweers (1976, Equation 18) wind function (Equation (S11.2)) and the equilibrium temperature. In the method it is assumed the water column is well mixed and the heat flux at the bed of the water body can be neglected (Finch, 2001, pages 2772). For each daily time-step, the following nine equations are computed:

$$
\begin{aligned}
& \lambda E=\frac{\Delta\left(R_{n}^{w}-G_{w}\right)+\gamma \lambda f(u)\left(v_{a}^{*}-v_{a}\right)}{(\Delta+\gamma)} \\
& \lambda f(u)=0.864(4.4+1.82 u)
\end{aligned}
$$

where $E$ is daily lake evaporation $\left(\mathrm{mm} \mathrm{day}^{-1}\right), R_{n}^{w}$ is the net daily radiation $\left(\mathrm{MJ} \mathrm{m}^{-2} \mathrm{day}^{-1}\right)$ based on the surface water temperature, $G_{w}$ is the daily change in heat storage ( $\mathrm{MJ} \mathrm{m}^{-2}$ day $\left.{ }^{1}\right), \lambda$ is the latent heat of vaporisation ( $\left.\mathrm{MJ} \mathrm{kg}^{-1}\right),\left(v_{a}^{*}-v_{a}\right)$ is the vapour pressure deficit $(\mathrm{kPa})$ at air temperature, $\gamma$ is psychrometric constant $\left(\mathrm{kPa} \mathrm{K}^{-1}\right), \Delta$ is the slope of the saturation vapour curve $\left(\mathrm{kPa} \mathrm{K}^{-1}\right)$ at air temperature, and $u$ is the mean daily wind speed $\left(\mathrm{m} \mathrm{s}^{-1}\right)$ at $10 \mathrm{~m}$. (Note that many wind measuring instruments are at a height of $2 \mathrm{~m}$ rather than $10 \mathrm{~m}$ and for those situations the wind speed needs to be adjusted by Equation (S4.4).)

However, before $R_{n}^{w}$ and $G_{w}$ can be estimated the daily surface water temperature of the lake needs to be estimated as follows: 


$$
T_{w, i}=T_{e}+\left(T_{w, i-1}-T_{e}\right) e^{\frac{1}{\tau}}
$$

where $T_{w, i}, T_{w, i-1}$ are the surface water temperatures $\left({ }^{\circ} \mathrm{C}\right)$ on day $i$ and day $i-1$ respectively, and $T_{e}$ is the equilibrium temperature $\left({ }^{\circ} \mathrm{C}\right)$ and $\tau$ is equilibrium temperature time constant (days). $T_{e}$ and $\tau$ are estimated as follows:

$$
T_{e}=T_{w b}+\frac{R_{w b}^{*}}{4 \sigma\left(T_{w b}+273.1\right)^{3}+\lambda f(u)\left(\Delta_{\mathrm{wb}}+\gamma\right)} \text { (Finch, 2001, page 2773) }
$$

where $R_{w b}^{*}$ is the net radiation $\left(\mathrm{MJ} \mathrm{m}^{-2}\right.$ day $\left.^{-1}\right)$ based on wet-bulb temperature $\left(T_{w b}\right)\left({ }^{\circ} \mathrm{C}\right)$ and is estimated by:

$$
\begin{aligned}
& R_{w b}^{*}=(1-\alpha) R_{s}+R_{i l}-C_{f}\left[\sigma\left(T_{a}+273.1\right)^{4}+4 \sigma\left(T_{a}+273.1\right)^{3}\left(T_{w b}-T_{a}\right)\right] \\
& \tau=\frac{\rho_{w} c_{w} h_{w}}{4 \sigma\left(T_{w b}+273.1\right)^{3}+\lambda f(u)\left(\Delta_{\mathrm{wb}}+\gamma\right)} \text { (Finch, 2001, page 2772) }
\end{aligned}
$$

where $\tau$ is the equilibrium temperature time constant (days), $T_{w b}$ is the mean daily wet-bulb temperature $\left({ }^{\circ} \mathrm{C}\right), R_{S}$ is the shortwave solar radiation $\left(\mathrm{MJ} \mathrm{m}^{-2}\right.$ day $\left.^{-1}\right), \alpha$ is the albedo for a water surface (Finch (2001) estimated using Payne (1972)), $R_{i l}$ is incoming longwave radiation ( $\mathrm{MJ} \mathrm{m}^{-2}$ day $\left.^{-1}\right), C_{f}$ is a cloudiness factor, $\sigma$ is the Stefan-Boltzman constant (MJ m ${ }^{-}$ ${ }^{2} \mathrm{~K}^{-4}$ day $\left.^{-1}\right), T_{a}$ is mean daily air temperature $\left({ }^{\circ} \mathrm{C}\right)$ at screen height, $\Delta_{\mathrm{wb}}$ is the slope of the saturation vapour curve $\left(\mathrm{kPa} \mathrm{K}^{-1}\right)$ at wet-bulb temperature, $\gamma$ is the psychrometric constant $\left(\mathrm{kPa} \mathrm{K}^{-1}\right), \rho_{w}$ is the density of water $\left(\mathrm{kg} \mathrm{m}^{-3}\right), c_{w}$ is the specific heat of water $\left(\mathrm{MJ} \mathrm{m}^{-2} \mathrm{~K}^{-4}\right.$ day ${ }^{1}$ ), and $h_{w}$ is the depth of the lake (m).

Thus, having an estimate of the surface water temperatures from Equation (S11.3), $R_{n}^{w}$ and $G_{w}$ are estimated from:

$$
\begin{aligned}
& R_{n}^{w}=(1-\alpha) R_{s}+R_{i l}-C_{f}\left[\sigma\left(T_{a}+273.1\right)^{4}+4 \sigma\left(T_{a}+273.1\right)^{3}\left(T_{w, i-1}-T_{a}\right)\right] \\
& G_{w}=\rho_{w} c_{w} h_{w}\left(T_{w, i}-T_{w, i-1}\right)
\end{aligned}
$$

where $R_{n}^{w}$ is the net radiation given the surface water temperature, $T_{w, i}, T_{w, i-1}$ are the surface water temperature on day $i$ and day $i-1$ respectively.

Next, $\lambda E$ can be estimated using Equation S11.1 and the depth of water $h_{w}$ on day $i+1$ is estimated as:

$$
h_{i+1}=h_{i}+P_{i+1}-E_{i}
$$

where $P_{i+1}$ is the rainfall measured on day $i+1$ and $E_{i}$ is the lake evaporation on day $i$.

According to deBruin (1982, page 270) because water bodies up to $10 \mathrm{~m}$ deep are generally well mixed by wind, the model is of practical significance. The meteorological data are assumed to be land-based (Finch, 2001, page 2771) and the model uses a daily time-step.

The model was applied by Finch (2001) to a small reservoir at Kempton Park, UK resulting in the annual evaporation being $6 \%$ lower than the measured value.

\section{Shallow lake evaporation by finite difference model (Finch and Gash, 2002)}

Finch and Gash (2002) proposed a finite difference approach as an alternative to estimating shallow lake evaporation. The steps are set out as follows (Finch and Gash, 2002, Figure 1):

1. Estimate $\propto$ (shortwave albedo for the water surface). 
2. Set the first estimate of $T_{w}$ (average water temperature) at the beginning of the current time-step to the value at the end of the previous time-step.

3. Calculate the average $T_{w}$.

4. Calculate $R_{n}$ (net radiation).

5. Calculate $f(u)$ ( $u$ is wind speed at a height of $10 \mathrm{~m}$ ).

6. Calculate $\lambda E$ (latent heat flux) and $H$ (sensible heat flux).

7. Calculate $W$ (change in heat storage in water column during the current time-step).

8. Calculate a new estimate of $T_{w}$ at the end of the time-step.

9. Is the difference between the last estimate of $T_{w}$ and the present one $<0.01$ ?

10. If no, return to step 3, otherwise proceed to the next time-step.

The equations to estimate the above variables are as follows (Finch and Gash, 2002):

$$
\begin{aligned}
& \propto=f(g, \theta) \\
& g=\frac{R_{s}}{\frac{s_{c o n} \sin \theta}{d_{r}^{2}}} 1 \\
& T_{w}=T_{w, i-1}+\left(\frac{T_{w, i}-T_{w, i-1}}{2}\right) \\
& R_{n w}=R_{s}(1-\alpha)+R_{i l}-C_{f} \sigma\left(T_{w}+273.1\right)^{4} \\
& f(u)=\frac{0.216 u}{\Delta+\gamma} \text { for } T_{w} \leq T_{a} \\
& f(u)=\frac{0.216 u\left[1+10 \frac{\left(T_{w}-T_{a}\right)}{u^{2}}\right]^{0.5}}{\Delta+\gamma} \text { for } T_{w}>T_{a} \\
& \lambda E=f(u)\left(v_{w}^{*}-v_{d}\right) \\
& H=\gamma f(u)\left(T_{w}-T_{a}\right) \\
& \Delta W=R_{n}-\lambda E-H \\
& T_{w, i}=T_{w, i-1}+\frac{\Delta W}{\rho_{w} c_{w} h_{w}}
\end{aligned}
$$

where $\alpha$ is shortwave albedo for the water surface, $R_{S}$ is the incoming shortwave radiation $\left(\mathrm{MJ} \mathrm{m}^{-2} \mathrm{~d}^{-1}\right), S_{\text {con }}$ is the solar constant $=0.0820 \mathrm{MJ} \mathrm{m}^{-2}$ day $^{-1}, \theta$ is the Sun's altitude $\left(^{\circ}\right), d_{r}$ is the ratio of the actual to mean Earth-Sun separation or the inverse relative distance Earth-Sun, $T_{w}$ is average water temperature $\left({ }^{\circ} \mathrm{C}\right), T_{w, i}$ and $T_{w, i-1}$ are, respectively, the estimated water temperature $\left({ }^{\circ} \mathrm{C}\right)$ at the end of the current and previous periods, $T_{a}$ is the air temperature $\left({ }^{\circ} \mathrm{C}\right)$ at the reference height, $R_{n w}$ is the net radiation (MJ $\left.\mathrm{m}^{-2} \mathrm{~d}^{-1}\right), R_{i l}$ is incoming longwave radiation $\left(\mathrm{MJ} \mathrm{m}^{-2}\right.$ day $^{-1}$ ),$C_{f}$ is a cloudiness factor, $\sigma$ is the Stefan-Boltzman constant ( $\mathrm{MJ} \mathrm{m}^{-2}$ $\mathrm{K}^{-4}$ day $\left.^{-1}\right), \Delta$ is the slope of the saturation vapour pressure curve at air temperature $\left(\mathrm{kPa} \mathrm{K}^{-1}\right)$, $\gamma$ is the psychrometric constant $\left(\mathrm{kPa} \mathrm{K}^{-1}\right), u$ is wind speed $\left(\mathrm{m} \mathrm{s}^{-1}\right)$ at a height of $10 \mathrm{~m}, v_{w}^{*}$ is the saturation vapour pressure at the water temperature $(\mathrm{kPa}), v_{d}$ is the vapour pressure at the reference height $(\mathrm{kPa}), \lambda E$ is the latent heat flux $\left(\mathrm{MJ} \mathrm{m}^{-2} \mathrm{~d}^{-1}\right), H$ is the sensible heat flux (MJ $\left.\mathrm{m}^{-2} \mathrm{~d}^{-1}\right), \Delta W$ is change in heat storage in water column during the current time-step (MJ m $\mathrm{m}^{-2} \mathrm{~d}^{-}$ $\left.{ }^{1}\right), \rho_{w}$ is the density of water $\left(\mathrm{kg} \mathrm{m}^{-3}\right), c_{w}$ is the specific heat of water, and $h_{w}$ is the depth of water $(\mathrm{m})$.

\footnotetext{
${ }^{1}$ In Equation (S11.11), we have adopted Payne's equation (Payne, 1972, Equation 3; see also Berger et al, 1993, Equation 2) and Simpson and Paulson (1979, Equation 2) in which $d_{r}^{2}$ is used rather than $d_{r}$ as published in the Finch and Gash (2002) paper.
} 
$R_{S}$ is either measured solar radiation or estimated from Equation S3.9 and $R_{i l}$ may be estimated from Equation (S3.16). Finch and Gash (2002) used Payne (1972, Table 1) to estimate $\propto$ knowing $g$ and $\theta . g$ requires $d$ to be estimated which is computed from:

$$
d_{r}^{2}=1+0.033 \cos \left(\frac{2 \pi}{365} D o Y\right)
$$

where $D o Y$ is day of year $(D o Y=1,2, \ldots, 365)$.

$\theta$ is estimated as follows (Al-Rawi, 1991, Equation 1):

$\sin \theta=\cos ($ lat $) \cos (\delta) \cos \left(\omega_{s}\right)+\sin ($ lat $) \sin (\delta)$

where lat is latitude in radians, $\delta$ is the solar declination angle in radians, and $\omega_{s}$ is the sunset hour angle in radians. $\delta$ and $\omega_{s}$ can be estimated from Equations (S9.18) and (S9.17) respectively.

Lake evaporation by Penman-Monteith equation based on the equilibrium temperature (McJannet et al., 2008b)

McJannet et al. (2008b) adopted the Penman-Monteith as the basis of applying the equilibrium temperature to estimate lake evaporation for a range of water bodies - shallow and deep lakes and an irrigation canal. Their approach is similar to that used by Finch (2001). We reproduce below the method proposed and tested by McJannet et al. (2008b). Evaporation is estimated as follows:

$$
E_{M c J}=\frac{1}{\lambda}\left(\frac{\Delta_{w}\left(Q^{*}-G_{w}\right)+\frac{86400 \rho_{a} c_{a}\left(v_{w}^{*}-v_{a}\right)}{r_{a}}}{\Delta_{w}+\gamma}\right)
$$

where $E_{M c J}$ is the evaporation from the water body $\left(\mathrm{mm} \mathrm{day}^{-1}\right), Q^{*}$ is the net radiation (MJ m ${ }^{-}$ ${ }^{2}$ day $\left.^{-1}\right), G_{w}$ is the change in heat storage in the water body $\left(\mathrm{MJ} \mathrm{m}^{-2}\right.$ day $\left.^{-1}\right), \rho_{a}$ is the density of air $\left(\mathrm{kg} \mathrm{m}^{-3}\right), c_{a}$ is the specific heat of air $\left(\mathrm{MJ} \mathrm{kg}^{-1} \mathrm{~K}^{-1}\right), v_{w}^{*}$ is the saturation vapour pressure at water temperature $(\mathrm{kPa}), v_{a}$ is the daily vapour pressure $(\mathrm{kPa})$ taken at 9:00 am, $\lambda$ is the latent heat of vaporisation $\left(\mathrm{MJ} \mathrm{kg}^{-1}\right), \Delta_{w}$ is the slope of the saturation water vapour curve at water temperature $\left(\mathrm{kPa}^{\circ} \mathrm{C}^{-1}\right), \gamma$ is the psychrometric constant $\left(\mathrm{kPa}^{\circ} \mathrm{C}^{-1}\right)$, and $r_{a}$ is the aerodynamic resistance $\left(\mathrm{s} \mathrm{m}^{-1}\right)$ and is defined by Calder and Neal (1984, page 93) and McJannet et al. (2008b, Appendix B, Equation 10) as:

$$
r_{a}=\frac{\rho_{a} c_{a}}{\gamma\left(\frac{f(u)}{86400}\right)}
$$

where from Sweers (1976, page 398) and modified by McJannet et al. (2008b, Appendix B, Equation 11) and converting units from $\mathrm{W} \mathrm{m}^{-2} \mathrm{mbar}^{-1}$ to $\mathrm{MJ} \mathrm{m}^{-2} \mathrm{kPa}-1$ day $^{-1}$ yields:

$$
f(u)=\left(\frac{5}{A}\right)^{0.05}\left(3.80+1.57 u_{10}\right)
$$

where $u_{10}$ is the wind speed $\left(\mathrm{m} \mathrm{s}^{-1}\right)$ at $10 \mathrm{~m}$ and $A\left(\mathrm{~km}^{2}\right)$ is the area of the water body, and other variables are defined previously. (For elongated water bodies, the square of the width was adopted as the area (Sweers, 1976, page 398).)

$Q^{*}$ in Equation (S11.22) is defined as:

$$
Q^{*}=R_{S}(1-\alpha)+\left(R_{i l}-R_{o l}\right)
$$

where $R_{S}$ is the total daily incoming shortwave radiation $\left(\mathrm{MJ} \mathrm{m}^{-2}\right.$ day $\left.^{-1}\right), \alpha$ is albedo for water (=0.08), $R_{i l}$ is the incoming longwave radiation $\left(\mathrm{MJ} \mathrm{m}^{-2} \mathrm{day}^{-1}\right)$, and $R_{o l}$ is the outgoing longwave radiation $\left(\mathrm{MJ} \mathrm{m}^{-2}\right.$ day $\left.^{-1}\right)$. 


$$
R_{i l}=\left(C_{f}+\left(1-C_{f}\right)\left(1-\left(0.261 \exp \left(-7.77 \times 10^{-4} T_{a}^{2}\right)\right)\right)\right) \sigma\left(T_{a}+273.15\right)^{4}
$$

where $C_{f}$ is the fraction of cloud cover, $T_{a}$ is the mean daily air temperature $\left({ }^{\circ} \mathrm{C}\right)$, and $\sigma$ is the Stefan-Boltzmann constant $\left(\mathrm{MJ} \mathrm{m}^{-2} \mathrm{~K}^{-4} \mathrm{day}^{-1}\right)$.

$$
R_{o l}=0.97 \sigma\left(T_{w}+273.15\right)^{4}
$$

where $T_{w}$ is the water temperature $\left({ }^{\circ} \mathrm{C}\right)$ which will vary for each time-step and must be estimated before Equation (S11.22) can be applied.

Because the heat storage in a water body affects surface water temperatures and, therefore, evaporation, it is necessary to predict heat storage changes over time which depend on the equilibrium temperature $\left(T_{e}\right)$, the time constant for the storage $(\tau)$, as well as the water temperature $\left(T_{w}\right)$. Equilibrium temperature is the surface temperature at which the net rate of heat exchange is zero (see Section 2.1.4). Again, following McJannet et al. (2008b, Equation 23), we estimate water temperature, based on de Bruin (1982, Equation 10), from the following equation:

$$
T_{w}=T_{e}+\left(T_{w 0}-T_{e}\right) \exp \left(-\frac{1}{\tau}\right)
$$

where $T_{w 0}$ is the water temperature $\left({ }^{\circ} \mathrm{C}\right)$ in the previous time-step, $T_{e}$ is the equilibrium temperature $\left({ }^{\circ} \mathrm{C}\right)$, and $\tau$ is the time constant (day).

Following McJannet et al. (2008b, Equation 5), the time constant $(\tau)$ in days is given by (de Bruin, 1982, Equation 4):

$$
\tau=\frac{\rho_{w} c_{w} h_{w}}{4 \sigma\left(T_{w b}+273.15\right)^{3}+f(u)\left(\Delta_{\mathrm{wb}}+\gamma\right)}
$$

where $\rho_{w}$ is the density of water $\left(\mathrm{kg} \mathrm{m}^{-3}\right), c_{w}$ is the specific heat of water $\left(\mathrm{MJ} \mathrm{kg}^{-1} \mathrm{~K}^{-1}\right), h_{w}$ is the water depth (m), $\Delta_{w b}$ is the slope of the saturation water vapour curve $\left(\mathrm{kPa}^{\circ} \mathrm{C}^{-1}\right)$ estimated at wet-bulb temperature $\left(T_{n}\right)\left({ }^{\circ} \mathrm{C}\right)$. The water depth $h_{w}$ could be a time-series if required (see Equation (S11.9).

The equilibrium temperature is estimated from (de Bruin, 1982, Equation 3):

$$
T_{e}=T_{w b}+\frac{Q_{w b}^{*}}{4 \sigma\left(T_{w b}+273.15\right)^{3}+f(u)\left(\Delta_{\mathrm{wb}}+\gamma\right)}
$$

where $Q_{w b}^{*}$ is the net radiation at wet-bulb temperature and is estimated by:

$$
Q_{w b}^{*}=R_{s}(1-\alpha)+\left(R_{i l}-R_{o l}^{w b}\right)
$$

and where $R_{o l}^{w b}$ is the outgoing longwave radiation $\left(\mathrm{MJ} \mathrm{m}^{-2}\right.$ day $^{-1}$ ) at wet-bulb temperature and is estimated as follows:

$$
R_{o l}^{w b}=\sigma\left(T_{a}+273.15\right)^{4}+4 \sigma\left(T_{a}+273.15\right)^{3}\left(T_{w b}-T_{a}\right)
$$

The change in heat storage, $G_{w}$, is calculated from (McJannet et al. (2008b, Equation 31):

$$
G_{w}=\rho_{w} c_{w} h_{w}\left(T_{w}-T_{w 0}\right)
$$

Thus, for the time-step in question, $T_{w}$ and $G_{w}$ are now known and $E_{M c J}$ in Equation (S11.22) can be computed.

The McJannet et al. (2008b) model operates at a daily time-step. 
Based on the above approach, McJannet et al. (2008b) applied gridded climate data to estimate average daily (and monthly) evaporation for a range of water bodies from an irrigation canal to five large lakes. Overall, the modelled estimates are within $10 \%$ of the independent evaporation estimates (McJannet et al., 2008b, Section 5.7), however, the correlation coefficient between monthly modelled and observed evaporation values is very low for two of the lake studies.

A worked example is provided in Appendix S19.

The differences between Finch (2001) and McJannet et al. (2008b) procedures to estimate lake evaporation are:

\begin{tabular}{|l|l|}
\hline \multicolumn{1}{|c|}{ Finch (2001) } & \multicolumn{1}{c|}{ McJannet et al. (2008b) } \\
\hline Adopted Penman (1948) equation & Adopted Penman-Monteith equation \\
\hline Wind function depends on wind speed & $\begin{array}{l}\text { Wind function depends on wind speed and lake } \\
\text { area }\end{array}$ \\
\hline $\begin{array}{l}\text { Adjusted water level for daily rainfall and } \\
\text { daily evaporation loss }\end{array}$ & $\begin{array}{l}\text { No adjustment of water level for rainfall or } \\
\text { evaporation }\end{array}$ \\
\hline Tested on one 10 m lake in UK & $\begin{array}{l}\text { Tested on three shallows lakes, a weir, an } \\
\text { irrigation channel and two deep reservoirs }\end{array}$ \\
\hline
\end{tabular}

\section{Lake evaporation by lake-specific vertical temperature profiles}

Sometimes for a lake, monthly or seasonal vertical water temperature profiles are available that can be used to estimate the vertical water body heat flux ( $G_{w}$ in Equations (S11.1) and (11.22)). Fennessey (2000) provides an example for a shallow lake in Massachusetts, U.S as follows:

$G_{w}$ is defined more precisely as a function of time

$$
G_{w}(t)=\frac{d H(t)}{d t}
$$

where $H(t)$ is the total heat energy content of the lake per unit area of the lake surface at time $t\left(\mathrm{MJ} \mathrm{m}^{-2}\right)$ and is computed by:

$$
H(t)=\frac{\rho_{w} c_{w}}{A_{s}} \sum_{i=1}^{m}\left[\frac{T_{w}\left(z_{i+1}\right)+T_{w}\left(z_{i}\right)}{2}\right] V_{i}
$$

where the lake is segregated into $m$ horizontal layers, each layer being $\left(z_{i+1}-z_{i}\right)$ thick $(\mathrm{m})$, $\rho_{w}$ is the density of water $\left(\mathrm{kg} \mathrm{m}^{-3}\right), c_{w}$ is the specific heat of water $\left(\mathrm{MJ} \mathrm{kg}^{-1} \mathrm{~K}^{-1}\right), A_{s}$ is the surface area of the lake $\left(\mathrm{m}^{2}\right), T_{w}\left(z_{i}\right)$ and $T_{w}\left(z_{i+1}\right)$ are respectively the water temperature at $z_{i}$ and $z_{i+1}$, and $V_{i}$ is the volume $\left(\mathrm{m}^{3}\right)$ of each layer defined by:

$$
V_{i}=\frac{\left(A_{i+1}+A_{i}\right)\left(z_{i+1}-z_{i}\right)}{2}
$$

Thus, $G_{w}(t)$ can be incorporated in the Penman based equation of Finch (2001) (Equation S11.1) or in the Penman-Monteith based equation of McJannet et al. (2008b) (Equation S11.22). 


\section{Supplementary Material}

\section{Appendix S12 Estimating evaporation from lakes covered by vegetation}

Brezny et al. (1973, Table 1) measured the evaporation rate of cattail, Typha augustfolia L., in $0.36 \mathrm{~m}^{2}$ tanks in Rajashan, India. Over approximately 75 days, they found that the evaporation from tanks with plants was 52\% more than the evaporation from tanks without plants. In contrast, based on a comparison of measured evaporation from Barren Box Swamp (a lake covered with cattail, Typha orientalis PRESL., in NSW, Australia) compared with a lake devoid of vegetation, Linacre et al. (1970, Table IV) observed over three days 34\% less evaporation from the swamp compared to a nearby lake without vegetation. Linacre et al. (1970, page 385) attributed the lower observed evaporation from swamp compared with the lake evaporation to lower albedo of the clear water in the lake, to the shelter provided by the reeds in the swamp, and to the internal resistance to water movement of the reeds. These contrasting results illustrate the difficulty in assessing the impact of vegetation on evaporation from lakes.

There is an extensive body of literature addressing the question of evaporation from lakes covered by vegetation. Abtew and Obeysekera (1995) summarise the results of 19 experiments which, overall, show that the transpiration of macrophytes is greater than open surface water. However, most experiments were not carried out in situ. On the other hand, Mohamed et al. (2008) lists the results of 11 in situ studies (estimating evaporation by eddy correlation or Bowen Ratio procedures) in which wetland evaporation is overall less than open surface water.

Based on theoretical considerations and a literature survey, Idso (1981) offered the following observations. Firstly, reliable experiments assessing the relative rates of evaporation from vegetated water bodies and open surface water must be conducted in situ (Idso (1981, page 46). Secondly, for extensive water bodies covered by vegetation, evaporation will most likely be lower than the open surface water estimate (Idso (1981, page 47). It is noted that Anderson and Idso (1987, page 1041) concluded that canopy surface geometry is important in the evaporative process and, therefore, for small or narrow canopies (e.g., macrophytes along stream reaches where advective energy is significant), evaporative water losses greater than open water can occur.

Drexler et al. (2004, page 2072) in a review of models and methods to estimate wetland evapotranspiration offered the following comments.

1. For many wetland types, the physical processes are poorly characterised.

2. Generalisation is difficult because of variable nature of the results, even within well-studied vegetation types.

3. The wetland environment is very varied, making it particularly difficult to measure ET.

4. Seasonal variation of ET is also an important consideration.

A number of models - Penman (Appendix S4), Penman-Monteith (Appendix S5), the Shuttleworth-Wallace variation of Penman-Monteith (Appendix S5), and Priestley-Taylor (Section 2.1.3) - have been used in several studies (Wessel and Rouse, 1994; Abtew and Obeysekera, 1995; Souch et al. 1998; Bidlake, 2000; Lott and Hunt, 2001; Jacobs et al., 2002; Drexler et al., 2004) to estimate the rate of evaporation from a lake covered by vegetation. Table S7 summarises seven comparisons and suggests that the weighted Penman-Monteith method which is able to account for variations of $r_{a}$ and $r_{s}$ for different vegetation surface 
performs satisfactorily. For this model, and based on one experiment, the mean model estimate of lake evaporation compared to a mean measured value was 1.10.

Readers are referred to a very recent review by Clulow et al (2012) in which they discuss, inter alia, under what conditions Penman, Priestley-Taylor and Penman-Monteith models can be used to estimate actual evaporation from a lake covered by vegetation. 


\section{Supplementary Material}

\section{Appendix S13 Estimating potential evaporation in rainfall-runoff modelling}

Several procedures including Penman-Monteith, Priestley-Taylor and Morton have been used in daily and monthly rainfall-runoff modelling at a daily or monthly time-step to estimate potential evaporation/evapotranspiration. In the Penman-Monteith model the aerodynamic and surface roughness coefficients ( $r_{a}$ and $r_{s}$ respectively) need to be specified in Equation (5). Some typical values of $r_{a}$ and $r_{s}$ are listed in Table S2. In a sensitivity analysis in which the Penman-Monteith equation was incorporated into the SHE model (Abbott et al., 1986a, b), Beven (1979, page 176 and Figure 5) adopted constant values of $r_{a}$ $=46 \mathrm{~s} \mathrm{~m}^{-1}$ for grass and $4 \mathrm{~s} \mathrm{~m}^{-1}$ for pine forest. However, values varied from mid-day $\left(r_{s}=\right.$ $50 \mathrm{~s} \mathrm{~m}^{-1}$ for grass and $100 \mathrm{~s} \mathrm{~m}^{-1}$ for pine forest) to mid-night ( $r_{s}=200 \mathrm{~s} \mathrm{~m}^{-1}$ for grass and $400 \mathrm{~s} \mathrm{~m}^{-1}$ for pine forest). Beven concluded that the evapotranspiration estimates were very dependent on the values of the aerodynamic and canopy resistance parameters.

In using the Priestley-Taylor algorithm (Equation (6)) for estimating catchment potential evapotranspiration, the parameter $\alpha_{P T}$ needs to be specified. Zhang et al (2001, Equation 4) adopted 1.28 and Raupach et al. (2001, page 1152) recommended 1.26. It should be noted that the $\alpha_{P T}$ 'constant' is commonly set to 1.26 although optimised values vary greatly depending on the moisture and advective conditions in which the measurements are made (see Table S8). This is not surprising as the Priestley-Taylor algorithm was developed assuming non-advective conditions and without recourse to measurement of the aerodynamic component.

One of the advantages of Morton's (1983a) CRAE method to estimate potential evapotranspiration is that it does not require wind data as input and, therefore, has been used extensively in Australia to estimate historical monthly potential evapotranspiration in rainfallrunoff modelling (Chiew and Jayasuria, 1990; Chiew and McMahon, 1993; Chiew et al., 1993; Jones et al., 1993; Siriwardena et al., 2006). In many water engineering applications, analysis depends on measured or estimated monthly runoff and potential evaporation over an extended period, often more than 100 years.

There are at least two options available to analysts to estimate Morton's $E T_{W e t}$ in Australia. One approach is to use the mean monthly areal potential values (equivalent to wet environment areal evapotranspiration using Morton's nomenclature) produced jointly by the CRC for Catchment Hydrology and the Bureau of Meteorology in 2001 (see http://www.bom.gov.au/climate/averages and Wang et al. (2001) with detailed methodology described in Chiew et al. (2002)). For daily modelling, the mean monthly values can be disaggregated into equal daily values. A major disadvantage with this approach is that there is no variation in potential evapotranspiration from year to year. However, Chapman (2003, Section 5) applied four rainfall-runoff models to 15 catchments in Australia and concluded that, in terms of modelling daily streamflow, equally good results could be obtained by using average monthly potential evapotranspiration data in the place of daily potential evapotranspiration values. Rather than adopting average monthly values, Oudin et al. (2005) used average daily values in an application of four rainfall-runoff models to 308 catchments in Australia, France and the United States. They concluded that the average daily potential evaporation values resulted in modelled runoffs that were little different to those produced using daily varying potential evaporation (Oudin et al., 2005, Tables 3 and 4). 
The second option is to estimate Morton's wet environmental evapotranspiration from climate data using Equation (18). Chiew and Jayasuria (1990) reviewed Morton's wet environmental evapotranspiration and compared, for three locations in south-eastern Australia, daily estimates of Morton's wet environmental evapotranspiration with Penman's free-water evaporation. They concluded that (i) Morton's model can estimate successfully daily global and net radiation (Chiew and Jayasuria, 1990, page 293); (ii) Morton's wet environment evaporation can be used to represent potential evapotranspiration in rainfallrunoff modelling (Chiew and Jayasuria, 1990, page 293); (It should be noted that this assessment was based on Penman rather than the more appropriate Penman-Monteith model.) (iii) Morton's $E T_{W e t}$ cannot estimate low potential evapotranspiration values accurately and underestimates high values (Chiew and Jayasuria, 1990, page 291).

Based on data for 19 climate stations in Australia from 1970 to 1989, Chapman (2001) demonstrated that overall pan evaporation data are a better estimate of potential evapotranspiration than maximum air temperature. Furthermore, he developed the following simple relationship (applicable only to Australia) that could be used if no other data were available to estimate potential evaporation for catchment modelling purposes:

$$
E T_{e q P M}=A_{p} E_{P a n}+B_{p}
$$

where $E T_{\text {eqPM }}$ is the daily equivalent Penman-Monteith potential evaporation (mm day ${ }^{-1}$ ), $E_{\text {Pan }}$ is the daily Class-A pan evaporation (mm day ${ }^{-1}$ ), and $A_{p}$ and $B_{p}$ are given by:

$$
\begin{aligned}
& A_{p}=0.17+0.011 \text { Lat } \\
& B_{p}=10^{(0.66-0.211 \text { Lat })}
\end{aligned}
$$

where $L a t$ is the latitude of the catchment in degrees South. 


\section{Supplementary Material}

\section{Appendix S14 Estimating evaporation of intercepted rainfall}

It is recognised that interception is variable in space and in time. According to Klaassen et al. (1998) the interception storage of water in dense forests is an important process and varies seasonally (Gerrits et al., 2010) and across vegetation types. Crockford and Richardson (2000) note that because interception is dependent on rainfall and other meteorological variables it is difficult to make conclusions about interception losses for specific vegetation types.

Because potential evaporation rates are higher in the hotter months of a year and lower during colder months, interception is seasonal. Other factors such as rainfall intensity, wind, and snow also impact interception storage and, hence, interception evaporation (Gerrits et al., 2010). Gerrits et al. (2010) note that although interception storage can be very variable; for the beech forest they studied in Luxembourg, its size played a minor role in evaporation. Stewart (1977) has shown that the evaporation of transpired water is very different to the evaporation of intercepted water and, hence, it is important that these two components are considered separately.

Although Herbst et al. (2008) state that the Gash model (Gash, 1979) is the most widely and successfully used interception model, Gerrits et al. (2010) adopted the Rutter model (Rutter et al., 1971, 1975) in their analysis. In his model, Gash (1979) incorporated the Penman-Monteith equation which was found by Herbst et al. (2008) to give estimates of wet canopy evaporation equivalent to those estimates from the eddy covariance energy balance approach. In the 1971 Rutter model the authors (Rutter et al., 1971) incorporated the Penman (1956) equation to estimate potential evaporation.

Teklehaimanot and Jarvis (1991) concluded from their experiments that evaporation rates from a wet canopy could be satisfactorily modelled by the Penman (1948) equation. Moreover, they further showed that the actual evaporation from a partially wet canopy could be modelled by multiplying the Penman evaporation by $C_{r e t} / S_{\text {can }}$, where $C_{r e t}$ is the amount of water retained on the canopy $(\mathrm{mm})$ and $S_{\text {can }}$ is the storage capacity of the canopy $(\mathrm{mm})$.

Readers are referred to a recent and comprehensive review by Muzylo et al. (2009), who addressed the theoretical basis of 15 interception models including their evaporation components, who identified inadequacies and research questions, and who noted there were few comparative studies and little information about uncertainty in measured and modelled parameters.

\section{Modelling evapotranspiration-interception in an urban area}

Grimmond and Oke (1991) developed a hydrologic model of an urban area at an hourly time-step to estimate evaporation over a range of meteorological conditions. The model includes the Penman (1948) equation modified by Monteith (1965) for vegetation surface and the Rutter et al. (1971) interception model modified by Shuttleworth (1978) to provide a smooth transition between wet and dry vegetation canopies. In addition, anthropogenic heat flux and stored heat flux were also modelled. The model was tested for a small urban area in Vancouver, Canada and according to the authors the model showed promise. 


\section{Supplementary Material}

\section{Appendix S15 Estimating bare soil evaporation}

Following Philip (1957), Ritchie (1972, page 1205) proposed a two-stage model to estimate bare soil evaporation. Salvucci (1997) developed further the Ritchie approach defining the evaporation loss for stage-1 by:

$$
E_{\text {stage } 1}=\bar{E}_{\text {Penman }} \times t_{1}
$$

where $E_{\text {stage } 1}$ is the cumulative stage-1 bare soil evaporation $(\mathrm{mm})$ which, according to Allen et al. (1998, page 145), should not exceed the readily evaporable water (REW) which they define as the maximum depth of water that can be evaporated from the top-soil without restriction. Typical REW values are: sand $2-7 \mathrm{~mm}$, loam $8-10 \mathrm{~mm}$ and clay $8-12 \mathrm{~mm}$. $t_{1}$ is the length of the stage- 1 atmosphere-controlled evaporation period (day) which is defined as:

$$
t_{1}=\frac{R E W}{\bar{E}_{\text {Penman }}}
$$

$\bar{E}_{\text {Penman }}$ is the daily average stage-1 actual evaporation (mm day $\left.{ }^{-1}\right)$ and is assumed to be at or near the rate of Penman evaporation. McVicar et al. (2012, page 183) prefers to use the term energy-limited rather than stage-1. Alternatively, a more rigorous procedure to estimate $t_{1}$ is recommended by Dingman (1992, page 293) who suggests the end of stage-1 is readily observed from ground or satellite observations of albedo.

Discussing evaporation from bare soil, Monteith (1981, pages 10 and 11) observes that "When bare soil is thoroughly wetted, the soil surface behaves like water in so far as the relative humidity of the air in contact with the surface is $100 \%$ ”. Monteith (1981, page 11) further adds that as a matter of observation the rate of evaporation "....is usually very close to the rate for adjacent short vegetation, despite differences in radiative and aerodynamic properties”.

Stage-2 evaporation (the water-limited stage, McVicar et al. (2012, page 183)), is dependent on stage- 1 and two limiting cases need to be considered.

1. Where the unsaturated hydraulic conductivity $\left(\mathrm{mm} \mathrm{day}^{-1}\right), K_{u s}<<\bar{E}_{\text {Penman }}$. This would occur with relatively low permeability soils.

2. Where $K_{u s} \gg \bar{E}_{\text {Penman }}$ and, therefore, the cumulative drainage is much greater than the cumulative actual evaporation.

Salvucci (1997, Equations 18 and 19 respectively) developed the following empirical equations for the two cases:

$$
\begin{aligned}
& \text { For } K_{u s}<<\bar{E}_{\text {Penman }} \\
& E_{\text {bsoil }}(t)=E_{\text {stage } 1}\left[-0.621+1.621\left(\frac{t}{t_{1}}\right)\right]^{0.5}, t \geq t_{1} \\
& \text { For } K_{u s}>\bar{E}_{\text {Penman }} \\
& E_{\text {bsoil }}(t)=E_{\text {stage } 1}\left[1+0.811 \ln \left(\frac{t}{t_{1}}\right)\right], t \geq t_{1}
\end{aligned}
$$

where $E_{\text {bsoil }}(t)$ is the cumulative bare soil evaporation up to time t.

As a check on the total evaporable water (TEW), typical values for a range of soils are provided by Allen et al. (1998, Table 19). For example, sand $=6-12 \mathrm{~mm}$, loam $=16-22$ $\mathrm{mm}$ and clay $=22-29 \mathrm{~mm}$. TEW is defined by Allen et al. (1998, Equation 73) as: 


$$
T E W=10\left(\theta_{F C}-0.5 \theta_{W P}\right) z_{e}
$$

where $\theta_{F C}$ is the soil moisture content (\%) at field capacity, $\theta_{W P}$ is the soil moisture content (\%) at wilting point, $z_{e}$ is the depth of the surface soil layer that is subject to drying from evaporation. If this is unknown, Allen et al. (1998, page 144) recommend $z_{e}=0.10-0.15 \mathrm{~m}$.

It is interesting to note that Penman (1948, page 137) observed from his experiments that freshly wetted bare soil evaporated at about $90 \%$ of the rate observed for open surface water for the same weather conditions.

Based on FAO56 methodology (Allen et al., 1998), Allen et al. (2005) developed a twostage strategy (energy limited and water limited stages) to estimate bare soil evaporation. Mutziger et al (2005) applied the methodology to seven data sets and concluded that model accuracy was about $\pm 15 \%$. 


\section{Supplementary Material}

\section{Appendix S16 Class-A pan evaporation equations and pan coefficients}

Although some researchers, e.g., Watts and Hancock (1984, page 295), are critical of an evaporative pan as a reliable climatic instrument (they list 10 potential problems), it should be noted that Roderick et al. (2009b, Section 4) comment “...that the pan evaporation record provides the only direct measurement of changing evaporative demand..." which is crucial in climate change studies. In Australia, 60 stations have been identified as high quality Class-A pan evaporation stations (Jovanovic et al., 2008).

Equations: Kohler et al. (1955)

Kohler et al. (1955) (see Dingman (1992, Equation 7.41)) developed the following empirical equations to estimate daily open-water evaporation, $E_{f w}\left(\mathrm{~mm} \mathrm{day}^{-1}\right)$ from Class-A pan evaporation data:

$$
\begin{aligned}
& E_{f w}=0.7\left[E_{\text {Pan }}+0.064 p \alpha_{\text {Pan }}\left(0.37+0.00255 u_{\text {Pan }}\right)\left|T_{\text {Pan }}-T_{a}\right|^{0.88}\right] \text { for } T_{\text {Pan }}>T_{a} \\
& E_{f w}=0.7\left[E_{\text {Pan }}-0.064 p \alpha_{\text {Pan }}\left(0.37+0.00255 u_{\text {Pan }}\right)\left|T_{P a n}-T_{a}\right|^{0.88}\right] \text { for } T_{\text {Pan }}<T_{a}
\end{aligned}
$$

where $E_{\text {Pan }}$ is the daily evaporation measured by an unguarded Class-A pan (mm day-1), $p$ is the atmospheric pressure $(\mathrm{kPa}), \alpha_{P a n}$ is the proportion of energy exchanged through the sides of the pan and is specified in Equation (S16.3), $u_{P a n}$ is the average daily wind speed at a height of $150 \mathrm{~mm}$ above the pan $\left(\mathrm{km} \mathrm{day}^{-1}\right)$, and $T_{p a n}$ and $T_{a}$ are respectively the mean daily pan water and air temperature $\left({ }^{\circ} \mathrm{C}\right)$.

$$
\alpha_{\text {Pan }}=0.34+0.0117 T_{\text {Pan }}-3.5 \times 10^{-7}\left(T_{\text {Pan }}+17.8\right)^{3}+0.00135 u_{\text {Pan }}^{0.36}
$$

Wind run for anemometers not at $150 \mathrm{~mm}$ above the pan should be adjusted using Equation (S4.4). Based on an intercontinental comparison, Burman (1976) concluded that the Kohler et al. (1955) equations were superior to empirical methods proposed by Christiansen (1968) and Oliver (1961) which are not included here.

\section{Equations: Chiew \& McMahon (1992)}

Chiew and McMahon (1992, Appendix) developed daily, 3-day, weekly and monthly pan coefficients as simple linear regressions of the form:

$$
E_{P e n, j}=I_{j}+G_{j} E_{P a n, j}
$$

where for month $j, E_{P e n, j}$ is the Penman(1948) estimate of evaporation for a land environment rather than open water, $E_{P a n, j}$ is the evaporation from a Class-A pan, and $I_{j}$ and $G_{j}$ are respectively the intercepts and the gradients of daily, 3-day, weekly and monthly totals. Values of $I_{j}$ and $G_{j}$ for 26 climate stations in Australia are given in Chiew and McMahon (1992).

\section{Equations: Allen et al (1998)}

Equations for estimating Reference Crop evapotranspiration, $E_{R C}$, are presented by Allen et al. (1998, page 55, Table 7) taking into account the site of the pan in terms of the upwind fetch as follows:

$$
E T_{R C}=K_{\text {Pan }} E_{\text {Pan }}
$$


where $K_{P a n}$ is the pan coefficient given by:

for a green vegetated fetch ( 1 to $1000 \mathrm{~m}$ ) within a dry area at least $50 \mathrm{~m}$ wide

$$
\begin{aligned}
K_{\text {Pan }}=0.108 & -0.0286 u_{2}+0.0422 \ln (F E T)+0.1434 \ln \left(R H_{\text {mean }}\right) \\
& -0.000631[\ln (F E T)]^{2} \ln \left(R H_{\text {mean }}\right)
\end{aligned}
$$

for a dry fetch (1 to $1000 \mathrm{~m}$ ) within a green vegetated area at least $50 \mathrm{~m}$ wide

$$
\begin{aligned}
K_{\text {Pan }}=0.61+ & 0.00341 R H_{\text {mean }}-0.000162 u_{2} R H_{\text {mean }}-0.00000050 u_{2} F E T \\
& +0.00327 u_{2} \ln (F E T)-0.00289 u_{2} \ln \left(86.4 u_{2}\right) \\
& -0.0106 \ln \left(86.4 u_{2}\right) \ln (F E T)+0^{\prime} 00063[\ln (F E T)]^{2} \ln \left(86.4 u_{2}\right)
\end{aligned}
$$

where FET is the fetch or length of the identified surface $(\mathrm{m}), u_{2}$ is the daily wind speed at 2 m height, and $R H_{\text {mean }}$ is the mean daily relative humidity (\%). According to Allen et al. (1998, Table 7), Equations (S16.6) and (S16.7) should not be used outside the following ranges $1 \mathrm{~m} \leq F E T \leq 1000 \mathrm{~m}, 30 \% \leq R H_{\text {mean }} \leq 84 \%$, and $1 \mathrm{~ms}^{-1} \leq u_{2} \leq 8 \mathrm{~m} \mathrm{~s}^{-1}$.

A range of pan coefficients based on Equations (S16.6) and (S16.7) are displayed in Table S9 which illustrates the importance of appropriately specifying the microclimate around a pan in order to have a representative estimate of Reference Crop evapotranspiration.

Because $E_{P a n}=\frac{E T_{R C}}{f_{P a n}}$, we are able to use the table to explore how the evaporating power (in this case being represented by pan evaporation $E_{\text {Pan }}$ ) is affected quantitatively by the characteristics of a site. For example, the pan evaporation under a light wind, low humidity and a green vegetated fetch will be reduced by $14 \%$ for a 10 m fetch compared with a 1000 $\mathrm{m}$ one; for a dry fetch under the same conditions, the pan evaporation will increase by $\sim 20 \%$.

\section{Equations: Snyder et al. (2005)}

Based on pan data in California, Snyder et al. (2005, Equations 6, 8 and 9) proposed the following set of empirical equations to estimate reference crop evaporation.

$$
\begin{aligned}
& E T_{R C}=10 \sin \left[\left(\frac{E_{p a}}{19.2}\right) \frac{\pi}{2}\right] \\
& E_{p a}=E_{p a n} F_{100} \\
& F_{100}=-0.0035[\ln (F)]^{2}+0.0622[\ln (F)]+0.79
\end{aligned}
$$

where $E T_{R C}$ is the reference crop evapotranspiration (mm day $\left.{ }^{-1}\right), E_{\text {pan }}$ is the Class-A pan evaporation (unscreened) (mm day ${ }^{-1}$ ) and $F$ is the upwind grass fetch $(\mathrm{m})$. The method is suitable for semi-arid conditions but would require calibration for humid or windier climates (Snyder et al., 2005, page 252).

Ghare et al. (2006) introduced modifications to the Snyder equations but field testing in Italy and Serbia by Trajkovic and Kolakovic (2010) showed that the original Snyder model performed better.

\section{Computed monthly and annual Class-A pan coefficients}

Although it is not possible to check independently that pan coefficients are correct, one can compare computed values with those found in the literature. Published results of estimating the pan coefficients for the two Penman wind functions (Equations S4.5 and S4.6) are presented in Table S10 along with pan coefficients for Reference Crop evapotranspiration 
and the Priestley-Taylor potential evaporation. The exceptionally low pan coefficients for Priestley-Taylor are based on 16 climate stations in Jordon. The coefficients are plotted against mean annual unscreened Class-A pan evaporation in Figure S2 which illustrates, at least for this arid environment, that adopting a spatially constant pan coefficient may be unwise. This observation is consistent with McVicar et al. (2007, Figure 10) who observed for the Coarse Sandy Hill catchments in north-central China both spatial and seasonal variations in pan coefficients.

Published monthly and annual open-water pan coefficients are often extrapolated to other locations. Care needs to be taken as several local factors will impact pan coefficients including relative humidity (Alvarez et al., 2007; Hoy and Stephens, 1979; Kohler et al., 1955), reservoir dimensions (Alvarez et al., 2007), degree of stratification (Hoy and Stephens, 1979), presence of aquatic plants (Winter, 1981), and lake turbidity and salinity (Grayson et al., 1996). Locally calibrated coefficients are preferred.

\section{Australian pan coefficients}

In Australia, in order to prevent the consumption of water by birds and animals, bird guards (wire screens) were installed progressively on the Class-A evaporation pans during the late 1960s and early 1970s, and by 1975 most pans were operating with screens which reduce the evaporation. van Dijk (1985) compared the evaporation recorded from evaporation pans with and without bird guards at four Australian locations between 1967 to 1971 . The average monthly effect at the four locations ranged from $4.1 \%$ to $8.2 \%$ reduction in measured evaporation, with an average of $6.6 \%$. These reductions are less than the values of $13 \%$ for humid areas and $10 \%$ for semi-arid regions noted in a review by Lincare (1994). Based on the findings of van Dijk (1985), the Australian Bureau of Meteorology (2007) recommends an annual conversion factor of $+7 \%$. Jovanovic et al. (2008) have developed a high-quality monthly pan evaporation data set that includes 60 locations across Australia covering the period from about 1970 to present for monitoring evaporation trends.

In Australia, the associated climate data required to estimate open-water evaporation $\left(E_{f w}\right)(\mathrm{mm} / \mathrm{unit}$ time) using Equation (S16.1) or (S16.2) are not available at many pan evaporation sites and, as a consequence, monthly (or annual) pan coefficients are developed using:

$$
E_{f w, j}=K_{j} E_{P a n, j}
$$

where $j$ is the specific month and $K_{j}$ is the average monthly pan coefficient. Traditionally, $K_{j}$ is assumed constant, although Linacre (1994, Figure 1) using Stanhill's (1976) data for 12 sites world-wide found that for very high evaporation rates $K_{j}$ decreased from the nominal 0.7 value.

Hoy and Stephens $(1977 ; 1979)$ calculated the monthly pan coefficients of seven Australian reservoirs by comparing the evaporation of a Class-A pan with the heat budget method over several years. The average monthly pan estimates are listed in Table S11. Annual pan coefficients were estimated for a greater number of Australian reservoirs by Hoy and Stephens (1977; 1979) and these results are listed in Table S12.

We have computed monthly pan coefficients for 68 sites across Australia by correlating monthly evaporation values from Class-A evaporation pans with corresponding Penman evaporation estimates using his 1956 wind function, based on measured daily climate data at the same or a nearby location, thus yielding open-water evaporation. Thirty-nine of the 68 sites are part of the high quality evaporation pan network (Jovanovic et al., 2008, Table 1); 
another 29 stations with monthly pan coefficients have been included in the analysis for spatial completeness. Pan coefficients are presented in Table S6. At least 10 monthly values are used in calculating $79.4 \%$ of the computed monthly pan coefficients. The analysis of the results in the table shows that mean monthly pan coefficients (weighted for length of record) across the 68 Australian stations is 0.80. This average value compares with 0.76 (based on published data in Table S10 for Penman (1956) and Penman (1948) the latter adjusted by Equation (S4.8) to be equivalent to Penman (1956)). It should be noted that in computing the monthly solar radiation term in the Penman model, the coefficients $a_{s}$ and $b_{s}$ in Equation (S3.9) were optimised to 0.05 and 0.65 respectively (Appendix S6).

For many practical problems, annual evaporation estimates need to be disaggregated into monthly values or monthly evaporation values into daily values. This process is not straightforward, when there is no concurrent at-site climate data which could be used to provide guidance as to how the annual or monthly values should be partitioned.

For annual evaporation, a standard approach is to use monthly pan coefficients if available. Another approach, that is available to Australian analysts, is to apply the average monthly values of point potential evapotranspiration for the given location and pro rata the values to sum to the annual evaporation. Maps for each calendar month are available in Wang et al. (2001). This approach is based on the recent analysis by Kirono et al. (2009, Figure 3) who found that, for 28 locations around Australia, Morton's potential evapotranspiration $E T_{\text {Pot }}$ correlated satisfactorily $\left(\mathrm{R}^{2}=0.81\right)$ with monthly Class-A pan evaporation although over-estimating pan evaporation by $8 \%$.

For monthly disaggregation to daily data in Australia one could utilize the analysis of Rayner (2005) who reports on synthetic gridded daily Class-A pan evaporation data based on solar radiation and vapour pressure deficit (Jeffrey et al., 2001). The grids are at a spatial resolution of $0.05^{\circ}(\sim 5 \mathrm{~km})$ and cover the period 1919 to present. McVicar et al. (2007, page 211) note, however, that if pan coefficients are spatially averaged across a range of climates the averaged value will tend to be damped.

\section{Modifying pan data for estimating evaporation from a deep lake}

To estimate deep lake evaporation from pan data, Webb (1966, Equation 3) proposed an alternative approach based on vapour pressure to estimate monthly lake evaporation by summing daily values as follows:

$$
E_{L, d}=1.50 \frac{v_{L}^{*}-v_{4}}{v_{P}^{*}-v_{4}} E_{\text {pan }}^{\prime}
$$

where $E_{L, d}$ is the daily estimate of lake evaporation $\left(\mathrm{mm}\right.$ day $\left.^{-1}\right), E^{\prime}$ pan is the daily pan evaporation (mm day $\left.{ }^{-1}\right), v_{L}^{*}$ is the afternoon average lake saturation vapour pressure (mbar), $v_{P}^{*}$ is the afternoon maximum pan saturation vapour pressure (mbar), and $v_{4}$ is the afternoon average vapour pressure $4 \mathrm{~m}$ above the ground surface (mbar). The monthly evaporation value is the sum of the daily values. The empirical coefficient of 1.50 was established from Lake Hefner data. 


\section{Supplementary Material}

\section{Appendix S17 Comparing published evaporation estimates}

A detailed review of the literature identified 27 papers in which comparisons were made between model estimates of potential or actual evaporation or evapotranspiration and field measurements (water balance studies, Bowen Ratio or eddy correlation), lysimeter observation or comparisons between evaporation equations. Detailed discussion of field measurements of evaporation are outside the scope of this paper. We refer readers to Harbeck (1958), Grant (1975), Myrup et al. (1979), Brutsaert (1982), Dingman (1992, Sections 7.8.2 and 7.8.3), Lenters et al. (2005), and Ali et al. (2008) for applications of the techniques. Details for each of the 27 studies are listed Table 5. For each study two items of information are generally provided in the table - the ratio of the average model values (daily, monthly or annual) to a base value, and a measure of error generally as a root mean square error or standard error of estimate. For four studies, multiple sets of results are available.

The bias results (ratios in Table 5) are consolidated in Table 6 under six headings. Under the first two headings each model result is compared with measured observations. For the six lake studies a water balance, eddy correlation or Bowen Ratio estimate were the basis of the comparison. For the seven non-lake studies, the base estimates were from eddy correlation or Bowen Ratio experiments. The third comparison of four studies is based on lysimeter observations. The remaining three sets of comparisons are between various models and Penman-Monteith, Priestley-Taylor or Hargreaves-Samani estimates. The results are summarised in Figure 3 where each model ratio value includes at least two studies.

In interpreting these results, readers should note the comment of Winter and Rosenberry (1995, page 983) who stated that "Regardless of their intended use, it is not uncommon for equations developed for determination of potential evapotranspiration from vegetation to be used for determination of evaporation from open water”.

The information in Figure 3 requires some interpretation. Firstly, the ratios in column (1) "Lakes", column (2) "Lysimeter" and column (3) "Land" may be regarded as absolute estimates in the sense that the modelled estimates are compared against measured evaporation. Secondly, ratios in columns (4) "Relative to PM" and (5) "Relative to PT" are relative to Penman-Monteith and Priestley-Taylor set to a ratio value of 1.00 . Thirdly, the values in columns (1) and (2) are for open-water ("Lakes") or "Lysimeter" measurements, in which water is not limiting in either comparison. On the other hand, values in column (3) will have been influenced by the availability of soil moisture to the plants and by the vegetation type and, therefore, will not be evaporating or transpiring at a potential rate. This would explain why Turc (Tu) and the Priestley-Taylor (PT) values differ markedly between columns (2) and (3).

Table 5 also contains error information mainly as a root mean square error (RMSE) or as a standard error of estimate (SEE). We have summarised the relevant results in Table 7 which lists the root mean square error $\left(\mathrm{mm} \mathrm{day}^{-1}\right)$ or the standard error of estimate (mm day ${ }^{1}$ ). Because the values of RMSE or SEE were available for Priestley-Taylor in all comparisons, relative errors (as the ratio of RMSE or SEE for the particular model to that for PT) have been computed. These results are summarised as the median for each method. As a guide, the median RMSE for the six Priestley-Taylor analyses is $0.97 \mathrm{~mm}^{-1 a y}{ }^{-1}$ and $0.66 \mathrm{~mm}$ day $^{-1}$ for the eight SEE values. 


\section{Supplementary Material}

\section{Appendix S18 Comparing evaporation estimates based on measured climate data for six Australian automatic weather stations}

Table S13 shows the results of estimating annual evaporation for 14 daily and monthly evaporation/evapotranspiration models based separately on daily and monthly climate data recorded at six widely distributed Australian automatic weather stations over the period January 1979 to March 2010. The latitude and longitude of each station are listed in the table along with the mean annual rainfall estimated for the concurrent period used in the computation of evaporation estimates. Annual values are the sum of 12 monthly means. The number of days and complete months of data available at each station is as follows: Perth Airport (6238 days, 192 months), Darwin Airport (11307 days, 334 months), Alice Springs Airport (11288 days, 320 months), Brisbane Airport (3674 days, 111 months), Melbourne Airport (3842 days, 116 months), and Grove (Companion) (9622 days, 241 months). The authors advise that care needs to be exercised in extending more widely any conclusions arising from this analysis of only six stations.

The results in the table are listed under four main groups: those that estimate actual open-water evaporation (i) Penman 1956 (P56), Priestley-Taylor (PT), Makkink (Ma); (ii) those that estimate reference crop evaporation - FAO-56 Reference Crop (FAO-56 RC), Blaney-Criddle (BC), Hargreaves-Samani (HS), modified Hargreaves (mod H), Turc (Tu); (iii) models that estimate actual evapotranspiration - Morton (Mo), Brutsaert-Strickler (BS), Granger-Gray (GG), Szilagyi-Jozsa SJ); and (iv) three additional methods that include Thornthwaite's monthly potential estimates (Th), PenPan modelled estimates of actual ClassA pan evaporation (PP), and actual evaporation measured by a Class-A evaporation pan. In interpreting these results readers should note that we have applied each method as set out in the relevant reference except we adopted a time-step of both one day and one month. For some models the recommended time-step for analysis is longer than one day. This information is provided where the model is discussed in the paper.

For the daily data in each group, the ratio of the annual evaporation to the value for a key method is calculated and listed as the "Daily ratio". Also for each station, the ratio of annual estimates based on monthly and daily data ( $\mathrm{M}$ to $\mathrm{D}$ ratio) are compared. Several observations follow:

1. Relative to the key procedure in each group, the evaporation estimates in Table S13 are reasonably consistent, excepted for Blaney-Criddle, across the six sites which have very different climates. As noted in Appendix S9 the Blaney-Criddle procedure was developed for application in the dry western United States and, therefore, may not perform successfully in regions subject to a different climate (like Melbourne or Grove) where the procedure appears to perform inadequately. See also item 9 below.

2. On averaging the daily ratios for the open water group, the actual evaporation estimates for Priestley-Taylor and Makkink are 0.88× and 0.59× the Penman 1956 estimate. This is consistent with our summary of published data presented in Table 6 and Figure 3.

3. For the reference crop group, Hargreaves-Samani and Turc are $1.10 \times$ and $0.90 \times$ the FAO-56 Reference Crop average, again consistent with the lysimeter data listed in Table 6 and Figure 3.

4. The PenPan estimates for the six stations are consistent with the values plotted in Figure S3 which are based on 68 Australian stations.

5. The results in Table S13 show that for Penman 1956, Priestley-Taylor, Makkink, FAO56 Reference Crop, Turc, Granger-Gray and PenPan there is less than $~ 2 \%$ difference in 
annual evaporation estimates using a daily or a monthly time-step. However, for Szilagyi-Jozsa and Brutsaert-Strickler, the monthly values are respectively $7 \%$ and $10 \%$ higher than the daily values whereas for Hargreaves-Samani and Blaney-Criddle the monthly values are $14 \%$ and $22 \%$ lower than the daily estimates.

6. In the analysis we observed that Brusaert-Strickler and Szilagyi-Jozsa generated negative daily evapotranspiration (12.7\% and $15.9 \%$ of days respectively). This inadequacy was noted by Brutsaert and Strickler (1979, page 448) in the analysis of their model results. In our analysis the negative evaporations occurred mainly in winter (May through to August).

7. It was also observed that for Grove using Szilagyi-Jozsa model, unrealistically high equilibrium temperatures (say $>100^{\circ} \mathrm{C}$ ) were computed for $2.8 \%$ of days. These unrealistic temperatures appeared to occur mainly on days when the difference between maximum and minimum humidity is around zero.

8. On average, mean annual actual evaporation estimates at a site should be less than mean annual rainfall at the site. Brusaert-Strickler, Granger-Gray and Szilagyi-Jozsa meet this criterion for four, three and three of the six sites respectively. On the other hand, all Morton's estimates were less than the mean annual rainfalls for all sites.

9. Blaney and Criddle also generated many negative daily evapotranspiration estimates, even for Alice Springs which climate-wise is semi-arid and not too dissimilar to the dry western United States. 


\section{Supplementary Material}

\section{Appendix S19 Worked examples}

This set of worked examples is based on data from the Automatic Weather Station 015590 Alice Springs Airport (Australia). The daily data and other relevant information for the worked examples are for the 20 July 1980 as follows:

Station: Alice Springs Airport

Station reference number: 015590

Latitude: $23.7951^{\circ} \mathrm{S}$

Elevation: $546 \mathrm{~m}$

Maximum daily air temperature: $21.0^{\circ} \mathrm{C}$

Minimum daily air temperature: $2.0^{\circ} \mathrm{C}$

Maximum relative humidity: $71 \%$

Minimum relative humidity: 25\%

Daily sunshine hours: 10.7 hours

Wind run at $2 \mathrm{~m}$ height: $51 \mathrm{~km} \mathrm{day}^{-1}\left(=51 \times 1000 /(24 \times 60 \times 60)=0.5903 \mathrm{~m} \mathrm{~s}^{-1}\right)$

General constants used in worked examples:

Solar constant $\left(G_{S c}\right)=0.0820 \mathrm{MJ} \mathrm{m}^{-2} \mathrm{~min}^{-1}$

Stefan-Boltzmann $(\sigma)=4.903 \times 10^{-9} \mathrm{MJ} \mathrm{m}^{-2}$ day $^{-1}{ }^{\circ} \mathrm{K}^{-4}$

von Kármán constant $(k)=0.41$

Latent heat of vaporization $(\lambda)=2.45 \mathrm{MJ} \mathrm{kg}^{-1}$

Mean density of air $\left(\rho_{a}\right)=1.20 \mathrm{~kg} \mathrm{~m}^{-3}$ at $20^{\circ} \mathrm{C}$

Specific heat of air $\left(c_{a}\right)=0.001013 \mathrm{MJ} \mathrm{kg}^{-1} \mathrm{~K}^{-1}$

Mean density of water $\left(\rho_{w}\right)=997.9 \mathrm{~kg} \mathrm{~m}^{-3}$ at $20^{\circ} \mathrm{C}$

Specific heat of water $\left(c_{w}\right)=0.00419 \mathrm{MJ} \mathrm{kg}^{-1} \mathrm{~K}^{-1}$

Specific constants used in worked examples:

Albedo for water $=0.08$ (adopted from Table S3)

Albedo for reference crop $\alpha=0.23$ (adopted from Table S3)

Priestley-Taylor $\alpha_{P T}=1.26$ for PT equation

Priestley-Taylor $\alpha_{P T}=1.28$ for BS equation

Worked example 1: Intermediate calculations for daily analysis

Estimate the values of the intermediate variables associated with computing daily evaporation.

Mean daily temperature $\left(\boldsymbol{T}_{\text {mean }}\right)$

$T_{\text {mean }}=\frac{T_{\max }+T_{\min }}{2}($ see Equation $(\mathrm{S} 2.1))$

$T_{\text {mean }}=\frac{21.0+2.0}{2}=11.5^{\circ} \mathrm{C}$

Saturation vapour pressure at $T_{\max }\left(v_{T \max }^{*}\right)$

$v_{\text {Tmax }}^{*}=0.6108 \exp \left[\frac{17.27 T_{\max }}{T_{\max }+237.3}\right]$ (see Equation (S2.5))

$v_{\text {Tmax }}^{*}=0.6108 \exp \left[\frac{17.27 \times 21.0}{21.0+237.3}\right]=2.4870 \mathrm{kPa}$ 
Saturation vapour pressure at $\boldsymbol{T}_{\min }\left(\boldsymbol{v}_{\text {Tmin }}^{*}\right)$

$v_{\text {Tmin }}^{*}=0.6108 \exp \left[\frac{17.27 T_{\min }}{T_{\min }+237.3}\right]$ (see Equation (S2.5))

$v_{\text {Tmin }}^{*}=0.6108 \exp \left[\frac{17.27 \times 2.0}{2.0+237.3}\right]=0.7056 \mathrm{kPa}$

Daily saturation vapour pressure $\left(v_{a}^{*}\right)$

$v_{a}^{*}=\frac{v_{T \max }^{*}+v_{T \min }^{*}}{2}($ see Equation (S2.6))

$v_{a}^{*}=\frac{2.4870+0.7056}{2}=1.5963 \mathrm{kPa}$

Mean daily actual vapour pressure $\left(v_{a}\right)$

$v_{a}=\frac{v_{T \min }^{*} \frac{R H_{\max }}{100}+v_{T \max }^{*} \frac{R H_{\min }}{100}}{2}$ (see Equation (S2.7))

$v_{a}=\frac{0.7056 \frac{71}{100}+2.4870 \frac{25}{100}}{2}=0.5614 \mathrm{kPa}$

Slope of saturation vapour pressure at $\boldsymbol{T}_{\text {mean }}(\Delta)$

$\Delta=4098\left(0.6108 \operatorname{Exp}\left(\frac{17.27 T_{\text {mean }}}{T_{\text {mean }}+237.3}\right)\right) /\left(T_{\text {mean }}+237.3\right)^{2}$ (see Equation (S2.4))(S19.10)

$\Delta=4098\left(0.6108 \operatorname{Exp}\left(\frac{17.27 \times 11.5}{11.5+237.3}\right)\right) /(11.5+237.3)^{2}=0.0898 \mathrm{kPa}{ }^{\circ} \mathrm{C}^{-1}$

Atmospheric pressure

$p=101.3\left(\frac{293-0.0065 \text { Elev }}{293}\right)^{5.26}$ (see Equation (S2.10))

$p=101.3\left(\frac{293-0.0065 \times 546}{293}\right)^{5.26}=95.01027 \mathrm{kPa}$

Psychrometric constant

$\gamma=0.00163 \frac{p}{\lambda}$ (see Equation (S2.9))

$\gamma=0.00163 \frac{95.01027}{2.45}=0.0632 \mathrm{kPa}^{\circ} \mathrm{C}^{-1}$

\section{Day of Year}

1980 is a leap year, therefore

$D o Y=31+28+31+30+31+30+20+1=202$ (see Equations (S3.21 to S3.23)) (S19.16)

Inverse relative distance Earth to Sun $\left(d_{r}\right)$

$d_{r}^{2}=1+0.033 \cos \left(\frac{2 \pi}{365} D o Y\right)$ (see Equation (S3.6))

$d_{r}^{2}=1+0.033 \cos \left(\frac{2 \pi}{365} 202\right)=0.9688$

Solar declination $(\delta)$

$\delta=0.409 \sin \left(\frac{2 \pi}{365} D o Y-1.39\right)$ (see Equation (S3.7))

$\delta=0.409 \sin \left(\frac{2 \pi}{365} 202-1.39\right)=0.3557$ 


\section{Sunset hour angle $\left(\omega_{s}\right)$}

$\omega_{s}=\operatorname{arcos}[-\tan ($ lat $) \tan (\delta)]$ (see Equation (S3.8))

Latitude (lat) is in radians, hence lat $=\pi \frac{-23.7951}{180}=-0.4153$ radians

noting the negative value as Alice Springs is in the southern hemisphere.

$\omega_{s}=\operatorname{arcos}[-\tan (-0.4153) \tan (0.3557)]=1.4063$

Maximum daylight hours $(N)$

$N=\frac{24}{\pi} \omega_{S}$ (see Equation (S3.11))

$N=\frac{24}{\pi} 1.4063=10.7431$ hours

\section{Worked example 2: Estimate $\boldsymbol{R}_{\boldsymbol{n}}$ for daily analysis}

\section{Extraterrestrial radiation $\left(R_{a}\right)$}

$R_{a}=\frac{1440}{\pi} G_{s c} d_{r}^{2}\left[\omega_{s} \sin (\right.$ lat $) \sin (\delta)+\cos ($ lat $\left.) \cos (\delta) \sin \left(\omega_{s}\right)\right]$ (see Equation (S3.5))(S19.26) where $G_{s c}$ is the solar constant

$$
\begin{aligned}
& R_{a}=\frac{24 x 60}{\pi} 0.082 \times 0.9688\left[\begin{array}{c}
1.4063 \sin (-0.4153) \sin (0.3557) \\
+\cos (-0.4153) \cos (0.3557) \sin (1.4063)
\end{array}\right] \\
& =23.6182 \mathrm{MJ} \mathrm{m}^{-2} \mathrm{day}^{-1}
\end{aligned}
$$

\section{Clear sky radiation $\left(\boldsymbol{R}_{\text {so }}\right)$}

$R_{\text {so }}=\left(0.75+2 \times 10^{-5}\right.$ Elev) $R_{a}$ (see Equation (S3.4))

$R_{\text {so }}=\left(0.75+2 \times 10^{-5} \times 546\right) 23.6182=17.9716 \mathrm{MJ} \mathrm{m}^{-2}$ day $^{-1}$

\section{Incoming solar radiation $\left(R_{s}\right)$}

$R_{s}=\left(a_{s}+b_{s} \frac{n}{N}\right) R_{a}$ (see Equation (S3.9))

Adopting $a_{s}=0.23$ and $b_{s}=0.50$ (see Appendix S3) and noting there were 10.7 hours of sunshine for the day being analysed

$$
R_{s}=\left(0.23+0.5 \frac{10.7}{10.7431}\right) 23.6182=17.1940 \mathrm{MJ} \mathrm{m}^{-2} \text { day }^{-1}
$$

Note: If measured values of solar radiation $\left(R_{S}\right)$ were available, the daily analysis would begin here.

\section{Net longwave radiation $\left(R_{n l}\right)$}

$$
R_{n l}=\sigma\left(0.34-0.14 \bar{v}_{a}^{0.5}\right)\left(\frac{\left(T_{\max }+273.2\right)^{4}+\left(T_{\min }+273.2\right)^{4}}{2}\right)\left(1.35 \frac{R_{S}}{R_{S o}}-0.35\right) \text { (see }
$$

Equation (S3.3))

where $\sigma$ is the Stefan-Boltzmann constant 0.35

$$
R_{n l}=4.903 \times 10^{-9}\left(0.34-0.14 \times 0.5614^{0.5}\right)\left(\frac{(21+273.2)^{4}+(2+273.2)^{4}}{2}\right)\left(1.35 \frac{17.194}{17.9716}-\right.
$$




$$
R_{n l}=7.1784 \mathrm{MJ} \mathrm{m}^{-2} \text { day }^{-1}
$$

\section{Net incoming shortwave radiation $\left(R_{n s}\right)$}

$$
R_{n s}=(1-\alpha) R_{s} \text { (see Equation (S3.2)) }
$$

where $\alpha$ is the albedo for the evaporating surface, which will depend on the evaporating surface. In the worked examples that follow, water and reference crop surfaces are considered:

water $\alpha=0.08$

$R_{n s}=(1-\alpha) R_{S}=(1-0.08) 17.1940=15.8184 \mathrm{MJ} \mathrm{m}^{-2} \mathrm{day}^{-1}$

reference crop $\alpha=0.23$

$R_{n s}=(1-\alpha) R_{s}=(1-0.23) 17.1940=13.2393 \mathrm{MJ} \mathrm{m}^{-2} \mathrm{day}^{-1}$

Net radiation $\left(R_{n}\right)$

$R_{n}=R_{n s}-R_{n l}$ (see Equation (S3.1))

Thus for water $R_{n}=R_{n s}-R_{n l}=15.8184-7.1784=8.6401 \mathrm{MJ} \mathrm{m}^{-2} \mathrm{day}^{-1}$

For reference crop $R_{n}=R_{n s}-R_{n l}=13.2393-7.1784=6.0610 \mathrm{MJ} \mathrm{m}^{-2}$ day $^{-1}$

(S19.39)

Worked example 3: Estimate daily open-water evaporation using Penman equation

$E_{\text {Penow }}=\frac{\Delta}{\Delta+\gamma} \frac{R_{n w}}{\lambda}+\frac{\gamma}{\Delta+\gamma} E_{a}$ (see Equation (S4.1))

$\frac{\Delta}{\Delta+\gamma}=\frac{0.0898}{0.0898+0.0632}=0.5870$

$\frac{\gamma}{\Delta+\gamma}=\frac{0.0632}{0.0898+0.06325}=0.4130$

Adopting the Penman 1956 wind function gives:

$E_{a}=f(u)\left(v_{a}^{*}-v_{a}\right)$ (see Equations (S4.2) and (S4.3))

$E_{a}=(1.313+1.381 \times 0.5903)(1.5963-0.5614)=2.2025 \mathrm{~mm} \mathrm{day}^{-1}$

$E_{\text {Penow }}=0.5870 \frac{8.6401}{2.45}+0.4130 \times 2.2025=2.9797 \mathrm{~mm} \mathrm{day}^{-1}$

Worked example 4: Estimate daily reference crop evapotranspiration for short grass using the FAO-56 Reference Crop procedure

$E T_{R C s h}=\frac{0.408 \Delta\left(\mathrm{R}_{\mathrm{n}}-\mathrm{G}\right)+\gamma \frac{900}{\mathrm{~T}+273} \mathrm{u}_{2}\left(v_{a}^{*}-v_{a}\right)}{\Delta+\gamma\left(1+0.34 \mathrm{u}_{2}\right)}$ (see Equation (S5.18))

In this example we assume the soil flux, G, is zero which according to Allen et al., (1998, page 54; Shuttleworth, 1992, page 4.10) is a reasonable assumption for daily analysis.

$$
\begin{gathered}
E T_{R C s h}=\frac{0.408 \times 0.0898(6.0610-0)+0.0632 \frac{900}{11.5+273} 0.5903(1.5963-0.5614)}{0.0898+0.0632(1+0.34 \times 0.5903)} \\
E T_{R C s h}=\frac{0.22206+0.10538}{0.16578}=2.0775 \mathrm{~mm} \mathrm{day}^{-1}
\end{gathered}
$$


Worked example 5: Estimate daily reference crop evapotranspiration for rye grass at Alice Springs using the Matt-Shuttleworth model

There are five steps in the procedure which includes Equations (S5.34) - (S5.37). The first step is to estimate the average height and surface resistance $\left(\left(r_{s}\right)_{c}\right)$ for rye grass, which from Shuttleworth and Wallace (2009) Table 3, is $0.30 \mathrm{~m}$ and $66 \mathrm{~s} \mathrm{~m}^{-1}$ respectively. Next, the climatological resistance is computed.

$$
\begin{aligned}
& r_{\text {clim }}=86400 \frac{\rho_{a} c_{a}(V P D)}{\Delta R_{n}} \text { (see Equation (S5.34)) } \\
& r_{\text {clim }}=86400 \frac{1.20 \times 0.001013(1.5963-0.5614)}{0.0898 \times 6.0610}=199.9 \mathrm{~s} \mathrm{~m}^{-1}
\end{aligned}
$$

The third step is to estimate $\frac{V P D_{50}}{V P D_{2}}$ from Equation (S5.35)

$$
\frac{V P D_{50}}{V P D_{2}}=\left(\frac{302(\Delta+\gamma)+70 \gamma u_{2}}{208(\Delta+\gamma)+70 \gamma u_{2}}\right)+\frac{1}{r_{c l i m}}\left[\left(\frac{302(\Delta+\gamma)+70 \gamma u_{2}}{208(\Delta+\gamma)+70 \gamma u_{2}}\right)\left(\frac{208}{u_{2}}\right)-\left(\frac{302}{u_{2}}\right)\right]
$$

where $\left(\frac{302(\Delta+\gamma)+70 \gamma u_{2}}{208(\Delta+\gamma)+70 \gamma u_{2}}\right)=\left(\frac{302(0.0898+0.0632)+70 \times 0.0632 \times 0.5903}{208(0.0898+0.0632)+70 \times 0.0632 \times 0.5903}\right)=1.4177$

$$
\frac{V P D_{50}}{V P D_{2}}=1.4177+\frac{1}{199.9}\left[1.4177\left(\frac{208}{0.5903}\right)-\left(\frac{302}{0.5903}\right)\right]=1.3574
$$

Next, $r_{c}^{50}$ is estimated from Equation (S5.36)

$$
r_{c}^{50}=\frac{1}{(0.41)^{2}} \ln \left[\frac{\left(50-0.67 h_{c}\right)}{\left(0.123 h_{c}\right)}\right] \ln \left[\frac{\left(50-0.67 h_{c}\right)}{\left(0.0123 h_{c}\right)}\right] \frac{\ln \left[\frac{(2-0.08)}{0.0148}\right]}{\ln \left[\frac{(50-0.08)}{0.0148}\right]}
$$

for $h_{c}=0.3 \mathrm{~m}$

$$
r_{c}^{50}=\frac{1}{(0.41)^{2}} \ln \left[\frac{(50-0.67 \times 0.3)}{(0.123 \times 0.3)}\right] \ln \left[\frac{(50-0.67 \times 0.3)}{(0.0123 \times 0.3)}\right] \frac{\ln \left[\frac{(2-0.08)}{0.0148}\right]}{\ln \left[\frac{(50-0.08)}{0.0148}\right]}=244.2 \mathrm{~s} \mathrm{~m}^{-1}
$$

The final step is to calculate $E T_{c}$ from Equation (S5.37)

$$
\begin{aligned}
& E T_{c}=\frac{1}{\lambda} \frac{\Delta R_{n}+\frac{\rho_{a} c_{p} u_{2}\left(V P D_{2}\right)}{r_{c}^{50}}\left(\frac{V P D_{50}}{V P D_{2}}\right)}{\Delta+\gamma\left(1+\frac{\left(r_{S}\right)_{c} u_{2}}{r_{c}^{50}}\right)} \\
& E T_{C}=\frac{1}{2.45} \frac{0.0898 \times 6.6061+\frac{1.20 \times 0.001013 \times 0.5903(1.5963-0.5614)}{244.2}(1.3574)}{0.0898+0.0632\left(1+\frac{660.5903}{244.2}\right)}=1.4847 \mathrm{~mm} \mathrm{day}^{-1}
\end{aligned}
$$

Worked example 6: Estimate daily actual evapotranspiration using the AdvectionAridity (Bruitsaert-Strickler) model

$$
E T_{A c t}^{B S}=\left(2 \alpha_{P T}-1\right) \frac{\Delta}{\Delta+\gamma} \frac{R_{n}}{\lambda}-\frac{\gamma}{\Delta+\gamma} f\left(u_{2}\right)\left(v_{a}^{*}-v_{a}\right) \text { (see Equation (S8.2)) }
$$

Note for BS equation, $\alpha_{P T}=1.28$ for rural catchments, and for this example $R_{n}$ is based on an albedo value of 0.23 (Equation (S19.36)). The 1948 Penman wind function is adopted (Equation S4.11). 


$$
\begin{aligned}
& \begin{array}{l}
E T_{A c t}^{B S}= \\
(2 \times 1.28-1)
\end{array} \frac{0.0898}{0.0898+0.0632} \frac{6.0610}{2.45}-\frac{0.0632}{0.0898+0.0632}(2.626+1.381 \times 0.5903)(1.5963- \\
& 0.5614 \\
& \quad E T_{\text {Act }}^{B S}=2.2651-1.4711=0.7940 \mathrm{~mm} \mathrm{day}^{-1}
\end{aligned}
$$

\section{Worked example 7: Estimate daily actual evapotranspiration using the Granger-} Gray model

$$
E T_{A c t}^{G G}=\frac{\Delta G_{g}}{\Delta G_{g}+\gamma} \frac{R_{n}-G}{\lambda}+\frac{\gamma G_{g}}{\Delta G_{g}+\gamma} E_{a} \text { (see Equation (S8.4)) }
$$

For this worked example we set $\mathrm{G}=0$, and note that Granger and Gray (1989, page 26) adopted the Penman (1948) wind function. Granger-Gray procedure estimates evapotranspiration rates for non-saturated lands. To illustrate the procedure, $R_{n}$ is based on an albedo value of 0.23 (Equation S19.36)).

$E_{a}$ is estimated from:

$$
\begin{aligned}
& E_{a}=f(u)\left(v_{a}^{*}-v_{a}\right)(\text { see Equation (S4.2)) } \\
& E_{a}=(2.626+1.381 \times 0.5903)(1.5963-0.5614)=3.5614 \mathrm{~mm} \mathrm{day}^{-1} \\
& D_{p}=\frac{E_{a}}{E_{a}+\frac{R_{n}-G}{\lambda}} \text { (see Equation (S8.6)) } \\
& D_{p}=\frac{3.5614}{3.5614+\frac{6.0610-0}{2.45}}=0.5901 \\
& G_{g}=\frac{1}{0.793+0.20 e^{4.902 D p}}+0.006 D_{p} \text { (see Equation (S8.5)) } \\
& G_{g}=\frac{1}{0.793+0.20 e^{4.902 \times 0.5901}}+0.006 \times 0.5901=0.2307 \\
& E T_{A c t}^{G G}=\frac{0.0898 \times 0.2307}{0.0898 \times 0.2307+0.0632} \frac{6.0610-0}{2.45}+\frac{0.0632 \times 0.2307}{0.0898 \times 0.2307+0.0632} 3.5614 \\
& E T_{\text {Act }}^{G G}=0.6107+0.6188=1.2295 \mathrm{~mm} \mathrm{day}^{-1}
\end{aligned}
$$

Worked example 8: Estimate daily actual evapotranspiration using the SzilagyiJozsa model

$$
\begin{aligned}
E T_{A c t}^{S J} & =2 E_{P T}\left(T_{e}\right)-E_{P e n}(\text { see Equation (S8.7)) } \\
\frac{R_{n}}{\lambda E_{P e n}} & =1+\gamma \frac{T_{e}-T_{a}}{v_{e}^{*}-v_{a}}(\text { see Equation (S8.8)) }
\end{aligned}
$$

For this example procedure $R_{n}$ is based on an albedo value of 0.23 (Equation S19.34)) and, therefore, $E_{P e n}$ needs to be recomputed incorporating $R_{n}=6.0610 \mathrm{MJ} \mathrm{m}^{-2}$ day $^{-1}$ and Penman's 1948 wind function resulting in $E_{P e n}=2.9221 \mathrm{~mm} \mathrm{day}^{-1}$.

To estimate $T_{e}$ (the equilibrium temperature) from Equation (S19.69), a numerical solution is required as $v_{e}^{*}$ is a function of $T_{e}$. Equation (S19.69) is rearranged as follows:

$$
T_{e}=T_{a}-\frac{1}{\gamma}\left[1-\frac{R_{n}}{\lambda E_{P e n}}\right]\left(v_{e}^{*}-v_{a}\right)
$$

noting from Equation (S2.5) that $v_{e}^{*}=0.6108 \exp \left[\frac{17.27 T_{e}}{T_{e}+237.3}\right]$ 
Using Microsoft Excel Goal Seek, $T_{e}=9.900{ }^{\circ} \mathrm{C}$ (for $T_{a}=11.5^{\circ} \mathrm{C}, R_{n}=6.0610 \mathrm{MJ} \mathrm{m}^{-2}$ day $^{-1}, E_{P e n}=2.923 \mathrm{~mm} \mathrm{day}^{-1}$, and $\left.v_{e}^{*}=1.2197 \mathrm{kPa}\right)$. To compute $E_{A c t}^{S J}$, we need $E_{P T}\left(T_{e}\right)$. From Equation (6) and setting $G=0$, and $\Delta$ for $T_{e}=9.900{ }^{\circ} \mathrm{C}$ is equal to 0.0818 , and $\alpha_{P T}=$ 1.31 (see penultimate paragraph in Appendix S8 under heading Szilagyi-Jozsa model), we obtain;

$$
\begin{aligned}
& E_{P T}\left(T_{e}\right)=\alpha_{P T}\left[\frac{\Delta}{\Delta+\gamma} \frac{R_{n}}{\lambda}\right] \\
& E_{P T}\left(9.900^{\circ} \mathrm{C}\right)=1.31\left[\frac{0.0818}{0.0818+0.0632} \times \frac{6.0610}{2.45}\right]=1.8285 \mathrm{~mm} \mathrm{day}^{-1} \\
& E_{\text {Act }}^{S J}=2 \times 1.8285-2.923=0.7340 \mathrm{~mm} \mathrm{day}^{-1}
\end{aligned}
$$

\section{Worked example 9: Estimate daily Class-A pan evaporation using the PenPan model}

$$
E_{\text {PenPan }}=\frac{\Delta}{\Delta+a_{p} \gamma} \frac{R_{N P a n}}{\lambda}+\frac{a_{p} \gamma}{\Delta+a_{p} \gamma} f_{\text {Pan }}(u)\left(v_{a}^{*}-v_{a}\right) \text { (see Equation (S6.1)) }
$$

where $a_{p}$ is an empirical constant $=2.4$

$$
P_{\text {rad }}=1.32+4 \times 10^{-4} \text { lat }+8 \times 10^{-5} \text { lat }^{2} \text { (see Equation (S6.6)) }
$$

Noting $\varphi$ is in absolute value of latitude in degrees

$$
\begin{aligned}
& P_{\text {rad }}=1.32+4 \times 10^{-4} \times 23.7951+8 \times 10^{-5} \times(23.7951)^{2}=1.3748 \\
& f_{\text {dir }}=-0.11+1.31 \frac{R_{S}}{R_{a}}(\text { see Equation (S6.5)) } \\
& f_{\text {dir }}=-0.11+1.31 \frac{17.1940}{23.6182}=0.8437 \\
& R_{\text {SPan }}=\left[f_{\text {dir }} P_{\text {rad }}+1.42\left(1-f_{\text {dir }}\right)+0.42 \alpha_{\text {sS }}\right] R_{S} \text { (see Equation (S6.4)) }
\end{aligned}
$$

where $\alpha_{S S}=0.26$ (assuming short grass Table S3)

$$
\begin{aligned}
& R_{\text {SPan }}=[0.8437 \times 1.3748+1.42(1-0.8437)+0.42 \times 0.26] 17.1940 \\
& R_{\text {SPan }}=25.6375 \mathrm{MJ} \mathrm{m}^{-2} \mathrm{day}^{-1} \\
& R_{N \text { Pan }}=\left(1-\alpha_{A}\right) R_{S P a n}-R_{n l} \text { (see Equation (S6.3)) }
\end{aligned}
$$

where $\alpha_{A}=0.14$ (Appendix S6)

$$
\begin{aligned}
& R_{N P a n}=(1-0.14) 25.6375-7.1784=14.8699 \mathrm{MJ} \mathrm{m}^{-2} \text { day }^{-1} \\
& \left.f_{\text {Pan }}(u)=1.201+1.621 u_{2} \text { (see Equation }(\mathrm{S} 6.2)\right) \\
& f_{\text {Pan }}(u)=1.201+1.621 \times 0.5903=2.1578 \\
& E_{\text {PenPan }}=\frac{0.0898}{0.0898+2.4 \times 0.0632} \frac{14.8699}{2.45}+\frac{2.4 \times 0.0632}{0.0898+2.4 \times 0.0632} 2.1578(1.5963-0.5614)(\mathrm{S} 19.89) \\
& E_{\text {PenPan }}=2.2570+1.4027=3.6587 \mathrm{~mm} \mathrm{day}^{-1}
\end{aligned}
$$

For a screened Class-A pan, $E_{\text {PenPan }}=0.93 * 3.6597=3.4035 \mathrm{~mm} \mathrm{day}^{-1}$.

A discussion regarding the screen factor of 0.93 can be found in Appendix S16. 

model

Worked example 10: Estimate daily potential evaporation using the Makkink

$$
\begin{aligned}
E_{\text {Mak }} & =0.61\left(\frac{\Delta}{\Delta+\gamma} \frac{R_{S}}{2.45}\right)-0.12 \text { (see Equation (S9.6)) } \\
E_{\text {Mak }} & =0.61\left(\frac{0.0898}{0.0898+0.0632} \frac{17.1940}{2.45}\right)-0.12=2.3928 \mathrm{~mm} \mathrm{day}^{-1}
\end{aligned}
$$

Worked example 11: Estimate daily reference crop evapotranspiration using the Blaney-Criddle model

$$
E T_{B C}=\left(0.0043 R H_{\text {min }}-\frac{n}{N}-1.41\right)+b_{v a r} p_{y}\left(0.46 T_{a}+8.13\right)
$$

(see Equation (S9.7))

$$
b_{\text {var }}=e_{0}+e_{1} R H_{\text {min }}+e_{2} \frac{n}{N}+e_{3} u_{2}+e_{4} R H_{\min } \frac{n}{N}+e_{5} R H_{\text {min }} u_{2}
$$

(see Equation (S9.8))

$$
\begin{gathered}
b_{\text {var }}=0.81917-0.0040922 \times 25+1.0705 \times \frac{10.7}{10.7431}+0.065649 \times 0.5903- \\
0.0059684 \times 25 \frac{10.7}{10.7431}-0.0005967 \times 25 \times 0.5903=1.6644
\end{gathered}
$$

$p_{y}$ is the percentage of actual day-light hours for the day compared to the number of day-light hour during the entire year $\left(N_{\text {year }}\right)$. The latter can be computed from Equation (S3.11) as follows:

$$
N_{\text {year }}=\sum_{J=1}^{365,366}\left(\frac{24}{\pi} \omega_{s}\right) \text { (see Equation (S3.11)) }
$$

For non-leap years and leap years $N_{\text {year }}=4380$ and 4393 respectively.

Thus $p_{y}=100 \frac{n}{N_{\text {year }}}=100 \frac{10.7}{4393}=0.2436$

$$
\begin{aligned}
& E T_{B C}=\left(0.0043 \times 25-\frac{10.7}{10.7431}-1.41\right)+1.6644 \times 0.2436(0.46 \times 11.5+8.13) \\
& E T_{B C}=-2.2985+5.4411=3.1426 \mathrm{~mm} \mathrm{day}^{-1}
\end{aligned}
$$

Worked example 12: Estimate daily reference crop evapotranspiration using the Turc model

Turc (1961) proposed two equations, one for humid days and another for non-humid days (see Appendix S9). As the average humidity for Alice Springs on 7 July 1980 was 48\%, the equation for non-humid days is adopted.

$$
E T_{\text {Turc }}=0.013\left(23.88 R_{S}+50\right)\left(\frac{T_{a}}{T_{a}+15}\right)\left(1+\frac{50-R H}{70}\right)
$$

(see Equation (S9.11))

$$
E T_{\text {Turc }}=0.013(23.88 \times 17.1940+50)\left(\frac{11.5}{11.5+15}\right)\left(1+\frac{50-36.5}{70}\right)=2.6727 \mathrm{~mm} \mathrm{day}^{-1}(\mathrm{~S} 19.100)
$$

Worked example 13: Estimate daily reference crop evapotranspiration using the Hargreaves-Samani model 
$E T_{H S}=0.0135 C_{H S} \frac{R_{a}}{\lambda}\left(T_{\max }-T_{\min }\right)^{0.5}\left(T_{a}+17.8\right)$

(see Equation (S9.12))

$C_{H S}=0.00185\left(T_{\max }-T_{\min }\right)^{2}-0.0433\left(T_{\max }-T_{\min }\right)+0.4023$

(see Equation (S9.13))

$C_{H S}=0.00185(21-2)^{2}-0.0433(21-2)+0.4023=0.2475$

$E T_{H S}=0.0135 \times 0.2475 \frac{23.6182}{2.45}(21-2)^{0.5}(11.5+17.8)=4.1129 \mathrm{~mm} \mathrm{day}^{-1}$

Worked example 14: Estimate monthly reference crop evapotranspiration using the modified Hargreaves model

The modified Hargreaves method operates at a monthly time-step. The appropriate data for Alice Springs for July 1980 is as follows:

Mean maximum daily temperature: $19.500^{\circ} \mathrm{C}$

Mean minimum daily temperature: $4.119{ }^{\circ} \mathrm{C}$

Mean monthly temperature: $11.810{ }^{\circ} \mathrm{C}$

Maximum humidity: $77.968 \%$

Minimum humidity: 33.032\%

Daily sunshine hours: 8.34 hours

Wind run at 2 m height: $74.677 \mathrm{~km} \mathrm{day}^{-1}\left(=74.677 \times 1000 /(24 \times 60 \times 60)=0.8643 \mathrm{~m} \mathrm{~s}^{-1}\right)$

Rainfall for month: $10.8 \mathrm{~mm}$

Mean diurnal temperature range for July: $(19.500-4.119)=15.381^{\circ} \mathrm{C}$

$E T_{\text {Harg }, j}=0.0013 S_{O}\left(T_{j}+17.0\right)\left(\overline{T D}_{j}-0.0123 P_{j}\right)^{0.76}$

(see Equation (S9.14))

$$
S_{0}=15.392 d_{r}^{2}\left(\omega_{s} \sin (\text { lat }) \sin (\delta)+\cos (\text { lat }) \cos (\delta) \sin \left(\omega_{s}\right)\right)
$$

(see Equation (S9.15))

$$
S_{0}=15.392 \times 0.9688\left(\begin{array}{c}
1.4063 \sin (-0.4153) \sin (0.3557) \\
+\cos (-0.4153) \cos (0.3557) \sin (1.4063)
\end{array}\right)=9.6710
$$

$E T_{\text {Harg }, j}=0.0013 \times 9.6710(11.810+17.0)(15.381-0.0123 \times 10.8)^{0.76}$

$E T_{\text {Harg }, j}=2.8721 \mathrm{~mm} \mathrm{day}^{-1}=2.8721 \times 31=89.035 \mathrm{~mm} \mathrm{month}^{-1}$

Worked example 15: Estimate daily potential evaporation using the PriestleyTaylor model

$E_{P T}=\alpha_{P T}\left[\frac{\Delta}{\Delta+\gamma} \frac{R_{n}}{\lambda}-\frac{G}{\lambda}\right] \quad$ (see Equation (6))

Assuming $G=0.0, \frac{\Delta}{\Delta+\gamma}=0.5870, R_{n}=8.6401 \mathrm{MJ} \mathrm{m}^{-2}$ day $^{-1}$ (for water), and adopting $\alpha_{P T}=1.26$ (see Section 2.1.3), we obtain

$$
E_{P T}=1.26\left[0.5870 \frac{8.6401}{2.45}-\frac{0.0}{2.45}\right]=2.6083 \mathrm{~mm} \mathrm{day}^{-1}
$$


Worked example 16: Estimate monthly potential evapotranspiration using the Thornthwaite equation

Use the Thornthwaite equation to estimate the average monthly potential evapotranspiration for July at Alice Springs. The Thornthwaite estimates are computed from mean daily temperatures and mean daily day-light hours for each month. At Alice Springs, the mean daily temperature $\left({ }^{\circ} \mathrm{C}\right)$ for each month, based on the whole record, are:

Jan 29.11; Feb 28.32; Mar 25.18; Apr 20.85; May 15.70; Jun 12.43

Jul 11.90; Aug 14.56; Sep 19.86; Oct 23.22; Nov 26.40; Dec 28.07

The mean daily hours of day-light are estimated from Equation (S19.24) and for July the value is 10.68 hours.

$$
\bar{E}_{T h, j}=16\left(\frac{\overline{h r d a y}}{12}\right)\left(\frac{\text { daymon }}{30}\right)\left(\frac{10 \bar{T}_{J}}{I}\right)^{a_{T h}} \text { (see Equation (S9.2)) }
$$

Thus the average potential evapotranspiration for the month of July is estimated as:

$$
\begin{aligned}
& I=\sum_{j=1}^{12}\left(\frac{\bar{T}_{j}}{5}\right)^{1.514}=111.1827 \\
& a=6.75 \times 10^{-7} I^{3}-7.71 \times 10^{-5} I^{2}+0.01792 I+0.49239 \\
& a= \\
& 6.75 \times 10^{-7} \times(111.1827)^{3}-7.71 \times 10^{-5} \times(111.1827)^{2}+0.01792 \times 111.1827+ \\
& 0.49239=2.4594
\end{aligned}
$$

$\overline{h r d a y}$ is the mean daily day-light hours in a given month. From observed data for the month of July at Alice Springs $\overline{h r d a y}=10.68$ hours.

$$
\begin{aligned}
& \bar{E}_{T h, J u l}=16\left(\frac{\overline{\text { hrday }}}{12}\right)\left(\frac{\text { daymon }}{30}\right)\left(\frac{10 \bar{T}_{J}}{I}\right)^{a_{T h}} \\
& \bar{E}_{T h, J u l}=16\left(\frac{10.68}{12}\right)\left(\frac{31}{30}\right)\left(\frac{10 \times 11.90}{111.1827}\right)^{2.4594}=17.391 \mathrm{~mm} \mathrm{month}^{-1}
\end{aligned}
$$

\section{Worked example 17: Estimating deep lake evaporation using Kohler and Parmele model}

Use the Kohler and Parmele (1967) model to estimate the monthly evaporation for September 1999 for a hypothetical deep lake near Melbourne. The following data are available:

Lake area at full supply level (FSL) $\left(A_{L}\right): 1.74 \mathrm{~km}^{2}$

Lake capacity: $26.8 \mathrm{GL}$

Average water depth $(\bar{h}): 27.0 \mathrm{~m}$

Catchment area of lake at full supply level: $3.5 \mathrm{~km}^{2}$ (The lake is an off-stream reservoir)

Contents at beginning of September $1999\left(V_{1}\right): 25.000 \mathrm{GL}$

Lake water temperature at beginning of September $1999\left(T_{L 1}\right): 10.5{ }^{\circ} \mathrm{C}$

Contents at end of September $1999\left(V_{2}\right)$ : 24.1194GL

Lake water temperature at end of September $1999\left(T_{L 2}\right): 11.6{ }^{\circ} \mathrm{C}$

Average lake temperature during September $1999\left(T_{w}\right): 10.8^{\circ} \mathrm{C}$

Rainfall for September $1999\left(P_{d}\right): 60 \mathrm{~mm}\left(2.0 \mathrm{~mm}^{\text {day }}{ }^{-1}\right)$ 
Average temperature of rain falling on reservoir in September $1999\left(T_{p}\right): 10^{\circ} \mathrm{C}$

Average air temperature for September $1999\left(T_{a}\right): 13.37^{\circ} \mathrm{C}$

Atmospheric pressure $(p): 1004.22(\mathrm{hPa})(=100.422 \mathrm{kPa})$

Wind run for September $1999(u)$ : $329.1 \mathrm{~km} \mathrm{day}^{-1}$

Surface water inflow for September $1999\left(S W_{\text {in }}\right)$ : assume $0.40 \mathrm{~mm}^{-1} \mathrm{day}^{-1}$ at FSL

Average temperature of surface water inflow for September $1999\left(T_{\text {swin }}\right): 11^{\circ} \mathrm{C}$ at FSL)

Surface water outflow for September $1999\left(S W_{\text {out }}\right): 1.00 \mathrm{GL}$ (equivalent to $19.16 \mathrm{~mm}$

Average temperature of surface water outflow for September $1999\left(T_{\text {swout }}\right): 10.8^{\circ} \mathrm{C}$

Assume no groundwater inflow or outflow

Specific constants for Worked Examples 17 and 18:

Density of air $\left(\rho_{a}\right): 1.2 \mathrm{~kg} \mathrm{~m}^{-3}$

Density of water $\left(\rho_{w}\right): 997.9 \mathrm{~kg} \mathrm{~m}^{-3}$

Effective emissivity of water $\left(\varepsilon_{w}\right): 0.95$

Specific heat of water $\left(c_{w}\right): 4.19 \mathrm{~kJ} \mathrm{~kg}^{-1}{ }^{\circ} \mathrm{C}^{-1}$

Height at which the wind speed and vapour pressure are measured $\left(z_{m}\right): 2.0 \mathrm{~m}$

Zero-plane displacement $\left(z_{d}\right): \sim 0.000 \mathrm{~m}$

Roughness height of surface $\left(z_{0}\right): 0.001 \mathrm{~m}$ for water

Latent heat of vaporization $(\lambda): 2.45 \mathrm{MJ} \mathrm{kg}^{-1}$

Stefan-Boltzmann constant $(\sigma): 4.903 \times 10^{-9} \mathrm{MJ} \mathrm{m}^{-2}$ day $^{-1} \mathrm{~K}^{-4}$

Slope of the vapour pressure curve based on an average September 1999 air temperature of $13.37^{\circ} \mathrm{C}(\Delta): 0.10008 \mathrm{kPa}^{\circ} \mathrm{C}^{-1}$

Psychrometric constant for Melbourne $(\gamma): 0.0665 \mathrm{kPa}^{\circ} \mathrm{C}^{-1}$

To estimate the monthly evaporation for the hypothetical deep lake based on Kohler and Parmele (1967) we apply the following equations at a daily time-step:

$$
\begin{aligned}
& E_{D L}=E_{\text {Penow }}+\alpha_{K P}\left(A_{w}-\frac{\Delta Q}{\Delta t}\right) \text { (see Equation (S10.1)) } \\
& \alpha_{K P}=\frac{\Delta}{\Delta+\gamma+\frac{4 \varepsilon_{w} \sigma\left(T_{w}+273.2\right)^{3}}{\rho_{w} \lambda K_{E} u}} \text { (see Equation (S10.2)) } \\
& A_{w}=\frac{c_{w} \rho_{w}}{\lambda}\left(P_{d} T_{p}+S W_{\text {in }} T_{\text {swin }}-S W_{\text {out }} T_{\text {Swout }}+G W_{\text {in }} T_{\text {gwin }}-G W_{\text {out }} T_{\text {gwout }}\right) \\
& \text { (see Equation }(\mathrm{S} 10.3)) \\
& \Delta Q=\frac{c_{w} \rho_{w}}{A_{L} \lambda}\left(V_{2} T_{L 2}-V_{1} T_{L 1}\right) \text { (see Equation (S10.4)) } \\
& \left.K_{E}=0.622 \frac{\rho_{a}}{p \rho_{w}} \frac{1}{6.25\left[\ln \left(\frac{z_{m}-z_{d}}{z_{0}}\right)\right]^{2}} \quad \text { (see Equation }(\mathrm{S} 10.5)\right) \\
& K_{E}=0.622 \frac{1.2}{\left(\frac{1004.22}{10}\right) \times 997.9} \times \frac{119.17)}{6.25\left[\ln \left(\frac{2.0-0.000}{0.001}\right)\right]^{2}}=2.0627 \times 10^{-8} \\
& \alpha_{K P}=\frac{0.10008}{0.10008+0.0665+\frac{4 \times 0.95 \times 4.903 \times 10^{-9}(10.8+273.2)^{3}}{997.9 \times 2.45 \times 2.0627 \times 10^{-8} \times(329.1 \times 1000)}}=0.52045 \\
& A_{w}=\left(\frac{4.19}{1000}\right) \frac{997.9}{2.45}\left[\left(\frac{2.0}{1000}\right) \times 10+\left(\frac{0.4}{1000}\right) \times 11-\left(\frac{19.16}{1000}\right) \times 10.8+0-0\right]=-0.3115 \text { mm day }^{-1}
\end{aligned}
$$




$$
\begin{aligned}
\Delta Q & =\left(\frac{4.19}{1000}\right) \frac{997.9}{\left(1.74 \times 10^{6}\right) 2.45}\left(24.1194 \times 10^{6} \times 11.6-25.000 \times 10^{6} \times 10.5\right) \frac{1}{30} \\
& =0.5651 \mathrm{~mm} \mathrm{day}^{-1}
\end{aligned}
$$

$E_{P e n}$ for September 1999 at the lake near Melbourne has been computed (separately from this worked example) as $117.2 \mathrm{~mm}\left(3.91 \mathrm{~mm} \mathrm{day}^{-1}\right)$

$$
\begin{aligned}
E_{D L} & =3.91+0.5204\left(-0.3115-\frac{0.5651}{1}\right) \\
& =3.91-0.4562=3.45 \mathrm{~mm} \mathrm{day}^{-1}=103.5 \mathrm{~mm} \text { evaporation for September } 1999 .
\end{aligned}
$$

\section{Worked example 18: Estimating deep lake evaporation using Vardavas and Fountoulakis model}

This worked example is for the same hypothetical deep lake described in Worked Example 17. The exercise is to estimate lake evaporation for September 1999. Vardavas and Fountoulakis (1996, Section 1) adopted a monthly time-step.

$$
\begin{aligned}
& E_{D L}=\left(\frac{\Delta}{\Delta+\gamma}\right) E_{S}+\left(\frac{\gamma}{\Delta+\gamma}\right) E_{a} \text { (see Equation (S10.7)) } \\
& E_{S}=\frac{1}{\lambda}\left(R_{n}+\Delta H_{j, j-1}\right) \text { (see Equations (S10.8) and (S10.9)) } \\
& \Delta H_{j, j-1}=-48.6 \bar{h} \frac{\Delta T_{w l}}{t_{m}} \text { (see Equation (S10.9)) }
\end{aligned}
$$

From the data in worked example 16:

$$
\Delta H_{j, j-1}=-48.6 \times 27.0 \frac{11.6-10.5}{30}=-48.114 \mathrm{~W} \mathrm{~m}^{-2}
$$

Convert this from $\mathrm{W} \mathrm{m} \mathrm{m}^{-2}$ to $\mathrm{MJ} \mathrm{m}^{-2}$ day-1 $^{-1}\left(1 \mathrm{~W}=1 \mathrm{~J} \mathrm{sec}^{-1}\right)$

$$
\Delta H_{j, j-1}=-48.114 \times 0.0864=-4.1570 \mathrm{MJ} \mathrm{m}^{-2} \text { day }^{-1}
$$

Assume for September $1999 R_{n}=9.3469 \mathrm{MJ} \mathrm{m}^{-2} \mathrm{day}^{-1}$

$$
\begin{aligned}
& E_{s}=\frac{1}{2.45}(9.3469+(-4.1570))=2.1183 \mathrm{~mm} \mathrm{day}^{-1} \\
& E_{a}=C_{u} \bar{u}\left[v_{a}^{*}\left(T_{a}\right)-v_{a}\left(T_{a}\right)\right] \text { (see Equations (S10.10) and (S10.11)) }
\end{aligned}
$$

noting that the vapour pressure deficit $v_{a}^{*}\left(T_{a}\right)-v_{a}\left(T_{a}\right)$ is in units of mbar (Vardavas, 1987, page 249).

First we need to estimate $u_{*}$ from

$$
\bar{u}=\frac{u_{*}}{k} \ln \left(\frac{z_{2} u_{*}}{0.135 v}\right) \text { (see Equation (S10.16)) }
$$

where $k$ is the von Kármán constant of 0.41

$$
\begin{aligned}
& v=2.964 \times 10^{-7} \frac{T_{a}^{3 / 2}}{p} \text { (see Equation }(\mathrm{S} 10.15) \text { ) } \\
& v=2.964 \times 10^{-7} \frac{(13.37+273.2)^{3 / 2}}{\frac{1004.22}{10}}=1.4318 \times 10^{-5} \mathrm{~m}^{2} \mathrm{~s}^{-1}
\end{aligned}
$$

Thus for a wind speed of $3.809 \mathrm{~m} \mathrm{~s}^{-1}$, Equation (S19.133) is

$$
3.809=\frac{u_{*}}{0.41} \ln \left(\frac{2.0 u_{*}}{0.135 \times 1.4318 \times 10^{-5}}\right)
$$




$$
\begin{aligned}
& \text { Using Microsoft Excel Goal Seek, } u_{*}=0.132 \mathrm{~m} \mathrm{~s}^{-1} \\
& \left.C_{u}=\frac{3966}{T_{a} \ln \left(\frac{z_{2}}{z_{o v}}\right) \ln \left(\frac{z_{1}}{z_{o m}}\right)} \text { (see Equation }(\mathrm{S} 10.12)\right) \\
& z_{o m}=0.135 \frac{v}{u_{*}}=0.135 \frac{1.4318 \times 10^{-5}}{0.132}=1.4643 \times 10^{-5} \\
& z_{o v}=0.624 \frac{v}{u_{*}}=0.624 \frac{1.4318 \times 10^{-5}}{0.132}=6.7685 \times 10^{-5} \\
& C_{u}=\frac{3966}{(13.37+273.2) \ln \left(\frac{2.0}{6.7685 \times 10^{-5}}\right) \ln \left(\frac{2.0}{1.4643 \times 10^{-5}}\right)} \\
& =0.1137 \mathrm{~mm} \mathrm{day}^{-1} /\left(\mathrm{m} \mathrm{s}^{-1} \mathrm{mbar}\right)
\end{aligned}
$$

which is within the range 0.11 to $0.13 \mathrm{~mm} \mathrm{day}^{-1} /\left(\mathrm{m} \mathrm{s}^{-1}\right.$ mbar) estimated for Australian reservoirs as noted by Vardavas (1987, page 264).

Assume for this hypothetical example the vapour pressure deficit $=0.6152 \mathrm{kPa}$

$$
E_{a}=C_{u} \bar{u}\left[v_{a}^{*}\left(T_{a}\right)-v_{a}\left(T_{a}\right)\right]=0.1137 \times 3.809 \times(0.6152 \times 10)
$$

where the factor 10 in the last set of brackets converts $\mathrm{kPa}$ to mbar

$$
\begin{aligned}
& =2.664 \mathrm{~mm} \mathrm{day}^{-1} \\
E_{D L} & =\left(\frac{0.10008}{0.10008+0.0665}\right) 2.1183+\left(\frac{0.0665}{0.10008+0.0665}\right) 2.664 \\
& =2.336 \mathrm{~mm} \mathrm{day}^{-1}=70.1 \mathrm{~mm} \text { evaporation for September } 1999 .
\end{aligned}
$$

\section{Worked example 19: Estimating lake evaporation based on the equilibrium} temperature by McJannet et al. (2008)

Estimate for a hypothetical lake near Alice Springs, the evaporation for 20 July 1980. The following details are available:

Average lake area: $5 \mathrm{~km}^{2}$

Average lake depth: $10 \mathrm{~m}$

Latitude: $23.7951^{\circ} \mathrm{S}$

Elevation: $546 \mathrm{~m}$

Lake water temperature for 19 July was $10.8734{ }^{\circ} \mathrm{C}$.

The meteorological data for 20 July 1980 are listed at the beginning of this appendix. For the purposes of this example, the fraction of cloud cover $\left(C_{f}\right)$ is based on Equation (S3.18) where $K_{\text {ratio }}=\frac{R_{s}}{R_{s o}}=\frac{17.1940}{17.9716}=0.9567$ and hence $C_{f}=2\left(1-K_{\text {ratio }}\right)=0.08654$.

Adjust wind speed to equivalent of $10 \mathrm{~m}$ height.

$$
u_{10}=u_{2} \frac{\ln \left(\frac{10}{z_{0}}\right)}{\ln \left(\frac{2}{z_{0}}\right)}
$$

where $z_{0}=0.0002 \mathrm{~m}$ (adopted from Table S2 for open sea)

$$
u_{10}=0.5903 \frac{\ln \left(\frac{10}{0.0002}\right)}{\ln \left(\frac{2}{0.0002}\right)}=0.6934
$$


Estimate the values of the intermediate variables associated with computing daily evaporation in addition to those in Worked Example 1.

Dew point temperature $\left(T_{d}\right)$

$T_{d}=\frac{116.9+237.3 \ln \left(v_{a}\right)}{16.78-\ln \left(v_{a}\right)}$ (see Equation (S2.3))

From Equation S19.9 $v_{a}=0.5614 \mathrm{kPa}$

$T_{d}=\frac{116.9+237.3 \ln (0.5614)}{16.78-\ln (0.5614)}=-1.1579{ }^{\circ} \mathrm{C}$

Wet-bulb temperature $\left(T_{w b}\right)$

$T_{w b}=\frac{0.00066 \times 100 T_{a}+\frac{4098 v_{a}}{\left(T_{d}+237.3\right)^{2}} T_{d}}{0.00066 \times 100+\frac{4098 v_{a}}{\left(T_{d}+237.3\right)^{2}}}($ see Equation (S2.2))
$T_{w b}=\frac{0.00066 \times 100 \times 11.5+\frac{4098 \times 0.5614}{(-1.1579+237.3)^{2}}(-1.1579)}{0.00066 \times 100+\frac{4098 \times 0.5614}{(-1.1579+237.3)^{2}}}=6.6311^{\circ} \mathrm{C}$

Slope of saturation vapour pressure curve at wet-bulb temperature $\left(\Delta_{w b}\right)$

$\Delta_{w b}=\frac{4098\left[0.6108 \exp \left(\frac{17.27 T_{w b}}{T_{w b}+237.3}\right)\right]}{\left(T_{w b}+237.3\right)^{2}}$ (see Equation (S2.4))

where $\Delta_{w b}$ is the slope of the saturation vapour pressure curve at wet-bulb temperature

$$
\Delta_{w b}=\frac{4098\left[0.6108 \exp \left(\frac{17.27 \times 6.6311}{6.6311+237.3}\right)\right]}{(6.6311+237.3)^{2}}=0.06727 \mathrm{kPa}{ }^{\circ} \mathrm{C}^{-1}
$$

Wind function $(\boldsymbol{f}(\boldsymbol{u}))$

$$
\begin{aligned}
& f(u)=\left(\frac{5}{A}\right)^{0.05}\left(3.80+1.57 u_{10}\right)(\text { see Equation }(\mathrm{S} 11.24)) \\
& f(u)=\left(\frac{5}{5}\right)^{0.05}(3.80+1.57 \times 0.6934)=4.8887
\end{aligned}
$$

Aerodynamic resistance $\left(r_{a}\right)$

$$
\begin{aligned}
& r_{a}=\frac{\rho_{a} c_{a}}{\gamma\left(\frac{f(u)}{86400}\right)} \text { (see Equation (S11.23)) } \\
& r_{a}=\frac{1.20 \times 0.001013}{0.0632\left(\frac{4.8887}{86400}\right)}=339.9 \mathrm{~s} \mathrm{~m}^{-1}
\end{aligned}
$$

The next step is to compute the net radiation. For 20 July 1980, $R_{s}$ and $R_{n s}$ were

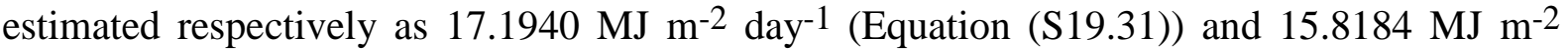
day $^{-1}$ (Equation (S19.35)) noting that albedo for water is 0.08 . Incoming longwave radiation is estimated from:

$$
R_{i l}=\left(C_{f}+\left(1-C_{f}\right)\left(1-\left(0.261 \exp \left(-7.77 \times 10^{-4} T_{a}^{2}\right)\right)\right)\right) \sigma\left(T_{a}+273.15\right)^{4} \text { (see }
$$

Equation (S11.26))

$$
\begin{aligned}
& R_{i l}=\left(0.08654+(1-0.08654)\left(1-\left(0.261 \exp \left(-7.77 \times 10^{-4} 11.5^{2}\right)\right)\right)\right) \\
& \times 4.903 \times 10^{-9}(11.5+273.15)^{4}=25.2641 \mathrm{MJ} \mathrm{m}^{-2} \mathrm{day}^{-1}
\end{aligned}
$$


Outgoing longwave radiation as a function of wet-bulb temperature is estimated from: $R_{o l}^{w b}=\sigma\left(T_{a}+273.15\right)^{4}+4 \sigma\left(T_{a}+273.15\right)^{3}\left(T_{w b}-T_{a}\right)$ (see Equation (S11.32))

$R_{o l}^{w b}=4.903 \times 10^{-9}(11.5+273.15)^{4}+4 \times 4.903 \times 10^{-9}(11.5+273.15)^{3}$

$(6.6311-11.5)=29.9866 \mathrm{MJ} \mathrm{m}^{-2}$ day $^{-1}$

$Q_{w b}^{*}=R_{s}(1-\alpha)+\left(R_{i l}-R_{o l}^{w b}\right)$ (see Equation (S11.31))

$Q_{w b}^{*}=15.8184+25.2641-29.9866=11.0959 \mathrm{MJ} \mathrm{m}^{-2}$ day $^{-1}$

We now need to calculate the time constant $(\tau)$ and the equilibrium temperature $\left(T_{e}\right)$.

$$
\begin{aligned}
\tau & =\frac{\rho_{w} c_{w} h_{w}}{4 \sigma\left(T_{w b}+273.15\right)^{3}+f(u)\left(\Delta_{\mathrm{wb}}+\gamma\right)} \text { (see Equation (S11.29)) } \\
\tau & =\frac{997.9 \times 0.00419 \times 10}{4 \times 4.903 \times 10^{-9}(6.6311+273.15)^{3}+4.8887(0.06727+0.0632)}=39.1739 \text { days } \\
T_{e} & =T_{w b}+\frac{Q_{w b}^{*}}{4 \sigma\left(T_{w b}+273.15\right)^{3}+f(u)\left(\Delta_{\mathrm{wb}}+\gamma\right)} \text { (see Equation (S11.30)) } \\
T_{e} & =6.6311+\frac{11.0959}{4 \times 4.903 \times 10^{-9}(6.6311+273.15)^{3}+4.8887(0.06727+0.0632)}=17.0269
\end{aligned}
$$

The next step is to estimate today's water temperature given yesterday's water temperature (assume $T_{w 0}=10.8734$ )

$$
\begin{aligned}
& T_{w}=T_{e}+\left(T_{w 0}-T_{e}\right) \exp \left(-\frac{1}{\tau}\right) \text { (see Equation (S11.28)) } \\
& T_{w}=17.0269+(10.8734-17.0269) \exp \left(-\frac{1}{39.1739}\right)=11.0285^{\circ} \mathrm{C}
\end{aligned}
$$

As we have an estimate of the water temperature, we can now estimate the change in heat storage $\left(G_{w}\right)$, the slope of the saturation vapour pressure curve at water temperature $\left(\Delta_{w}\right)$, the saturation vapour pressure at water temperature $\left(v_{w}^{*}\right)$, and the lake evaporation $\left(E_{M c J}\right)$.

$$
\begin{aligned}
\mathrm{G}_{\mathrm{w}} & =\rho_{w} c_{w} h_{w}\left(T_{w}-T_{w 0}\right)(\text { see Equation }(\mathrm{S} 11.33)) \\
\mathrm{G}_{\mathrm{w}} & =997.9 \times 0.00419 \times 10(11.0285-10.8734)=6.4850 \mathrm{MJ} \mathrm{m}^{-2} \mathrm{day}^{-1} \\
\Delta_{w} & =\frac{4098\left[0.6108 \exp \left(\frac{17.27 T_{w}}{T_{w}+237.3}\right)\right]}{\left(T_{w}+237.3\right)^{2}}(\text { see Equation }(\mathrm{S} 2.4)) \\
\Delta_{w} & =\frac{4098\left[0.6108 \exp \left(\frac{17.27 \times 11.0285}{11.0285+237.3}\right)\right]}{(11.0285+237.3)^{2}}=0.08740 \mathrm{kPa}{ }^{\circ} \mathrm{C}^{-1} \\
v_{w}^{*} & =0.6108 \exp \left[\frac{17.27 T_{w}}{T_{w}+237.3}\right] \quad(\text { see Equation }(\mathrm{S} 2.5)) \\
v_{w}^{*} & =0.6108 \exp \left[\frac{17.27 \times 11.0285}{11.0285+237.3}\right]=1.3152 \mathrm{kPa}
\end{aligned}
$$

The penultimate step is to recompute the net radiation given the water temperature.

$R_{n s}$ and $R_{i l}$ will not change as they are essentially unaffected by the surface temperature. However, the outgoing longwave radiation $\left(R_{o l}\right)$ is a function of water temperature which is now known.

$$
R_{o l}=0.97 \sigma\left(T_{w}+273.15\right)^{4} \text { (see Equation (S11.27)) }
$$


$R_{o l}=0.97 \times 4.903 \times 10^{-9}(11.0285+273.15)^{4}=31.0169 \mathrm{MJ} \mathrm{m}^{-2} \mathrm{day}^{-1}$

Thus,

$\mathrm{Q}^{*}=R_{S}(1-\alpha)+\left(R_{i l}-R_{o l}\right)$ (see Equation (S11.25))

$\mathrm{Q}^{*}=15.8184+(25.2641-31.0169)=10.0656 \mathrm{MJ} \mathrm{m}^{-2}$ day $^{-1}$

$E_{M C J}=\frac{1}{\lambda}\left(\frac{\Delta_{\mathrm{w}}\left(\mathrm{Q}^{*}-\mathrm{G}_{\mathrm{w}}\right)+\frac{86400 \rho_{a} c_{a}\left(v_{W}^{*}-v_{a}\right)}{r_{a}}}{\Delta_{\mathrm{w}}+\gamma}\right)$ (see Equation (S11.22))

$E_{M C J}=\frac{1}{2.45}\left(\frac{0.087340(10.0656-6.4850)+\frac{86400 \times 1.2 \times 0.001013(1.3152-0.5614)}{339.9}}{0.08732+0.0632}\right)$

(S19.178)

$E_{M c J}=1.4796 \mathrm{~mm} \mathrm{day}^{-1}$

(S19.179) 


\section{Supplementary Material}

\section{Appendix S20 Listing of Fortran 90 version of Morton's WREVAP program}

The following program listing called Program WREVAP, which is a slightly modified version of Morton's WREVAP model, is written in Fortran 90 and follows closely the steps set out in Appendix C of Morton (1983a). The deep lake sub-routine is based on Morton (1986, Section 3).

The program uses a monthly time-step and requires the following input data: for each month, average daily temperature $\left({ }^{\circ} \mathrm{C}\right)$, average daily relative humidity $(\%)$, and average daily sunshine hours. Other data required as input are mean annual precipitation $(\mathrm{mm})$, latitude (decimal degree and negative for the southern hemisphere), and elevation of the station (m). For deep lake evaporation, lake salinity (ppm) and average lake depth (m) are also required. The outputs from the CRAE sub-model are monthly net solar radiation (mm), monthly potential evapotranspiration (mm), monthly wet areal evapotranspiration (mm) and monthly actual areal evapotranspiration (mm); from the CRWE sub-model are net radiation at the water surface, potential evaporation and actual shallow lake evaporation; and from CWLE sub-model are net radiation at the water surface, potential evaporation and actual deep lake evaporation.

\section{Structure of Program WREVAP}

Program WREVAP calculates the actual evapotranspiration from a landscape (catchment) environment, evaporation from a shallow lake and evaporation from a deep lake based on Morton's (1983a,b; 1986) WREVAP program. The program WREVAP is a slightly modified version of Morton's WREVAP and consists of one module (WREVAP data) and five subroutines (crae, crwe, crle1, crle2 and sub1). crae, crwe and crle represent Morton's three program CRAE, CRWE and CRLE. Two versions of CRLE are include: crle1 calculates lake evaporation assuming the water depth in the lake is constant, and crle2 calculates lake evaporation assuming the water depth in the lake varies on a monthly basis.

The structure of Program WREVAP is shown in the figure below where:

WREVAP data Variable declarations and constants

crae Calculates the actual evapotranspiration from landscape

crwe Calculates evaporation from shallow lake

crle1 Calculates evaporation from deep lake (constant depth)

crle2 Calculates evaporation from deep lake (variable depth)

sub1 Calculates the solar radiation

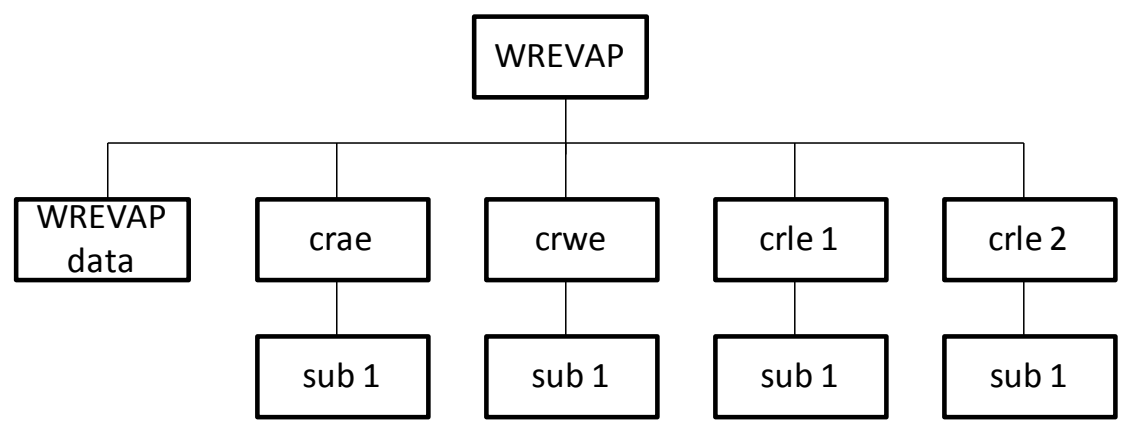


Input data: latitude (degrees), station height (m), mean annual precipitation (mm year ${ }^{-1}$ ), number of months, monthly temperature $\left({ }^{\circ} \mathrm{C}\right)$, relative humidity $(\%)$, sunshine hours $(\mathrm{h})$, lake depth (m), salinity (ppm).

The input data is supplied to the program via two files: a parameter file and a data file.

Parameter file: WREVAP.par

\section{Example:}

Melbourne.dat

Melbourne.out

1

\section{Data file:}

Record

$1 \quad$ Station header

2 Latitude, station height, mean annual rainfall and number of months

3 Data header

4 year, month, number of days, temperature, relative humidity and sunshine hours

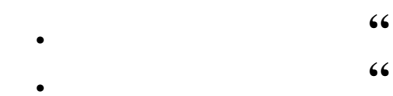

Example: Melbourne.dat (for crae and crwe)

8628286 MELBOURNE AIRPORT

-37.666 113.4660201

Year Month Day Temperature $\mathrm{RH} \quad \mathrm{SH}$

$\begin{array}{llllll}1993 & 5 & 31 & 12.54 & 72.58 & 8.88\end{array}$

$\begin{array}{llllll}1993 & 6 & 30 & 10.12 & 76.73 & 7.08\end{array}$

$\begin{array}{llllll}1993 & 7 & 31 & 9.90 & 75.74 & 10.03\end{array}$

$\begin{array}{llllll}1993 & 8 & 31 & 11.62 & 69.44 & -9999\end{array}$

$\begin{array}{llllll}1993 & 9 & 30 & 12.12 & 75.97 & 9.63\end{array}$

$\begin{array}{llllll}1993 & 10 & 31 & 13.16 & 70.58 & 11.20\end{array}$

$\begin{array}{llllll}1993 & 11 & 30 & 15.15 & 71.00 & 10.95\end{array}$

$\begin{array}{llllll}1993 & 12 & 31 & 16.80 & 68.94 & 9.53\end{array}$

\begin{tabular}{|c|c|c|c|c|c|}
\hline \multicolumn{6}{|c|}{ Example: } \\
\hline \multicolumn{6}{|c|}{$\begin{array}{l}\text { Example: ThomsonRe } \\
\text { Thomson Reservoir }\end{array}$} \\
\hline-37.75 & 2415.0 & 1090 & 3622.9523 & & \\
\hline Year & Month & Day & Temperature & RH & $\mathrm{SH}$ \\
\hline 2007 & 3 & 31 & 16.59 & 69.96 & 8.02 \\
\hline 2007 & 4 & 30 & 13.45 & 74.71 & 7.31 \\
\hline 2007 & 5 & 31 & 12.56 & 73.88 & 5.20 \\
\hline 2007 & 6 & 30 & 6.94 & 85.04 & 3.91 \\
\hline 2007 & 7 & 31 & 6.98 & 79.93 & 4.45 \\
\hline 2007 & 8 & 31 & 9.33 & 72.12 & 6.58 \\
\hline 2007 & 9 & 30 & 9.77 & 69.64 & 7.03 \\
\hline
\end{tabular}




$\begin{array}{llllll}2007 & 10 & 31 & 12.77 & 64.85 & 7.86 \\ 2007 & 11 & 30 & 15.43 & 75.45 & 8.42 \\ 2007 & 12 & 31 & 17.28 & 69.95 & 8.43\end{array}$

Example: ThomsonReservoirVD.dat (for crle2)

Thomson Reservoir -37.752 415.010903623

Year Month Day Temperature $\mathrm{RH}$ SH Depth

$\begin{array}{lllllll}2007 & 3 & 31 & 16.59 & 69.96 & 8.02 & 22.52\end{array}$

$\begin{array}{lllllll}2007 & 4 & 30 & 13.45 & 74.71 & 7.31 & 21.99\end{array}$

$\begin{array}{lllllll}2007 & 5 & 31 & 12.56 & 73.88 & 5.20 & 21.69\end{array}$

$\begin{array}{lllllll}2007 & 6 & 30 & 6.94 & 85.04 & 3.91 & 21.79\end{array}$

$\begin{array}{lllllll}2007 & 7 & 31 & 6.98 & 79.93 & 4.45 & 23.39\end{array}$

$\begin{array}{lllllll}2007 & 8 & 31 & 9.33 & 72.12 & 6.58 & 24.26\end{array}$

$\begin{array}{lllllll}2007 & 9 & 30 & 9.77 & 69.64 & 7.03 & 24.86\end{array}$

$\begin{array}{lllllll}2007 & 10 & 31 & 12.77 & 64.85 & 7.86 & 25.26\end{array}$

$\begin{array}{lllllll}2007 & 11 & 30 & 15.43 & 75.45 & 8.42 & 25.52\end{array}$

$\begin{array}{lllllll}2007 & 12 & 31 & 17.28 & 69.95 & 8.43 & 25.62\end{array}$ 


\section{Program WREVAP (Fortran 90)}

Lines designated as !C-1 to !C-39 identify the equivalent equations in Morton (1983a, Appendix C) and those designated as ! (3) to ! (8) are from Morton (1986). A list of variables is provided at the end of the program.

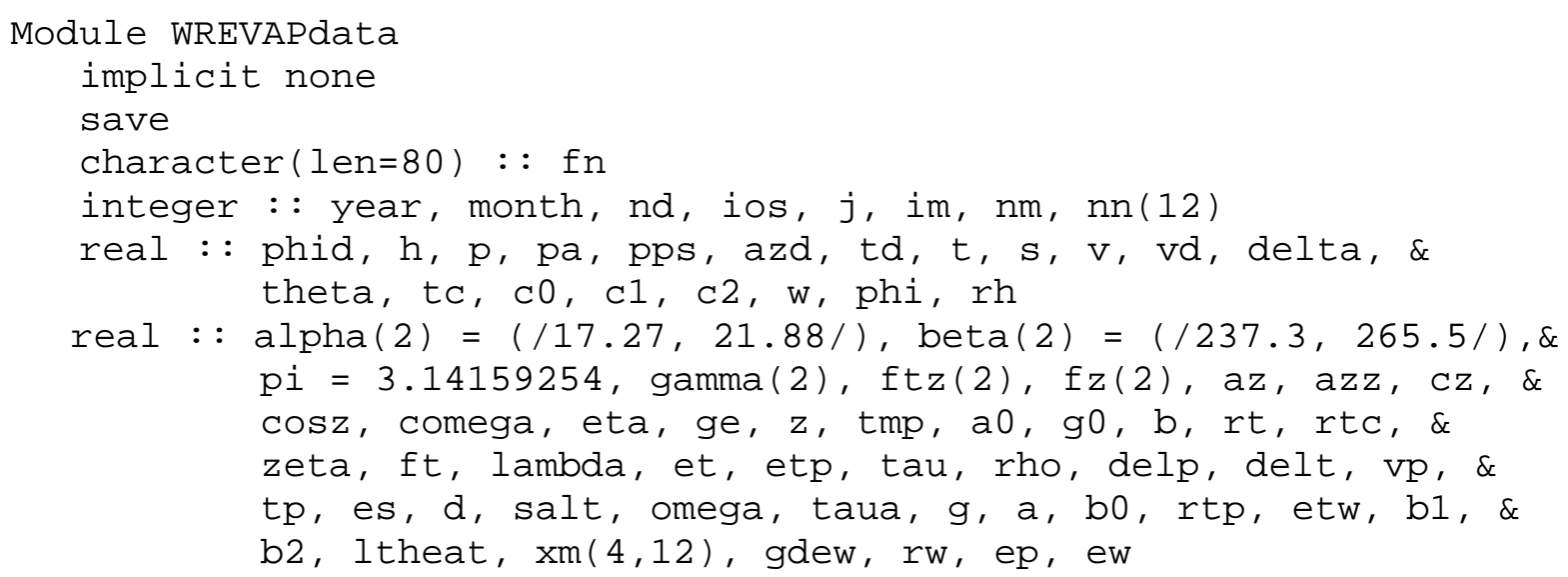




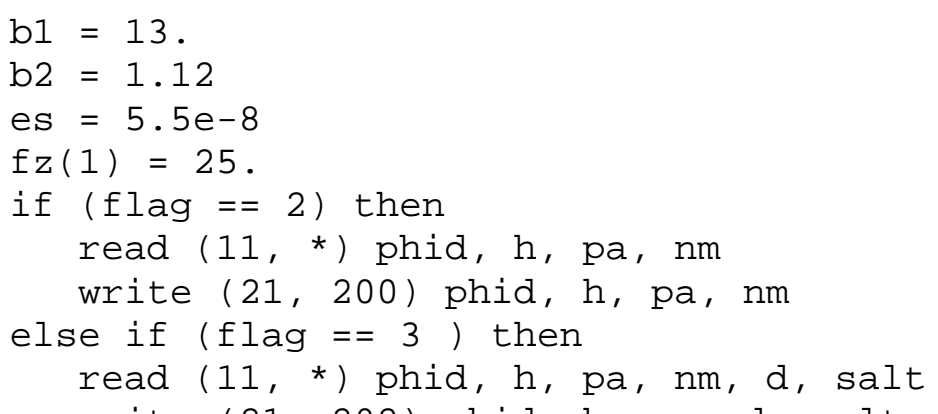

write $(21,202)$ phid, h, pa, d, salt, nm

202 format ('Latitude $=$ ', f7.2, ' Station height =', \&

f8.2, ' $\mathrm{m}$ ', ' Mean annual precipitation $=1$, \&

f8.1, ' $\mathrm{mm}$ '/ ' Lake depth =', f7.2, ' $\mathrm{m}$ ', \&

' Salt $=$ ', f8.1, ' ppm', ' \# of months =', i5 )

else if ( $f l a g==4$ ) then

read $(11, *)$ phid, $h, p a, n m$, salt

write $(21,203)$ phid, h, pa, salt, nm

203 format ('Latitude $=$ ', f7.2, ' Station height =', \&

f8.2, ' $\mathrm{m}$ ', ' Mean annual precipitation $=1$, \&

f8.1, ' $\mathrm{mm}^{\prime} /$ ' Salt $=$ ', f8.1, ' $\mathrm{ppm}{ }^{\prime}, \quad \&$

end if

' \# of months $=$ ', i5 )

end if

read $\left(11,{ }^{*}\right)$

! Skip a line

phi $=$ phid $^{*}$ pi/180.

! Compute the ratio of atmospheric pressure at the station to that

! at sea level

pps $=((288 .-0.0065 * h) / 288) * * 5.256$

! C - 1

$\mathrm{p}=\mathrm{pps}^{*} 1013$.

! Estimate the zenith value of the dry season snow free clear sky

! albedo

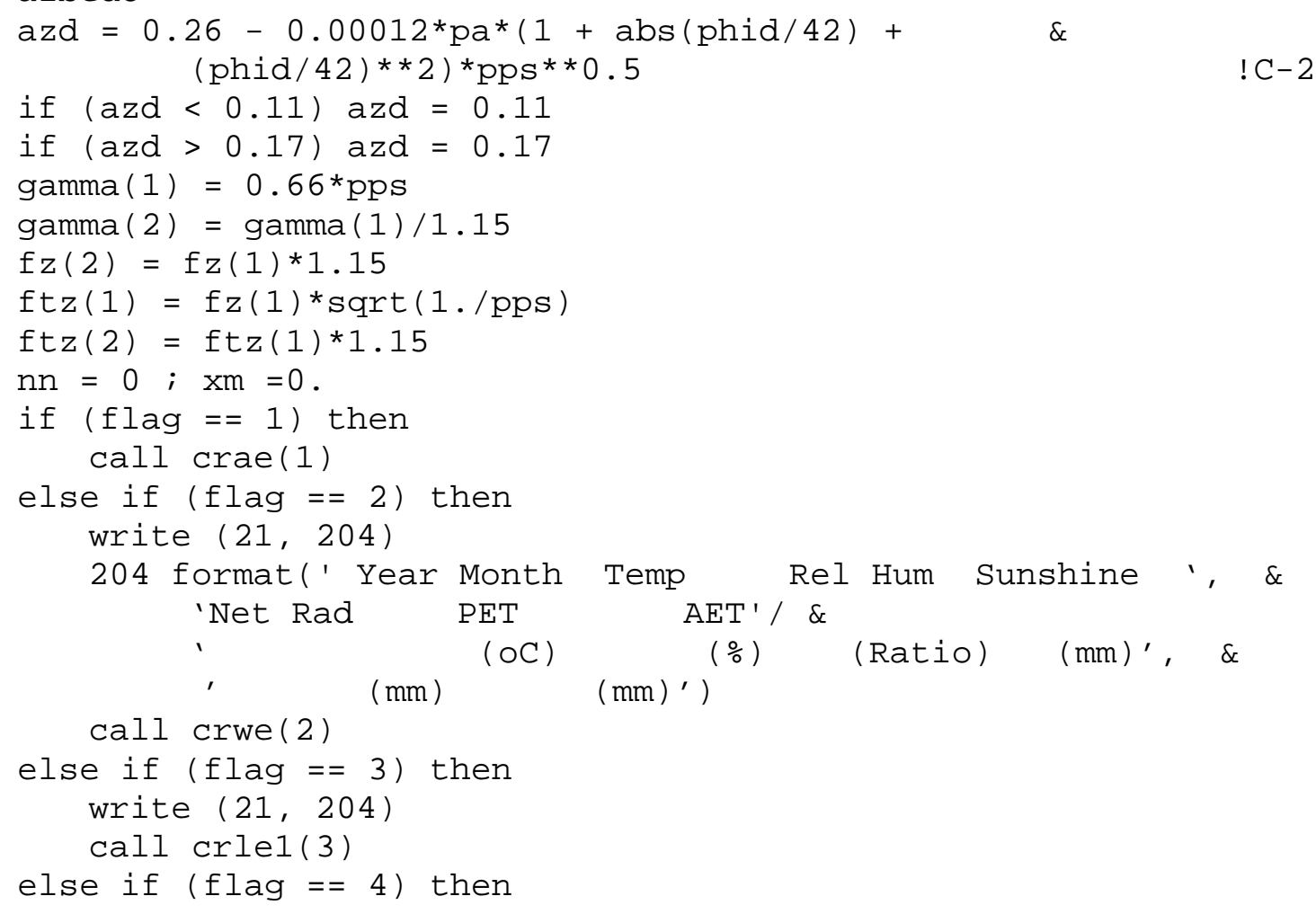


write $(21,205)$

205 format (', Year Month Temp

Depth Net Rad

(m)

call crle2(4)

end if

end program WREVAP

subroutine crae(flag)

Calculates the actual evapotranspiration from landscape use WREVAPdata

implicit none

integer : : flag

do $\mathrm{im}=1, \mathrm{~nm}$

read $\left(11,{ }^{*}\right.$, iostat $=$ ios $)$ year, month, nd, $t, r h, s$

if $($ ios $<0)$ exit

if $(s<0$. . OR. $r h<0$. . OR. $t<-999$.$) cycle$

call sub1(flag)

Estimate the net radiation for soil-plant surfaces at air temperature ( $r t)$, the stability factor ( $s f)$, the vapour pressure coefficient $(\mathrm{ft})$ and the heat transfer

coefficient (lambda)
$r t=(1 .-a) * g-b$
! C -27
$r t c=r t$
if $($ rtc $<0$.$) rtc =0$.
zeta $=1 . /\left(0.28^{*}(1 .+v d / v)+\right.$ delta*rtc*pps**0.5/\& $(\operatorname{gamma}(j) * b \odot * f z(j) *(v-v d)))$
! $\mathrm{C}-28$
!C-28a
if $($ zeta $<1$.$) zeta =1$.
$f t=f z(j) / z e t a / p p s * * 0.5$
! C -29
!C-29a
! $\mathrm{C}-30$
lambda $=\operatorname{gamma}(j)+4 \cdot{ }^{*} e s^{*}(\mathrm{t}+273) * * 3 / \mathrm{ft}$
! $\mathrm{C}-31$

Estimate the final values from the following quickly converging iterative solution of the vapour transfer and energy balance equations

$$
\begin{aligned}
& \mathrm{tp}=\mathrm{t} \\
& \mathrm{vp}=\mathrm{v} \\
& \text { delp }=\text { delta }
\end{aligned}
$$

do

$$
\begin{aligned}
& \text { delt }=\left(r t / f t+v d-v p+\operatorname{lambda}^{*}(t-t p)\right) / \& \\
& \text { (delp + lambda) } \\
& t p=t p+d e l t \\
& v p=6.11^{*} \exp (\operatorname{alpha}(j) * t p /(t p+\operatorname{beta}(j))) \\
& \text { ! C }-32 \\
& \text { ! } \mathrm{C}-33 \\
& \operatorname{delp}=\operatorname{alpha}(j) * \operatorname{beta}(j) * v p /(\operatorname{tp}+\operatorname{beta}(j)) * * 2 \\
& \text { if }(\text { abs }(\text { delt })<0.01) \text { exit }
\end{aligned}
$$

end do

Estimate the potential evapotranspiration (etp), the net radiation for soil-plant surfaces at equilibrium temperature ( $r$ tp) and the wet-environment areal evapotranspiration (etw) etp $=r t-l a m b d a * f t *(t p-t)$ ! $\mathrm{C}-36$

$r t p=e t p+\operatorname{gamma}(j) * f t *(t p-t)$

! $\mathrm{C}-37$

etw $=b 1+b 2 * r t p /(1 .+\operatorname{gamma}(j) / \operatorname{del} p)$

! $\mathrm{C}-38$

if $($ etw $<$ etp/2.) etw $=$ etp/2.

! $\mathrm{C}-38 \mathrm{a}$

if $($ etw $>$ etp) etw = etp

!C-38a

Estimate the areal evapotranspiration (et) from the 


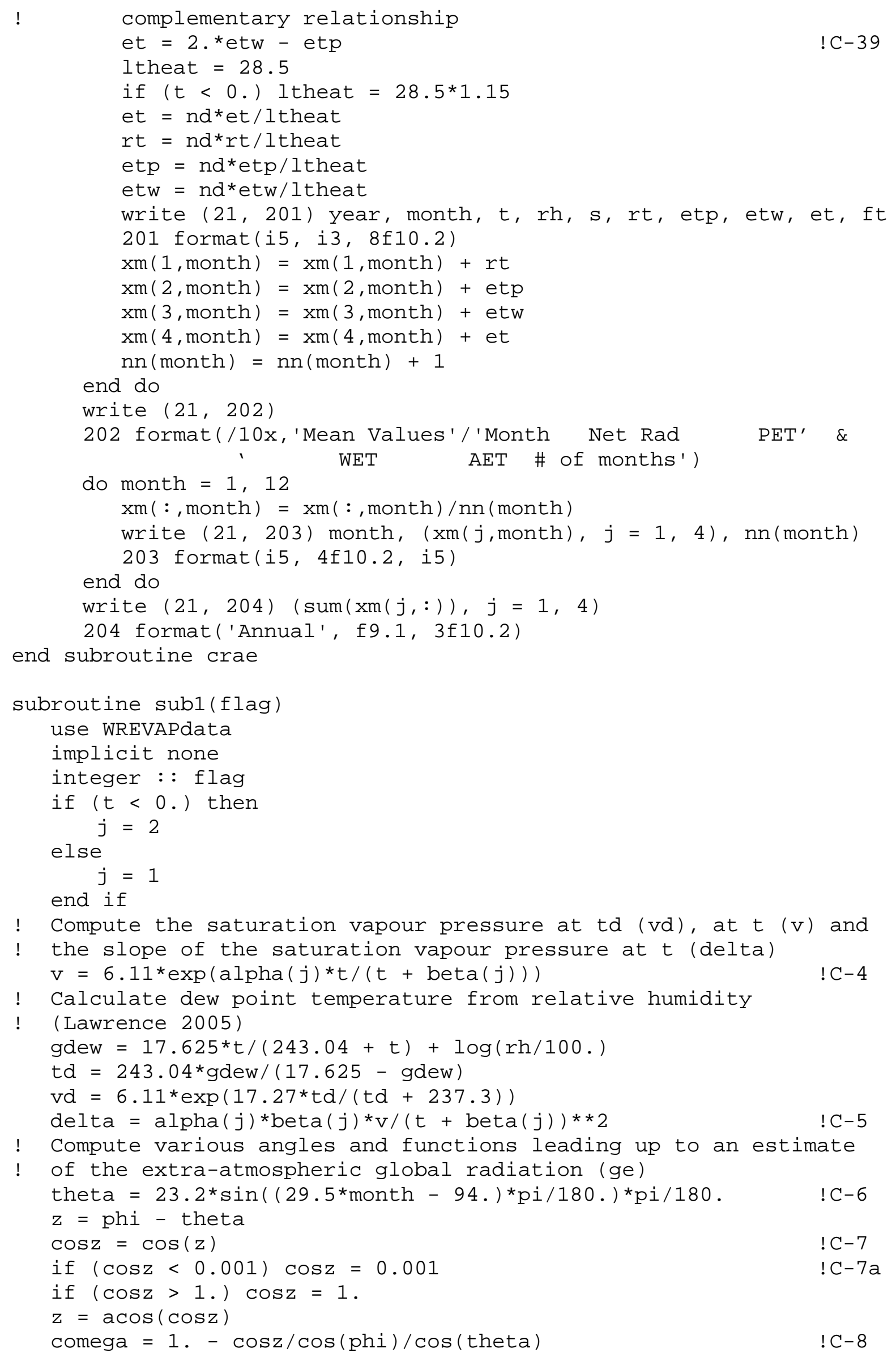


if $($ comega $<-1$.$) comega =-1$.

!C-8a

omega $=\operatorname{acos}($ comega $)$

$\mathrm{cz}=\cos z+(\sin ($ omega $) /$ omega -1.$){ }^{*} \cos (\mathrm{phi}){ }^{*} \cos ($ theta $) \quad$ !C -9

eta $=1 .+\sin \left(\left(29.5^{*}\right.\right.$ month -106$\left.) * \mathrm{pi} / 180.\right) / 60 . \quad$ !C -10

ge $=1354^{*}$ omega* $\mathrm{cz} / \mathrm{pi} / \mathrm{eta} /$ eta

! -11

Estimate the zenith value of snow-free clear-sky albedo (azz),

zenith value of clear-sky albedo (az) and the clear sky

albedo $(a \odot)$

if $(f \operatorname{lag}>1)$ then

else

$$
\text { azz }=0.05
$$

$$
a z z=a z d
$$

! C -12

if $(a z z>$

end if

$c \Theta=v-v d$

! $\mathrm{C}-12 \mathrm{a}$

if $(c \Theta<\Theta). c \Theta=\Theta$.

! C -13

if $(c \odot>1). c \Theta=1$.

! $\mathrm{C}-13 \mathrm{a}$

$a z=a z z+\left(1 .-c{ }^{*} c 0\right) *(0.34-a z z)$

! $\mathrm{C}-13 \mathrm{a}$

$\mathrm{a} \Theta=a z^{*}\left(\exp (1.08)-\left(2.16^{*} \mathrm{cos} z / \mathrm{pi}+\&\right.\right.$

$\left.\sin (z)) * \exp \left(0.012^{*} z^{*} 180 . / p i\right)\right) / 1.473 /(1 .-\sin (z))$

! $\mathrm{C}-14$

! Estimate precipitable water $(w)$ and a turbidity coefficient (tc)

$w=v d /(0.49+t / 129$.

! C -16

$\mathrm{c} 1=21-\mathrm{t}$

if $(c 1<0) c 1=$.0 .

! $\mathrm{C}-17$

if $(\mathrm{c} 1>5.) \mathrm{c} 1=5$.

$\mathrm{tc}=\left(0.5+2.5^{*} \mathrm{cz}{ }^{*} \mathrm{cz}\right){ }^{*} \exp \left(\mathrm{c} 1^{*}(\mathrm{pps}-1).\right)$

! $-17 \mathrm{a}$

! $\mathrm{C}-17 \mathrm{a}$

Compute the transmittancy of clear skies to direct beam

! C-18

! solar radiation (tau)

$\operatorname{tau}=\exp \left(-0.089^{*}(\mathrm{pps} / \mathrm{cz}){ }^{* *} \odot .75-0.083^{*}(\mathrm{tc} / \mathrm{cz}){ }^{* *} \odot .90-\&\right.$ $\left.0.029 *(\mathrm{w} / \mathrm{cz})^{* *} 0.60\right)$

! C -19

! Estimate the part of tau that is the result of absorption (taua)

taua $=\exp \left(-0.0415^{*}(\mathrm{tc} / \mathrm{cz}){ }^{*} 0.90-(0.0029 * * 0.5) * \&\right.$

$$
(w / c z) * * 0.3)
$$

! C-20

$\operatorname{tmp}=\exp \left(-0.0415^{*}(\mathrm{tc} / \mathrm{cz}){ }^{*} 0.90-0.029 *(\mathrm{w} / \mathrm{cz}){ }^{* *} 0.6\right)$

if (taua $<$ tmp) taua $=$ tmp

!C-20a

! Compute the clear-sky global radiation $(g \odot)$ and the incident

! global radiation ( $g$ )

go $=g^{*} \operatorname{tau}^{*}\left(1 .+(1 .-\operatorname{tau} /\right.$ taua $\left.) *\left(1 .+a{ }^{*} \operatorname{tau}\right)\right)$

! C-21

$\mathrm{s}=\mathrm{s} * \mathrm{pi} / 24$. /omega

if $(s>1) s=$.

$g=s^{*} g \odot+(0.08+0.30 * s) *(1 .-s) * g e$

!C-22

! Estimate the average albedo (a)

$a=a 0^{*}\left(s+(1 .-s) *\left(1 .-z^{*} 180 / p i / 330\right)\right)$

! C-23

! Estimate the proportional increase in atmospheric radiation

! due to clouds (rho)

$\mathrm{c} 2=10 .{ }^{*}(\mathrm{vd} / \mathrm{v}-\mathrm{s}-0.42)$

! C -24

if $(\mathrm{c} 2<0.) \mathrm{c} 2=0$.

!C-24a

if $(\mathrm{c} 2>1.) \mathrm{c} 2=1$.

!C-24a

rho $=0.18^{*}((1 .-c 2) *(1 .-s) * * 2+c 2 *(1 .-s) * * 0.5) / p p s$

!C-25

! Calculate the net long-wave radiation loss for soil-plant

! surface at air temperature (b)

$\mathrm{b}=\mathrm{es}^{*}(\mathrm{t}+273)^{* *} 4^{*}\left(1 .-\left(0.71+0.007^{*} \mathrm{vd} \mathrm{d}^{*} \mathrm{pps}\right) *(1 .+\mathrm{rho})\right) ! \mathrm{C}-26$

tmp $=0.05^{*} e s^{*}(t+273) * * 4$

if $(b<t m p) b=t m p$

end subroutine sub1

!C-26a 


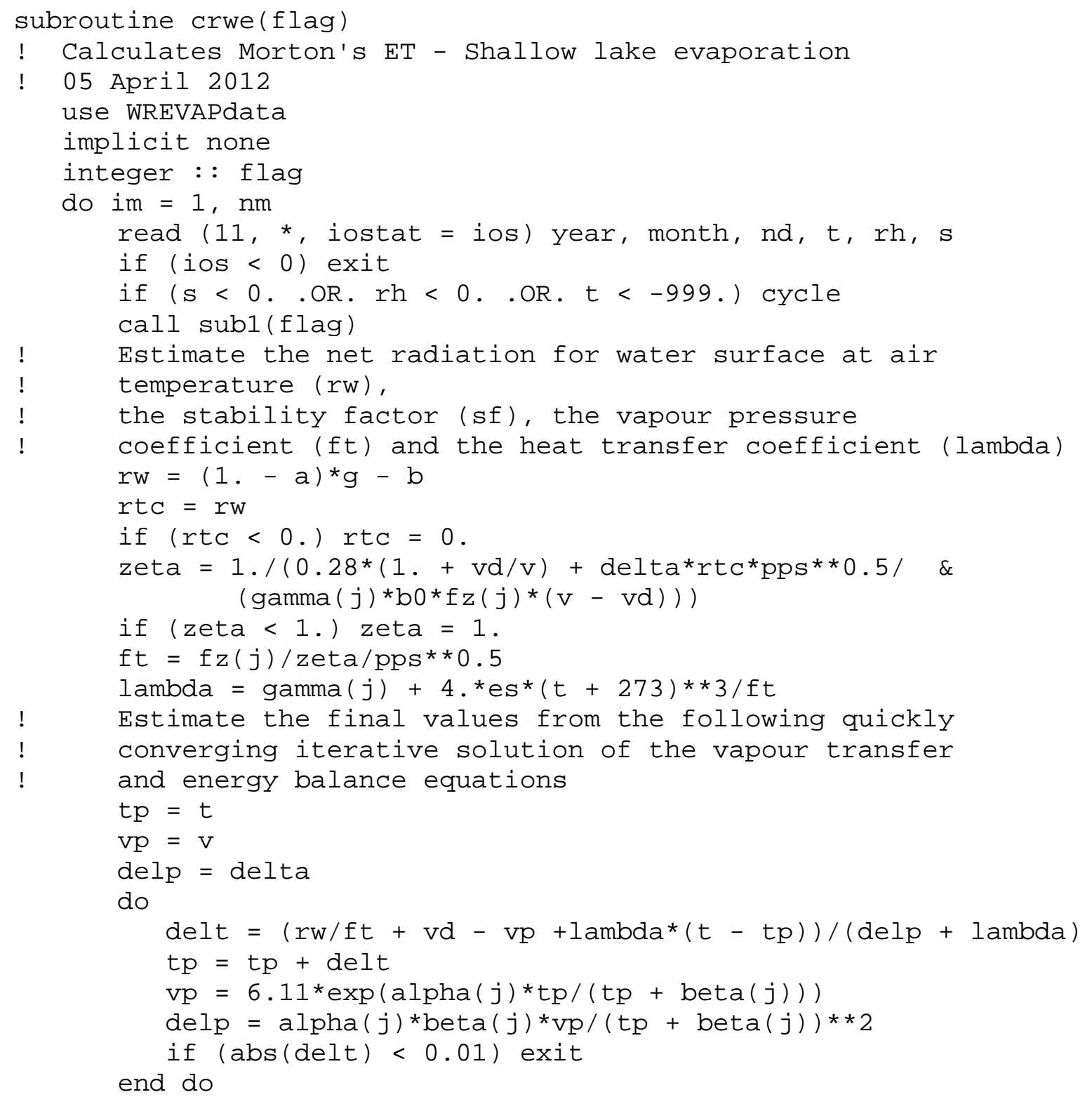

Estimate the potential evaporation (ep), the net radiation for soil-plant surfaces at equilibrium temperature ( $r t p$ ) and the shallow lake evaporation (ew)

ep $=r w-l a m b d a * f t^{*}(t p-t)$

$r t p=e p+\operatorname{gamma}(j) * f t *(t p-t)$

$\mathrm{ew}=\mathrm{b} 1+\mathrm{b} 2^{*} \mathrm{rtp} /(1 .+\operatorname{gamma}(j) / \mathrm{delp})$

if $(\mathrm{ew}<\mathrm{ep} / 2$. $)$ ew $=\mathrm{ep} / 2$.

if $($ ew $>$ ep $)$ ew $=$ ep

ltheat $=28.5$

if $(t<\odot$.$) ltheat =28.5 * 1.15$

ep $=n^{*}$ ep $/$ ltheat

$r w=n d^{*} r w / l$ theat

$\mathrm{ew}=\mathrm{nd}^{*} \mathrm{ew} / \mathrm{ltheat}$

write $(21,201)$ year, month, $t, r h, s, r w$, ep, ew

201 format (i5, i3, 6f10.2)

$\mathrm{xm}(1$, month $)=\mathrm{xm}(1$, month $)+r w$

$x \mathrm{xm}(2$, month $)=x \mathrm{~m}(2$, month $)+\mathrm{ep}$ 
end do

$\mathrm{xm}(3$, month $)=\mathrm{xm}(3$, month $)+\mathrm{ew}$
$\mathrm{nn}($ month $)=\mathrm{nn}($ month $)+1$

write $\left(21,{ }^{*}\right)$ ' Mean values'

write $(21, *)$ 'Month Net Rad PET AET'

do month $=1,12$

$\mathrm{xm}(:$, month $)=\mathrm{xm}(:$, month $) / \mathrm{nn}($ month $)$

write $(21,203)$ month, $(x m(j$, month $), j=1,3)$

end do

203 format (i5, 4f10.2)

write $(21,204)(\operatorname{sum}(x m(j,:)), j=1,3)$

204 format ('Annual', f9.1, 3f10.2)

end subroutine crwe

subroutine crle1(flag)

! Calculates Morton's ET - Deep lake evaporation

! 05 April 2012

use WREVAPdata

implicit none

integer, parameter :: $\mathrm{nmx}=360$

integer :: ic, iy $(n m x)$, mon $(n m x)$, tnd $(n m x)$, flag

real : : $\operatorname{tg} w(n m x), \operatorname{tv}(n m x), \operatorname{tvd}(n m x), \operatorname{ts}(n m x), g l(n m x), \&$

do $\mathrm{im}=1, \mathrm{~nm}$ $\operatorname{tt}(n m x), \operatorname{trh}(n m x), \operatorname{tdelta}(n m x)$

read $\left(11,{ }^{*}\right.$, iostat $=$ ios $)$ year, month, nd, $t, r h, s$

if $($ ios $<0)$ exit

if $(\mathrm{s}<0$. . OR. $r \mathrm{~h}<0$. . OR. $\mathrm{t}<-999$. $)$ cycle

call sub1(flag)

$\operatorname{tgw}(i m+12)=(1 .-a) * g-b$

$\mathrm{tt}(\mathrm{im})=\mathrm{t}$

$\operatorname{trh}(i m)=r h$

$\operatorname{ts}(i m)=s$

$\operatorname{tv}(\mathrm{im})=\mathrm{v}$

$\operatorname{tvd}(i m)=v d$

tdelta $(i m)=\operatorname{delta}$

iy $(\mathrm{im})=$ year

$\operatorname{tnd}(i m)=$ nd

end do

mon $(i m)=$ month

call deepLake( $n m x, n m$, tgw, gl, d, salt)

do $\mathrm{im}=1, \mathrm{~nm}$

$\mathrm{t}=\mathrm{tt}(\mathrm{im})$

$r h=\operatorname{trh}(i m)$

$\mathrm{s}=\mathrm{ts}(\mathrm{im})$

$v=\operatorname{tv}(i m)$

$\mathrm{vd}=\operatorname{tvd}(\mathrm{im})$

delta $=$ tdelta $(\mathrm{im})$

Estimate the net radiation for water surface at air

temperature ( $r w)$,

the stability factor (sf), the vapour pressure coefficient

$(\mathrm{ft})$ and the heat transfer coefficient (lambda)

$r w=g l(i m)$

$r t c=r w$

if $(r t c<0) r t c=$.0 .

zeta $=1 . /\left(0.28^{*}(1 .+v d / v)+\right.$ delta*rtc*pps** $0.5 / \quad \&$ 


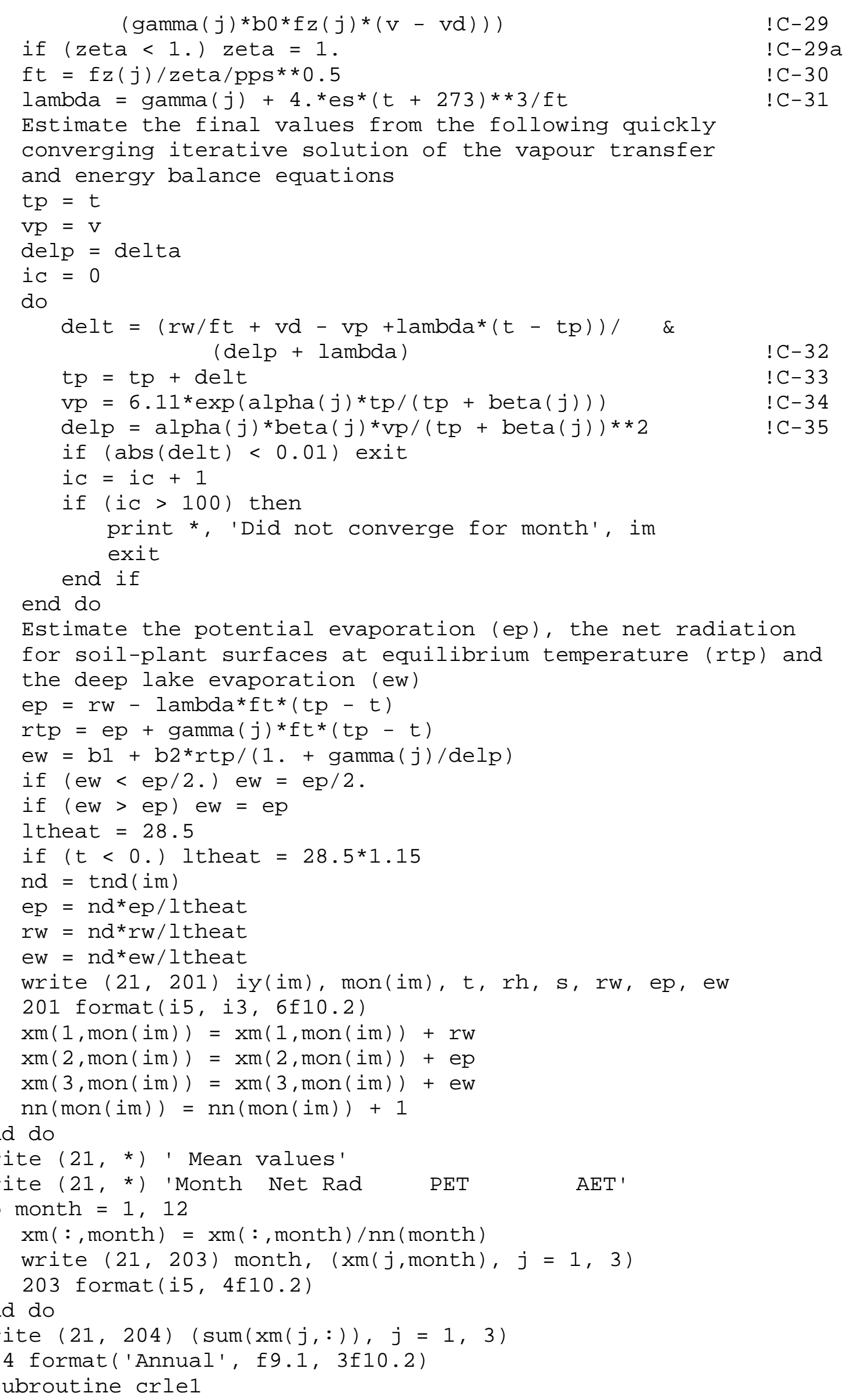


subroutine deepLake( $\mathrm{nmx}, \mathrm{nm}, \operatorname{tgw}, \mathrm{gl}, \mathrm{d}$, salt)

! Calculates the available solar and waterborne heat(gl) using

! Morton 1986

implicit none

integer :: $i m, n m x, n m, t i, t 1, i, i 1, i i$

real : : $g w(n m x), \operatorname{tg} w(n m x), g l(n m x), t \Theta, t, g l b, g l e, \&$

salt, $d, f, k$

to $=0.96+0.013^{*} d$

if $\left(t \odot<0.039^{*} d\right)$ t $\odot=0.039^{*} d$

if $\left(t \odot>0.13^{*} d\right) t \odot=0.13^{*} d$

$\mathrm{t}=\mathrm{t} \Theta /(1 .+\mathrm{salt} / 27000) *{ }^{*} 2$

if $(\mathrm{t}>6.) \mathrm{t}=6$.

$\mathrm{k}=\mathrm{t} \odot /\left(1 .+(\mathrm{d} / 93)^{* *} 7\right)$

! Calculates the delayed solar and waterborne energy (gw)

$\mathrm{ti}=$ int $(\mathrm{t})$

$\mathrm{t} 1=\mathrm{ti}+1$

$f=t-t i$

$i=12$

$\operatorname{tgw}(1: 12)=\operatorname{tgw}(13: 24)$

do $\mathrm{im}=1, \mathrm{~nm}$

$i=i+1$

$i 1=i-t 1$

$i i=i-t i$

$g w(i m)=\operatorname{tg} w(i i)+f^{*}(\operatorname{tg} w(i 1)-\operatorname{tgw}(i i))$

end do

! Calculates the available solar and waterborne heat(gl)

glb $=50$.

do $i=1,2$

do $i m=1,12$

gle $=g l b+(g w(i m)-g l b) /(k+0.5)$

$g l(i m)=(g l b+g l e) / 2$.

end do

$$
g l b=g l e
$$

end do

do $i \mathrm{~m}=1, \mathrm{~nm}$

$g l e=g l b+(g w(i m)-g l b) /(k+\odot .5)$

$g l(i m)=(g l b+g l e) / 2$.

glb $=$ gle

end do

end subroutine deepLake

subroutine crle2(flag)

! Calculates Morton's ET - Deep lake evaporation

! 05 April 2012

use WREVAPdata

implicit none

integer, parameter : : $\mathrm{nmx}=360$

integer :: ic, iy $(n m x)$, mon $(n m x)$, tnd $(n m x)$, flag

real : : $\operatorname{tg} w(n m x), \operatorname{tv}(n m x), \operatorname{tvd}(n m x), \operatorname{ts}(n m x), g l(n m x), \&$

do $\mathrm{im}=1, \mathrm{~nm}$ $\operatorname{tt}(n m x), \operatorname{trh}(n m x), \operatorname{tdelta}(n m x), \operatorname{da}(n m x)$

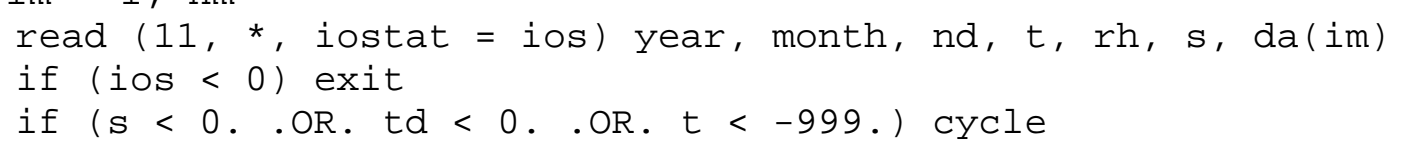




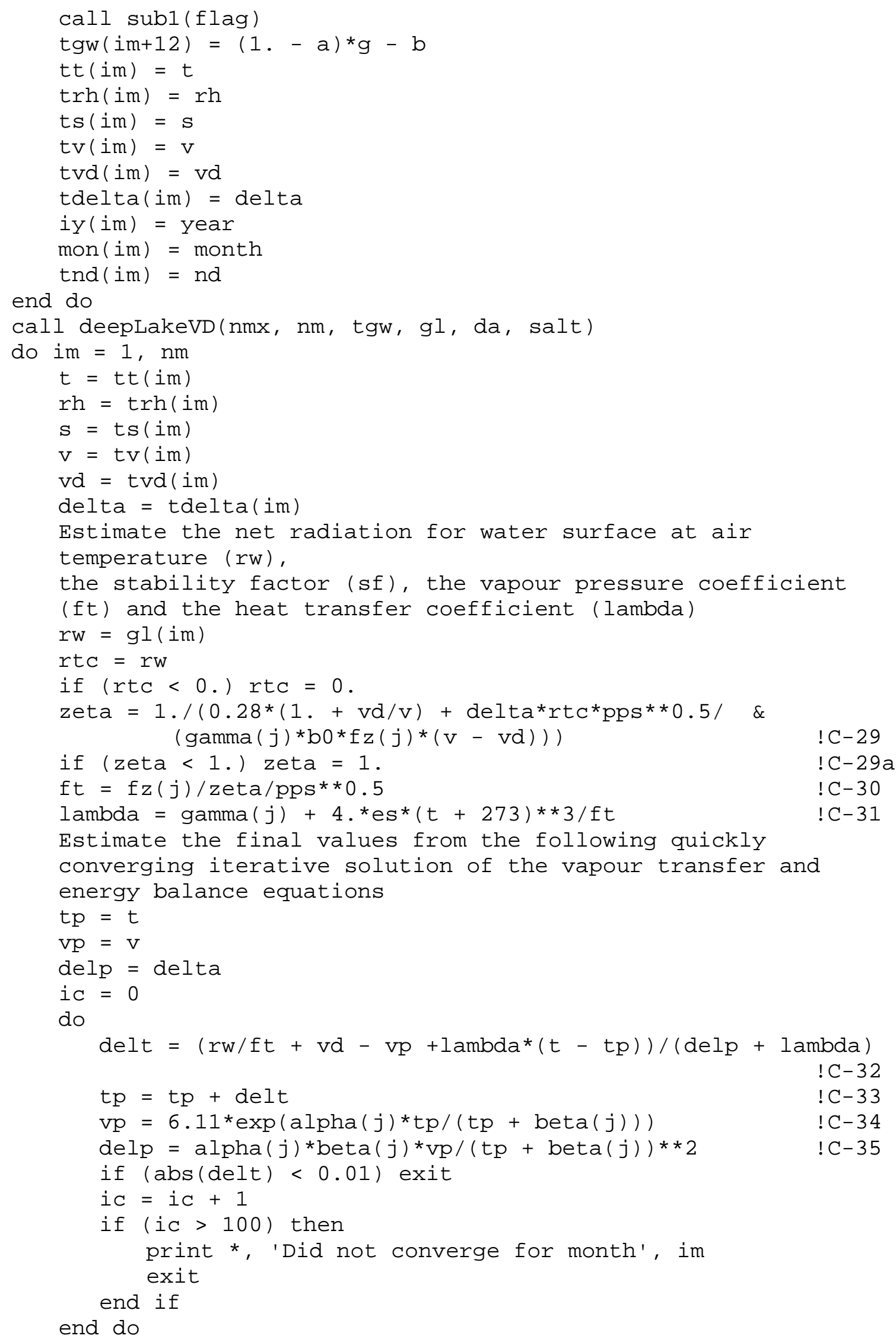

Estimate the potential evaporation (ep), the net radiation for soil-plant 


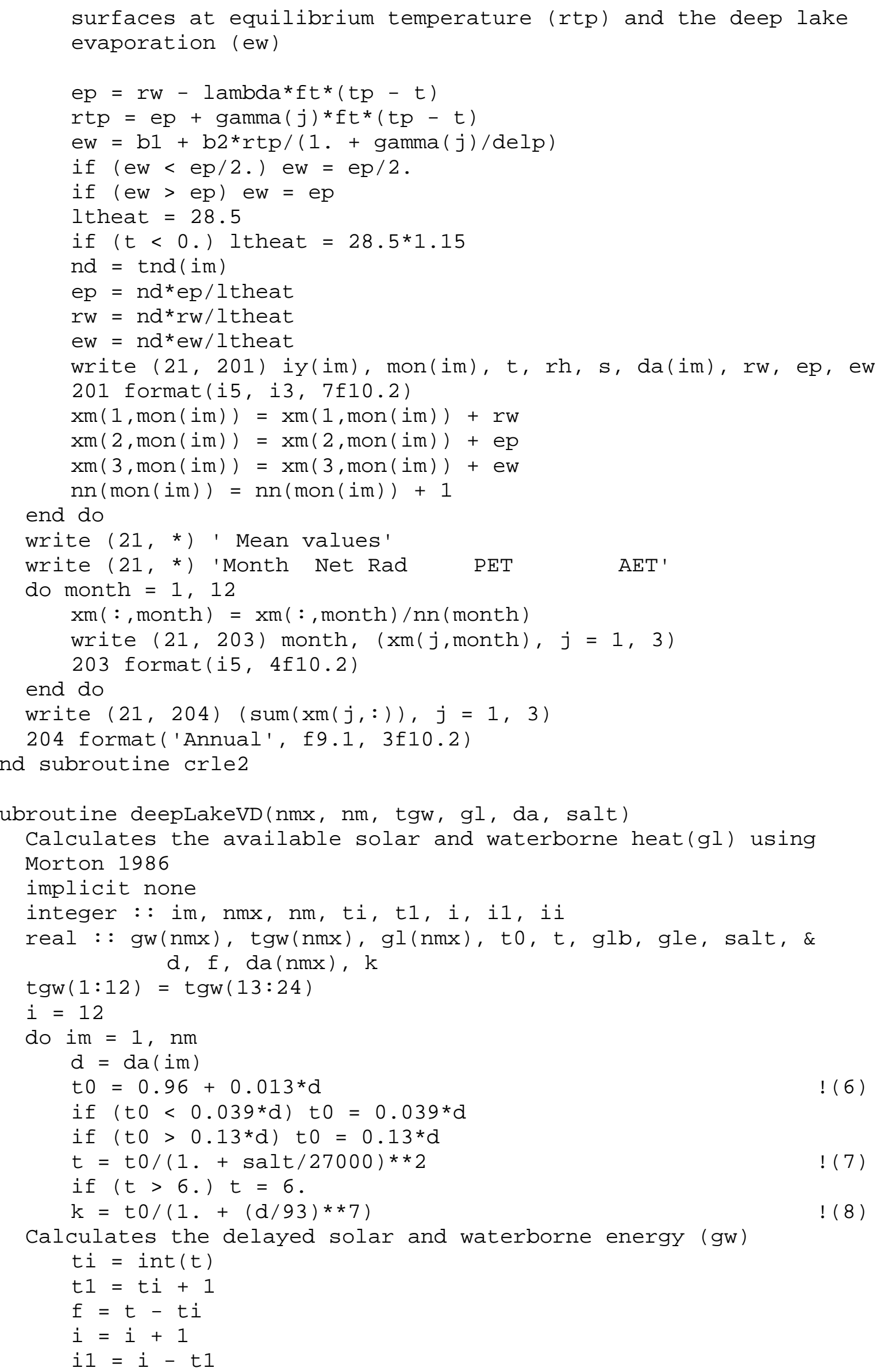




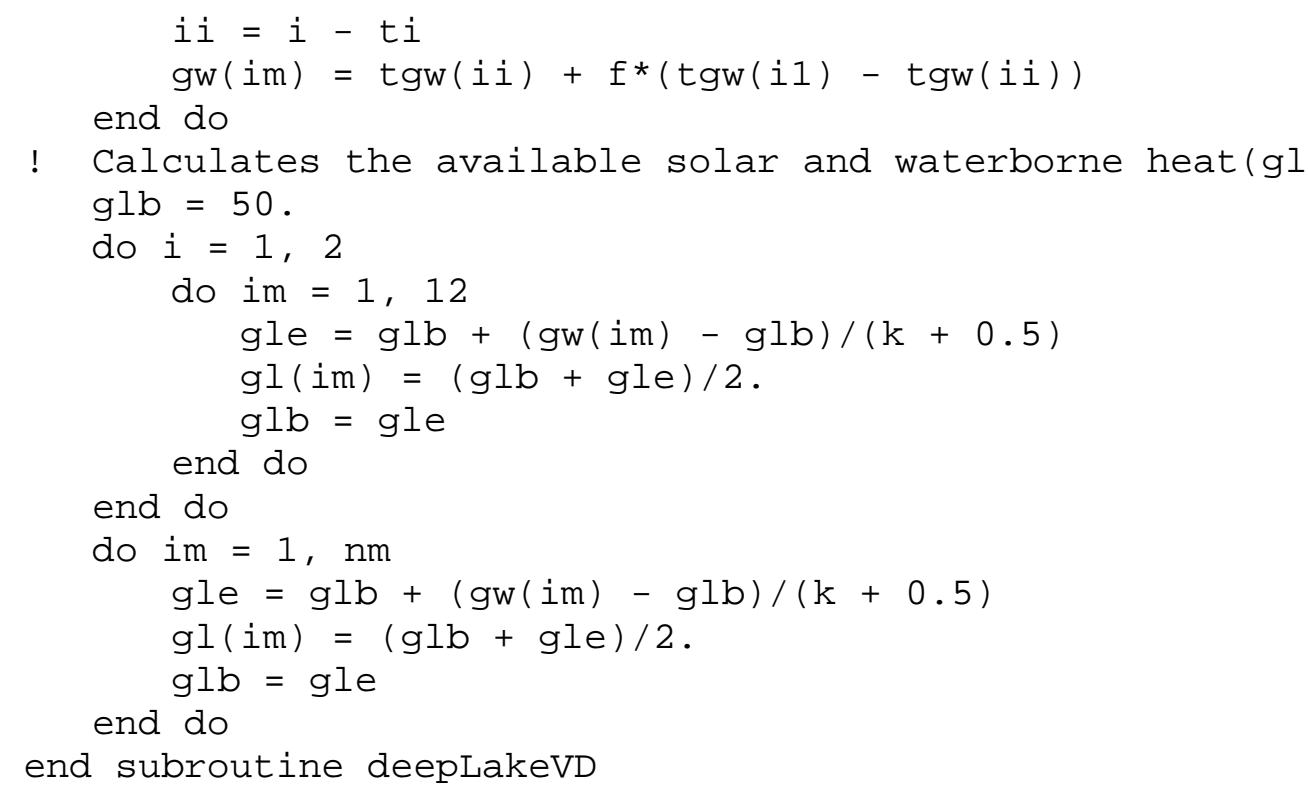

end subroutine deepLakeVD 


\section{Key variables used in Program WREVAP}

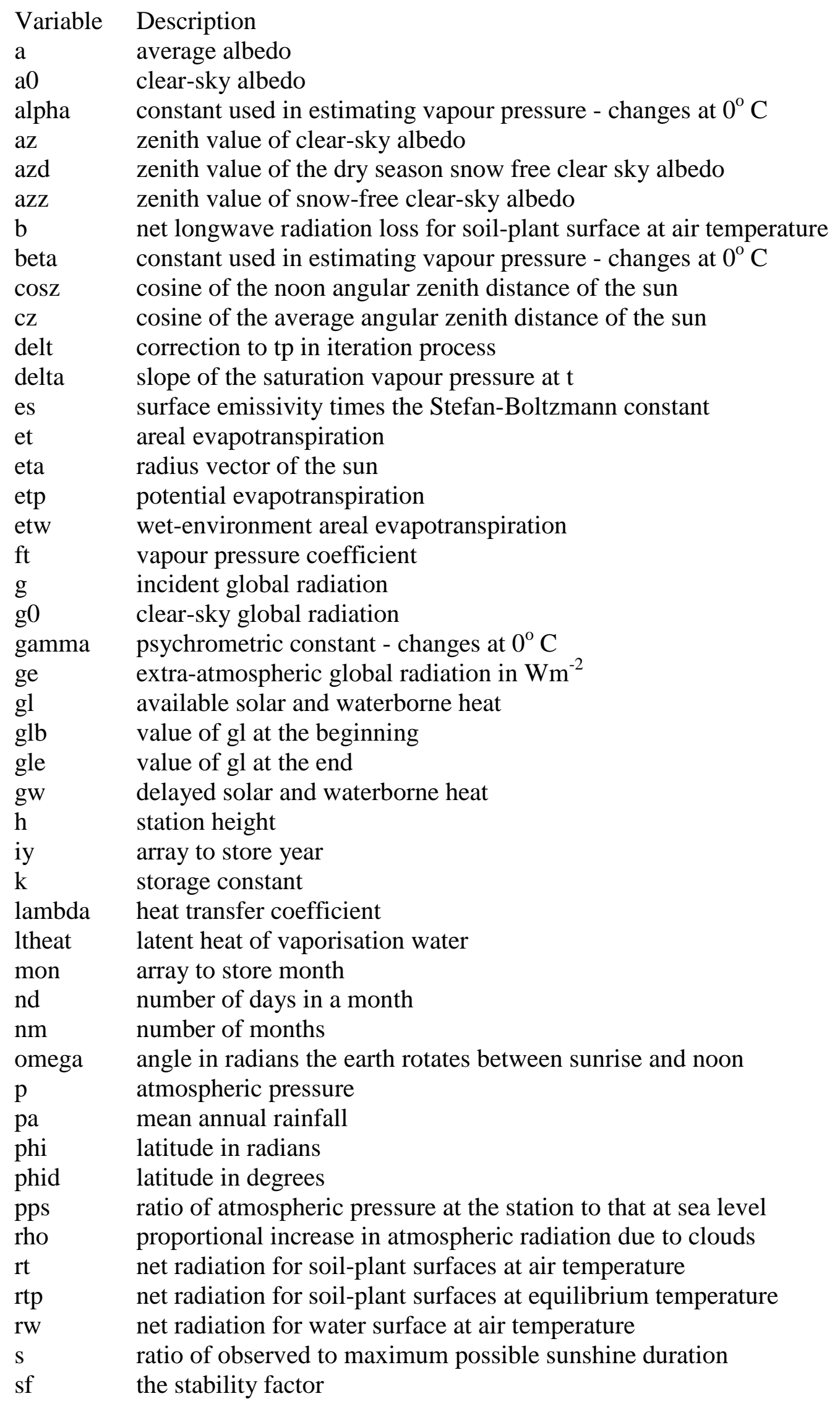




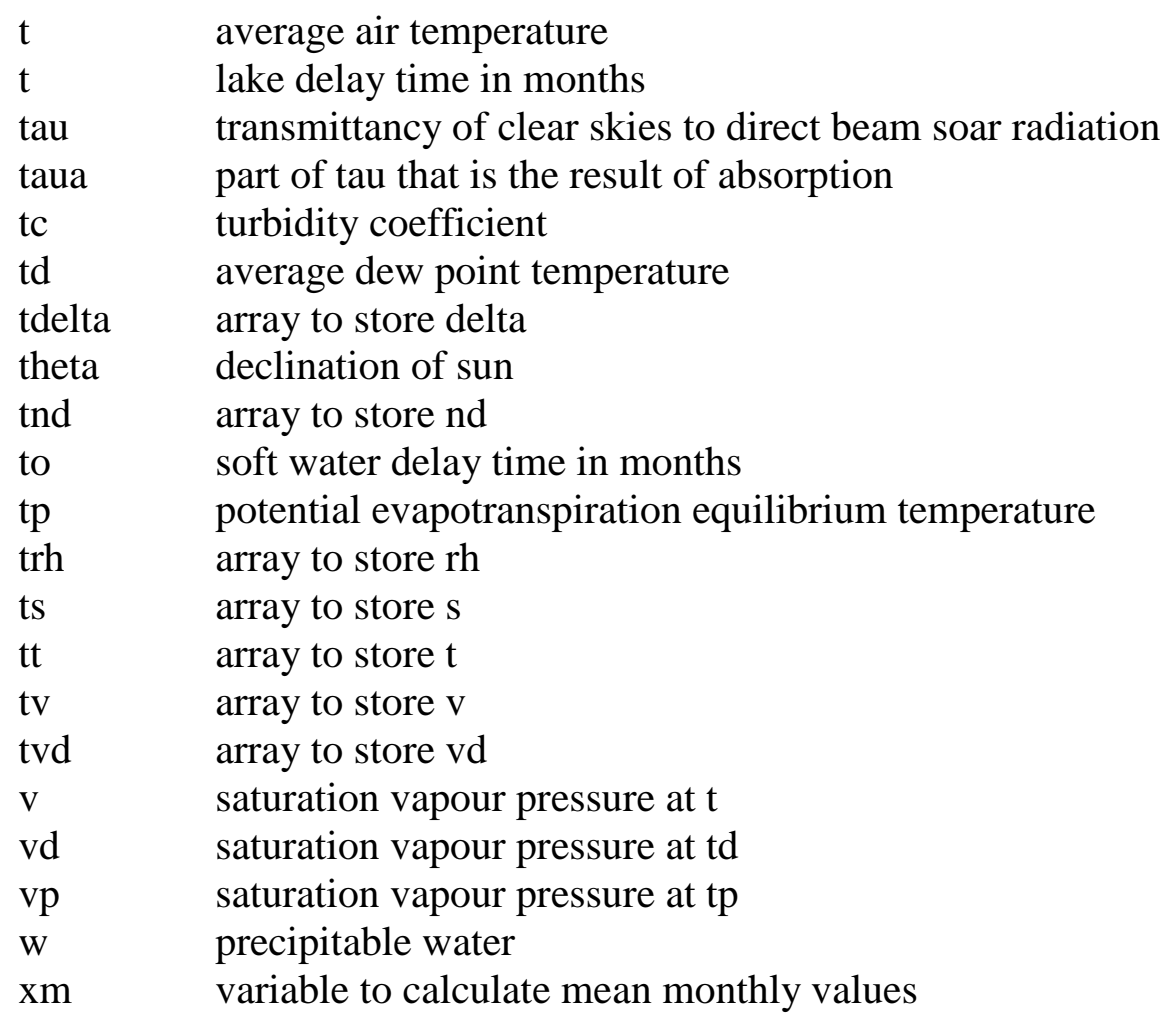




\section{Supplementary Material}

\section{Appendix S21 Worked example of Morton's CRAE, CRWE and CRLE models within the WREVAP framework}

List of variables that are used in this appendix are taken from Morton (1983a, Appendix D) and from Morton (1986))

(Note these variables are different to those adopted in Appendix S20 and in the main text and other appendices.)

\begin{tabular}{|c|c|c|}
\hline Variable & Description & Units \\
\hline$a$ & Average albedo & dimensionless \\
\hline$a_{0}$ & Clear-sky albedo & dimensionless \\
\hline$a_{z}$ & Zenith value of clear-sky albedo & dimensionless \\
\hline$a_{z d}$ & Zenith value of the dry-season snow-free clear sky albedo & dimensionless \\
\hline$a_{z z}$ & Zenith value of clear-sky snow-free albedo & dimensionless \\
\hline$B$ & $\begin{array}{l}\text { Net longwave radiation loss for soil-plant surface at air } \\
\text { temperature }\end{array}$ & $\mathrm{W} \mathrm{m}^{-2}$ \\
\hline$b_{0}$ & Constant & undefined \\
\hline$b_{1}$ & Constant & $\mathrm{W} \mathrm{m}^{-2}$ \\
\hline$b_{2}$ & Constant & undefined \\
\hline$c_{0}$ & $v-v_{D}$ & mbar \\
\hline$c_{1}$ & Working variable & ${ }^{\circ} \mathrm{C}$ \\
\hline$c_{2}$ & Working variable & dimensionless \\
\hline$E_{P}$ & Potential evaporation & 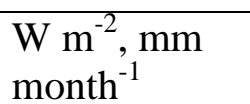 \\
\hline$E_{T}$ & Actual areal evapotranspiration & $\begin{array}{l}\mathrm{W} \mathrm{m}{ }^{-2}, \mathrm{~mm} \\
\mathrm{month}^{-1}\end{array}$ \\
\hline$E_{T P}$ & Potential evapotranspiration & $\begin{array}{l}\mathrm{W} \mathrm{m}{ }^{-2}, \mathrm{~mm} \\
\text { month }^{-1}\end{array}$ \\
\hline$E_{T W}$ & Wet-environment areal evapotranspiration & $\begin{array}{l}\mathrm{W} \mathrm{m}{ }^{-2}, \mathrm{~mm} \\
\mathrm{month}^{-1}\end{array}$ \\
\hline$E_{W}$ & Shallow lake evaporation & $\begin{array}{l}\mathrm{W} \mathrm{m}{ }^{-2}, \mathrm{~mm} \\
\mathrm{month}^{-1}\end{array}$ \\
\hline$f_{T}$ & Vapour transfer coefficient & $\mathrm{W} \mathrm{m} \mathrm{mbar}^{-2}$ \\
\hline$f_{z}$ & Constant used in estimating $f_{T}$ & $\mathrm{~W} \mathrm{~m} \mathrm{mbar}^{-1}$ \\
\hline G & Incident global radiation & $\mathrm{W} \mathrm{m}^{-2}$ \\
\hline$G_{E}$ & Extra-atmospheric global radiation & $\mathrm{W} \mathrm{m}^{-2}$ \\
\hline$G_{L}$ & Available (routed) solar and waterborne energy & $\mathrm{W} \mathrm{m}^{-2}$ \\
\hline$G_{L B}$ & Available solar and waterborne heat energy at the beginning & $\mathrm{W} \mathrm{m}^{-2}$ \\
\hline
\end{tabular}




\begin{tabular}{|c|c|c|}
\hline & of the month & \\
\hline$G_{L E}$ & $\begin{array}{l}\text { Available solar and waterborne heat energy at the end of the } \\
\text { month }\end{array}$ & $\mathrm{W} \mathrm{m}^{-2}$ \\
\hline$G_{o}$ & Clear-sky global radiation & $\mathrm{W} \mathrm{m}^{-2}$ \\
\hline$G_{W}^{0}$ & Solar plus waterborne heat input & $\mathrm{W} \mathrm{m^{-2 }}$ \\
\hline$G_{W}^{t}$ & Delayed solar and waterborne energy inputs & $\mathrm{W} \mathrm{m^{-2 }}$ \\
\hline $\begin{array}{l}G_{W}^{[t]} \\
G_{W}^{[t+1]}\end{array}$ & Value of $G_{W}^{0}$ computed $\left[t_{L}\right]$ and $\left[t_{L}+1\right]$ months & $\mathrm{W} \mathrm{m}^{-2}$ \\
\hline $\bar{h}$ & Average depth of lake & $\mathrm{m}$ \\
\hline$H$ & Site elevation & $\mathrm{m}$ \\
\hline$i$ & Month number & dimensionless \\
\hline$j$ & Turbidity coefficient & undefined \\
\hline$P_{A}$ & Mean annual rainfall & mm year $^{-1}$ \\
\hline$p$ & Atmospheric pressure at station & mbar \\
\hline$p_{s}$ & Atmospheric pressure at mean sea level & mbar \\
\hline$\frac{p}{p_{s}}$ & $\begin{array}{l}\text { Ratio of atmospheric pressure at station to atmospheric } \\
\text { pressure at mean sea level }\end{array}$ & dimensionless \\
\hline$R H$ & Mean daily relative humidity & $\%$ \\
\hline$R_{n l}$ & Net longwave radiation & $\mathrm{W} \mathrm{m}^{-2}$ \\
\hline$R_{S}$ & Measured incoming solar radiation & $\mathrm{W} \mathrm{m}^{-2}$ \\
\hline$R_{T}$ & Net radiation at soil-plant surface at air temperature & $\mathrm{W} \mathrm{m} \mathrm{m}^{-2}$ \\
\hline$R_{T C}$ & $R_{T}$ with $R_{T C} \geq 0$ & $\mathrm{~W} \mathrm{m^{-2 }}$ \\
\hline$R_{T P}$ & $\begin{array}{l}\text { Net radiation at the soil-plant surface for equilibrium } \\
\text { temperature }\end{array}$ & $\mathrm{W} \mathrm{m} \mathrm{m}^{-2}$ \\
\hline$R_{W}$ & Net radiation for water surface at air temperature & $\mathrm{W} \mathrm{m} \mathrm{m}^{-2}$ \\
\hline$S$ & Average lake salinity & ppm \\
\hline$S$ & Ratio of observed to maximum possible sunshine duration & dimensionless \\
\hline$S_{c}$ & Storage coefficient & months \\
\hline$t_{0}$ & Soft water delay time & months \\
\hline$t_{L}$ & Lake lag or delay time & months \\
\hline$\left[t_{L}\right]$ & Integral component of the lake lag & months \\
\hline$T$ & Mean daily air temperature for month & ${ }^{\circ} \mathrm{C}$ \\
\hline$T_{D}$ & Mean daily dew point temperature for month & ${ }^{\circ} \mathrm{C}$ \\
\hline$T_{P}$ & Equilibrium temperature & ${ }^{\circ} \mathrm{C}$ \\
\hline$T_{P}^{\prime}$ & Trial value of $T_{P}$ in iteration process & ${ }^{\circ} \mathrm{C}$ \\
\hline
\end{tabular}




\begin{tabular}{|c|c|c|}
\hline$W$ & Precipitable water vapour & $\mathrm{mm}$ \\
\hline$Z$ & Noon angular zenith distance of sun & radian \\
\hline$z$ & Average angular zenith distance of the Sun & radian \\
\hline$\alpha$ & $\begin{array}{l}\text { Constant Equations (S21.12 and S21.78); albedo Equation } \\
\text { (S21.97) }\end{array}$ & $\begin{array}{l}{ }^{\circ} \mathrm{C} ; \\
\text { dimensionless }\end{array}$ \\
\hline$\beta$ & Constant Equations (S21.12 and S21.78) & ${ }^{\circ} \mathrm{C}$ \\
\hline$\gamma$ & Psychrometric constant & $\mathrm{mbar}^{\circ} \mathrm{C}^{-1}$ \\
\hline$\delta h$ & Water borne heat input & $\mathrm{W} \mathrm{m} \mathrm{m}^{-2}$ \\
\hline$\Delta$ & Saturation vapour pressure curve at $T$ & $\operatorname{mbar}^{\circ} \mathrm{C}^{-1}$ \\
\hline$\Delta_{P}$ & Slope of saturation vapour pressure curve at $T_{P}$ & $\operatorname{mbar}^{\circ} \mathrm{C}^{-1}$ \\
\hline$\Delta_{T}^{\prime}$ & Slope of saturation vapour pressure curve at $T_{P}^{\prime}$ & mbar ${ }^{\circ} \mathrm{C}^{-1}$ \\
\hline$\left[\delta T_{P}\right]$ & Adjustment to $T_{P}$ in iteration process & ${ }^{\circ} \mathrm{C}$ \\
\hline$\varepsilon$ & Surface emissivity & dimensionless \\
\hline$\xi$ & Stability factor & undefined \\
\hline$\eta$ & Radius vector of sun & undefined \\
\hline$\theta$ & Declination of sun & radians \\
\hline$\lambda$ & Heat transfer coefficient & mbar ${ }^{\circ} \mathrm{C}^{-1}$ \\
\hline$\rho$ & Proportional increase in atmospheric radiation due to clouds & dimensionless \\
\hline$\sigma$ & Stefan-Boltzmann constant & $\mathrm{W} \mathrm{m} \mathrm{m}^{-2} \mathrm{~K}^{-4}$ \\
\hline$\tau$ & Transmittancy of clear sky to direct beam radiation & undefined \\
\hline$\tau_{a}$ & Proportion of $\tau$ that is the result of absorption & undefined \\
\hline$v$ & $\begin{array}{l}\text { Mean daily saturation vapour pressure at air temperature for } \\
\text { month }\end{array}$ & mbar \\
\hline$v_{D}$ & $\begin{array}{l}\text { Mean daily saturation vapour pressure at dew point } \\
\text { temperature for month }\end{array}$ & mbar \\
\hline$v_{P}$ & $\begin{array}{l}\text { Mean daily saturation vapour pressure at equilibrium } \\
\text { temperature for month }\end{array}$ & mbar \\
\hline$v_{P}^{\prime}$ & Trial value of $v_{P}$ in iteration process & mbar \\
\hline$\varnothing$ & Latitude & degree, radians \\
\hline$\omega$ & Angle the earth rotates between sunrise and noon & radian \\
\hline
\end{tabular}

\section{CRAE: Estimate actual evaporation}

Use Morton's CRAE model to estimate the potential and actual evaporation for July 1980 at Alice Springs (Bureau of Meteorology, Australia station number 15590). Although the general methodology is presented in Appendix S7, the following procedure follows the detailed steps in Morton (1983a, Appendix C) and the Fortran program in Appendix S20. The symbols adopted here are those used by Morton and are different to those used in the Morton Fortran program (Appendix S20) and in the other appendices. 
The site conditions at Alice Spring automatic weather station are as follows:

Latitude (Ø)

Site elevation $(H)$

Mean annual rainfall $\left(P_{A}\right)$

The meteorological data for July 1980 is:

Mean daily air temperature $(T)$

Mean daily relative humidity $(R H)$

Mean daily sunshine hours $-23.7951^{\circ} \mathrm{S}$ (negative for southern hemisphere) -0.4153 radian

$546 \mathrm{~m}$

$285.8 \mathrm{~mm}$ year $^{-1}$

$11.8^{\circ} \mathrm{C}$ day $^{-1}$

$55.5 \%$ day $^{-1}$

8.35 hour day $^{-1}$

Because Morton assumes dew point temperature is available to estimate saturation vapour pressure rather than relative humidity, we carry out the following preliminary calculations to estimate dew point temperature $\left(T_{D}\right)$ as follows (Lawrence, 2005, Equation 8):

$$
T_{D}=\frac{243.04\left[\ln \left(\frac{R H}{100}\right)+\frac{17.625 T}{243.04+T}\right]}{17.625-\ln \left(\frac{R H}{100}\right)-\frac{17.625 T}{243.04+T}}
$$

where $T$ is air temperature $\left({ }^{\circ} \mathrm{C}\right), R H$ is the relative humidity (\%).

For July 1980, Alice Springs

$$
T_{D}=\frac{243.04\left[\ln \left(\frac{55.5}{100}\right)+\frac{17.625 \times 11.8}{243.04+11.8}\right]}{17.625-\ln \left(\frac{55.5}{100}\right)-\frac{17.625 \times 11.8}{243.04+11.8}}=3.1755^{\circ} \mathrm{C}
$$

To maintain consistency with Morton's (1983a) procedure, we adopt the units he used in his Appendix C namely $\mathrm{W} \mathrm{m}^{-2}$ for radiation, mbar for vapour pressure and ${ }^{\circ} \mathrm{C}$ for temperature. We also adopt Morton's nomenclature and record below Morton's equation numbers in italics.

The following two equations refer to the site conditions.

Equation C-1: Compute the ratio $\left(\frac{p}{p_{s}}\right)$ of atmospheric pressure at Alice Springs station $(p)$ to that at sea level $\left(p_{s}\right)$ :

$$
\begin{aligned}
& \left.\frac{p}{p_{s}}=[(288-0.0065 H) / 288)\right]^{5.256} \\
& \left.\frac{p}{p_{s}}=[(288-0.0065 \times 546) / 288)\right]^{5.256}=0.9369
\end{aligned}
$$

Equation $C$-2: Estimate the zenith value of the dry-season snow-free clear sky albedo $\left(a_{z d}\right)$ :

$$
a_{z d}=0.26-0.00012 P_{A}\left(\frac{p}{p_{s}}\right)^{0.5}\left[1+\left|\frac{\emptyset}{42}\right|+\left(\frac{\emptyset}{42}\right)^{2}\right]
$$

where $\emptyset$ is the latitude in decimal degree (negative for the southern hemisphere).

$$
\begin{aligned}
a_{z d} & =0.26-0.00012 \times 285.8(0.9369)^{0.5}\left[1+\left|\frac{-23.7951}{42}\right|+\left(\frac{-23.7951}{42}\right)^{2}\right] \\
& =0.1973
\end{aligned}
$$

Equation C-2a: $0.11 \leq a_{z d} \leq 0.17$

Hence, given Equation C-2a, adopt $a_{z d}=0.17$.

The following sequential operations are carried out for each month. 
Initially, we need to compute the mean maximum daylight hours for July at Alice Springs. The procedure is described earlier in Appendix S19 - see Equation (S3.11). The value is 10.68 hours. The mean daily sunshine for July 1980 was recorded as 8.34 hour day ${ }^{-1}$ giving a ratio of observed to maximum possible sunshine duration $(S)$ of 0.7818 .

Equation $C$-3: Compute the saturation vapour pressure $\left(v_{D}\right)$ at dew point temperature $\left({ }^{\circ} \mathrm{C}\right)$

$$
\begin{aligned}
& v_{D}=6.11 \exp \left[\frac{17.27 T_{D}}{T_{D}+237.3}\right] \\
& v_{D}=6.11 \exp \left[\frac{17.27 \times 3.1755}{3.1755+237.3}\right]=7.6751 \mathrm{mbar}
\end{aligned}
$$

Equation $C$-4: Compute the saturation vapour pressure $(v)$ at air temperature $\left({ }^{\circ} \mathrm{C}\right)$

$$
\begin{aligned}
& v=6.11 \exp \left[\frac{17.27 T}{T+237.3}\right] \\
& v=6.11 \exp \left[\frac{17.27 \times 11.8}{11.8+237.3}\right]=13.8463 \mathrm{mbar}
\end{aligned}
$$

Equation C-5: Compute the slope of the saturation vapour pressure $(\Delta)$ curve at $T{ }^{\circ} \mathrm{C}$.

$$
\Delta=\frac{\alpha \beta v}{(T+\beta)^{2}}
$$

$\alpha=17.27^{\circ} \mathrm{C}$ when $T \geq 0{ }^{\circ} \mathrm{C}$, otherwise $\alpha=21.88{ }^{\circ} \mathrm{C}$ (Morton, 1983a, page 60)

$\beta=237.3^{\circ} \mathrm{C}$ when $T \geq 0{ }^{\circ} \mathrm{C}$, otherwise $\beta=265.5^{\circ} \mathrm{C}$ (Morton, 1983a, page 60)

$$
\Delta=\frac{17.27 \times 237.3 \times 13.8463}{(11.8+237.3)^{2}}=0.9145 \mathrm{mbar}
$$

Equation C-6: Compute angles and functions for estimating extra-terrestrial global radiation.

$$
\theta=23.2 \sin (29.5 i-94)
$$

where $i$ is month of year, for July $i=7$, and $\theta$ is in degrees (Morton, 1983a, Item (1)).

$$
\theta=\left(23.2 \sin \left((29.5 \times 7-94) \frac{\pi}{180}\right)\right) \frac{\pi}{180}=0.3741 \text { radian }
$$

As Morton's equations are based on degrees, the inner $\frac{\pi}{180}$ converts degrees to radians and the outer converts the resulting angle in degrees to radians.

\section{Equation C-7:}

$$
\begin{aligned}
& \cos Z=\cos (\varnothing-\theta) \\
& \cos Z=\cos (-0.4153-0.3741)=0.7043 \\
& Z=\operatorname{arcos}(0.7043)=0.7894 \text { radian }
\end{aligned}
$$

Equation C-7a: $\cos Z \geq 0.001$

Hence Equation C-7a is satisfied

Equation C-8:

$$
\begin{aligned}
& \cos \omega=1-\frac{\cos Z}{\cos \emptyset \cos \theta} \\
& \cos \omega=1-\frac{0.7043}{\cos (0.3741) \cos (-0.4153)}=0.1731 \\
& \omega=\operatorname{arcos}(0.1731)=1.3968 \text { radian }
\end{aligned}
$$


Equation C-8a: $\cos \omega \geq-1$

Hence Equation C-8a is satisfied

Equation C-9:

$$
\begin{aligned}
& \cos Z=\cos Z+\left[\frac{180}{\pi} \frac{\sin \omega}{\omega}-1\right] \cos \emptyset \cos \theta \\
& \cos Z=0.7043+\left[\frac{\sin (1.3968)}{1.3968}-1\right] \cos (-0.4153) \cos (0.3741)=0.4531
\end{aligned}
$$

Note: $\frac{180}{\pi}$ in Equation (S21.23) (from Morton, 1983a, Equation C-9) is deleted as $\omega$ is in radian.

Equation $C$-10: Compute the radius vector of the sun $(\eta)$

$$
\begin{aligned}
& \eta=1+\frac{1}{60} \sin (29.5 i-106) \\
& \eta=1+\frac{1}{60} \sin \left((29.5 \times 7-106) \frac{\pi}{180}\right)=1.0164
\end{aligned}
$$

Equation C-11: Compute of extra-terrestrial global radiation $\left(G_{E}\right)$

$$
\begin{aligned}
& G_{E}=\frac{1354}{\eta^{2}} \frac{\omega}{180} \cos Z \\
& G_{E}=\frac{1354}{(1.0164)^{2}} \frac{1.3968}{\pi} 0.4531=264.0388 \mathrm{~W} \mathrm{~m}^{-2}
\end{aligned}
$$

Note: The division by $\pi$ rather than 180 in Equation S21.28 is because $\omega$ is in radian.

Equation $C$-12: Estimate the zenith value of snow-free clear sky albedo $\left(a_{z z}\right)$

$$
a_{z z}=a_{z d}=0.17
$$

Equation $C-12 a$ : $0.11 \leq a_{z z} \leq 0.5\left(0.91-\frac{v_{D}}{v}\right)$

$$
0.11 \leq a_{z z} \leq 0.5\left(0.91-\frac{7.6751}{13.8463}\right), 0.11 \leq a_{z z} \leq 0.1778
$$

Hence Equation C-12a is satisfied.

Equation C-13:

$$
\begin{aligned}
& c_{0}=v-v_{D} \\
& c_{0}=13.8463-7.6751=6.1712 \mathrm{mbar}
\end{aligned}
$$

Equation C-13a: $0 \leq c_{0} \leq 1$

Equation C-13a not satisfied, adopt $c_{0}=1$. This constraint will be effective during snow cover when the vapour pressure deficit is less than one mbar.

Equation $C$-14: Estimate the zenith value of the clear-sky albedo $\left(a_{z}\right)$

$$
\begin{aligned}
& a_{z}=a_{z z}+\left(1-c_{0}^{2}\right)\left(0.34-a_{z z}\right) \\
& a_{z}=0.17+(1-1)(0.34-0.17)=0.17
\end{aligned}
$$

Equation C-15: Estimate the clear-sky albedo $\left(a_{0}\right)$

$$
a_{0}=\frac{a_{z}\left[\exp (1.08)-\left(\frac{2.16 \cos Z}{\pi}+\sin Z\right) \exp (0.021 Z)\right]}{1.473(1-\sin Z)}
$$




$$
a_{0}=\frac{0.17\left[\exp (1.08)-\left(\frac{2.16 \times 0.7043}{\pi}+\sin 0.7894\right) \exp \left(0.021 \times 0.7894 \frac{180}{\pi}\right)\right]}{1.473(1-\sin 0.7894)}=0.3540
$$

Note: $\frac{180}{\pi}$ in Equation (S21.38) is to adjust $Z$ from radian to degree.

Equation $C$-16: Estimate the precipitable water $(W)$ in $\mathrm{mm}$.

$$
\begin{aligned}
& W=\frac{v_{D}}{0.49+\frac{T}{129}} \\
& W=\frac{7.6751}{0.49+\frac{11.8}{129}}=13.1994 \mathrm{~mm}
\end{aligned}
$$

Equation C-17:

$$
\begin{aligned}
& c_{1}=21-T \\
& c_{1}=21-11.8=9.2
\end{aligned}
$$

Equation C-17a is not satisfied, adopt $c_{1}=5$.

Equation $C$-18: Compute the turbidity coefficient $(j)$

$$
\begin{aligned}
& j=\left(0.5+2.5 \cos ^{2} z\right) \exp \left[c_{1}\left(\frac{p}{p_{s}}-1\right)\right] \\
& j=\left(0.5+2.5(0.4531)^{2}\right) \exp [5(0.9369-1)]=0.7391
\end{aligned}
$$

Equation C-19: Compute the transmittancy of clear sky to direct beam radiation $(\tau)$

$$
\begin{aligned}
& \tau=\exp \left[-0.089\left(\frac{p}{p_{s}} \frac{1}{\cos z}\right)^{0.75}-0.083\left(\frac{j}{\cos z}\right)^{0.90}-0.029\left(\frac{w}{\cos z}\right)^{0.60}\right] \\
& \tau=\exp \left[-0.089\left(0.9369 \frac{1}{0.4531}\right)^{0.75}-0.083\left(\frac{0.7391}{0.4531}\right)^{0.90}-0.029\left(\frac{13.1994}{0.4531}\right)^{0.60}\right] \\
& \tau=0.6055
\end{aligned}
$$

Equation C-20: Estimate the proportion of $\tau$ that is the result of absorption $\left(\tau_{a}\right)$

$$
\begin{aligned}
& \tau_{a}=\exp \left[-0.0415\left(\frac{j}{\cos z}\right)^{0.90}-(0.0029)^{0.5}\left(\frac{w}{\cos z}\right)^{0.3}\right] \\
& \tau_{a}=\exp \left[-0.0415\left(\frac{0.7391}{0.4531}\right)^{0.90}-(0.0029)^{0.5}\left(\frac{13.1994}{0.4531}\right)^{0.3}\right]=0.8085
\end{aligned}
$$

Equation C-20a: $\tau_{a} \geq \exp \left[-0.0415\left(\frac{j}{\cos z}\right)^{0.90}-0.029\left(\frac{w}{\cos z}\right)^{0.6}\right]$

Checking Equation C-20a constraint

$$
\tau_{a} \geq \exp \left[-0.0415\left(\frac{0.7391}{0.4531}\right)^{0.90}-0.029\left(\frac{13.1994}{0.4531}\right)^{0.6}\right] \geq 0.7530
$$

Equation C-20a constraint is satisfied.

Equation C-21: Compute clear-sky global radiation $\left(G_{o}\right)$

$$
\begin{aligned}
& G_{o}=G_{E} \tau\left[1+\left(1-\frac{\tau}{\tau_{a}}\right)\left(1+a_{0} \tau\right)\right] \\
& G_{o}=264.0388 \times 0.6055\left[1+\left(1-\frac{0.6055}{0.8085}\right)(1+0.3540 \times 0.6055)\right]
\end{aligned}
$$




$$
G_{o}=208.6217 \mathrm{~W} \mathrm{~m}^{-2}
$$

Equation $C$-22: Compute the incident global radiation $(G)$

$$
\begin{aligned}
& G=S G_{o}+(0.08+0.30 S)(1-S) G_{E} \\
& G=0.7818 \times 208.6217+(0.08+0.30 \times 0.7818)(1-0.7818) 264.0388 \\
& G=181.2221 \mathrm{~W} \mathrm{~m}^{-2}
\end{aligned}
$$

Equation C-23: Estimate the average albedo $(a)$

$$
\begin{aligned}
& a=a_{0}\left[S+(1-S)\left(1-\frac{Z}{330}\right)\right] \\
& a=0.3540\left[0.7818+(1-0.7818)\left(1-\frac{0.7894}{330} \frac{180}{\pi}\right)\right]=0.3434
\end{aligned}
$$

Equation C-24:

$$
\begin{aligned}
& c_{2}=10\left(\frac{v_{D}}{v}-S-0.42\right) \\
& c_{2}=10\left(\frac{7.6751}{13.8463}-0.7818-0.42\right)=-6.4749
\end{aligned}
$$

Equation C-24a: $0 \leq c_{2} \leq 1$

Constraint Equation C-24a is not satisfied, hence set $c_{2}=0$

Equation C-25: Estimate the proportional increase in atmospheric radiation due to clouds $(\rho)$

$$
\begin{aligned}
& \rho=0.18\left[\left(1-c_{2}\right)(1-S)^{2}+c_{2}(1-S)^{0.5}\right] \frac{p_{s}}{p} \\
& \rho=0.18\left[(1-0)(1-0.7818)^{2}+0(1-0.7818)^{0.5}\right] \frac{1}{0.9369}=0.009147
\end{aligned}
$$

Equation C-26: Compute net longwave radiation loss for soil-plant surface at air temperature $(B)$

$$
B=\varepsilon \sigma(T+273)^{4}\left[1-\left(0.71+0.007 v_{D} \frac{p}{p_{S}}\right)(1+\rho)\right]
$$

From Morton (1983a, page 64), $\varepsilon$ (emissivity) $=0.92, \sigma$ (Stefan-Boltzmann constant $)=$ $5.67 \times 10^{-8} \mathrm{~W} \mathrm{~m}^{-2} \mathrm{~K}^{-4}$. Thus,

$$
\begin{aligned}
& B=0.92 \times 5.67 \times 10^{-8}(11.8+273)^{4}\left[\begin{array}{c}
1-(0.71+0.007 \times 7.6751 \times 0.9369) \\
(1+0.009147)
\end{array}\right] \\
& B=79.8629 \mathrm{~W} \mathrm{~m}^{-2}
\end{aligned}
$$

Equation $C-26 a: B \geq 0.05 \varepsilon \sigma(T+273)^{4}$

$$
\text { Constraint }=0.05 \times 0.92 \times 5.67 \times 10^{-8}(11.8+273)^{4}=17.1594
$$

and thus Equation C-26a constraint is satisfied.

Equation C-27: Estimate net radiation at soil-plant surface at air temperature

$$
\begin{aligned}
& R_{T}=(1-a) G-B \\
& R_{T}=(1-0.3434) 181.2221-79.8629=39.1275 \mathrm{~W} \mathrm{~m}^{-2}
\end{aligned}
$$

Equation C-28: $R_{T C}=R_{T}=39.1275 \mathrm{~W} \mathrm{~m}^{-2}$

Equation C-28a: $R_{T C} \geq 0$, and constraint is satisfied.

Equation C-29: Compute stability factor $(\xi)$ 


$$
\frac{1}{\xi}=0.28\left(1+\frac{v_{D}}{v}\right)+\frac{\Delta R_{T C}}{\gamma \mathrm{p}\left(\frac{p_{s}}{p}\right)^{0.5} b_{0} f_{z}\left(v-v_{D}\right)}
$$

From Morton (1983a, page 64), $b_{0}=1$ for the CRAE model, and noting that $\gamma \mathrm{p}=$ $\gamma p_{s}\left(\frac{p}{p_{s}}\right), f_{z}$ and $\gamma p_{s}$ are respectively $28.0 \mathrm{~W} \mathrm{~m}^{-2} \mathrm{mbar}^{-1}$ and $0.66 \mathrm{mbar}^{\circ} \mathrm{C}^{-1}$ for $T \geq 0{ }^{\circ} \mathrm{C}$. For $T<0, f_{z}=28.0 \times 1.15 \mathrm{~W} \mathrm{~m}^{-2} \mathrm{mbar}^{-1}$ and $\gamma p_{s}=0.66 / 1.15 \mathrm{mbar}^{\circ} \mathrm{C}^{-1}$.

$$
\frac{1}{\xi}=0.28\left(1+\frac{7.6751}{13.8463}\right)+\frac{0.9145 \times 39.1275}{0.66 * 0.9369(1 / 0.9369)^{0.5} 1 \times 28.0(13.8463-7.6751)}=0.7594
$$

Equation C-29a: $\frac{1}{\xi} \leq 1$. Constraint is satisfied.

Equation C-30: Estimate the vapour transfer coefficient $\left(f_{T}\right)$

$$
\begin{aligned}
& f_{T}=\frac{1}{\xi}\left(\frac{p_{s}}{p}\right)^{0.5} f_{z} \\
& f_{T}=0.7594\left(\frac{1}{0.9369}\right)^{0.5} 28.0=21.9676
\end{aligned}
$$

Equation $C$-31: Estimate the heat transfer coefficient $(\lambda)$

$$
\begin{aligned}
& \lambda=\gamma \mathrm{p}+\frac{4 \varepsilon \sigma(T+273)^{3}}{f_{T}} \\
& \lambda=0.66 \times 0.9369+\frac{4 \times 0.92 \times 5.67 \times 10^{-8}(11.8+273)^{3}}{21.9676}=0.8378
\end{aligned}
$$

The penultimate step in estimating Morton CRAE evaporations is to estimate the potential evapotranspiration equilibrium temperature. This can be found by using Morton's (1983a, Equations C-32 to C-35) converging iterative process. The four equations are as follows:

Equation C-32: $\left[\delta T_{P}\right]=\frac{\left[\frac{R_{T}}{f_{T}}+v_{D}-v_{P}^{\prime}+\lambda\left(T-T_{P}^{\prime}\right)\right]}{\left(\Delta_{P}^{\prime}+\lambda\right)}$

Equation $C-33: T_{P}=T_{P}^{\prime}+\left[\delta T_{P}\right]$

Equation $C-34: v_{P}=6.11 \exp \left[\frac{\alpha T_{P}}{\left(T_{P}+\beta\right)}\right]$

Equation C-35: $\Delta_{P}=\frac{\alpha \beta v_{P}}{\left(T_{P}+\beta\right)^{2}}$

Initial values of $T_{P}^{\prime}, v_{P}^{\prime}$ and $\Delta_{P}^{\prime}$ are chosen equal to $T, v$ and $\Delta$ and intermediate values of $T_{P}, v_{P}$ and $\Delta_{P}$ are calculated from Equations C-33, C-34 and C-35 and $\left[\delta T_{P}\right]$ from Equation C-32. The intermediate values then replace the initial values in Equations C-33, C34 and C-35, again calculating $\left[\delta T_{P}\right]$. This process is repeated until $\left[\delta T_{P}\right] \leq 0.01{ }^{\circ} \mathrm{C}$. As the table below shows, only two iterations were required to solve for $T_{P}$ for our example.

\begin{tabular}{|c|c|c|}
\hline Initial values & Initial pass & $2^{\text {nd }}$ pass \\
\hline$T_{P}^{\prime}=11.8$ & $T_{P}=9.2947$ & $T_{P}=9.1963$ \\
\hline$v_{P}^{\prime}=13.8463$ & $v_{P}=11.7150$ & $v_{P}=11.6376$ \\
\hline$\Delta_{P}^{\prime}=0.9145$ & $\Delta_{P}=0.7895$ & $\Delta_{P}=0.7849$ \\
\hline$\left[\delta T_{P}\right]=-2.5053$ & {$\left[\delta T_{P}\right]=-0.0982$} & {$\left[\delta T_{P}\right]=-0.0001$} \\
\hline
\end{tabular}


Equation $C$-36: Estimate potential evapotranspiration $\left(E_{T P}\right)$

$$
\begin{aligned}
& E_{T P}=R_{T}-\lambda f_{T}\left(T_{P}-T\right) \\
& E_{T P}=39.1275-0.8378 \times 21.9676(9.1963-11.8) \\
& E_{T P}=87.0472 \mathrm{~W} \mathrm{~m}^{-2}
\end{aligned}
$$

Equation C-37: Estimate net radiation $\left(R_{T P}\right)$ at the soil-plant surface for equilibrium temperature.

$$
\begin{aligned}
& R_{T P}=E_{T P}+\gamma \mathrm{p} f_{T}\left(T_{P}-T\right) \\
& R_{T P}=87.0472+0.66 \times 0.9369 \times 21.9676(9.1963-11.8) \\
& R_{T P}=51.6792 \mathrm{~W} \mathrm{~m}^{-2}
\end{aligned}
$$

Equation C-38: Estimate wet-environment areal evapotranspiration $\left(E_{T W}\right)$

$$
E_{T W}=b_{1}+\frac{b_{2}}{\left(1+\frac{\gamma p}{\Delta_{P}}\right)} R_{T P}
$$

Morton (1983a, page 65) recommended values for $b_{1}$ and $b_{2}$ as $14 \mathrm{~W} \mathrm{~m}^{-2}$ and 1.20 respectively.

$$
E_{T W}=14+\frac{1.20}{\left(1+\frac{0.66 \times 0.9369}{0.7849}\right)} 51.6792=48.6877 \mathrm{~W} \mathrm{~m}^{-2}
$$

Equation C-38a: Constraint is $\frac{1}{2} E_{T P} \leq E_{T W} \leq E_{T P}$. The constraint is satisfied.

Equation $C$-39: Estimate actual areal evapotranspiration $\left(E_{T}\right)$

$$
\begin{aligned}
& E_{T}=2 E_{T W}-E_{T P} \\
& E_{T}=2 \times 48.6877-87.0472=10.3282 \mathrm{~W} \mathrm{~m}^{-2}
\end{aligned}
$$

The final step is to convert evaporation in power unit of $\mathrm{W} \mathrm{m}^{-2}$ to evaporation units of $\mathrm{mm}$ day $^{-1}$ by dividing by the latent heat of vaporization which for $T \geq 0^{\circ} \mathrm{C}$ is $28.5 \mathrm{~W}$ day $\mathrm{kg}^{-1}$ and for $\mathrm{T}<0^{\circ} \mathrm{C}$, it is $28.5 \times 1.15 \mathrm{~W}$ day $\mathrm{kg}^{-1}$. Hence,

$$
\begin{aligned}
& E_{T P}=87.0472 \mathrm{~W} \mathrm{~m}^{-2}=\frac{87.0472}{28.5}=3.0543 \mathrm{~mm} \mathrm{day}^{-1} \\
& E_{T W}=48.6877 \mathrm{~W} \mathrm{~m}^{-2}=\frac{48.6877}{28.5}=1.7083 \mathrm{~mm} \mathrm{day}^{-1} \\
& E_{T}=10.3282 \mathrm{~W} \mathrm{~m}{ }^{-2}=\frac{10.3282}{28.5}=0.3624 \mathrm{~mm} \mathrm{day}^{-1}
\end{aligned}
$$

In conclusion, the July 1980 evaporation rates at Alice Springs are as follows:

$E_{T P}$ (potential evapotranspiration) $=3.0543 \times 31=94.7 \mathrm{~mm} \mathrm{month}^{-1}$

$E_{T W}$ (wet-environment areal evapotranspiration) $=1.7083 \times 31=53.0 \mathrm{~mm}$ month $^{-1}$

$E_{T}$ (actual areal evapotranspiration $)=0.3624 \times 31=11.2 \mathrm{~mm} \mathrm{month}^{-1}$

\section{CRWE: Estimate shallow lake evaporation}


To estimate shallow lake evaporation, the CRWE model, which is a slightly modified version of CRAE, may be used. The modifications are listed in Morton (1983a, Section 2.6) as follows:

1. The snow-free clear-sky albedo $\left(a_{z z}\right)$ is set to a constant value of 0.05 . This allows Equations C-2, C-12 and their constraints to be deleted.

2. The emissivity $(\varepsilon)$ in Equations C-26, C26a and C31 is set to 0.97. Hence, $\varepsilon \sigma$ becomes $5.5 \times 10^{-8} \mathrm{~W} \mathrm{~m}^{-2} \mathrm{~K}^{-4}$.

3. In Equations C-29 and C-30, $f_{z}$ is $25.0 \mathrm{~W} \mathrm{~m}^{-2} \mathrm{mbar}^{-1}$ for $T \geq 0$, and $28.75 \mathrm{~W} \mathrm{~m}^{-2}$ $\mathrm{mbar}^{-1}$ for $T<0$.

4. In Equation C-29, $b_{0}=1.12$.

5. Values for $b_{1}$ and $b_{2}$ are $13 \mathrm{~W} \mathrm{~m}^{-2}$ and 1.12 respectively.

6. To reflect the change in the type of evaporation that is taking place in Equations C-27, C-36 and C-38, $R_{T}$ becomes $R_{W}, E_{T P}$ becomes $E_{P}$ and $E_{T W}$ becomes $E_{W}$ (shallow lake evaporation).

Applying these modifications to the CRAE model for July 1980 at Alice Springs yields the following results:

\begin{tabular}{|c|c|c|c|c|c|c|c|c|}
\hline $\begin{array}{l}\text { Morton } \\
\text { equation } \\
\text { number }\end{array}$ & Variable & Result & $\begin{array}{l}\text { Morton } \\
\text { equation } \\
\text { number }\end{array}$ & Variable & Result & $\begin{array}{l}\text { Morton } \\
\text { equation } \\
\text { number }\end{array}$ & Variable & Result \\
\hline C-1 & $\frac{p}{p_{s}}$ & 0.9369 & C16 & $W$ & 13.199 & C-29 & $\frac{1}{\xi}$ & 1.0935 \\
\hline C-3 & $v_{D}$ & 7.6751 & C-17 & $c_{1}$ & 9.2 & C-30 & $f_{T}$ & 28.243 \\
\hline $\mathrm{C}-4$ & $v$ & 13.8463 & C-18 & $j$ & 0.7391 & C-31 & $\lambda$ & 0.7983 \\
\hline C-5 & $\Delta$ & 0.9145 & C-19 & $\tau$ & 0.6055 & C-32 & {$\left[\delta T_{P}\right]$} & 0.0000 \\
\hline C-6 & $\theta$ & 0.3741 & $\mathrm{C}-20$ & $\tau_{a}$ & 0.8085 & C-33 & $T_{P}$ & 9.6680 \\
\hline C-7 & $\cos Z$ & 0.7043 & C-21 & $G_{o}$ & 202.55 & C-34 & $v_{P}$ & 12.013 \\
\hline C-8 & $\cos \omega$ & 0.1731 & $\mathrm{C}-22$ & $G$ & 176.47 & C35 & $\Delta_{P}$ & 0.8072 \\
\hline C-9 & $\cos Z$ & 0.4531 & C-23 & $a$ & 0.1010 & C-36 & $E_{P}$ & 122.352 \\
\hline C-10 & $\eta$ & 1.0164 & C-24 & $c_{2}$ & -6.475 & C-37 & $R_{T P}$ & 85.282 \\
\hline C-11 & $G_{E}$ & 264.04 & C-25 & $\rho$ & 0.00913 & C-38 & $E_{W}$ & 71.946 \\
\hline C-13 & $c_{0}$ & 6.1712 & C-26 & $B$ & 84.203 & & \multirow{3}{*}{\begin{tabular}{|l|}
$E_{W}$ \\
(lake \\
evaporat \\
ion)
\end{tabular}} & \multirow{3}{*}{$\begin{array}{l}2.52 \mathrm{~mm} \\
\text { day }^{-1} \text { or } \\
78.3 \mathrm{~mm} \\
\text { month }^{-1}\end{array}$} \\
\hline C-14 & $a_{z}$ & 0.05 & C-27 & $R_{W}$ & 74.446 & & & \\
\hline C-15 & $a_{0}$ & 0.1041 & C-28 & $R_{T C}$ & 74.446 & & & \\
\hline
\end{tabular}

\section{CRLE: Incorporating water borne energy input and available solar plus water borne energy routing for deep lake evaporation}

Estimate the March 2008 evaporation for the Thomson Reservoir, a deep lake $120 \mathrm{~km}$ east of Melbourne (latitude $37.75^{\circ} \mathrm{S}$, elevation $415 \mathrm{~m}$, average depth $(\bar{h}) 22.95 \mathrm{~m}$, and average salinity ( $s) 23 \mathrm{ppm})$. 
The method is based on Morton (1986). The soft water delay time, the lake delay time and the storage coefficient are computed first:

$$
t_{0}=0.96+0.013 \bar{h} \text { with } 0.039 \bar{h} \leq t_{0} \leq 0.13 \bar{h} \text { (see Equation (S7.15)) }
$$

where $t_{0}$ is soft water delay time.

$t_{0}=0.96+0.013 \times 22.95=1.2584$ months

$t_{0}$ is within the range $0.039 \bar{h}=0.8950$ and $0.13 \bar{h}=2.9835$

$t_{L}=\frac{t_{0}}{\left(1+\frac{s}{27000}\right)^{2}}$ with $t \leq 6.0$ (see Equation (S7.16))

where $t_{L}$ is lake lag or delay time and $s$ is lake salinity in ppm

$$
\begin{aligned}
t_{L} & =\frac{1.2584}{\left(1+\frac{23}{27000}\right)^{2}}=1.2563 \text { months (which is less than 6.0) } \\
S_{C} & =\frac{t_{0}}{\left[1+\left(\frac{\bar{h}}{93}\right)^{7}\right]} \text { (see Equation (S7.14)) }
\end{aligned}
$$

where $S_{c}$ is storage constant (months)

$$
S_{c}=\frac{1.2584}{\left[1+\left(\frac{22.95}{93}\right)^{7}\right]}=1.2583 \text { months }
$$
follows:

The sequential steps in the computation of monthly deep lake evaporation are as

Step 1: Estimate and add together solar and water borne heat input, thus

$$
G_{W}^{0}=(1-\alpha) R_{s}-R_{n l}+\delta h \text { (see Equation (S7.10)) }
$$

where $G_{W}^{0}$ is the solar input (the superscript refers to the current month) plus waterborne heat input ( $\delta h)$ and $\alpha$ is the albedo for water.

In this example, because the Thomson Reservoir is very large and there is no waterborne input, $\delta h=0$. Values of $G_{W}^{0}$ and $G_{L E}$ (see step 3 below) for January 2008 and February 2008 are:

\begin{tabular}{|c|c|c|c|}
\hline & January 2008 & February 2008 & March 2008 \\
\hline$G_{W}^{0}\left(\mathrm{~W} \mathrm{~m}^{-2}\right)$ & 187 & 152 & 120 \\
\hline$G_{L E}\left(\mathrm{~W} \mathrm{~m}^{-2}\right)$ & 160 & 175 & Not required \\
\hline
\end{tabular}

Step 2: Estimate the delayed solar and waterborne energy inputs (see Appendix S7).

$$
G_{W}^{t}=G_{W}^{\left[t_{L}\right]}+\left(t_{L}-\left[t_{L}\right]\right)\left(G_{W}^{\left[t_{L}+1\right]}-G_{W}^{\left[t_{L}\right]}\right) \text { (see Equation (S7.11)) }
$$

where $\left[t_{L}\right]$ and $\left(t_{L}-\left[t_{L}\right]\right)$ are the integral and fractional components of the lake lag or delay time, $t_{L}$, (months), $G_{W}^{\left[t_{L}\right]}$ and $G_{W}^{\left[t_{L}+1\right]}$ are respectively the value $\left(\mathrm{W} \mathrm{m}{ }^{-2}\right)$ of $G_{W}^{0}$ computed $\left[t_{L}\right]$ and $\left[t_{L}+1\right]$ months previously. In this example, from Equation (S21.94) $t_{L}=1.2563$ months and, therefore, $\left[t_{L}\right]=1$ month and $\left(t_{L}-\left[t_{L}\right]\right)=0.2563$ months.

Thus to estimate $G_{W}^{t}$ for March 2008, Equation (S21.98) becomes 


$$
\begin{aligned}
& G_{W}^{M a r 08}=G_{W}^{[\text {Feb08 }]}+\left(t_{L}-\left[t_{L}\right]\right)\left(G_{W}^{[\text {Jan08 }]}-G_{W}^{[\text {Feb08 }]}\right) \\
& G_{W}^{M a r 08}=152+(0.2563)(187-152)=160.71 \mathrm{~W} \mathrm{~m}^{-2}
\end{aligned}
$$

Step 3: Compute the available and water borne energy.

$$
\begin{aligned}
& G_{L E}=G_{L B}+\frac{G_{W}^{t}-G_{L B}}{0.5+S_{c}} \text { (see Equation (S7.12)) } \\
& G_{L}=0.5\left(G_{L E}+G_{L B}\right) \text { (see Equation (S7.13)) }
\end{aligned}
$$

where $G_{L B}$ and $G_{L E}$ are respectively the available solar and waterborne heat energy $\left(\mathrm{W} \mathrm{m}{ }^{-2}\right)$ at the beginning and end of the month

$$
\begin{aligned}
& G_{L E}^{M a r 08}=G_{L E}^{F e b 08}+\frac{G_{W}^{M a r 08}-G_{L E}^{F e b 08}}{0.5+S_{C}} \\
& G_{L E}^{M a r 08}=175+\frac{160.71-175}{0.5+1.2583}=166.87 \mathrm{~W} \mathrm{~m}^{-2} \\
& G_{L}^{M a r 08}=0.5\left(G_{L E}^{M a r 08}+G_{L E}^{F e b 08}\right) \\
& G_{L}^{\text {Mar } 08}=0.5(166.87+175)=170.94 \mathrm{~W} \mathrm{~m}^{-2}
\end{aligned}
$$

Step 4: Convert the available energy per month to a monthly lake evaporation rate by applying the sequence of steps set out in the worked example CRAE: Estimate actual evaporation after Equation S21.87 where

$$
R_{T C}=G_{L}^{M a r 08}=170.94 \mathrm{~W} \mathrm{~m}^{-2}
$$
$186 \mathrm{~mm}$.

These calculations yield the March 2008 lake evaporation for Thomson Reservoir as 


\section{References for Supplementary Material}

Abbott, M.B., Bathurst, C., Cunge, J.A., O’Connell, P.E., and Rasmussen, J., 1986a. An introduction to the European Hydrological System - Systeme Hydrologique Europeen, SHE. 1. History and philosophy of a physically-based, distributed modelling system. Journal of Hydrology, 87, 45-59.

Abbott, M.B., Bathurst, C., Cunge, J.A., O’Connell, P.E., and Rasmussen, J., 1986b. An introduction to the European Hydrological System - Systeme Hydrologique Europeen, SHE. 1. Structure of a physically-based, distributed modelling system. Journal of Hydrology, 87, 61-77.

Abtew, W. and Obeysekera, J., 1995. Lysimeter study of evapotranspiration of Cattails and comparison of three methods. Transactions American Society of Agricultural Engineers 38 (1), 121-129.

Adam, J.C., Clark, E.A., Lettenmaier, D.P., and Wood, E.F., 2006. Correction of global precipitation products for orographic effects. Journal of Climate 19, 15-38.

Al-Rawi, M.N.A., 1991. A simple, accurate and reliable method for measuring the Sun's elevation and orientation. Renewable Energy 1 (2), 231-235.

Alexandris, S., Stricevic, R., and Petkovic, S., 2008. Comparative analysis of reference evapotranspiration from the surface of rainfed grass in central Serbia, calculated by six empirical methods against the Penman-Monteith formula. European Water 21/22, 17-28.

Ali, S., Ghosh, N.C., and Singh, R., 2008. Evaluating best evaporation estimate model for water surface evaporation in semi-arid India. Hydrological Processes 22, 1093-1106.

Allen, J.B. and Crow, F.T, 1971. Predicting lake evaporation by performance of evaporation, ponds, pans and tanks. Transactions of the American Society of Agricultural Engineers 14 (3), 458-463.

Allen, R. G. and Brockway, C. E., 1983 Estimating Consumptive Use on a Statewide Basis. Proceedings of the 1983 Irrigation Specialty Conference, ASCE, Jackson, Wyo., 7989.

Allen, R.G. and Pruitt, W.O., 1986. Rational Use of The FAO Blaney-Criddle Formula. Journal Irrigation and Drainage Engineering 112 (2), 139-155.

Allen, R.G., Pereira, L.S., Raes, D., and Smith, M., 1998. Crop evapotranspiration Guidelines for computing crop water requirements FAO Irrigation and Drainage Paper 56. Food and Agriculture Organization of the United Nations.

Allen, R.G., Pruitt, W.O., Raes, D., Smith, M., and Pereira, L.S., 2005. Estimating evaporation from bare soil and the crop coefficient for the initial period using common soils information. Journal of Irrigation and Drainage Engineering 131 (1), 14-23.

Alvarez, M.V., Gonzalez-Real, M.M., Baille, A., and Molina Martinez, J.M., 2007. A novel approach for estimating the pan coefficient of irrigation water reservoirs: Application to South Eastern Spain. Agricultural Water Management, 92: 29 - 40.

Amatya, D.M., Skaggs, R.G., and Gregory, J.D., 1995. Comparison of methods for estimating REF-ET. Journal of Irrigation and Drainage Engineering 121 (6), 427-435.

Amer, K.H. and Hatfield, J.L., 2004. Canopy resistance as affected by soil and meteorological factors in potato. Journal of Agronomy 96 (4), 978-985. 
Anderson, M.G. and Idso, S.B., 1987. Surface geometry and stomatal conductance effects on evaporation from aquatic macrophytes. Water Resources Research 23 (6), 10371042.

ASCE, 2005. The ASCE Standardized Reference Evapotranspiration Equation. Eds Allen, R.G., Walter, I.A., Elliott, R., Howell, T., Itenfisu, D., and Jensen, M., American Society of Civil Engineers. . The ASCE standardized reference evapotranspiration equation. Task Committee on Standardized Reference Evapotranspiration., EWRI-American Society Civil Engineers 59pp.

Australian Bureau of Meteorology, 2007. Australian daily evaporation. Technical Notes, National Climate Centre. Product Code IDCJCO.

Bahel, V., Srinivasan, R., and Bakhsh, H., 1986. Solar radiation for Dhahran, Saudi Arabia. Energy 11, 985-989.

Barton, I.J., 1979. A parameterization of the evaporation from nonsaturated surfaces. Journal of Applied Meteorology 18, 43-47.

Benson, R.B., Paris, M.V., Sherry, J.E., and Justus, C.G., 1984. Estimation of daily and monthly direct, diffuse and global solar radiation from sunshine duration measurements. Solar Energy 32, 523-535.

Berger, A., Loutre, M-F., and Tricot, C., 1993. Insolation and Earth’s orbital periods. Journal of Geophysical Research 90 (D6), 10341-10362.

Beven, K., 1979. A sensitivity analysis of the Penman-Monteith actual evapotranspiration estimates. Journal of Hydrology 44, 169-190.

Bidlake, W.R., 2000. Evapotranspiration from a bulrush-dominated wetland in the Klamath Basin, Oregon. Journal of the American Water Resources Association 36 (6), 13091320.

Black, T.A., 1979. Evapotranspiration from Douglas-fir stands exposed to soil water deficits. Water Resources Research 15 (1), 164-170.

Black, P.E., 2007 Revisiting the Thornthwaite and Mather water balance. Journal of the American Water Resources Association 43 (6), 1604-1605.

Blaney, H.F., 1959. Monthly consumptive use requirements for irrigated crops. Journal of Irrigation and Drainage Division, American Society of Civil Engineers 85 (IR1), 1-12.

Bowen, I.S., 1926. The ratio of heat loss by conduction and by evaporation from any water surface. Physical Review 27, 779-787.

Brezny, O., Mehta, I., and Sharma, R.K., 1973. Studies on evapotranspiration of some aquatic weeds. Weed Science 21 (3), 197-204.

Bristow, K.L. and Campbell, G.S., 1984. On the relationship between incoming solar radiation and daily maximum and minimum temperature. Agricultural and Forest Meteorology 31 (2), 159-166.

Brown, T.C., Hobbins, M.T., and Ramírez, J.A., 2008. Spatial distribution of water supply in the coterminous United States. Journal of the American Water Resources Association 44 (6), 1474-1487.

Brutsaert, W., 1982. Evaporation into the atmosphere. Dordrecht, Holland: D. Reidel Publishing Company. 
Brutsaert, W. and Strickler, H., 1979. An advection-aridity approach to estimate actual regional evapotranspiration. Water Resources Research 15, 443-449.

Burman, R.D. 1976. Intercontinental comparison of evaporation estimates Journal of the Irrigation and Drainage Division, 102 (1), 109-118.

Cabral, O.M.R., Rocha, H.R., Gash, J.H.C., Ligo, M.A.V., Freitas, H.C., and Tatsch, J.D., 2010. The energy and water balance of a Eucalyptus plantation in southeast Brazil. Journal of Hydrology 388, 208-216.

Calder, I.R. and Neal, C., 1984. Evaporation from saline lakes: a combination equation approach. Hydrological Sciences Journal 29, 89-97.

Carlson, T., 2007. An overview of the "triangle method" for estimating surface evapotranspiration and soil moisture from satellite imagery. Sensors 7 (8), 1612-1629. doi: 10.3390/s7081612.

Chapman, T.G., 2001. Estimation of daily potential evaporation for input to rainfallrunoff models. In Ghassemi, F., Post, D., Sivapalan, M., and Vertessy, R. (Eds), MODSIM2001: Integrating models for Natural Resources Management across Disciplines, Issues and Scales. MSSANZ, 1, 293-298.

Chapman, T.G., 2003. Estimation of evaporation in rainfall-runoff models. MODSIM 2003 International Congress on Modelling and Simulation, Townsville, Queensland, Australia.

Chen, R., Ersi, K., Yang, J., Lu, S., and Zhao, W., 2004. Validation of five global radiation models with measured daily data in China. Energy Conversion and Management 45, 1759-1769.

Chiew, F.H.S. and Jayasuria, L.N.N., 1990. Applicability of Morton's complementary relationship method of estimating evapotranspiration in rainfall-runoff modelling. Conference on Agricultural Engineering, Toowoomba. The Institution of Engineers Australia.

Chiew, F.H.S. and Leahy, C.P., 2003. Comparison of evapotranspiration variables in evapotranspiration maps for Australia with commonly used evapotranspiration variables. Australian Journal of Water Resources 7, 1-11.

Chiew, F.H.S. and McMahon, T.A., 1991. The applicability of Morton's and Penman’s evapotranspiration estimates in rainfall-runoff modelling. Water Resources Bulletin 27 (4), 611-620.

Chiew, F.H.S. and McMahon, T.A., 1992. An Australian comparison of Penman potential evapotranspiration estimates and Class A evaporation pan data. Australian Journal of Soil Science 30, 101-112.

Chiew, F.H.S. and McMahon, T.A., 1993. Complete set of daily rainfall, potential evaporation and streamflow for twenty-eight unregulated Australian catchments. Centre for Environmental Hydrology, The University of Melbourne.

Chiew, F.H.S., Stewardson, M.J., and McMahon, T.A., 1993. Comparison of six rainfall-runoff modelling approaches. Journal of Hydrology 147, 1-36.

Chiew, F.H.S., Kamaladasa, N.N., Malano, H.M., and McMahon, T.A. 1995. PenmanMonteith, FAO-24 reference crop evapotranspiration and class-A pan data in Australia. Agricultural Water Management 28, 9-21. 
Chiew, F, Wang, Q.J., McConachy, F., James, R., Wright, W, and de Hoedt, G., 2002. Evapotranspiration maps for Australia. Proceedings of $27^{\text {th }}$ Hydrology and Water Resources Symposium, Institution of Engineers Australia, CDROM (ISBN 0-8582-5778-5).

Chin, D.A., 2011. Thermodynamic consistency of potential evapotranspiration estimates in Florida. Hydrological Processes 25, 288-301.

Christiansen, J.E., 1968. Pan evaporation and evapotranspiration from climatic data. Journal of the Irrigation and Drainage Division, ASCE 94 (IR2), Paper 5988.

Cogley, J.G., 1979. The albedo of water as a function of latitude. Monthly Weather Review 107, 775-781.

Cohen, S., Ianetz, A., and Stanhill, G., 2002. Evaporative climate changes at Bet Dagan, Israel, 1964-1998. Agricultural and Forest Meteorology 111, 83-91.

Clulow, A.D., Everson. C.S., Mengistu, M.G., Jarmain, C., Jewitt, G.P.W., Price, J.S., and Grundling, P.-L., 2012. Measurement and modelling of evaporation from a coastal wetland in Maputaland, South Sfrica. Hydrology and Earth System Sciences 16, 3233-3247.

Crockford, R.H. and Richardson, D.P., 2000. Partitioning of rainfall into throughfall, stemflow and interception: effect of forest type, ground cover and climate. Hydrological Processes 14, 2903-2920.

Davenport, A.G., 1960. Rationale for determining design wind velocities. Journal American Society of Civil Engineers ST-86, 39-68.

Davies, J.A. and Allen, C.D., 1973. Equilibrium, potential and actual evaporation from cropped surfaces in southern Ontario. Journal of Applied Meteorology 12, 649-657.

de Bruin, H.A.R., 1978. A simple model for shallow lake evaporation. Journal of Applied Meteorology 17, 1132-1134.

de Bruin, H.A.R., 1981. The determination of (reference crop) evapotranspiration from routine weather data. Proceedings of Technical Meeting 38. Committee for Hydrological Research TNO, Evaporation in relation to hydrology. Proceedings and Informations 28, 2537.

de Bruin, H.A.R., 1982. Temperature and energy balance of a water reservoir determined from standard weather data of a land station. Journal of Hydrology 59, 261-274.

de Bruin, H.A.R., 1987. From Penman to Makkink. Proceedings of Technical Meeting 44. Committee for Hydrological Research TNO, J.C. Hooghart (Ed.) Evaporation and weather. Proceedings and Informations 39, 5-31.

de Bruin, H.A.R. and Holtslag, A.A.M., 1982. A simple parameterization of the surface fluxes of sensible and latent heat during daytime compared with the Penman-Monteith concept. Journal of Applied Meteorology 21, 1610-1621.

Dingman, S.L., 1992. Physical Hydrology. Prentice Hall.

Donohue, R.J., Roderick, M.L. and McVicar, T.R., 2008. Deriving consistent long-term vegetation information from AVHRR reflectance data using a cover-triangle-based framework. Remote Sensing of Environment 112 (6), 2938-2949.

Donohue, R.J., McVicar, T.R., and Roderick, M.L., 2009. Climate-related changes in Australian vegetation cover as inferred from satellite observations for 1981-2006. Global Change Biology 15 (4), 1025-1039. 
Donohue, R.J., McVicar, T.R., Li, L.T., and Roderick, M.L., 2010a. A data resource for analysing dynamics in Australian ecohydrological conditions. Austral Ecology 35 (5), 593594, doi: 10.1111/j.1442-9993.2010.02144.x.

Donohue, R.J., McVicar, T.R., and Roderick, M.L., 2010b. Assessing the ability of potential evaporation formulations to capture the dynamics in evaporative demand within a changing climate. Journal of Hydrology 386, 186-197.

Doorenbos, J. and Pruitt, W.O., 1992. Guidelines for predicting crop water requirements. FAO Irrigation and Drainage Paper 24. Food and Agriculture Organization of the United Nations.

Douglas, E.M., Beltrán-Przekurat, A., Niyogi, D., Pielke, R.A., and Vörösmarty, C.J., 2009. The impact of agricultural intensification and irrigation on land-atmosphere interactions and Indian monsoon precipitation - A mesoscale modeling perspective. Global and planetary Change 67, 117-128.

Drexler, J.D., Snyder, R.L., Spano, D., and Paw U, K.T., 2004. A review of models and micrometeorological methods used to estimate wetland evapotranspiration. Hydrological Processes 18, 2071-2101.

Droogers, P. and Allen, R.G., 2002. Estimating reference evapotranspiration under inaccurate data conditions, Irrigation and Drainage Systems 16, 33-45.

Dunin, F.X. and Greenwood, E.A.N., 1986. Evaluation of the ventilated chamber for measuring evaporation from a forest. Hydrological Processes 1, 47-62.

Dunne, T. and Leopold, L.B., 1978. Water in Environmental Planning. W. H. Freeman and Company, New York, NY, USA.

Duru, J.O., 1984. Blaney-Morin-Nigeria evapotranspiration model. Journal of Hydrology 70, 71-83.

Edinger, J.E., Duttweiler, D.W., and Geyer, J.C., 1968. The response of water temperature to meteorological conditions. Water Resources Research 4 (5), 1137-1143.

Elhaddad, A., Garcia, L.S., and Chávez, J.L., 2011. Using a surface energy balance model to calculate spatially distributed actual evapotranspiration. Journal of Irrigation and Drainage Engineering, ASCE, 137 (1), 17-26.

Elsawwaf, M., Willems, P., and Feyen, J., 2010. Assessment of the sensitivity and prediction uncertainty of evaporation models applied to Nasser Lake, Egypt. Journal of Hydrology 395, 10-22.

Federer, C. A., Vörösmarty, C., and Fekete, B., 1996. Intercomparison of Methods for Calculating Potential Evaporation in Regional Global Water Balance Models, Water Resources Research 32 (7), 2315-2321.

Fennessey, N.M, 2000. Estimating average monthly lake evaporation in the Northeast United States. Journal American Water Resources Association 36 (4), 759-769.

Ficke, J.F., 1972. Comparison of evaporation computation method, Pretty Lake. United States Geological Survey Professional Paper 686-A, 48 pp.

Finch, J.W., 2001. A comparison between measured and modelled open water evaporation from a reservoir in south-east England. Hydrological Processes 15, 2771-2778. 
Finch, J.W. and Gash, J.H.C., 2002. Application of a simple finite difference model for estimating evaporation from open water. Journal of Hydrology 255, 253-259.

Fisher, J.B., de Biase, T.A., Qi, Y., Xu, M., and Goldstein, A.H., 2005. Evapotranspiration models compared on a Sierra Nevada forest ecosystem. Environmental Modelling \& Software 20, 783-796.

Fleming, P.M., Brown, J.A.H., and Aitken, A.P., 1989. Evaporation in Botswana and Australia, the transference of equations and techniques between continents. Hydrology and Water Resources Symposium 1989, The Institution of Engineers, Australia National Conference Publication 89 (19), 58-65.

Flint, A.L. and Childs, S.W., 1991. Use of the Priestley-Taylor evaporation equation for soil water limited conditions in a small forest clearcut. Agricultural and Forest Meteorology 56, 247-260.

Fraedrich, K., Behlau, A., Kerath, G., and Weber, G., 1977. A simple model for estimating the evaporation from a shallow water reservoir. Tellus, 29, 428-434.

Frevert, D.K., Hill, R.W., and Braaten, B.C., 1983. Estimation of FAO evapotranspiration coefficients. Journal of Irrigation and Drainage ASCE 109 (IR2), 265270 .

Gash, J.H.C., 1979. An analytical model of rainfall interception by forests. Quarterly Journal of the Royal Meteorological Society 105, 43-55.

Gerrits, A.W.J., Pfister, L., and Savenije, H.H.G., 2010. Spatial and temporal variability of canopy and forest floor interception in a beech forest. Hydrological Processes 24, 30113025.

Ghare, A.D., Porey, P.D., and Ingle, R.N., 2006. "Discussion of 'Simplified estimation of reference evapotranspiration from pan evaporation data in California' by Snyder. R.L., Orang, M., Matyac, S., and Grismer, M.E.” Journal of Irrigation and Drainage Engineering 132 (5), 519-520.

Giles, D.G., Black, T.A., and Spittlehouse, D.L., 1984. Determination of growing season soil water deficits on a forested slope using water balance analysis. Canadian Journal of Forest Research 15, 107-114.

Glenn, E., Huete, A., Nagler, P, Hirschboeck, K., and Brown, P., 2007. Integrating remote sensing and ground methods to estimate evapotranspiration. Critical Reviews in Plant Sciences, 26, 139-168.

Glenn, E. P., Nagler, P. L., and Huete, A.R., 2010. Vegetation Index Methods for Estimating Evapotranspiration by Remote Sensing._Surveys in Geophysics 31 (6), 531-555. doi: 10.1007/s10712-010-9102-2.

Granger, R.J, 1998. Partitioning of energy during the snow-free season at the Wolf Creek Research Basin. In Proceedings of a Workshop held in Whitehorse. Pomeroy, J.W. and Granger, R.J. (eds), Yukon , 5-7 March, 33-43.

Granger, R.J. and Gray, D.M., 1989. Evaporation from natural nonsaturated surfaces. Journal of Hydrology 111, 21-29.

Granier, A., Huc., R., and Barigah, S.T., 1996. Transpiration of natural rain forest and its dependence on climatic factors. Agricultural and Forest Meteorology 78, 19-29. 
Grant, D.R., 1975. Comparison of evaporation measurements using different methods. Quarterly Journal of the Royal Meteorological Society 101, 543-550.

Grayson, R.B., Argent, R.M., Nathan, R.J., McMahon, T.A., and Mein, R.G., 1996. Hydrological Recipes - Estimation Techniques in Australian Hydrology. Cooperative Research Centre for Catchment Hydrology, Clayton, Australia.

Grimmond, C.S.B. and Oke, T.R., 1991. An evapotranspiration-interception model for urban areas. Water Resources Research 27 (1), 1739-1755.

Guerschman, J.P., Van Dijk, A.I.J.M., Mattersdorf, G., Beringer, J., Hutley, L.B., Leuning, R., Pipunic, R.C., and Sherman, B.S., 2009. Scaling of potential evapotranspiration with MODIS data reproduces flux observations and catchment water balance observations across Australia. Journal of Hydrology 369, 107-119.

Harbeck, G.E., 1958. Lake Hefner water-loss investigations. International Association Scientific Hydrology, 45, 437-443.

Harbeck, G.E., 1962. A practical field technique for measuring reservoir evaporation utilizing mass-transfer theory. U.S. Geological Survey Professional Paper 272-E.

Hargreaves, G.H. and Samani, Z.A., 1985. Reference crop evapotranspiration from temperature. Applied Engineering in Agriculture 1 (2), 96-99.

Harmsen, E.W., Pérez, A.G., and Winter, A., 2003. Estimating long-term average monthly evapotranspiration from pan evaporation data at seven locations in Puerto Rico. NOAA-CREST/NASA-EPSCoR Joint Symposium for Climate Studies, University of Puerto Rico - Mayaguez Campus. 7pp.

Herbst, M., Rosier, P.T.W., McNeil, D.D., and Harding, R.J., 2008. Seasonal variability of interception evaporation from the canopy of a mixed deciduous forest. Agricultural and Forest Meteorology 148, 1655-1667.

Hobbins, M.T., Ramírez, J.A., Brown, T.C., and Claessens, L.H.J.M., 2001a. The complementary relationship in estimation of regional evapotranspiration: The Complementary Relationship Areal Evapotranspiration and Advection-Aridity models. Water Resources Research 37 (5), 1367-1387.

Hobbins, M.T., Ramírez, J.A., and Brown, T.C. 2001b. Complementary relationship in the estimation of regional evapotranspiration: An enhanced Advection-Aridity model. Water Resources Research 37 (5), 1388-1401.

Hounam, C.E., 1973. Comparison between pan and lake evaporation. World Meteorological Organisation Technical Note 126, 52pp.

Hoy, R.D., 1977. Pan and lake evaporation in northern Australia. Hydrology Symposium 1977. The Institution of Engineers Australia, National Conference Publication No. 77/5, 57-61.

Hoy, R.D. and Stephens, S.K. 1977. Field study of evaporation - Analysis of data from Eucumbene, Cataract, Manton and Mundaring. A.W.R.C. Technical Paper 21, 195pp.

Hoy, R.D. and Stephens, S.K., 1979. Field study of lake evaporation - analysis of data from phase 2 storages and summary of phase 1 and phase2. Australian Water Resources Council Technical Report paper No. 41.

Hoyt, D.V., 1977. Percent of possible sunshine and the total cloud cover. Monthly Weather Review 105, 648-652. 
Idso, S.B., 1981. Relative rates of evaporative water losses from open and vegetation covered water bodies. Water Resources Bulletin 17 (1), 46-48.

Jacobs, J.M., Mergelsberg, S.L., Lopera, A.F., and Myers, D.A., 2002. Evapotranspiration from a wet prairie wetland under drought conditions: Paynes Prairie, Florida, USA. Wetlands 22 (2), 374-385.

Jarvis, P.G. and McNaughton, K.G., 1986. Stomatal control of transpiration: scaling up from leaf to region. Advances in Ecological Research 15, 1-49.

Jeffrey, S.J., Carter, J.O., Moodie, K.B., and Beswick, A.R., 2001. Using spatial interpolation to construct a comprehensive archive of Australian climate data. Environmental Modelling and Software 16 (4), 309-330.

Jensen, M.E., 2010 Estimating evaporation from water surfaces. Presentation at CSU/ARS Evapotranspiration Workshop, Fort Collins. (15 March 2010).

Jensen, M.E., Burman, R.D., and Allen, R.G., (Eds), 1990. Evapotranspiration and irrigation water requirements. ASCE Manuals and Reports on Engineering Practice 70.

Jia, L., X G., Liu, S., Huang, C., Yan, Y., and Liu, G., 2009. Regional estimation of daily to annual regional evapotranspiration with MODIS data in the Yellow River Delta wetland. Hydrology and Earth System Sciences 13, 1775-1787.

Johnson, F., and Sharma, A., 2010. A comparison of Australian open water body evaporation trends for current and future climates estimated from Class A evaporation pans and general circulation models. Journal of Hydrometeorology 11, 105-121.

Jones, D.A., Wang, W., and Fawcett, R., 2009. High-quality spatial climate data-sets for Australia. Australian Meteorological and Oceanographic Journal 58, 233-248.

Jones, R.N., Bowler, J.M., and McMahon, T.A., 1993. Modelling water budgets of closed lakes, western Victoria. Quaternary Australasia Papers 11 (1), 50-60.

Jovanovic, B., Jones, D., and Collins, D., 2008. A high-quality monthly pan evaporation dataset for Australia. Climatic Change 87, 517-535.

Jury, W.A. and Tanner, C.B., 1975. Advection modification of the Priestley and Taylor evapotranspiration formula. Agronomy Journal 67, 840-842.

Kalma, J.D., McVicar, T.R., and McCabe, M.F., 2008. Estimating land surface evaporation: A review of methods using remotely sensed surface temperature data. Surveys in Geophysics 29, 421-469.

Keijman, J.Q., 1974. The estimation of the energy balance of a lake from simple weather data. Boundary-Layer Meteorology 7, 399-407.

Keijman, J.Q. and Koopmans, R.W.R., 1973. A comparison of several methods of estimating the evaporation of Lake Flevo. International Association of Hydrological Sciences Symposium on Hydrology of Lakes, 225-232.

Kelliher, F.M., Leuning, R. and Schulze, E.D., 1993. Evaporation and canopy characteristics of coniferous forests and grasslands. Oecologia 95 (2), 153-163.

Kelliher, F.M., Leuning, R., Raupach, M.R. and Schulze, E.D., 1995. Maximum conductances for evaporation from global vegetation types. Agricultural and Forest Meteorology 73, 1-16. 
Kirono, D.G.C., Jones, R.N., and Cleugh, H.A., 2009. Pan-evaporation measurements and Morton-point potential evaporation estimates in Australia: are their trends the same? International Journal of Climatology 29: 711-718.

Klaassen, W., Bosveld, F., and de Water, E., 1998. Water storage and evaporation as constituents of rainfall interception. Journal of Hydrology 212-213, 36-50.

Kohler M.A., Nordenson, T.J., and Fox, W.E., 1955. Evaporation from pans and lakes. Weather Bureau research Paper 38, US Department of Commerce, Washington.

Kohler, M.A. and Parmele, L.H., 1967. Generalized estimates of free-water evaporation. Water Resources Research 3 (4), 997-1005.

Komatsu, H., 2005. Forest categorization according to dry-canopy evaporation rates in the growing season: comparison of the Priestley-Taylor coefficient values from various observation sites. Hydrological Processes 19, 3873-3896.

Kotwicki, V., 1994. The nature of evaporation from Lake Alexandrina. Water Down Under '94, Adelaide.

Kumagai, T., Saitoh, T.M., Sato, Y., Morooka, T., Manfroi, O.J., Kuraji. K., and Suzuki, M., 2004. Transpiration, canopy conductance and the decoupling coefficient of a lowland mixed dipterocarp forest in Sarawk, Borneo: dry spell effects. Journal of Hydrology 287, 237-251.

Lavery, B., Joung, G., and Nicholls, N., 1997. An extended high-quality historical rainfall dataset for Australia. Australian Meteorological Magazine 46, 27-38.

Lawrence, M.G., 2005. The relationship between relative humidity and the dewpoint temperature in moist air: a simple conversion and applications. Bulletin American Meteorological Society 86, 225-233.

Lenters, J., Kratz, T.K., and Bowser, C.J., 2005. Effects of climate variability on lake evaporation: results from a long-term energy budget of Sparkling Lake, northern Wisconsin (USA). Journal of Hydrology 308, 168-195. 63.

Linacre, E.T., 1968. Estimating the net-radiation flux. Agricultural Meteorology 5, 49-

Linacre, E.T., 1992. Climate Data and Resources. Routledge, Boca Raton, Fla.

Linacre, E.T., 1993. Data-sparse estimation of lake evaporation, using a simplified Penman equation. Agricultural and Forest Meteorology 64, 237-256.

Linacre, E.T., 1994. Estimating U.S. Class-A pan evaporation from few climate data. Water International 19, 5-14.

Linacre, E.T., Hicks, B.B., Sainty, G.R., and Grauze, G., 1970. The evaporation from a swamp. Agricultural Meteorology 7, 375-386.

Lott, R.B. and Hunt, R.J., 2001. Estimating evapotranspiration in natural and constructed wetlands. Wetlands 21 (4), 614-628.

Louche, A., Notton, G., Poggi, P., and Simonnot, G., 1991. Correlations for direct normal and global horizontal irradiation on a French Mediterranean site. Solar Energy 46, 261-266. 
Lu, J., Sun, G., McNulty, S.G., and Amatya, D.M., 2005. A comparison of six potential evapotranspiration methods for regional use in the Southeastern United States," Journal American Water Resources Association 41, 621-633.

Magnani, F., Leonardi, S., Tognetti, R., Grace, J., and Borghetti, M, 1998. Modelling the surface conductance of a broad-leaf canopy: effects of partial decoupling from the atmosphere. Plant Cell and Environment 21, 867-879.

Maidment, D.R. 1992. Handbook of Hydrology. McGraw-Hill Inc., New York.

Martinez-Lonano, J.A., Tena, F., Onrubia, J.E., and Rubia, J., 1984. The historical evolution of the Ángström formula and its modifications: review and bibliography. Agricultural and Forest Meteorology 33, 109-128.

McArthur, A.J., 1992. The Penman form equations and the value of Delta: a small difference of opinion or a matter of fact? Agricultural and Forest Meteorology 57, 305-308.

McCullough, E.C., 1968. Total daily radiant energy available extraterrestrially as a harmonic series in the day of the year. Arch. Met. Geoph. Biokl., Ser. B, 16, 129-143.

McCullough, E.C. and Porter, W.P., 1971. Computing clear day solar radiation spectra for the terrestrial ecological environment. Ecology 52 (6), 1008-1015.

McJannet, D., Cook, F., and Burn, S., 2008a. Evaporation reduction by manipulation of surface area to volume ratios: overview, analysis and effectiveness. CSIRO: Water for a Healthy Country National Research Flagship. Urban Water Security Research Alliance Technical Report No. 8.

McJannet, D.L., Webster. I.T., Stenson, M.P., and Sherman, B.S., 2008b. Estimating open water evaporation for the Murray-Darling Basin. A report to the Australian Government from the CSIRO Murray-Darling Basin Sustainable Yields Project.

McJannet, D.L., Webster, I.T., and Cook, F.J., 2012 An area-dependent wind function for estimating open water evaporation using land-based meteorological data. Environmental Modelling \& Software doi:10.1016/j.envsoft.2011.11.017.

McLeod, A.J. and Webster, I.T., 1996. A heat budget method of estimating evaporation from irrigation channels. Proceedings $23^{\text {rd }}$ Hydrology and Water Resources Symposium. The Institution of Engineers Australia 2, 373-379.

McNaughton, K.G. and Black, T.A., 1973. A study of evapotranspiration from a Douglas Fir forest using the energy balance approach. Water Resources Research 9, 15791590.

McNaughton, K.G. and Jarvis, P.G., 1991. Effects of spatial scale on stomatal control of transpiration. Agricultural and Forest Meteorology 54, 279-301.

McVicar, T.R. and Jupp, D.L.B., 2002. Using covariates to spatially interpolate moisture availability in the Murray-Darling basin - a novel use of remotely sensed data. Remote Sensing of Environment 79 (2-3), 199-212.

McVicar, T.R., Van Niel, T.G., Li, L-T., Hutchinson, M.F., Mu, X-M., and Liu, Z-H. 2007. Spatially distributing monthly reference evapotranspiration and pan evaporation considering topographical influences. Journal of Hydrology 338, 196-220.

McVicar, T.R., Van Niel, T.G., Li, L.T., Roderick, M.L., Rayner, D.P. Ricciardulli, L., and Donohue, R.J., 2008. Wind speed climatology and trends for Australia, 1975-2006: 
Capturing the stilling phenomenon and comparison with near-surface reanalysis output. Geophysical Research Letters, 35, L20403, doi:10.1029/2008GL035627.

McVicar, T.R., Roderick, M.L., Donohue, R.J., Li, L.T., Van Niel, T.G., Thomas, A., Grieser, J., Jhajharia, D., Himri, Y., Mahowald, N.M., Mescherskaya, A.V., Kruger, A.C., Rehman, S., and Dinpashoh, Y., 2012. Global review and synthesis of trends in observed terrestrial near-surface wind speeds: Implications for evaporation. Journal of Hydrology 416417, 182-205 doi:10.1016/j.jhydrol.2011.10.024.

Meinzer, F.C., Andrade, J.L., Goldstein, G., Holbrook, N.M., Cavelier, J., and Jackson, P., 1997. Control of transpiration from the upper canopy of a tropical forest: the role of stomatal, boundary layer and hydraulic architecture components. Plant Cell and Environment 20, 1242-1252.

Menges, H.O., Ertekin, C, and Sonmete, M.H., 2006. Evaluation of global solar radiation models for Konya, Turkey. Energy Conversion and Management 47, 3149-3173.

Meyer, W.S., 1999. Standard reference evaporation calculation for inland south eastern Australia. CSIRO Land and Water, Technical Report 35/98.

Milly, P.C.D., 1991. A refinement of the combination equations for evaporation. Surveys in Geophysics 12, 145-154.

Mohamed, Y.A., Bastiaanssen, W.G.M., Savenije, H.H.G., van den Hurk, B.J.J.M., and Finlayson, C.M., 2008. Evaporation from wetland versus open water: a theoretical explanation and an application with satellite data over the Sudd wetland. Manuscript.

Monteith, J.L., 1965. Evaporation and environment. In G.E. Fogg (Ed), The state and movement of water in living organisms. Symposium Society Experimental Biology 19, 205234., Cambridge University Press, London.

Monteith, J.L., 1981. Evaporation and surface temperature. Quarterly Journal of the Royal Meteorological Society 107 (451), 1-27.

Morton, F.I., 1979. Climatological estimates of lake evaporation. Water Resources Research 15 (1), 64-76.

Morton, F.I., 1983a. Operational estimates of areal evapotranspiration and their significance to the science and practice of hydrology. Journal of Hydrology, 66, 1-76.

Morton, F.I., 1983b. Operational estimates of lake evaporation. Journal of Hydrology, 66, 77-100.

Morton, F.I., 1986. Practical estimates of lake evaporation. Journal of Climate \& Applied Meteorology 25, 371-387.

Morton, F.I., Richard, F., and Fogarasi, S., 1985. Operational estimates of areal evapotranspiration and lake evaporation - Program WREVAP. NHRI Paper 24, Inland Waters Directorate, Environment Canada, Ottawa.

Mukammal, E.I. and Neumann, H.H., 1977. Application of the Priestley-Taylor evaporation model to assess the influence of soil moisture on the evaporation from a large weighing lysimter and class A pan. Boundary-Layer Meteorology 12, 243-256.

Mutziger, A.J., Burt, C.M., Howes, D.J., and Allen, R.G., 2005. Comparison of measured and FAO-56 modeled evaporation from bare soil. Journal of Irrigation and Drainage Engineering 131,(1), 59-72. 
Muzylo, A., Llorens, P., Valente, F., Keize, J.J., Domingo, F., and Gash, J.H.C., 2009. A review of rainfall interception modelling. Journal of Hydrology 370, 191-206.

Myrup, L.O., Powell, T.M., Godden, D.A., and Goldman, C.R., 1979. Climatological estimate of the average monthly energy and water budgets of Lake Tahoe, California-Nevada. Water Resources Research 15 (6), 1499-1508.

Nandagiri, L. and Kovoor, G.M., 2006. Performance Evaluation of Reference Evapotranspiration Equations across a Range of Indian Climates Journal of Irrigation and Drainage Engineering, 132, (3), 238-249.

New, M., Lister, D., Hulme, M., and Makin, I., 2002. A high-resolution data set of surface climate over global land areas. Climate Res., 21, 1-25.

Neuwirth, F., 1973. Experiences with evaporation pans at a shallow steppe-lake in Austria. International Association of Hydrological Science 'Hydrology of Lakes', Helsinki, 290-297.

Nimmo, W.R., 1964. Measurement of evaporation by pans and tanks. Australian Meteorological Magazine 46, 17-53.

Nordenson, T.J. and Baker, D.R., 1962. Comparative evaluation of evaporation instruments. Journal of Geophysical Research 67, 671-679.

Oliver,H., 1961. Irrigation and Climate. Edward Arnold Ltd., London, 250 pp.

Oudin, L., Michel, C., and Andtil, F., 2005. Which potential evapotranspiration input for a lumped rainfall-runoff model? Part 1 - Can rainfall-runoff models effectively handle detailed potential evapotranspiration inputs? Journal of Hydrology 303, 275-289

Page, J.K., 1961. The estimation of monthly mean values of daily total short wave radiation on vertical and inclined surfaces from sunshine records for latitudes 40_N-40_S. In: Proceedings of UN conference on new sources of energy, 378-90.

Paw U, K.T., 1992. A discussion of the Penman form equations and comparisons of some equations to estimate latent energy flux density. Agricultural and Forest Meteorology 57, 297-304.

Paw U, K.T. and Gao, W., 1988. Applications of solutions to non-linear energy budget equations. Agricultural and Forest Meteorology 43, 121-145.

Payne, R.E., 1972. Albedo of sea water. Journal of Atmospheric Research 29, 959-970.

Penman, H.L., 1948. Natural evaporation from open water, bare soil and grass. Proceedings Royal Society London, A193, 120-145.

Penman, H.L. 1956. Evaporation: An introductory survey. Netherlands Journal Agricultural Science 4: 9-29.

Philip, J.R., 1957. Evaporation and moisture and heat fields in the soil. Journal of Meteorology 14, 354-366.

Price, J.S., 1994. Evapotranspiration from a lakeshore Typha marsh on Lake Ontario. Aquatic Botany 48, 261-272.

Priestley, C.H.B. and Taylor, R.J., 1972. On the assessment of surface heat flux and evaporation using large scale parameters. Monthly Weather Review 100, 81-92.

Raupach, M.R., 2001. Combination theory and equilibrium evaporation. Quarterly Journal of the Royal Meteorological Society 127, 1149-1181. 
Raupach, M.R., Kirby, J.M., Barrett, D.J., Briggs, P.R., Lu, H., and Zhang, H., 2001. Balances of Water, Carbon, Nitrogen and Phosphorus in Australian Landscapes: (2) Model Formulation and Testing. CSIRO Land and Water Technical Report 41/01.

Rayner, D., 2005. Australian synthetic daily Class A pan evaporation. Queensland Department of Natural resources and Mines Technical Report.

Ritchie, J.T., 1972. Model for predicting evaporation from row crop with incomplete cover. Water Resources Research 8, 1204-1213.

Roderick, M.L., 1999 Estimating the diffuse component from daily and monthly measurements of global radiation Agricultural and Forest Meteorology 95, 169-185.

Roderick, M.L., Rotstayn, L.D., Farquhar, G.D. and Hobbins, M.T., 2007. On the attribution of changing pan evaporation. Geophysical Research Letters 34, L17403, doi:10.1029/2007GL031166.

Roderick, M.L., Hobbins, M.T., and Farquhar, G.D., 2009a. Pan evaporation trends and the terrestrial water balance. 1. Principles and observations. Geography Compass 3 (2), 746760.

Roderick, M.L., Hobbins, M.T., and Farquhar, G.D., 2009b. Pan evaporation trends and the terrestrial water balance. 1. Energy balance and interpretation. Geography Compass 3 (2), 761-780.

Rosenberry, D.O., Stannard, D.I., Winter, T.C., and Martinez, M.L., 2004. Comparison of 13 equations for determining evapotranspiration from a prairie wetland, Cottonwood Lake Area, North Dakota, USA. Wetlands 24 (3), 483.

Rotstayn, L.D., Roderick, M.L., and Farquhar, G.D., 2006. A simple pan-evaporation model for analysis of climate simulation: Evaluation over Australia. Geophysical Research Letters 33, L17715, doi:10.1029/2006GL027114, 206.

Rutter, A.J., Kershaw, K.A., Robbins, P.C., and Morton. A.J., 1971. A predictive model of rainfall interception in forests. I. Derivation of the model from observations in a plantation of Corsican pine. Agricultural Meteorology 9, 367-384.

Rutter, A.J., Morton, A.J., and Robins, P.C., 1975. A predictive model of rainfall interception in forests. II. Generalization of the model and comparison with observations in some coniferous and hardwood stands. Journal of Applied Ecology 12, 367-380.

Sacks, L.A., Lee, T.M., and Radell, M.J., 1994. Comparison of energy-budget evaporation losses from two morphometrically different Florida seepage lakes. Journal of Hydrology 156, 311-334.

Salvucci, G.D., 1997. Soil and moisture independent estimation of stage-two evaporation from potential evaporation and albedo or surface temperature. Water Resources Research 33 (1), 111-122.

Samani, Z., 2000. Estimating Solar Radiation and Evapotranspiration Using Minimum Climatological Data. Journal of Irrigation and Drainage Engineering 126, 265-278.

Saunders, R.W., 1990. The determination of broad-band surface albedo from AVHRR visible and near-infrared radiances. International Journal of Remote Sensing 11 (1), 49-67.

Scozzafava, M. and Tallini, M., 2001. Net infiltration in the Gran Sasso Massif of central Italy using the Thornthwaite water budget and curve number method. Hydrogeology Journal 9, 461-475. 
Sharma, M.L., 1984. Evapotranspiration from an Eucalytus community. Agricultural Water Management 8, 41-56.

Shaw, E.M., 1994. Hydrology in Practice. Chapman \& Hall, London, $3^{\text {rd }}$ Edition, 569 pp.

Shuttleworth, W.J., 1992. In: Maidment, D.R. (Ed.), Evaporation. McGraw-Hill, New York, pp. 4.1-4.53 (Chapter 4).

Shuttleworth, W.J. 1978. A simplified one dimensional theoretical description of the vegetation-atmosphere interaction. Boundary Layer Meteorology 14, 3-27.

Shuttleworth, W.J. 1988. Evaporation from Amazonian rainforest. Proceedings Royal Society London B 233, 321-246.

Shuttleworth, W.J. and Calder, I.R., 1979. Has the Priestley-Taylor equation any relevance to forest evaporation? Journal of Applied Meteorology 18, 639-646.

Shuttleworth, W.J. and Wallace, J.S. 1985. Evaporation from sparse crops - an energy combination theory. Quarterly Journal of the Royal Meteorological Society 111, 839-855.

Shuttleworth, W.J. and Wallace, J.S., 2009. Calculating the water requirements of irrigated crops in Australia using the Matt-Shuttleworth approach. Transactions of the American Society of Agricultural and Biological Engineers 52 (6), 1895-1906.

Silberstein, R.P., Sivapalan, M., Viney, N.R., Held, A., and Hatton, T.J., 2003. Modelling the energy balance of a natural jarrah (Eucalyptus marginata) forest. Agricultural and Forest Meteorology 115, 210-230.

Simpson, J.P. and Paulson, C.A., 1979. Mid-ocean observations of atmospheric radiation. Quarterly Journal of Royal Meteorological Society, 103, 487-502.

Siriwardena, L., Finlayson, B.L. and McMahon, T.A., 2006. The impact of land use change on catchment hydrology in large catchments: The Comet River, Central Queensland, Australia. Journal of Hydrology 326, 199-214.

Slatyer, R.O. and McIlroy, I.C., 1961. Practical Microclimatology. Commonwealth Scientific and Industrial Organisation, Australia, UNESCO.

Snyder. R.L., Orang, M., Matyac, S., and Grismer, M.E., 2005. Simplified estimation of reference evapotranspiration. From pan evaporation data in California. Journal of Irrigation and Drainage Engineering 131 (3), 249-253.

Sobrino, J.A., Gómez, M., Jiménez-Muñoz, J.C., Olioso, A., and Chehbouni, G., 2005. A simple algorithm to estimate evapotranspiration from DAIs data: Application to the DAISEX campaigns. Journal of Hydrology 315, 117-125.

Souch, C., Grimmond, C.S.B., and Wolfe, C.P., 1998. Evapotranspiration rates from wetlands with different disturbance histories: Indiana Dunes National Lakeshore. Wetlands 18 (2), 216-229.

Stanhill, G., 1963. Evaporation in Israel. Bulletin of Research Council of Israel 11G, 160-172.

Stanhill, G., 1969. Evaporation from Lake Tiberias: an estimate by the combined water balance-mass transfer approach. Israel Journal of Earth Science 18, 101-108.

Stanhill, G. 1976. The CIMO International Evaporimeter Comparisons. World Meteorological Organisation, Geneva Publication 449, 38pp. 
Stanhill, G., 2002. Is the Class A evaporation pan still the most practical and accurate method for determining irrigation water requirements? Agricultural and Forest Meteorology 112, 233-236.

Stannard, D.I., 1993. Comparison of Penman-Monteith, Shuttleworth-Wallace, and modified Priestley-Taylor Evapotranspiration models for wildland vegetation in semiarid rangeland. Water Resources Research 29 (5), 1379-1392.

Stewart, J.B., 1977. Evaporation from the wet canopy of a pine forest. Water Resources Research 13 (6), 915-921.

Stewart, R.B., Rouse, W.R., 1976. A simple method for determining the evaporation from shallow lakes and ponds. Water Resources Research 12 (4), 623-628.

Stewart, R.B. and Rouse, W.R., 1977. Substantiation of the Priestley and Taylor parameter alpha $=1.26$ for potential evaporation in high latitudes. Journal of Applied Meteorology 16, 649-650.

Stitger, C.J., 1980. Solar radiation as statistically related to sunshine duration: a comment using low-latitude data. Agricultural Meteorology 21, 173-178.

Sumner, D.M. and Jacobs, J.M., 2005. Utility of Penman-Monteith, Priestley-Taylor, reference evapotranspiration, and pan evaporation methods to estimate pasture evapotranspiration. Journal of Hydrology 308, 81-104.

Sweers, H.E., 1976. A nomograph to estimate the heat-exchange coefficient at the airwater interface as a function of wind speed and temperature; a critical survey of some literature. Journal of Hydrology 30, 375-401.

Szeicz, G., Endrödi, G., and Tajchman, S., 1969. Aerodynamic and surface factors in evaporation. Water Resources Research 5 (2), 380-396.

Szilagyi, J., 2001. Modeled areal evaporation trends over the conterminous United States. Journal of Irrigation and Drainage Engineering 127 (4), 196-200.

Szilagyi, J., 2007. On the inherent asymmetric nature of the complementary relationship of evaporation. Geophysical Research Letters 34, L02405, doi:10.1029/2006GL028708.

Szilagyi, J. and Jozsa, J., 2008. New findings about the complementary relationshipbased evaporation estimation methods. Journal of Hydrology 354, 171-186.

Szilagyi, J., Hobbins, M.T., and Jozsa, J., 2009. Modified Advection-Aridity model of evapotranspiration. Journal of Hydrologic Engineering 14 (6), 569-574.

Tang, R., Li, Z-L., and Tang, B., 2010. An application of the T-s-VI triangle method with enhanced edges determination for evapotranspiration estimation from MODIS data in and semi-arid regions: Implementation and validation Remote Sensing of Environment 114 (3), 540-551, doi: 10.1016/j.rse.2009.10.012.

Teklehaimont, Z. and Jarvis, P.G., 1991. Direct measurement of evaporation of intercepted water from forest canopies. Journal of Applied Ecology 28, 603-618.

Thom, A.S., Thony, J.-L., and Vauclin, M, 1981. On the proper employment of evaporation pans and atmometers in estimating potential transpiration. Quarterly Journal of the Royal Meteorological Society 107, 711-736.

Thornthwaite, C.W. 1948. An approach toward a rational classification of climate. Geographical Review 38 (1), 55-94. 
Thornthwaite, C.W. and Mather, J.R. 1957 Instructions and Tables for the Computing Potential Evapotranspiration and the Water Balance, Drexel Institute of Technology Publications in Climatology 10, 185-311.

Tiris, M., Tiris, C., and Erdalli, Y., 1997. Water heating systems by solar energy. Marmara Research Centre, Institute of Energy Systems and Environmental Research, NATO TU-COATING, Gebze, Kocaeli, Turkey [in Turkish].

Trajkovic, S. and Kolakovic. S., 2009. Evaluation of reference evapotranspiration equations under humid conditions. Water Resources Management 23, 3057-3067.

Trajkovic, S.and Kolakovic, S., 2010. Comparison of simplified pan-based equations for estimating reference evapotranspiration. Journal of Irrigation and Drainage Engineering 136 (2), 137-140.

Trajković, S. and Stojnić, V., 2007. Effect of wind speed on accuracy of Turc method in a humid climate. Facta Universitstis, Architecture and Civil Engineering 5 (2), 107-113.

Turc, L., 1954. Le bilan d'eau des sols. Relations entre les précipitations, l'evaporation et l'écoulement. Annual Agronomy 5, 491-596.

Turc, L., 1955. Le bilan d'eau des sols. Relations entre les précipitations, l'evaporation et l'écoulement. Annual Agronomy 6, 5-131.

Turc, L., 1961. Estimation of irrigation water requirements, potential evapotranspiration: A simple climatic formula evolved up to date (in French). Annual Agronomy 12, 13-49.

Ulgen, K. and Hepbasli. A., 2004. Solar radiation models. Part 1: a review. Energy Sources 26, 507-520.

Valiantzas, J.D., 2006. Simplified versions for the Penman evaporation equation using routine weather data. Journal of Hydrology 331, 690-702.

van Bavel, C.H.M., 1966. Potential evaporation: The combination concept and its experimental verification. Water Resources Research 2 (3), 455-467.

van Dijk, M.H., 1985. Reduction in evaporation due to the bird screen used in the Australian class-A pan evaporation network. Australian Meteorological Magazine 33, 181183.

Vardavas, I.M., 1987. Modelling the seasonal variation of net all-wave radiation flux and evaporation in a tropical wet-dry region. Ecological Modelling 39, 247-268.

Vardavas, I.M. and Fountoulakis, A., 1996. Estimation of lake evaporation from standard meteorological measurements: application to four Australian lakes in different climatic regions. Ecological Modelling 84, 139-150.

Wallace, J. and McJannet, D., 2010. Processes controlling transpiration in the rainforests of north Queensland, Australia. Journal of Hydrology 384, 107-117.

Wang, Q.J., Chiew, F.H.S., McConachy, F.L.N., James, R., de Hoedt, G.C., and Wright, W.J. 2001. Climatic Atlas of Australia Evapotranspiration. Bureau of Meteorology, Commonwealth of Australia.

Watts, P.J. and Hancock, N.H., 1984. Evaporation and potential evaporation - A practical approach for agricultural engineers. Conference on Agricultural Engineering, 
Bundaberg, The Institution of Engineers Australia, National Conference Publication 84 (6), 290-297.

Webb, E.K., 1966. A pan-lake evaporation relationship: Journal of Hydrology, 4:1-11.

Weeks, W.D., 1982. Evaporation: a case study using data from a lake in Eastern Queensland. Hydrology and Water resources Symposium, Melbourne, The Institution of Engineers, Australia, National Conference Publication 82(3), 189-193.

Wei $\beta$, M. and Menzel, L., 2008. A global comparison of four potential evapotranspiration equations and their relevance to stream flow modelling in semi-arid environments. Advances in Geoscience 18, 15-23.

Wessel, D.A. and Rouse, W.R., 1994. Modelling evaporation from wetland tundra. Boundary-Layer Meteorology 68, 109-130.

Wieringa, J., 1986. Roughness-dependent geographical interpolation of surface wind speed averages. Quarterly Journal of Royal Meteorological Society 112, 867-889.

Winter, T.C., 1981. Uncertainties in estimating the water balance of lakes. Water Resources Bulletin, 17: 82 - 115.

Winter, T.C. and Rosenberry, D.O., 1995. Evaluation of 11 equations for determining evaporation for a small lake in the north central United States. Water Resources Research 31 (4), 983-993.

$\mathrm{Xu}, \mathrm{C} . \mathrm{Y}$. and Chen, D. 2005. Comparison of seven models for estimation of evapotranspiration and groundwater recharge using lysimeter measurement data in Germany. Hydrological Processes 19, 3717-3734.

$\mathrm{Xu}, \mathrm{C.-Y.and} \mathrm{Singh,} \mathrm{V.P.,} \mathrm{2001.} \mathrm{Evaluation} \mathrm{and} \mathrm{generalisation} \mathrm{of} \mathrm{temperature-based}$ methods for calculating evaporation. Hydrological Processes 15, 305-319.

Yang, K., Koike, T., and Ye, B., 2006. Improving estimation of hourly, daily, and monthly solar radiation by importing global data sets. Agricultural and Forest Meteorology 137, 43-55.

Yang, J. and Wang, Y., 2011. Estimating evapotranspiration fraction by modeling twodimensional space of NDVI/albedo and day-night surface temperature difference: A comparative study. Advances in Water Resources 34, 512-518.

Yin, Z.-Y. and Brook, G.A., 1992. Evapotranspiration in the Okefenokee Swamp watershed: a comparison of temperature-based and water balance methods. Journal of Hydrology 131, 293-312.

Young, A.A., 1947. Some recent evaporation investigations. Transactions of the American Geophysical Union 28, 279-284.

Zhang, L., Dawes, W.R., and Walker G. R, 2001, Response of mean annual evapotranspiration to vegetation changes at catchment scale. Water Resources Research 37 (3), 701-708. 
Table S1 Values of specific constants

\begin{tabular}{|c|c|c|c|}
\hline Constant & Symbol & Value & Reference \\
\hline Atmospheric pressure & $p$ & $101.3\left(\frac{293-0.0065 \text { Elev }}{293}\right)^{5.26} \mathrm{kPa}^{*}$ & Dingman (1992, p. 224) \\
\hline Density of water & $\rho_{w}$ & $997.9 \mathrm{~kg} \mathrm{~m}^{-3}$ at $20^{\circ} \mathrm{C}$ & Dingman (1992, p. 542) \\
\hline Mean air density & $\rho_{a}$ & $1.20 \mathrm{~kg} \mathrm{~m}^{-3}$ at $20^{\circ} \mathrm{C}$ & Shaw $(1994$, p. 6$)$ \\
\hline Emissivity of water & $\varepsilon_{w}$ & 0.95 & Dingman (1992, p. 583) \\
\hline Surface emissivity & $\varepsilon_{S}$ & 0.92 (adopted by Morton) & Morton (1983b, p. 64) \\
\hline Specific heat of water & $c_{w}$ & $4.19 \mathrm{~kJ} \mathrm{~kg}^{-1}{ }^{\circ} \mathrm{C}^{-1}$ & $\begin{array}{l}\text { Maidment (1992, p. 7.23) } \\
\text { Morton (1979, p.72) }\end{array}$ \\
\hline Specific heat of air & $c_{a}$ & $1013 \mathrm{~J} \mathrm{~kg}^{-1} \mathrm{~K}^{-1}$ & $\begin{array}{l}\text { Allen et al. (1998, } \\
\text { Equation 8); McJannet et } \\
\text { al. (2008, page 43) }\end{array}$ \\
\hline $\begin{array}{l}\text { Latent heat of } \\
\text { vaporization }\end{array}$ & $\lambda$ & $\begin{array}{l}2.45 \mathrm{MJ} \mathrm{kg}^{-1} \text { at } 20^{\circ} \mathrm{C} \\
28.5 \mathrm{~W} \text { days } \mathrm{kg}^{-1}\end{array}$ & $\begin{array}{l}\text { Dingman (1992, p. 547) } \\
\text { Allen et al. (1998, p. 31) } \\
\text { Morton (1983b, p. 65) }\end{array}$ \\
\hline Psychrometr & $\gamma$ & $\gamma=0.00163 \frac{p}{\lambda} \mathrm{kPa}^{\circ} \mathrm{C}^{-1}$ & Dingman (1992, p. 225) \\
\hline $\begin{array}{l}\text { Stefan-Boltzmann } \\
\text { constant } \\
\text { von Kármán constant }\end{array}$ & $\sigma$ & $\begin{array}{l}4.90 \times 10^{-9} \mathrm{MJ} \mathrm{m}^{-2} \mathrm{day}^{-1} \mathrm{~K}^{-4} \\
5.67 \times 10^{-8} \mathrm{~W} \mathrm{~m}^{-2} \mathrm{~K}^{-4} \\
0.41\end{array}$ & $\begin{array}{l}\text { Dingman (1992, p. 582) } \\
\text { Morton (1983a, p.64) } \\
\text { Szeicz et al., 1969) p. } \\
\text { 380) }\end{array}$ \\
\hline
\end{tabular}

* Elev is elevation (m) 
Table S2 Roughness height, aerodynamic and surface resistance of typical surfaces

\begin{tabular}{|c|c|c|c|c|c|c|}
\hline Surface & Location & $\begin{array}{c}\text { Height of } \\
\text { surface } \\
\text { condition (m) }\end{array}$ & $\begin{array}{l}\text { Zero-plane } \\
\text { displacement } \\
(\mathrm{m})\end{array}$ & $\begin{array}{l}\text { Roughness } \\
\text { length } \\
(\mathrm{m})\end{array}$ & $\begin{array}{l}\text { Aerodynamic } \\
\text { resistance, } r_{a} \text {, } \\
\left(\mathrm{s} \mathrm{m}^{-1}\right)\end{array}$ & $\begin{array}{l}\text { Average surface } \\
\text { resistance, } r_{s} \text {, } \\
\left(\mathrm{s} \mathrm{m}^{-1}\right)\end{array}$ \\
\hline Open sea, fetch $>5 \mathrm{~km}$ & & & & 0.0002 o & see Appendix S4 & \\
\hline Open flat terrain: grass & & & & 0.03 o & & \\
\hline Desert & & $0.001 \mathrm{e}$ & $0.1 \mathrm{c}$ & $0.05 \mathrm{C}$ & & $200 \mathrm{e}$ \\
\hline Semi-desert & & & $0.5 \mathrm{c}$ & $0.1 \mathrm{c}$ & & \\
\hline Hypothetical reference crop & & $0.12 \mathrm{a}$ & & & $104 \mathrm{a}$ & $70 \mathrm{a}$ \\
\hline Well watered production crops & & & & & & $50 \mathrm{j}$ \\
\hline Short grass & & & $0.2 \mathrm{c}$ & $0.02 \mathrm{c}$ & & \\
\hline Tall grass & & & $1 \mathrm{C}$ & $0.1 \mathrm{c}$ & & \\
\hline Low crops & & & & $0.10 \mathrm{o}$ & & \\
\hline High crops & & & & 0.250 & & \\
\hline Evergreen shrub & & & $1 \mathrm{C}$ & $0.1 \mathrm{c}$ & & \\
\hline Deciduous shrub & & & $1 \mathrm{C}$ & $0.1 \mathrm{c}$ & & \\
\hline Parkland, bushes & & & & $0.5 \mathrm{o}$ & & \\
\hline Non-forest wetland & & $0.3 \mathrm{e}$ & & & & $152 \mathrm{e}$ \\
\hline Savannah/xeric shrub & & $8.0 \mathrm{e}$ & & & & $189 \mathrm{e}$ \\
\hline Coniferous forest & $\begin{array}{c}\text { Based on } 8 \\
\text { references world- } \\
\text { wide }\end{array}$ & $\begin{array}{c}8 \mathrm{e}, \mathrm{g} \\
(5-20) \\
25\end{array}$ & & & $\begin{array}{c}7 \text { e, g } \\
(5-14)\end{array}$ & $\begin{array}{c}50 \text { e, g } \\
(30-125) \\
189 \\
\end{array}$ \\
\hline Evergreen needleleaf forest & & & $15 \mathrm{c}$ & $1.0 \mathrm{c}$ & & \\
\hline
\end{tabular}




\begin{tabular}{|c|c|c|c|c|c|c|}
\hline Deciduous needleleaf forest & & & $20 \mathrm{c}$ & $1.0 \mathrm{C}$ & & \\
\hline Beech & $\begin{array}{c}\text { Northern } \\
\text { Apennines, Italy }\end{array}$ & & & & & $200 \mathrm{i}$ \\
\hline Evergreen broadleaf forest & & & $20 \mathrm{c}$ & $2.0 \mathrm{C}$ & & \\
\hline Deciduous broadleaf forest & & & $15 \mathrm{c}$ & $0.8 \mathrm{c}$ & & \\
\hline Eucalyptus plantation & $\begin{array}{c}\text { São Paulo State, } \\
\text { Brazil }\end{array}$ & $12-21 \mathrm{~b}$ & & & $\begin{array}{c}\text { summer } 19 \pm 14 \mathrm{~b} \\
\text { winter } 9 \pm 2\end{array}$ & $\begin{array}{c}\text { summer } 19 \pm 14 \mathrm{~b} \\
\text { winter } 167 \pm 292\end{array}$ \\
\hline Eucalyptus maculata & $\begin{array}{c}\text { Kioloa State } \\
\text { Forest,NSW, } \\
\text { Australia }\end{array}$ & & & & & $60 \mathrm{~d}$ \\
\hline Eucalyptus forest & $\begin{array}{l}\text { Collie, Western } \\
\text { Australia }\end{array}$ & & & & 51 & 501 \\
\hline Lower montane rainforest & Nth Q’ld, Australia & $25 \& 32 \mathrm{~m}$ & & & & $\begin{array}{c}\text { summer } 71 \& \\
163 \mathrm{~m} \\
\text { winter } 56 \& 119\end{array}$ \\
\hline Pristine lowland rain forest & Nth Q'ld, Australia & $27 \mathrm{~m}$ & & & & $\begin{array}{c}\text { summer } 171 \mathrm{~m} \\
\text { winter } 115 \\
\end{array}$ \\
\hline $\begin{array}{l}\text { Upper montane cloud } \\
\text { rainforest }\end{array}$ & Nth Q’ld, Australia & $8 \mathrm{~m}$ & & & & $\begin{array}{c}\text { summer } 317 \text { m } \\
\text { winter } 160\end{array}$ \\
\hline Mixed woodland & & & $20 \mathrm{c}$ & $0.8 \mathrm{C}$ & & \\
\hline Tropical rainforest & French Guiana & $\sim 28 \mathrm{~d}$ & & & & $140-170 \mathrm{~d}$ \\
\hline Tropical trees & Panama & & & & & $250-500 \mathrm{k}$ \\
\hline $\begin{array}{l}\text { Lowland mixed dipterocarp } \\
\text { forest }\end{array}$ & Sarawak, Borneo & $50 \mathrm{~h}$ & & & $10 \mathrm{~h}$ & $84 \mathrm{~h}$ \\
\hline $\begin{array}{l}\text { Regular large obstacle } \\
\text { coverage (suburb, forest) }\end{array}$ & & & & 1.00 & & \\
\hline
\end{tabular}

a: Allen et al. (1998, page 23), b: Cabral et al. (2010), c: Douglas et al. (2009), d: Dunin and Greenwood (1986, page 51), e: Federer et al. (1996), f: Granier et al. (1996), g: Kelliher et al.(1993), h: Kumagai et al. (2004), i: Magnani et al. (1998, page 870), j: McNaughton and Jarvis (1991), k: Meinzer et al. (1997), l: Sharma (1984, page 49), m : Wallace \& McJannet (2010), n: Watt \& Hancock (1984), o: Wieringa (1986, Table 1) based on Davenport (1960)

*Value is median of a range shown in parenthesis \# clonal Eucalyptus grandis $\times$ Eucalyptus urophylla 
Table S3 Albedo values

\begin{tabular}{|l|c|l|}
\hline \multicolumn{1}{|c|}{ Surface } & Albedo, $\alpha$ & \multicolumn{1}{|c|}{ Reference } \\
\hline Water* & 0.08 & Maidment (1992) \\
Desert (bare ground) & 0.30 & McVicar et al. (2007) \\
Semi-desert & 0.25 & Douglas et al. (2009) \\
Tundra & 0.20 & Douglas et al. (2009) \\
Short grass & 0.26 & Watts \& Hancock (1984) \\
Pasture (short grass) & 0.26 & McVicar et al. (2007), Douglas et al. (2009) \\
Reference (short) crop & 0.23 & Allen et al. (1998, page 51) \\
Long grass (1 m) & 0.16 & Watts \& Hancock (1984) \\
Irrigated crop & 0.18 & Douglas et al. (2009) \\
Crop/mixed farming & 0.20 & Douglas et al. (2009) \\
Evergreen shrub & 0.10 & Douglas et al. (2009) \\
Deciduous shrub & 0.20 & Douglas et al. (2009) \\
Sparse forest & 0.18 & McVicar et al. (2007) \\
Rain forest & 0.15 & Dingman (1992) \\
Eucalypts & 0.20 & Dingman (1992) \\
Evergreen needleleaf forest & 0.10 & Douglas et al. (2009) \\
Deciduous needleleaf forest & 0.20 & Douglas et al. (2009) \\
Evergreen broadleaf forest & 0.15 & Douglas et al. (2009) \\
Deciduous broadleaf forest & 0.20 & Douglas et al. (2009) \\
Forest (mixed woodland) & 0.15 & McVicar et al. (2007), Douglas et al. (2009) \\
Urban area & 0.25 & McVicar et al. (2007) \\
\hline
\end{tabular}

* Based on Cogley (1979), Jensen (2010, Table 1) provides a table of albedo values for water. Jensen's table shows that albedo for water has a seasonal pattern being high in winter and low in summer and increases from an average value of 0.065 at the equator to values varying from 0.11 to 0.36 at $60^{\circ}-70^{\circ} \mathrm{N}$ latitude. 
Table S4 Median, $10^{\text {th }}$ and $90^{\text {th }}$ percentile monthly evaporation based on data recorded at the 68 Australian AWSs for three Penman wind functions, and for FAO-56 Reference Crop and Priestley-Taylor algorithms expressed as a percentage of the Penman (1948) median estimate

\begin{tabular}{|l|ccccr|}
\hline \multicolumn{1}{|c|}{ Parameter } & $\begin{array}{c}\text { Penman } \\
\text { (1948) wind } \\
\text { function }\end{array}$ & $\begin{array}{c}\text { Penman } \\
\text { Penman } \\
\text { (1956) wind } \\
\text { function }\end{array}$ & $\begin{array}{c}\text { Linacre } \\
(1993)\end{array}$ & $\begin{array}{c}\text { FAO-56 } \\
\text { Reference } \\
\text { Crop }\end{array}$ & $\begin{array}{c}\text { Priestley- } \\
\text { Taylor }\end{array}$ \\
\hline Median & $100 \%$ & $-9.9 \%$ & $-15.8 \%$ & $-26.4 \%$ & $-17.1 \%$ \\
$10^{\text {th }}$ percentile & $-63.0 \%$ & $-67.5 \%$ & $-72.0 \%$ & $-74.3 \%$ & $-75.7 \%$ \\
$90^{\text {th }}$ percentile & $57.4 \%$ & $45.5 \%$ & $33.4 \%$ & $22.3 \%$ & $29.2 \%$ \\
\hline
\end{tabular}

Table S5 Guideline for defining shallow and deep lakes and the methods to estimate lake evaporation

\begin{tabular}{|c|c|c|c|}
\hline Shallow lake & $\begin{array}{l}\text { Average } \\
\text { depth (m) }\end{array}$ & Deep lake & $\begin{array}{l}\text { Average } \\
\text { depth } \\
\text { (m) }\end{array}$ \\
\hline \multicolumn{4}{|c|}{ Morton recommendations } \\
\hline \multicolumn{2}{|l|}{ Morton CRWE } & \multicolumn{2}{|l|}{ Morton CRLE } \\
\hline $\begin{array}{l}\text { Seasonal heat storage changes } \\
\text { (Morton, 1983b, page 84) and } \\
\text { water advection are not important }\end{array}$ & undefined & $\begin{array}{l}\text { For depths less than } 1.5 \text { m use } \\
\text { CRWE (Morton, 1986, page } \\
\text { 385) }\end{array}$ & 1.5 \\
\hline $\begin{array}{l}\text { Deep lakes are considered shallow } \\
\text { if one is interested only in annual } \\
\text { or mean annual evaporation } \\
\text { (Morton, 1983b, page } 84 \text { ) }\end{array}$ & undefined & $\begin{array}{l}\text { Seasonal heat storage changes } \\
\text { and water advection are } \\
\text { important }\end{array}$ & undefined \\
\hline \multicolumn{4}{|c|}{ Recommendations of other authors } \\
\hline \multicolumn{2}{|c|}{$\begin{array}{c}\text { Shallow lake without seasonal heat storage } \\
\text { analysis }\end{array}$} & \multicolumn{2}{|l|}{ Deep lake } \\
\hline Sacks et al (1994, Abstract) & 3 & $\begin{array}{l}\text { Vardavas \& Fountoulakis } \\
\text { (1996) }\end{array}$ & $3-23$ \\
\hline $\begin{array}{l}\text { Penman equation can be applied } \\
\text { without adjusting for heat storage } \\
\text { Monteith (1981, page 9) }\end{array}$ & $\begin{array}{l}\text { less than } \\
\text { “...a } \\
\text { metre or } \\
\text { so...” }\end{array}$ & Kohler \& Parmele (1967) & undefined \\
\hline de Bruin (1978, Section 2) & 3 & & \\
\hline \multicolumn{2}{|c|}{$\begin{array}{c}\text { Shallow lake with seasonal heat storage } \\
\text { analysis }\end{array}$} & & \\
\hline McJannet et al. (2008b) & $1-6$ & McJannet et al. (2008b) & $25-30$ \\
\hline Finch \& Gash (2002) & 10 & Finch \& Gash (2002) & 10 \\
\hline Finch (2001) & 10 & & \\
\hline Fennessey (2000) & 2 & & \\
\hline Sacks et al (1994, page 312) & $<5$ & & \\
\hline Fraedrich et al. (1977, Section 6) & 8 & & \\
\hline Stewart \& Rouse (1976, page 624) & 0.6 & & \\
\hline Keijman and Koopmans (1973) & 3.0 & & \\
\hline
\end{tabular}


Table S6 Mean monthly screened Class-A evaporation pan coefficients for estimating Penman open-water evaporation (1956 wind function) at 68 Australian locations

For each station, the second row of values specifies the number of months used to compute the mean monthly pan coefficients. Asterisk denotes high quality Class-A evaporation pan. nd is no data

\begin{tabular}{|c|c|c|c|c|c|c|c|c|c|c|c|c|c|c|c|c|}
\hline $\begin{array}{c}\text { BOM } \\
\text { ref. }\end{array}$ & Station name & Lat ${ }^{\circ} \mathrm{S}$ & $\begin{array}{c}\text { Long } \\
{ }^{\circ} \mathrm{E}\end{array}$ & Jan & Feb & Mar & Apr & May & Jun & Jul & Aug & Sep & Oct & Nov & Dec & Year \\
\hline \multirow{2}{*}{2012} & \multirow{2}{*}{ Halls Creek Airport* } & \multirow{2}{*}{-18.23} & \multirow{2}{*}{127.66} & 0.735 & 0.880 & 0.753 & 0.696 & 0.702 & 0.711 & 0.702 & 0.696 & 0.671 & nd & 0.709 & 0.697 & 0.723 \\
\hline & & & & 3 & 2 & 2 & 3 & 2 & 2 & 2 & 1 & 1 & 0 & 1 & 1 & \\
\hline \multirow{2}{*}{3003} & \multirow{2}{*}{ Broome Airport* } & \multirow{2}{*}{-17.95} & \multirow{2}{*}{122.24} & 0.822 & 0.842 & 0.866 & 0.816 & 0.742 & 0.743 & 0.768 & 0.788 & 0.859 & 0.897 & 0.882 & 0.837 & 0.822 \\
\hline & & & & 9 & 12 & 7 & 13 & 16 & 14 & 14 & 14 & 16 & 15 & 16 & 11 & \\
\hline \multirow{2}{*}{7178} & \multirow{2}{*}{ Paraburdoo } & \multirow{2}{*}{-23.20} & \multirow{2}{*}{117.67} & 0.607 & 0.571 & 0.591 & 0.614 & 0.564 & 0.654 & 0.594 & 0.644 & 0.635 & 0.587 & 0.608 & 0.591 & 0.605 \\
\hline & & & & 2 & 1 & 2 & 1 & 3 & 3 & 1 & 2 & 3 & 3 & 3 & 2 & \\
\hline \multirow{2}{*}{9021} & \multirow{2}{*}{ Perth Airport* } & \multirow{2}{*}{-31.93} & \multirow{2}{*}{115.98} & 0.825 & 0.821 & 0.782 & 0.818 & 0.827 & 0.850 & 0.915 & 0.984 & 0.979 & 0.960 & 0.903 & 0.862 & 0.877 \\
\hline & & & & 16 & 16 & 16 & 16 & 16 & 15 & 15 & 16 & 15 & 15 & 16 & 16 & \\
\hline \multirow{2}{*}{9034} & \multirow{2}{*}{ Perth Reg. Office* } & \multirow{2}{*}{-31.96} & \multirow{2}{*}{115.87} & 0.912 & 0.866 & 0.837 & 0.837 & 0.818 & 0.807 & 0.869 & 0.931 & 0.942 & 0.966 & 0.942 & 0.945 & 0.889 \\
\hline & & & & 14 & 11 & 11 & 11 & 13 & 11 & 10 & 11 & 11 & 9 & 12 & 12 & \\
\hline \multirow{2}{*}{9538} & \multirow{2}{*}{ Dwellingup } & \multirow{2}{*}{-32.71} & \multirow{2}{*}{116.06} & 0.880 & 0.867 & 0.864 & 0.921 & 0.813 & 0.789 & 0.748 & 0.912 & 0.933 & 1.028 & 0.963 & 0.923 & 0.887 \\
\hline & & & & 10 & 11 & 13 & 13 & 9 & 11 & 9 & 6 & 9 & 12 & 14 & 12 & \\
\hline \multirow{2}{*}{9592} & \multirow{2}{*}{ Permberton } & \multirow{2}{*}{-34.45} & \multirow{2}{*}{116.04} & 0.950 & 0.941 & 0.883 & 0.920 & 0.981 & 0.890 & nd & nd & 0.892 & 0.980 & 0.983 & 0.962 & 0.938 \\
\hline & & & & 3 & 4 & 2 & 2 & 1 & 1 & 0 & 0 & 1 & 1 & 1 & 2 & \\
\hline 9741 & Albany Airn & & 11780 & 0.827 & 0.822 & 0.809 & 0.856 & 0.859 & 0.830 & 0.882 & 0.938 & 0.970 & 0.987 & 0.917 & 0.856 & 0.879 \\
\hline $9 / 41$ & AID & & $11 \% .80$ & 16 & 15 & 12 & 15 & 17 & 16 & 15 & 17 & 13 & 15 & 18 & 15 & \\
\hline & & & & 0.650 & 0.656 & 0.650 & 0.686 & 0.727 & 0.765 & 0.755 & 0.747 & 0.718 & 0.694 & 0.678 & 0.659 & 0.699 \\
\hline 13017 & Giles & & 128.30 & 28 & 26 & 25 & 27 & 28 & 30 & 29 & 28 & 27 & 28 & 27 & 28 & \\
\hline & & & & 0.775 & 0.771 & 0.866 & 0.855 & 0.779 & 0.744 & 0.766 & 0.812 & 0.836 & 0.853 & 0.838 & 0.779 & 0.806 \\
\hline 14015 & Darwin $t$ & -12.42 & 130.89 & 10 & 12 & 13 & 25 & 24 & 29 & 26 & 29 & 30 & 25 & 17 & 16 & \\
\hline 14198 & Jabiru Airnort & -1266 & & 0.842 & 0.856 & 0.827 & 0.812 & 0.766 & 0.709 & 0.734 & 0.740 & 0.732 & 0.773 & 0.788 & 0.848 & 0.786 \\
\hline 14198 & Jabiru Aırport & -12.66 & 132.89 & 2 & 3 & 4 & 3 & 6 & 4 & 5 & 5 & 7 & 7 & 4 & 2 & \\
\hline 14508 & Gove Airnort* & -1227 & 13682 & 0.859 & 0.831 & 0.899 & 0.889 & 0.888 & 0.863 & 0.889 & 0.921 & 0.935 & 0.944 & 0.922 & 0.864 & 0.892 \\
\hline 14508 & Gove & .21 & 130.02 & 18 & 16 & 17 & 19 & 17 & 19 & 19 & 20 & 21 & 22 & 15 & 18 & \\
\hline
\end{tabular}




\begin{tabular}{|c|c|c|c|c|c|c|c|c|c|c|c|c|c|c|c|c|}
\hline \multirow{2}{*}{14513} & \multirow{2}{*}{ Wallaby Beach } & \multirow{2}{*}{-12.19} & \multirow{2}{*}{136.71} & nd & 0.773 & nd & 0.846 & 0.862 & 0.811 & 0.751 & 0.873 & 0.873 & 0.920 & 0.890 & 0.782 & 0.838 \\
\hline & & & & 0 & 1 & 0 & 3 & 3 & 3 & 3 & 3 & 5 & 5 & 4 & 3 & \\
\hline \multirow{2}{*}{14612} & \multirow{2}{*}{ Larrimah } & \multirow{2}{*}{-15.57} & \multirow{2}{*}{133.21} & 0.756 & 0.878 & 0.850 & 0.780 & 0.792 & 0.739 & 0.793 & 0.798 & 0.756 & 0.709 & 0.697 & 0.577 & 0.760 \\
\hline & & & & 4 & 3 & 4 & 3 & 1 & 3 & 2 & 2 & 6 & 1 & 3 & 3 & \\
\hline \multirow{2}{*}{14703} & \multirow{2}{*}{ Centre Island } & \multirow{2}{*}{-15.74} & \multirow{2}{*}{136.82} & nd & nd & 0.825 & 0.912 & 0.816 & 0.872 & 0.905 & 1.060 & 0.923 & 0.975 & 0.870 & 0.950 & 0.911 \\
\hline & & & & 0 & 0 & 1 & 2 & 1 & 2 & 2 & 1 & 2 & 3 & 2 & 2 & \\
\hline \multirow{2}{*}{14704} & \multirow{2}{*}{ McArthur River Mine } & \multirow{2}{*}{-16.44} & \multirow{2}{*}{136.08} & 0.700 & 0.721 & 0.773 & 0.734 & 0.694 & 0.666 & 0.671 & 0.701 & 0.703 & 0.688 & 0.700 & 0.660 & 0.701 \\
\hline & & & & 4 & 9 & 6 & 4 & 4 & 9 & 5 & 7 & 4 & 4 & 5 & 4 & \\
\hline \multirow{2}{*}{15135} & \multirow{2}{*}{$\begin{array}{l}\text { Tennant Creek } \\
\text { Airport* }\end{array}$} & \multirow{2}{*}{-19.64} & \multirow{2}{*}{134.18} & 0.644 & 0.667 & 0.632 & 0.601 & 0.623 & 0.648 & 0.657 & 0.649 & 0.627 & 0.632 & 0.633 & 0.646 & 0.638 \\
\hline & & & & 24 & 21 & 27 & 28 & 30 & 29 & 28 & 27 & 28 & 28 & 29 & 24 & \\
\hline \multirow{2}{*}{15590} & \multirow{2}{*}{ Alice Springs Airport* } & \multirow{2}{*}{-23.80} & \multirow{2}{*}{133.89} & 0.668 & 0.669 & 0.657 & 0.690 & 0.737 & 0.781 & 0.783 & 0.756 & 0.724 & 0.712 & 0.684 & 0.675 & 0.711 \\
\hline & & & & 24 & 27 & 25 & 21 & 26 & 24 & 25 & 25 & 28 & 26 & 26 & 24 & \\
\hline \multirow{2}{*}{15666} & \multirow{2}{*}{ Rabbit Flat } & & & 0.721 & 0.789 & 0.765 & 0.764 & 0.779 & 0.797 & 0.762 & 0.761 & 0.731 & 0.756 & 0.715 & 0.808 & 0.762 \\
\hline & & -20.18 & 130.01 & 4 & 8 & 7 & 7 & 7 & 6 & 6 & 8 & 7 & 9 & 7 & 3 & \\
\hline 16001 & Whomong A rodromo* & 2116 & 12601 & 0.695 & 0.687 & 0.691 & 0.715 & 0.731 & 0.790 & 0.788 & 0.777 & 0.766 & 0.759 & 0.725 & 0.711 & 0.736 \\
\hline 16001 & woomera Aerodrome* & -31.16 & 136.81 & 24 & 28 & 28 & 28 & 28 & 25 & 27 & 30 & 25 & 28 & 27 & 29 & \\
\hline & & & & 0.630 & 0.633 & 0.652 & 0.669 & 0.713 & 0.754 & 0.750 & 0.762 & 0.739 & 0.744 & 0.656 & 0.636 & 0.695 \\
\hline 17043 & Oodn & 7.56 & 135.45 & 5 & 5 & 5 & 4 & 5 & 6 & 5 & 4 & 4 & 3 & 5 & 4 & \\
\hline 18012 & Coduw & 3212 & & 0.828 & 0.816 & 0.793 & 0.773 & 0.781 & 0.834 & 0.831 & 0.848 & 0.841 & 0.835 & 0.823 & 0.821 & 0.819 \\
\hline 18012 & Ceduna A & -32.13 & $133 . \%$ & 23 & 27 & 28 & 29 & 29 & 28 & 29 & 28 & 27 & 28 & 28 & 29 & \\
\hline 23024 & A dolnide A innort & 2405 & 1205 & 0.827 & 0.808 & 0.789 & 0.786 & 0.800 & 0.833 & 0.858 & 0.866 & 0.890 & 0.886 & 0.862 & 0.831 & 0.836 \\
\hline 23034 & Adela & & 1 & 27 & 24 & 21 & 25 & 22 & 21 & 20 & 22 & 23 & 23 & 25 & 23 & \\
\hline 23000 & Adelaide (Kent & רי & 12067 & 0.905 & 0.895 & 0.922 & 0.890 & 0.912 & 0.925 & 0.937 & 0.979 & 0.969 & 0.995 & 0.938 & 0.920 & 0.932 \\
\hline 23090 & Town)* & 34.92 & 38.62 & 10 & 10 & 9 & 8 & 8 & 9 & 9 & 9 & 9 & 9 & 9 & 9 & \\
\hline & Nuriootpa & & & 0.803 & 0.791 & 0.787 & 0.844 & 0.887 & 0.925 & 0.992 & 0.971 & 0.980 & 0.935 & 0.857 & 0.815 & 0.882 \\
\hline 233 & Comparison* & & & 19 & 20 & 18 & 16 & 20 & 19 & 18 & 19 & 18 & 19 & 16 & 20 & \\
\hline & Nuriootpa & & 12001 & 0.804 & 0.783 & 0.780 & 0.820 & 0.814 & 0.908 & 0.924 & 0.944 & 1.043 & 0.947 & 0.880 & 0.836 & 0.874 \\
\hline 23373 & Viticultural* & -34.48 & 139.01 & 9 & 8 & 4 & 6 & 7 & 5 & 5 & 5 & 5 & 9 & 7 & 6 & \\
\hline 2107 & Io 0 & & & 0.785 & 0.790 & 0.797 & 0.849 & 0.858 & 0.899 & 0.940 & 0.929 & 0.933 & 0.892 & 0.834 & 0.804 & 0.859 \\
\hline 24024 & Loxton Res. Ce & -3 & 140.60 & 18 & 18 & 24 & 21 & 21 & 22 & 21 & 18 & 22 & 16 & 20 & 18 & \\
\hline
\end{tabular}




\begin{tabular}{|c|c|c|c|c|c|c|c|c|c|c|c|c|c|c|c|c|}
\hline \multirow{2}{*}{26021} & \multirow{2}{*}{ Mount Gambier Aero* } & \multirow{2}{*}{-37.75} & \multirow{2}{*}{140.77} & 0.920 & 0.907 & 0.876 & 0.918 & 0.949 & 1.013 & 1.031 & 1.024 & 1.039 & 1.044 & 0.991 & 0.945 & 0.972 \\
\hline & & & & 31 & 30 & 29 & 30 & 28 & 29 & 28 & 28 & 30 & 30 & 27 & 30 & \\
\hline \multirow{2}{*}{27045} & \multirow{2}{*}{ Weipa Aero* } & \multirow{2}{*}{-12.68} & \multirow{2}{*}{141.92} & 0.774 & 0.838 & 0.861 & 0.890 & 0.844 & 0.779 & 0.788 & 0.794 & 0.823 & 0.836 & 0.856 & 0.831 & 0.826 \\
\hline & & & & 4 & 5 & 3 & 9 & 14 & 15 & 13 & 16 & 10 & 13 & 8 & 8 & \\
\hline \multirow{2}{*}{29126} & \multirow{2}{*}{ Mount Isa Mine } & \multirow{2}{*}{-20.74} & \multirow{2}{*}{139.48} & 0.689 & 0.720 & 0.679 & 0.674 & 0.662 & 0.705 & 0.710 & 0.705 & 0.674 & 0.664 & 0.674 & 0.686 & 0.687 \\
\hline & & & & 11 & 10 & 10 & 10 & 10 & 11 & 11 & 9 & 11 & 12 & 12 & 3 & \\
\hline \multirow{2}{*}{29127} & \multirow{2}{*}{ Mount Isa Aero* } & \multirow{2}{*}{-20.68} & \multirow{2}{*}{139.49} & 0.745 & 0.752 & 0.729 & 0.706 & 0.726 & 0.736 & 0.749 & 0.745 & 0.723 & 0.709 & 0.718 & 0.727 & 0.730 \\
\hline & & & & 23 & 20 & 26 & 26 & 28 & 29 & 27 & 29 & 28 & 27 & 21 & 21 & \\
\hline \multirow{2}{*}{31011} & \multirow{2}{*}{ Cairns Aero* } & \multirow{2}{*}{-16.87} & \multirow{2}{*}{145.75} & 0.851 & 0.835 & 0.858 & 0.873 & 0.838 & 0.835 & 0.831 & 0.857 & 0.847 & 0.850 & 0.835 & 0.832 & 0.845 \\
\hline & & & & 12 & 10 & 11 & 16 & 22 & 24 & 24 & 24 & 25 & 26 & 22 & 19 & \\
\hline \multirow{2}{*}{32040} & \multirow{2}{*}{ Townsville Aero* } & \multirow{2}{*}{-19.25} & \multirow{2}{*}{146.77} & 0.824 & 0.821 & 0.812 & 0.773 & 0.771 & 0.762 & 0.777 & 0.794 & 0.809 & 0.814 & 0.812 & 0.827 & 0.800 \\
\hline & & & & 18 & 11 & 22 & 24 & 24 & 26 & 28 & 27 & 28 & 25 & 22 & 16 & \\
\hline \multirow{2}{*}{40223} & \multirow{2}{*}{ Brisbane Aero } & & & 0.848 & 0.822 & 0.830 & 0.836 & 0.858 & 0.857 & 0.860 & 0.844 & 0.859 & 0.848 & 0.845 & 0.841 & 0.846 \\
\hline & & -27.42 & 153.11 & 11 & 8 & 9 & 11 & 14 & 13 & 14 & 13 & 14 & 12 & 13 & 11 & \\
\hline 101728 & Prian Dacturec* & 2566 & 15175 & 0.773 & 0.794 & 0.786 & 0.772 & 0.752 & 0.738 & 0.755 & 0.787 & 0.806 & 0.813 & 0.806 & 0.772 & 0.779 \\
\hline 40428 & Brian $\mathrm{F}$ & -25.66 & 151.75 & 22 & 22 & 18 & 22 & 24 & 21 & 24 & 18 & 22 & 21 & 21 & 19 & \\
\hline 10042 & Drich 4 o & 2730 & 15212 & 0.857 & 0.856 & 0.847 & 0.858 & 0.856 & 0.849 & 0.856 & 0.885 & 0.880 & 0.863 & 0.877 & 0.844 & 0.861 \\
\hline 40842 & Brisba & -27.39 & 153.13 & 8 & 6 & 9 & 9 & 9 & 6 & 10 & 9 & 9 & 10 & 7 & 9 & \\
\hline 10077 & & 2140 & & 0.736 & 0.727 & 0.725 & 0.765 & 0.802 & 0.863 & 0.882 & 0.873 & 0.843 & 0.815 & 0.768 & 0.732 & 0.794 \\
\hline 48027 & Coba & -31.48 & 5.83 & 26 & 28 & 28 & 26 & 23 & 25 & 26 & 25 & 28 & 25 & 28 & 24 & \\
\hline & & & & 0.809 & 0.822 & 0.795 & 0.813 & 0.846 & 0.878 & 0.915 & 0.946 & 0.899 & 0.866 & 0.843 & 0.811 & 0.854 \\
\hline 53048 & More & -2 & 1 & 16 & 15 & 17 & 16 & 15 & 14 & 14 & 15 & 15 & 16 & 15 & 15 & \\
\hline & & & & 0.791 & 0.783 & 0.786 & 0.777 & 0.797 & 0.862 & 0.886 & 0.883 & 0.867 & 0.838 & 0.811 & 0.788 & 0.822 \\
\hline 53115 & Mor & 9.49 & 9.85 & 9 & 10 & 12 & 13 & 14 & 13 & 12 & 15 & 14 & 14 & 12 & 14 & \\
\hline & Gunnedah Res. & & & 0.713 & 0.687 & 0.708 & 0.675 & 0.667 & 0.649 & 0.558 & nd & nd & nd & 0.763 & 0.710 & 0.681 \\
\hline 55024 & Centre* & -3 & 1 & 1 & 2 & 3 & 3 & 1 & 3 & 1 & 0 & 0 & 0 & 3 & 3 & \\
\hline 55054 & Tamworth $\Lambda$ irnort & 3109 & 15095 & 0.806 & 0.795 & 0.809 & 0.802 & 0.858 & 0.904 & 0.912 & 0.962 & 0.896 & 0.876 & 0.863 & 0.830 & 0.859 \\
\hline 55054 & Tamwo & .09 & 15 & 11 & 10 & 12 & 12 & 12 & 14 & 12 & 9 & 10 & 11 & 9 & 10 & \\
\hline & & & & 0.873 & 0.857 & 0.837 & 0.871 & 0.810 & 0.783 & 0.799 & 0.888 & 0.908 & 0.906 & 0.921 & 0.879 & 0.861 \\
\hline 56018 & Inverell Res. Centre & -29.78 & 151.08 & 8 & 8 & 6 & 7 & 10 & 9 & 10 & 11 & 11 & 10 & 11 & 8 & \\
\hline
\end{tabular}




\begin{tabular}{|c|c|c|c|c|c|c|c|c|c|c|c|c|c|c|c|c|}
\hline \multirow{2}{*}{59040} & \multirow{2}{*}{ Coffs Harbour MO* } & \multirow{2}{*}{-30.31} & \multirow{2}{*}{153.12} & 0.839 & 0.850 & 0.835 & 0.838 & 0.842 & 0.827 & 0.844 & 0.865 & 0.890 & 0.889 & 0.869 & 0.886 & 0.856 \\
\hline & & & & 19 & 20 & 15 & 24 & 18 & 21 & 23 & 25 & 27 & 28 & 23 & 21 & \\
\hline \multirow{2}{*}{61078} & \multirow{2}{*}{ Williamtown RAAF* } & \multirow{2}{*}{-32.79} & \multirow{2}{*}{151.84} & 0.810 & 0.805 & 0.836 & 0.819 & 0.820 & 0.770 & 0.808 & 0.848 & 0.858 & 0.839 & 0.829 & 0.816 & 0.821 \\
\hline & & & & 25 & 23 & 23 & 22 & 24 & 20 & 25 & 25 & 26 & 26 & 24 & 25 & \\
\hline \multirow{2}{*}{61089} & \multirow{2}{*}{ Scone SCS* } & \multirow{2}{*}{-32.06} & \multirow{2}{*}{150.93} & 0.862 & 0.853 & 0.841 & 0.870 & 0.879 & 0.895 & 0.908 & 0.933 & 0.953 & 0.937 & 0.891 & 0.851 & 0.889 \\
\hline & & & & 12 & 13 & 14 & 13 & 14 & 14 & 13 & 15 & 14 & 12 & 13 & 12 & \\
\hline \multirow{2}{*}{66037} & \multirow{2}{*}{$\begin{array}{l}\text { Sydney Airport } \\
\text { AMO* }\end{array}$} & \multirow{2}{*}{-33.95} & \multirow{2}{*}{151.17} & 0.835 & 0.835 & 0.827 & 0.826 & 0.846 & 0.805 & 0.828 & 0.847 & 0.862 & 0.873 & 0.857 & 0.842 & 0.840 \\
\hline & & & & 27 & 22 & 28 & 23 & 19 & 26 & 25 & 26 & 24 & 22 & 26 & 26 & \\
\hline \multirow{2}{*}{67033} & \multirow{2}{*}{ Richmond RAAF } & \multirow{2}{*}{-33.60} & \multirow{2}{*}{150.78} & 0.839 & 0.837 & 0.846 & 0.842 & 0.899 & 0.880 & 0.869 & 0.850 & 0.849 & 0.848 & 0.854 & 0.825 & 0.853 \\
\hline & & & & 15 & 12 & 15 & 13 & 16 & 15 & 13 & 14 & 14 & 14 & 15 & 13 & \\
\hline \multirow{2}{*}{68076} & \multirow{2}{*}{$\begin{array}{l}\text { Nowra RAN Air } \\
\text { Station }\end{array}$} & \multirow{2}{*}{-34.94} & \multirow{2}{*}{150.55} & 0.783 & 0.774 & 0.796 & 0.764 & 0.735 & 0.685 & 0.771 & 0.786 & 0.790 & 0.784 & 0.789 & 0.785 & 0.770 \\
\hline & & & & 15 & 15 & 19 & 17 & 16 & 17 & 17 & 15 & 13 & 15 & 17 & 13 & \\
\hline \multirow{2}{*}{70014} & \multirow{2}{*}{$\begin{array}{l}\text { Canberra Airport } \\
\text { Comparison* }\end{array}$} & & & 0.785 & 0.791 & .770 & 0.801 & .820 & 0.849 & 0.881 & 0.879 & 0.873 & 0.883 & 0.852 & .811 & 0.833 \\
\hline & & 5.30 & 20 & 30 & 28 & 28 & 30 & 29 & 29 & 29 & 27 & 28 & 31 & 28 & 29 & \\
\hline 70015 & Canhorro Eorectry & 3530 & $1401,19+2$ & nd & nd & 0.677 & 0.812 & 0.860 & 0.973 & 0.943 & 0.994 & 0.933 & nd & nd & nd & 0.885 \\
\hline 70015 & Canberra Forestry & -35.30 & 149.1 & 0 & 0 & 1 & 1 & 1 & 1 & 1 & 1 & 1 & 0 & 0 & 0 & \\
\hline 77060 & Khonghon CMUL & כר אבי & 14014 & 0.869 & 0.867 & 0.867 & 0.958 & 1.022 & 1.221 & 1.227 & 1.164 & 1.040 & 1.028 & 0.949 & 0.873 & 1.007 \\
\hline$/ \angle 000$ & КnancoDan SIMHEA & -36.23 & 148.14 & 13 & 12 & 14 & 14 & 11 & 14 & 12 & 13 & 12 & 13 & 13 & 12 & \\
\hline 72150 & L & 2516 & 14714,48 & 0.815 & 0.813 & 0.810 & 0.865 & 0.944 & 0.984 & 1.069 & 1.097 & 1.053 & 0.988 & 0.893 & 0.843 & 0.931 \\
\hline 12150 & Wagga v & -35.16 & 7.46 & 24 & 25 & 23 & 21 & 23 & 22 & 22 & 22 & 24 & 22 & 20 & 23 & \\
\hline 76031 & & 3 & 1 & 0.793 & 0.785 & 0.785 & 0.819 & 0.840 & 0.882 & 0.921 & 0.925 & 0.889 & 0.864 & 0.838 & 0.811 & 0.846 \\
\hline 76031 & Mild & -34.24 & & 19 & 21 & 20 & 17 & 19 & 19 & 19 & 20 & 20 & 21 & 20 & 19 & \\
\hline & & & & 0.821 & 0.819 & 0.806 & 0.862 & 0.897 & 0.904 & 0.989 & 0.993 & 1.025 & 1.056 & 0.919 & 0.804 & 0.908 \\
\hline 82039 & Rutherglen Research* & 36.10 & 6.5 & 16 & 16 & 17 & 13 & 15 & 12 & 16 & 11 & 13 & 9 & 14 & 13 & \\
\hline 05077 & Enct Solo A innort* & 2012 & 1471,1 & 0.887 & 0.872 & 0.879 & 0.911 & 0.912 & 0.900 & 0.913 & 0.966 & 0.954 & 0.987 & 0.935 & 0.903 & 0.918 \\
\hline $850 / 2$ & East Sale Alrpo & -38.12 & $14 / .13$ & 25 & 26 & 26 & 26 & 28 & 25 & 29 & 26 & 29 & 23 & 25 & 27 & \\
\hline 85103 & Vallourn SEC & -3819 & 14632 & 0.885 & 0.820 & 0.917 & 0.935 & 1.070 & 0.914 & 0.959 & 1.007 & 1.101 & 1.029 & 1.033 & 0.940 & 0.968 \\
\hline & & & & 7 & 6 & 7 & 7 & 2 & 4 & 4 & 7 & 2 & 4 & 2 & 2 & \\
\hline 86282 & Melh & 767 & $1448>>2>$ & 0.835 & 0.816 & 0.799 & 0.795 & 0.847 & 0.868 & 0.872 & 0.892 & 0.859 & 0.887 & 0.895 & 0.838 & 0.850 \\
\hline 86282 & Melbourne Airport & -37.67 & 144.8 & 9 & 9 & 9 & 9 & 9 & 10 & 8 & 8 & 10 & 11 & 11 & 11 & \\
\hline
\end{tabular}




\begin{tabular}{|c|c|c|c|c|c|c|c|c|c|c|c|c|c|c|c|c|}
\hline \multirow{2}{*}{87031} & \multirow{2}{*}{ Laverton RAAF } & \multirow{2}{*}{-37.86} & \multirow{2}{*}{144.76} & 0.812 & 0.789 & 0.765 & 0.771 & 0.788 & 0.846 & 0.881 & 0.880 & 0.907 & 0.896 & 0.864 & 0.825 & 0.835 \\
\hline & & & & 16 & 20 & 20 & 21 & 20 & 19 & 20 & 17 & 17 & 15 & 19 & 18 & \\
\hline \multirow{2}{*}{88023} & \multirow{2}{*}{ Lake Eildon* } & \multirow{2}{*}{-37.23} & \multirow{2}{*}{145.91} & 1.015 & 1.010 & 1.034 & 1.139 & 1.281 & 1.444 & 1.546 & 1.405 & 1.281 & 1.229 & 1.145 & 1.028 & 1.213 \\
\hline & & & & 26 & 26 & 22 & 19 & 22 & 24 & 20 & 23 & 24 & 22 & 19 & 23 & \\
\hline \multirow{2}{*}{90103} & \multirow{2}{*}{ Hamilton Res. Station } & \multirow{2}{*}{-37.83} & \multirow{2}{*}{142.06} & 0.784 & 0.725 & 0.692 & 0.739 & 0.713 & 0.681 & 0.717 & 0.776 & 0.862 & 0.935 & 0.907 & 0.841 & 0.781 \\
\hline & & & & 15 & 14 & 9 & 11 & 7 & 7 & 11 & 9 & 12 & 9 & 9 & 12 & \\
\hline \multirow{2}{*}{91104} & \multirow{2}{*}{$\begin{array}{l}\text { Launceston Airport } \\
\text { Companion* }\end{array}$} & \multirow{2}{*}{-41.54} & \multirow{2}{*}{147.20} & 0.880 & 0.882 & 0.858 & 0.908 & 0.967 & 0.961 & 1.062 & 1.110 & 1.079 & 1.043 & .979 & .893 & 0.968 \\
\hline & & & & 20 & 20 & 20 & 20 & 18 & 15 & 15 & 19 & 18 & 22 & 19 & 19 & \\
\hline \multirow{2}{*}{91219} & \multirow{2}{*}{ Scottsdale } & \multirow{2}{*}{-41.17} & \multirow{2}{*}{147.49} & 1.008 & 1.024 & 1.009 & 1.065 & 1.007 & 0.936 & 0.952 & 1.062 & 1.105 & 1.137 & 1.101 & 1.027 & 1.036 \\
\hline & & & & 24 & 22 & 17 & 14 & 15 & 15 & 17 & 17 & 16 & 18 & 21 & 24 & \\
\hline \multirow{2}{*}{92038} & \multirow{2}{*}{ Swansea Post Office } & \multirow{2}{*}{-42.12} & \multirow{2}{*}{148.07} & 0.903 & 0.903 & 0.916 & 0.987 & 1.085 & 0.982 & 0.969 & 1.010 & 1.036 & 1.049 & 0.961 & 0.941 & 0.979 \\
\hline & & & & 2 & 2 & 2 & 2 & 2 & 2 & 2 & 2 & 2 & 2 & 2 & 1 & \\
\hline \multirow{2}{*}{94008} & \multirow{2}{*}{ Hobart Airport } & \multirow{2}{*}{-42.83} & \multirow{2}{*}{147.50} & 0.888 & 0.897 & 0.889 & 0.879 & 0.863 & 0.916 & 0.913 & 0.970 & 0.987 & 0.978 & 0.950 & 0.912 & 0.920 \\
\hline & & & & 19 & 22 & 20 & 20 & 20 & 21 & 21 & 22 & 21 & 21 & 20 & 19 & \\
\hline \multirow{2}{*}{94029} & \multirow{2}{*}{$\begin{array}{l}\text { Hobart (Ellerslie } \\
\text { Road) }\end{array}$} & & & 0.972 & 0.932 & 0.941 & 0.936 & 0.944 & 0.993 & 0.991 & 0.974 & 1.022 & 1.079 & 1.007 & 0.968 & 0.980 \\
\hline & & - & .33 & 15 & 16 & 16 & 15 & 15 & 16 & 13 & 15 & 14 & 15 & 15 & 14 & \\
\hline & & & 708 & 0.873 & 0.854 & 0.864 & 0.858 & 0.823 & 0.855 & 0.876 & 0.852 & 0.926 & 0.949 & 0.945 & 0.920 & 0.883 \\
\hline 94069 & Grov & 2.98 & 7.08 & 18 & 20 & 21 & 21 & 16 & 18 & 13 & 14 & 19 & 20 & 18 & 20 & \\
\hline 96033 & L jaw & 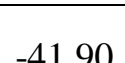 & 1 & 1.057 & nd & 1.075 & nd & nd & nd & nd & nd & nd & nd & 1.132 & 1.068 & 1.083 \\
\hline 90033 & Llaw & -5 & 1 & 3 & 0 & 1 & 0 & 0 & 0 & 0 & 0 & 0 & 0 & 2 & 2 & \\
\hline 97053 & Strathoordon Villa & -4 & 14605 & 0.973 & 0.955 & 0.947 & 0.870 & 0.946 & 0.765 & 0.708 & 0.748 & 0.890 & 0.989 & 1.023 & 0.947 & 0.897 \\
\hline צ & siratiguruent village & -4 & & 6 & 7 & 7 & 4 & 4 & 7 & 4 & 8 & 6 & 5 & 8 & 6 & \\
\hline
\end{tabular}


Table S7 Comparison of equations to estimate evaporation from a lake covered with vegetation

(Adv. and Disadv. are abbreviations for advantage and disadvantage, respectively.)

\begin{tabular}{|c|c|c|c|c|c|c|}
\hline Reference & Application & $\begin{array}{c}\text { Penman } \\
\text { (Section 2.1.1) }\end{array}$ & $\begin{array}{l}\text { Penman-Monteith } \\
\text { (Section 2.1.2) }\end{array}$ & $\begin{array}{l}\text { Weighted Penman- } \\
\text { Monteith } \\
\text { (Equation S5.30) }\end{array}$ & $\begin{array}{c}\text { Shuttleworth- } \\
\text { Wallace } \\
\text { (Equation S5.22) }\end{array}$ & $\begin{array}{l}\text { Priestley-Taylor } \\
\text { (Section 2.1.3) }\end{array}$ \\
\hline \multirow[t]{2}{*}{$\begin{array}{l}\text { Wessel \& } \\
\text { Rouse } \\
(1994) \\
\text { Table III }\end{array}$} & Wetland tundra & & $\begin{array}{l}\text { Adv: accurate if } r_{s} \text { is } \\
\text { available } \\
\text { Disadv: inadequate for } \\
\text { complex surfaces }\end{array}$ & $\begin{array}{l}\text { Adv: handle any } \\
\text { surfaces } \\
\text { Weight components } \\
\text { by surface area } \\
\end{array}$ & $\begin{array}{l}\text { Disadv: Cannot } \\
\text { model area with } \\
\text { no canopy. Not } \\
\text { recommended }\end{array}$ & \\
\hline & Bowen Ratio & & 0.75 (1.21)\# & $1.10(1.41)$ & 1.35 (1.65) & \\
\hline \multirow[t]{2}{*}{$\begin{array}{l}\text { Abtew \& } \\
\text { Obeysekera } \\
\text { (1995) } \\
\text { Figures } 7 \text { to } \\
9\end{array}$} & South Florida & $\begin{array}{l}\text { The two coefficients in } \\
\text { the wind function were } \\
\text { found by calibration }\end{array}$ & $\begin{array}{l}\text { Monteith (1965) } \\
r_{a} \text { from Equation } \\
\mathrm{S} 5.3 . r_{s} \text { varied from } \\
25 \mathrm{~s} \mathrm{~m}^{-1} \text { during high } \\
\text { ET season and } 90 \mathrm{~s} \\
\mathrm{~m}^{-1} \text { for rest of year. }\end{array}$ & & & $\begin{array}{l}\alpha=1.18 \text { by } \\
\text { calibration }\end{array}$ \\
\hline & $\begin{array}{l}\text { Lysimeter } \\
\text { within wetland } \\
\text { complex }\end{array}$ & $\begin{array}{l}\mathrm{P}=0.03+1.01 \mathrm{Meas} \\
\left(\text { see }=0.57 \mathrm{~mm} \mathrm{day}^{-1}\right)\end{array}$ & $\begin{array}{l}\mathrm{PM}=1.17+0.75 \mathrm{Meas} \\
\left(\mathrm{see}=0.39 \mathrm{~mm} \mathrm{day}^{-1}\right)\end{array}$ & & & $\begin{array}{c}\mathrm{PT}=1.15+070 \text { Meas } \\
\left(\mathrm{see}=0.53 \mathrm{~mm} \mathrm{day}^{-1}\right)\end{array}$ \\
\hline \multirow[t]{2}{*}{$\begin{array}{l}\text { Souch et al. } \\
\text { (1998) } \\
\text { Table } 3\end{array}$} & $\begin{array}{l}\text { Indiana, USA } \\
\text { Undisturbed site }\end{array}$ & $\begin{array}{l}\text { Penman modified by } \\
\text { Shuttleworth (1992) }\end{array}$ & $\begin{array}{l}r_{a} \text { from Shuttleworth } \\
(1992, \text { Equation } \\
4.2 .25) ; r_{s}=0 \text { for } \\
\text { standing water } \& r_{s}= \\
5 \mathrm{~s} \mathrm{~m}^{-1} \text { for vegetation }\end{array}$ & & & $\begin{array}{l}\text { Assumed vapour } \\
\text { pressure deficits } \\
\text { depressed, } \alpha=1\end{array}$ \\
\hline & $\begin{array}{l}\text { Eddy } \\
\text { correlation }\end{array}$ & $1.03(0.67)$ & $0.98(0.44)$ & & & $1.03(0.67)$ \\
\hline $\begin{array}{l}\text { Bidlake } \\
(2000) \\
\text { Table } 4 \\
\end{array}$ & $\begin{array}{l}\text { Wetland in } \\
\text { Oregon, USA } \\
\text { (semi-arid) }\end{array}$ & & $\begin{array}{l}\text { Several calibrations } \\
\text { were based on } r_{s} \text {. } \\
\text { Chosen best option }\end{array}$ & & & $\begin{array}{l}\text { Calibrated with } \alpha \\
\text { overall }<1\end{array}$ \\
\hline
\end{tabular}




\begin{tabular}{|c|c|c|c|c|c|c|}
\hline & $\begin{array}{l}\text { Eddy } \\
\text { correlation }\end{array}$ & & $0.98 *(1.04)$ & & & $0.92 *(1.00)$ \\
\hline \multirow{2}{*}{$\begin{array}{l}\text { Lott \& } \\
\text { Hunt } \\
(2001) \\
\text { Table } 2\end{array}$} & $\begin{array}{l}\text { Wisconsin, } \\
\text { USA }\end{array}$ & $\begin{array}{l}\text { Adopted Dunne \& } \\
\text { Leopold (1978) to } \\
\text { compute } E_{a}\end{array}$ & & & & \\
\hline & $\begin{array}{l}\text { Lysimeter and } \\
\text { water table } \\
\text { fluctuations }\end{array}$ & $\begin{array}{c}\text { Natural wetland } \\
0.70 \\
\text { Constructed wetland } \\
1.01\end{array}$ & & & & \\
\hline \multirow[t]{2}{*}{$\begin{array}{l}\text { Jacobs et } \\
\text { al. (2002) } \\
\text { Table } 3\end{array}$} & $\begin{array}{l}\text { Highland marsh } \\
\text { Florida, USA }\end{array}$ & Penman (1956) & $\begin{array}{l}r_{a}=\text { Monin-Obukhov } \\
\text { similarity for neutral } \\
\text { conditions }\end{array}$ & & & $\alpha=1.26$ \\
\hline & $\begin{array}{l}\text { Eddy } \\
\text { correlation }\end{array}$ & $1.31(1.83)$ & $1.14(1.62)$ & & & $1.39(1.59)$ \\
\hline \multirow[t]{2}{*}{$\begin{array}{l}\text { Drexler et } \\
\text { at. (2004) }\end{array}$} & & $\begin{array}{l}\text { Adv: Minimal data } \\
\text { Disadv: does not } \\
\text { account for } r_{s}\end{array}$ & $\begin{array}{l}\text { Adv: Minimal data, } \\
\text { accounts for } r_{s} \\
\text { Disadv: Can't handle } \\
\text { mixed vegetation, } \\
\text { hence } r_{a} \text { and } r_{s} \\
\text { difficult to estimate }\end{array}$ & $\begin{array}{l}\text { Adv: can handle } r_{a} \\
\text { and } r_{s} \text { for different } \\
\text { surfaces including } \\
\text { standing water }\end{array}$ & $\begin{array}{l}\text { Disadv: Does not } \\
\text { handle standing } \\
\text { water }\end{array}$ & $\begin{array}{l}\text { Disadv: No wind } \\
\text { component nor } r\end{array}$ \\
\hline & \multicolumn{6}{|c|}{ No quantitative comparisons } \\
\hline
\end{tabular}

\# Value is ratio of mean model estimate to mean measured estimate. Values in parentheses are root mean square error in mm day ${ }^{-1}{ }^{*}$ Value is based on the slope of the regression between the model and the measured values. 
Table S8 Measured values of Priestley-Taylor coefficient $\left(\alpha_{P T}\right)$

(Partly adapted from Flint and Childs (1991) and Fisher et al. (2005))

\begin{tabular}{|c|c|c|c|}
\hline$\alpha_{P T}$ & Surface & $\begin{array}{c}\text { Daily (24 hr) or } \\
\text { day-time (day- } \\
\text { light hour) }\end{array}$ & Reference \\
\hline 1.57 & Strongly advective conditions & na & Jury and Tanner (1975) \\
\hline 1.29 & Grass (soil at field capacity) & daily & $\begin{array}{l}\text { Mukammal and Neumann } \\
\text { (1977) }\end{array}$ \\
\hline 1.27 & Irrigated ryegrass & daily & Davies and Allen (1973) \\
\hline 1.26 & Saturated surface & daily & Priestley and Taylor (1972) \\
\hline 1.26 & Open-surface water & daily & Priestley and Taylor (1972) \\
\hline 1.26 & Wet meadow & daily & Stewart and Rouse (1977) \\
\hline 1.18 & Wet Douglas-fir forest & daily & $\begin{array}{l}\text { McNaughton and Black } \\
\text { (1973) }\end{array}$ \\
\hline 1.12 & Short grass & day-time & $\begin{array}{l}\text { De Bruin and Holtslag } \\
\text { (1982) }\end{array}$ \\
\hline 1.09 & Boreal broad-leaf deciduous $\mathrm{N}=1$ & daily & Komatsu (2005) \\
\hline 1.05 & Douglas-fir forest & daily & $\begin{array}{l}\text { McNaughton and Black } \\
\text { (1973) }\end{array}$ \\
\hline 1.04 & Bare soil surface & day-time & Barton (1979) \\
\hline 0.90 & Mixed reforestation (water limited) & daily & Flint and Childs (1991) \\
\hline 0.87 & Ponderosa pine (water limited) & day-time & Fisher et al. (2005) \\
\hline 0.85 & $\begin{array}{l}\text { Temperate broad-leaf deciduous } \mathrm{N} \\
=9\end{array}$ & day-time & Komatsu (2005) \\
\hline 0.84 & Douglas-fir forest (unthinned) & daily & Black (1979) \\
\hline 0.82 & $\begin{array}{l}\text { Tropical broad-leaf evergreen } \mathrm{N}= \\
7\end{array}$ & day-time & Komatsu (2005) \\
\hline 0.80 & Douglas-fir forest (thinned) & daily & Black (1979) \\
\hline 0.76 & $\begin{array}{l}\text { Temperate broad-leaf evergreen } \mathrm{N} \\
=5\end{array}$ & day-time & Komatsu (2005) \\
\hline 0.73 & Douglas-fir forest & day-time & Giles et al. (1984) \\
\hline 0.72 & Spruce forest & day-time & $\begin{array}{l}\text { Shuttleworth and Calder } \\
\text { (1979) }\end{array}$ \\
\hline 0.65 & $\begin{array}{l}\text { Temperate coniferous evergreen } \mathrm{N} \\
=35\end{array}$ & day-time & Komatsu (2005) \\
\hline 0.55 & Boreal coniferous evergreen $\mathrm{N}=8$ & day-time & Komatsu (2005) \\
\hline 0.53 & Boreal coniferous deciduous $\mathrm{N}=2$ & day-time & Komatsu (2005) \\
\hline
\end{tabular}

na: not known; $\mathrm{N}$ is the number of experimental sites 
Table S9 Effect of type and length fetch, wind speed and humidity on Class-A pan coefficients without bird-guard*

\begin{tabular}{|l|c|cc|cc|}
\hline Wind & $\begin{array}{c}\text { Fetch length } \\
(\mathrm{m})\end{array}$ & \multicolumn{2}{|c|}{$\begin{array}{c}\text { Green vegetated fetch in a } \\
\text { dry area }\end{array}$} & \multicolumn{2}{c|}{$\begin{array}{c}\text { Dry fetch in a green } \\
\text { vegetated area }\end{array}$} \\
\cline { 2 - 6 } & & $\begin{array}{c}\text { Low } \\
\text { humidity } \\
<40 \%\end{array}$ & $\begin{array}{c}\text { High } \\
\text { humidity } \\
>70 \%\end{array}$ & $\begin{array}{c}\text { Low } \\
\text { humidity } \\
<40 \%\end{array}$ & $\begin{array}{c}\text { High } \\
\text { humidity } \\
>70 \%\end{array}$ \\
\hline Light & 10 & 0.65 & 0.85 & 0.60 & 0.80 \\
$<2 \mathrm{~m} \mathrm{~s}^{-1}$ & 1000 & 0.75 & 0.85 & 0.50 & 0.70 \\
Strong & 10 & 0.55 & 0.65 & 0.50 & 0.65 \\
$5-8 \mathrm{~m} \mathrm{~s}^{-1}$ & 1000 & 0.60 & 0.75 & 0.40 & 0.55 \\
\hline
\end{tabular}

*Results were extracted from Allen et al. (1998, Table 5) 
Table S10 Published references listing annual Class-A pan coefficients based on the Penman equation with wind functions of Penman (1948) and Penman (1956), Reference Crop equation and Priestley-Taylor equation

\begin{tabular}{|c|c|c|c|c|c|c|c|}
\hline Reference & Location & $\begin{array}{l}\text { Number of } \\
\text { sites }\end{array}$ & $\begin{array}{l}\text { Time-step } \\
\text { D or } \mathrm{M}\end{array}$ & $\begin{array}{c}\text { Penman } \\
(1948)\end{array}$ & $\begin{array}{c}\text { Penman } \\
(1956)\end{array}$ & Reference Crop & $\begin{array}{l}\text { Priestley- } \\
\text { Taylor }\end{array}$ \\
\hline \multicolumn{8}{|c|}{ Screened pan } \\
\hline Weeks (1982) & Callide Dam, Queensland & 1 & $\mathrm{M}$ & 0.88 & & & \\
\hline Fleming et al. (1989) & $\begin{array}{c}\text { South Lake Wyangan, Vic, } \\
\text { Aus }\end{array}$ & 1 & M & & 0.76 & & \\
\hline Chiew et al. (1995) & Australia & 16 & $\mathrm{D} \& \mathrm{M}$ & & & 0.67 (FAO 24) & \\
\hline Cohen et al. (2002) & & 1 & $\mathrm{M}$ & & 1.03 & 0.77 & \\
\hline \multicolumn{8}{|c|}{ Coefficients adjusted to a screened pan coefficient } \\
\hline Young (1947)* & & & & 0.82 & & & \\
\hline Penman (1948)* & Rothamsted, UK & several & 6Ds \& M & 0.83 & & & \\
\hline Kohler et al. (1955)* & & & & $0.64-0.88$ & & & \\
\hline Harbeck (1958)* & & & & 0.74 & & & \\
\hline Nordenson \& Baker (1962)* & & & & 0.79 & & & \\
\hline Nimmo (1964)* & & & & $0.65-0.85$ & & & \\
\hline Stanhill (1969)* & & & & 0.75 & & & \\
\hline Allen \& Crow (1971)* & & & & $0.80-0.83$ & & & \\
\hline Ficke (1972)* & & & & 0.81 & & & \\
\hline Hounam (1973)* & & & & $0.77,0.86$ & & & \\
\hline Neuwirth (1973)* & & & & 0.77 & & & \\
\hline Hoy $(1977)^{*}$ & & & & 0.83 & & & \\
\hline Duru (1984)* & & & & 0.83 & & & \\
\hline Stanhill (2002) & World-wide & 18 & na & Penman ? & 0.68 & & \\
\hline Harmsen et al. (2003) & Puerto Rico & 7 & $\mathrm{M}$ & & & 0.84 & \\
\hline Sumner \& Jacobs (2005) & Florida, USA & 1 & $\mathrm{D}$ & & & 0.75 & \\
\hline Wei $\beta$ and Menzel (2008) & Jordon & & & & & & $\begin{array}{c}0.43 \\
(0.24-0.72)\end{array}$ \\
\hline
\end{tabular}

D: daily time-step, M: monthly time-step; na: not available * References from Linacre (1994) 
Table S11 Monthly Class-A evaporation pan coefficients for selected Australian lakes*

\begin{tabular}{|c|c|c|c|c|c|c|c|c|c|c|c|c|c|c|}
\hline $\begin{array}{l}\text { Station } \\
\text { name }\end{array}$ & Lat $^{\circ} \mathrm{S}$ & $\begin{array}{l}\text { Long } \\
{ }^{\circ} \mathrm{E}\end{array}$ & Jan & Feb & Mar & Apr & May & Jun & Jul & Aug & Sep & Oct & Nov & Dec \\
\hline $\begin{array}{l}\text { Lake } \\
\text { Eucumbene }\end{array}$ & 36.083 & 148.667 & 0.82 & 0.95 & 0.91 & 1.03 & 2.07 & 2.19 & 1.65 & 1.56 & 0.47 & 0.47 & 0.52 & 0.67 \\
\hline $\begin{array}{l}\text { Cataract } \\
\text { Reservoir }\end{array}$ & 34.333 & 150.833 & 0.98 & 1.07 & 1.11 & 1.14 & 1.22 & 1.25 & 1.12 & 0.75 & 0.76 & 0.80 & 0.88 & 0.93 \\
\hline $\begin{array}{l}\text { Manton } \\
\text { Reservoir }\end{array}$ & 12.833 & 131.083 & 1.13 & 1.09 & 1.06 & 1.01 & 0.94 & 0.85 & 0.79 & 0.75 & 0.83 & 0.88 & 0.91 & 1.10 \\
\hline $\begin{array}{l}\text { Mundaring } \\
\text { Reservoir }\end{array}$ & 31.916 & 116.166 & 1.02 & 1.06 & 1.12 & 1.18 & 1.15 & 1.18 & 1.01 & 0.91 & 0.81 & 0.78 & 0.79 & 0.94 \\
\hline $\begin{array}{l}\text { Blue } \\
\text { Lagoon }\end{array}$ & 38.183 & 146.366 & 0.92 & 0.95 & 0.94 & 0.91 & 0.88 & 0.88 & 0.7 & 0.77 & 0.94 & 0.94 & 1.06 & 0.96 \\
\hline $\begin{array}{l}\text { Lake } \\
\text { Wyangan }\end{array}$ & 34.283 & 146.033 & 0.86 & 0.86 & 0.87 & 0.82 & 0.78 & 0.69 & 0.66 & 0.68 & 0.82 & 0.97 & 0.85 & 0.83 \\
\hline $\begin{array}{l}\text { Rifle Creek } \\
\text { reservoir }\end{array}$ & 20.950 & 139.583 & 0.76 & 0.66 & 0.79 & 0.82 & 0.66 & 0.56 & 0.52 & 0.52 & 0.57 & 0.65 & 0.65 & 0.83 \\
\hline
\end{tabular}

*All pan coefficients are extracted from Hoy and Stephens (1979) 
Table S12 Annual Class-A evaporation pan coefficients for selected Australian lakes*

\begin{tabular}{|l|cc|c|}
\hline \multicolumn{1}{|c|}{ Station name } & Lat ${ }^{\circ} \mathrm{S}$ & Long ${ }^{\circ} \mathrm{E}$ & $\begin{array}{c}\text { Annual pan } \\
\text { coefficient }\end{array}$ \\
\hline Lake Menindee & 32.333 & 142.333 & 0.76 \\
Lake Pamamaroo & 32.300 & $142 . .466$ & 0.71 \\
Lake Cawdilla & 32.466 & 142.233 & 0.76 \\
Stephens Creek Reservoir & 31.833 & 141.500 & 0.74 \\
Lake Albacutya & 35.750 & 141.966 & 0.85 \\
Lake Hindmarsh & 36.083 & 141.916 & 0.79 \\
Lake Eucumbene & 36.083 & 148.667 & 0.87 \\
Cataract Reservoir & 34.333 & 150.833 & 0.98 \\
Manton Reservoir & 12.833 & 131.083 & 0.93 \\
Mundaring Reservoir & 31.916 & 116.166 & 1.00 \\
Blue Lagoon & 38.183 & 146.366 & 0.94 \\
Lake Wyangan South & 34.283 & 146.033 & 0.82 \\
Rifle Creek Reservoir & 20.950 & 139.583 & 0.68 \\
Lake Albert & 35.633 & 139.333 & 0.87 \\
Callide Dam & 24.400 & 150.617 & 0.87 \\
Lake Alexandrina & 35.750 & 139.283 & 0.66 \\
\hline
\end{tabular}

*All pan coefficients are extracted from Hoy and Stephens (1979) except for Callide Dam and Lake Alexandrina which are taken from Weeks (1982) and Kotwicki (1994, Table 2) respectively. 
Table S13 Comparison of annual estimates of evaporation ( $\mathrm{mm} \mathrm{day}^{-1}$ ) at six Australian locations by 13 daily and monthly models plus Class-A pan and mean annual rainfall for period January 1979 to March 2010*. (P56: Penman 1956; PT: Priestley-Taylor; Ma: Makkink; FAO56 RC: FAO-56 Reference Crop; BC: Blaney-Criddle; HS: Hargreaves-Samani; mod H: modified Hargreaves; Tu: Turc; Mo: Morton CRAE; BS: Brutsaert-Strickler; GG: Granger-Gray; SJ: Szilagyi-Jozsa; Th: Thornthwaite; PP; PenPan (adjusted for bird screen)

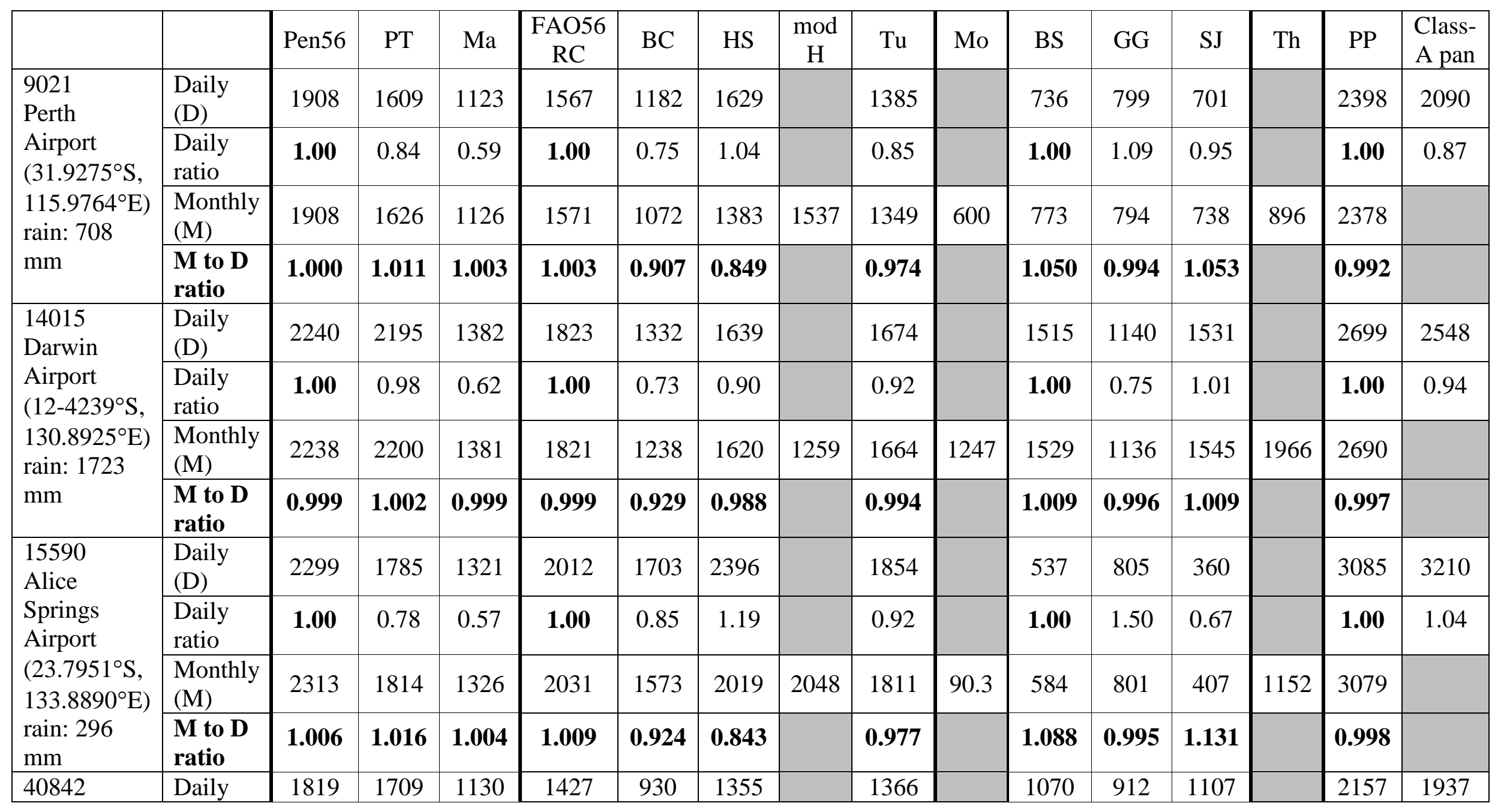




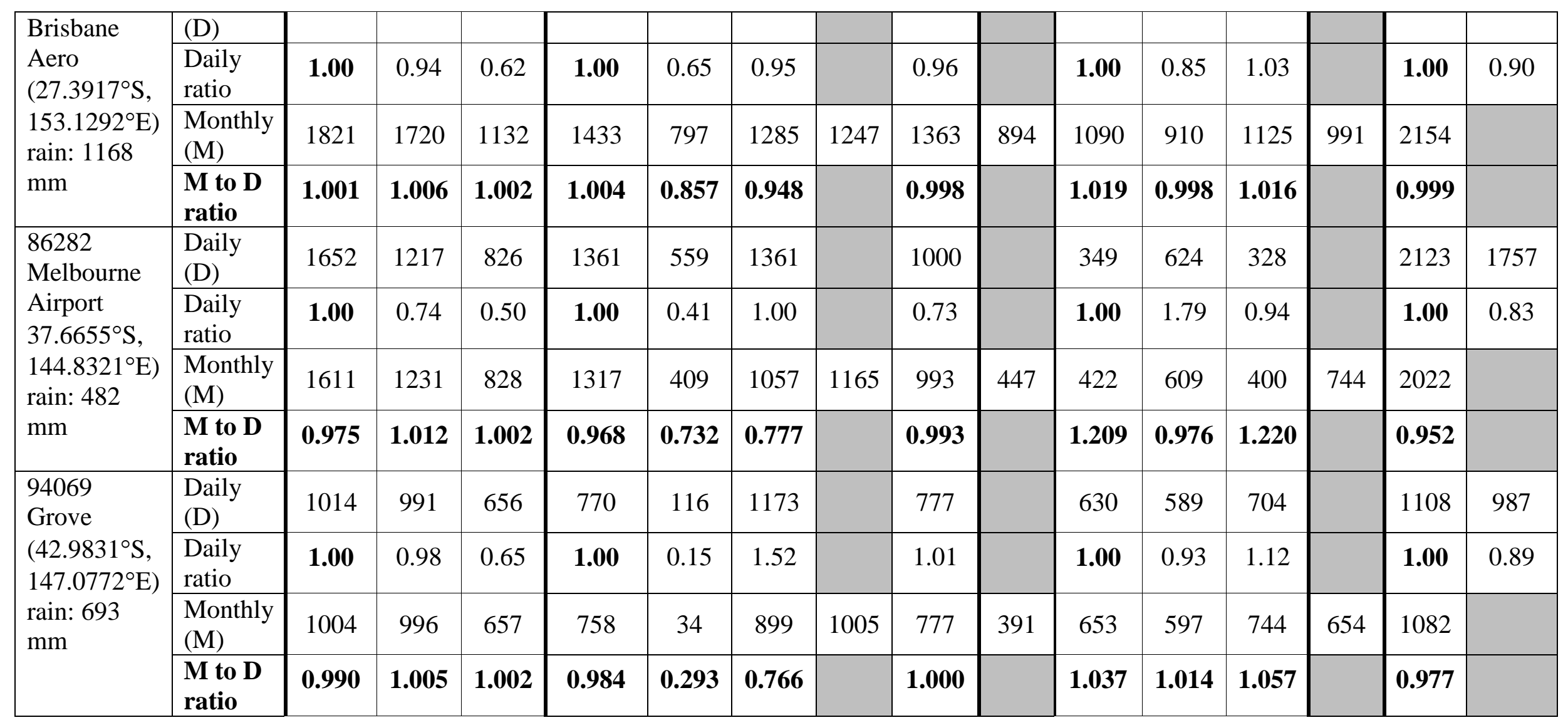

*All annual estimates are based on the sum of the average monthly values for the concurrent period of observation at each station. 


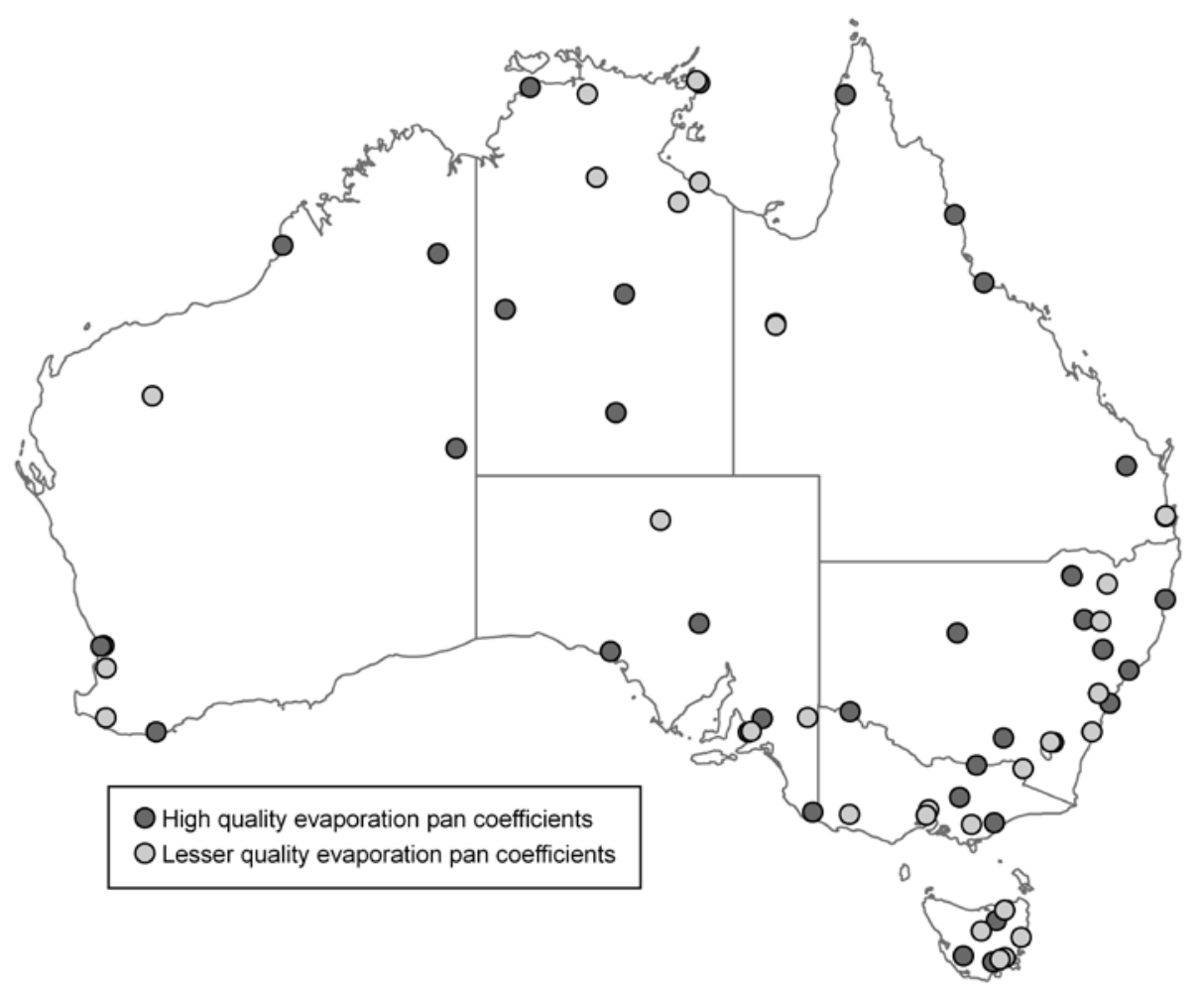

Figure S1 Location of the 68 Automatic Weather Stations and Class-A evaporation pans (of which 39 pans are high quality) used in the analyses

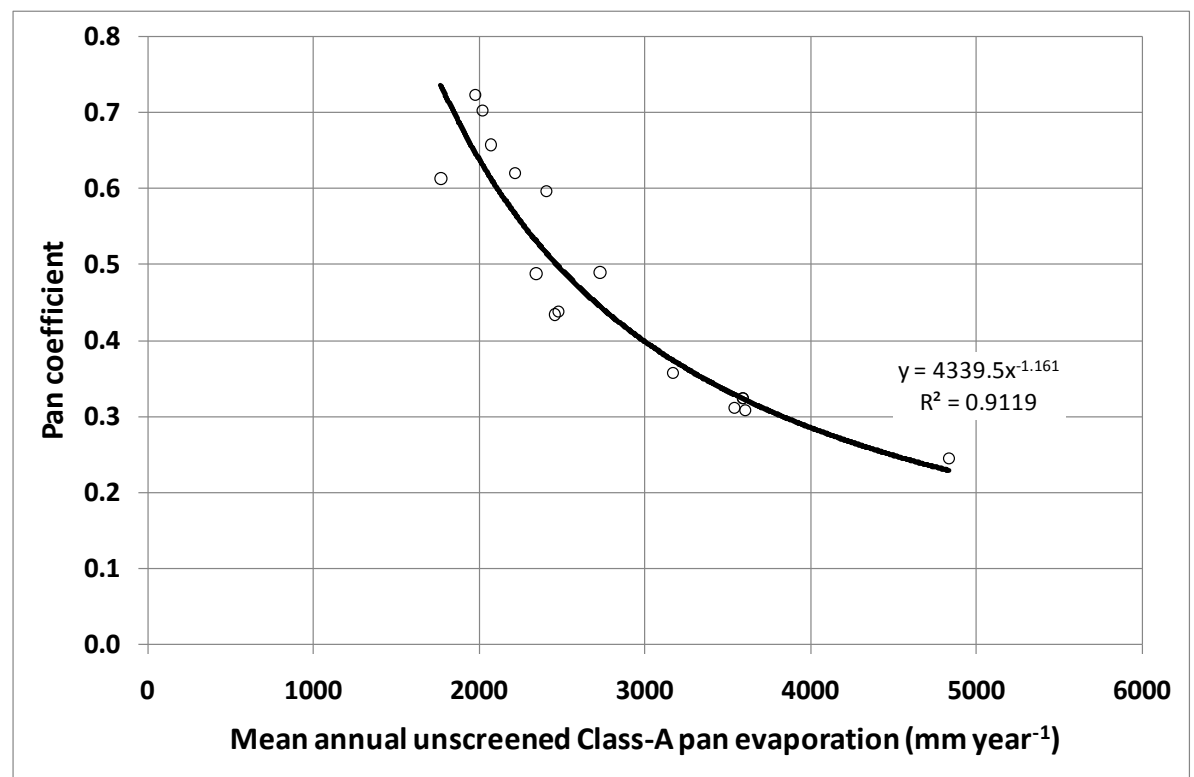

Figure S2 Plot showing Priestley-Taylor pan coefficients against mean annual unscreened Class-A pan evaporation based on six years of climate station data in Jordon (Wei $\beta$ and Menzel, 2008) 


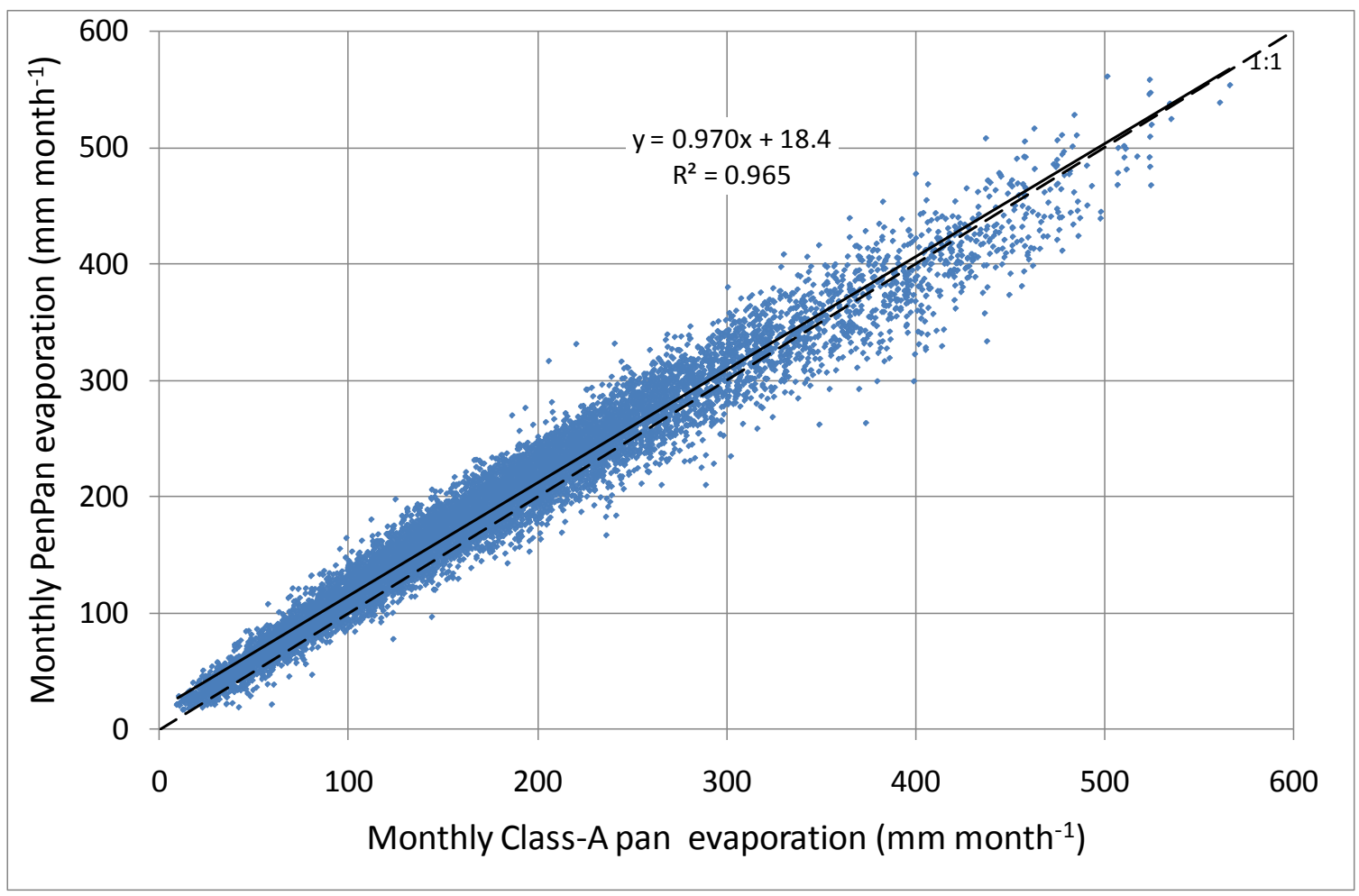

Figure S3 Comparison of monthly PenPan evaporation and Class-A pan evaporation for 68 Australian climate stations 